\title{
WestVirginiaUniversity
}

THE RESEARCH REPOSITORY @ WVU

Graduate Theses, Dissertations, and Problem Reports

2012

\section{Evaluation of a Community-Based Osteoporosis Educational Program}

Cynthia A. Smith

West Virginia University

Follow this and additional works at: https://researchrepository.wvu.edu/etd

\section{Recommended Citation}

Smith, Cynthia A., "Evaluation of a Community-Based Osteoporosis Educational Program" (2012).

Graduate Theses, Dissertations, and Problem Reports. 4920.

https://researchrepository.wvu.edu/etd/4920

This Dissertation is protected by copyright and/or related rights. It has been brought to you by the The Research Repository @ WVU with permission from the rights-holder(s). You are free to use this Dissertation in any way that is permitted by the copyright and related rights legislation that applies to your use. For other uses you must obtain permission from the rights-holder(s) directly, unless additional rights are indicated by a Creative Commons license in the record and/ or on the work itself. This Dissertation has been accepted for inclusion in WVU Graduate Theses, Dissertations, and Problem Reports collection by an authorized administrator of The Research Repository @ WVU.

For more information, please contact researchrepository@mail.wvu.edu. 
Evaluation of a Community-Based Osteoporosis Educational Program

Cynthia A. Smith, RN, MSN, FNP-BC, CCD

Doctoral Research Project submitted to the School of Nursing

at West Virginia University

in partial fulfillment of the requirements for the degree of

Doctor of Nursing Practice

Nan S. Leslie, PhD, WHNP-BC, RNC-Chair

Susan H. McCrone, PhD, RN

Ronald C. Hamdy, MD, FRCP, FACP-Content Advisor

Department of Nursing

Morgantown, WV

2012

Keywords: Osteoporosis; Education; Community; Nurse Practitioner; Fitness Center Copyright 2012 Cynthia A. Smith 


\author{
ABSTRACT \\ Evaluation of a Community-Based Osteoporosis Educational Program \\ Cynthia A. Smith
}

\title{
Background
}

Research has shown low levels of osteoporosis knowledge and utilization of bone healthy behaviors among community members. Osteoporosis educational programs have been shown to improve osteoporosis knowledge and bone healthy behaviors. A review of the literature on community-based osteoporosis education is suggestive a onetime program led by nurse would be of benefit. The purpose of this study was to evaluate the impact of an osteoporosis workshop led by a nurse practitioner that was held in a fitness center.

\section{Objectives}

Objectives of this evaluation include enhancing subjects' knowledge about osteoporosis and bone healthy behaviors, improving participants' perception of meeting personal bone healthy goals, improving participants' daily calcium and vitamin D intake, and improving subjects' physical activity levels.

\section{Design}

A repeated-measures design with measurements taken pre-intervention, immediately postintervention and one month post-intervention was used. Osteoporosis knowledge, subject perception of meeting bone healthy goals, daily calcium and vitamin D intake, and physical activity levels were measured. An anonymous survey was given to the subjects immediately post-intervention regarding their opinions and suggestions for the program.

\section{Subjects}

The population focus for the intervention was those at high risk for osteoporosis, postmenopausal women and men aged 50 years old and older.

\section{Results}

Subject perception of meeting personal bone healthy goals significantly improved postintervention. Osteoporosis knowledge significantly improved immediately post-intervention and at one month post-intervention. Daily supplemental and total calcium and vitamin D intakes increased significantly post-intervention. Significant increases in the days of the week and time spent engaging in moderate physical activity levels were found. The time spent walking on a typical day increased significantly. The majority of subjects reported the workshop was helpful and would recommend it to others.

\section{Recommendations}

The results of this study indicate a community-based osteoporosis educational intervention led by a nurse practitioner and held in a fitness center does improve participant perception of meeting bone healthy goals, osteoporosis knowledge, and the bone healthy behaviors of adequate daily calcium/vitamin D intakes and increased physical activity. Further studies using this intervention in more diverse populations are recommended. 


\section{Dedication}

I would like to dedicate this project to my beloved grandmother, Garnet Geneva White, whose bravery in the face of so many obstacles, including osteoporosis and multiple fragility fractures, was the inspiration for my work in nursing. It is my privilege to honor her memory by educating others with the fervent hope that to do so may aid others to avoid the potentially devastating consequences of osteoporosis. 


\section{Acknowledgements}

It is with deep gratitude and appreciation to those who have seen me through this journey the past four years that I write these acknowledgements.

- To my Capstone committee of Nan S. Leslie, PhD, RNC (Chair), Susan H. McCrone, PhD, RN, and Ronald C. Hamdy, MD, FRCP, FACP (Content Advisor), I cannot thank you enough for your support, recommendations, and encouragement. I am a far better clinician, writer, and person now than I was at the beginning of this endeavor.

- To my wonderful professors of West Virginia University who continually offered both encouragement and assistance along the way. Thank you for helping me to set the bar a little bit higher each time.

- To the patients, staff, nurses, and physicians of Renal Consultants, PLLC/Greater Charleston Dialysis/Greater Boone Dialysis who encouraged my doctoral studies with their kind words and support. A special thank you to Julian Espiritu, Jr., MD, FACP, whose unquestioning confidence in me buoyed me on the challenging days of this journey.

- To the staff and administration of the Charleston Family YMCA, Charleston, WV, whose generosity in hosting the osteoporosis workshops and opening them to the public at large was truly inspiring. In particular, the efforts and support of Celia Givens, Associate Executive Director, and Cindy Boggs, Healthy Living Coordinator, for these workshops is to be commended. Thank you so much for your support and your efforts in promoting and encouraging a healthy lifestyle.

- Words cannot express my gratitude to my family. To my parents, Bob and Shelba Smith, and to my sister, Tammy Williams, my brother-in-law, Will Williams, and my nephew, 
Sean Williams, your never-ending supply of love, patience, and support were never in doubt. 


\section{Table of Contents}

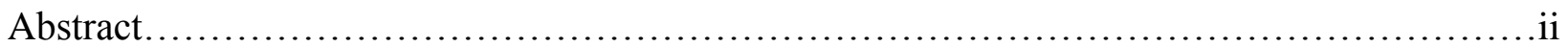

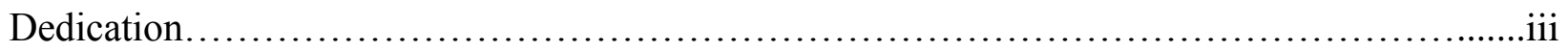

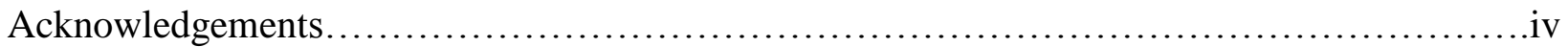

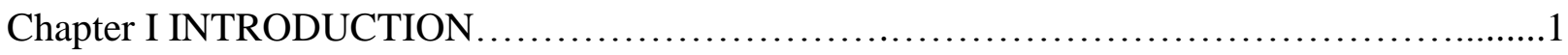

Chapter II BACKGROUND AND SIGNIFICANCE $\ldots \ldots \ldots \ldots \ldots \ldots \ldots \ldots \ldots \ldots \ldots \ldots \ldots \ldots \ldots 1$

Pathophysiology of Osteoporosis/Osteopenia.............................................. 1

Prevalence and Morbidity of Osteopenia/Osteoporosis.................................

West Virginia Prevalence Data for Osteoporosis and Osteopenia......................4

Chapter III RISK FACTORS FOR OSTEOPOROSIS/OSTEOPENIA $\ldots \ldots \ldots \ldots \ldots \ldots \ldots \ldots \ldots . . \ldots$

Chapter IV OSTEOPOROSIS KNOWLEDGE AND BELIEFS $\ldots \ldots \ldots \ldots \ldots \ldots \ldots \ldots \ldots \ldots \ldots . \ldots$

Chapter V BONE HEALTHY BEHAVIORS .........................................

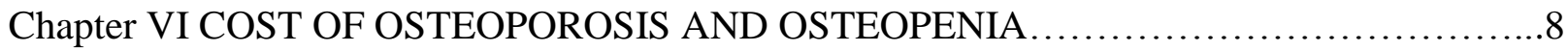

Chapter VII TREATMENT RECOMMENDATIONS FOR OSTEOPOROSIS AND

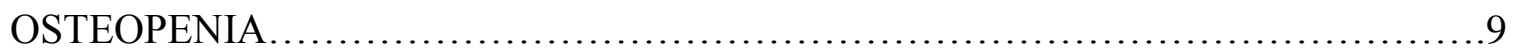

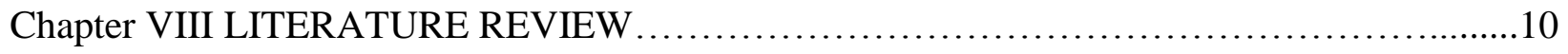

Randomized Controlled Trials.............................................. 12

Quasi-Experimental Studies..................................................24

Longitudinal Studies...................................................29

Synthesis..............................................................

Statewide Osteoporosis Program............................................. 38

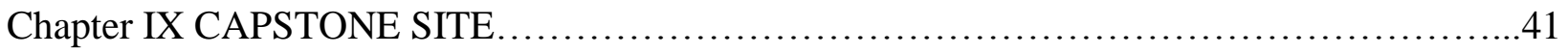

Chapter X CAPSTONE PROJECT DESIGN.......................................41 
Theoretical Foundation of the Capstone Project.................................42

Ethical Considerations........................................................... 46

Chapter XI INSTRUMENTS/QUESTIONNAIRES ..................................46

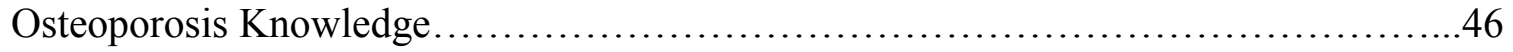

Calcium and Vitamin D Intake...........................................47

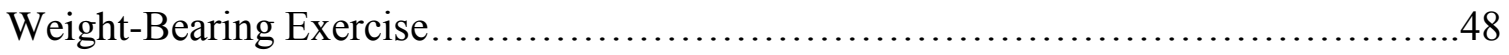

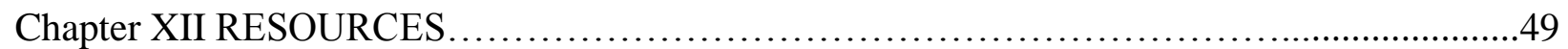

Chapter XIII RESULTS........................................................49

Instrument/Questionnaire Return Rates......................................51

Demographics....................................................... 54

Meeting Personal Bone Healthy Goals .........................................54

Osteoporosis Knowledge..................................................55

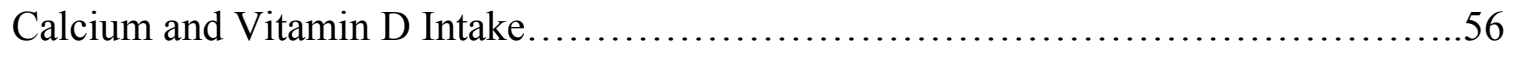

Activity Levels............................................................57

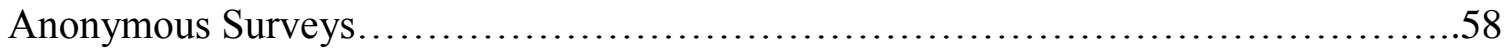

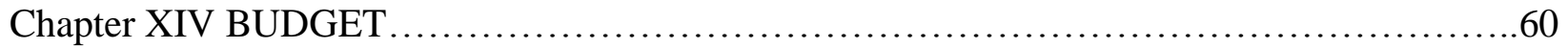

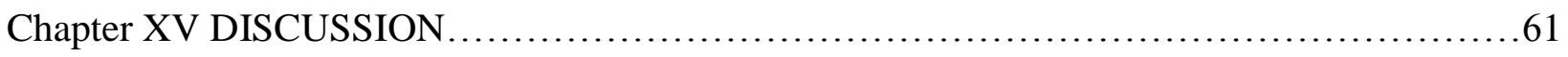

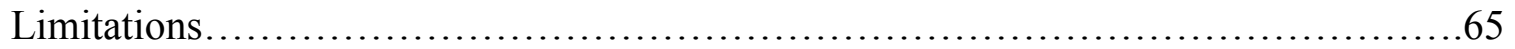

Chapter XVI CONCLUSION....................................................66

References...................................................................6 68

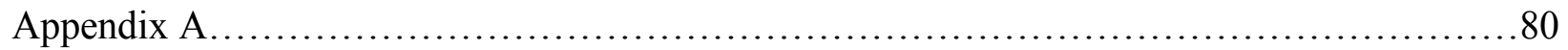

Appendix B................................................................. 81

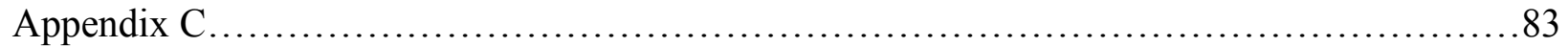




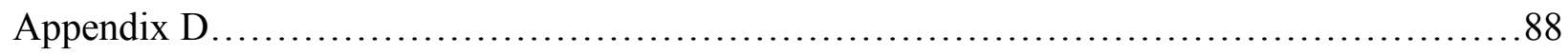

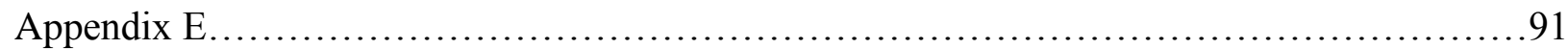

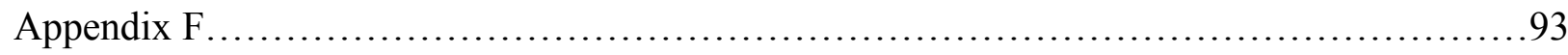

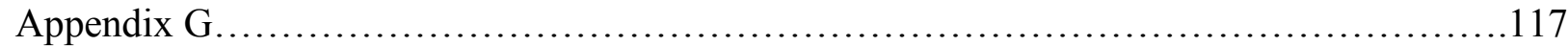

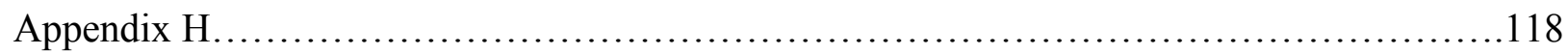

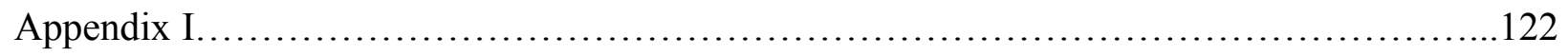

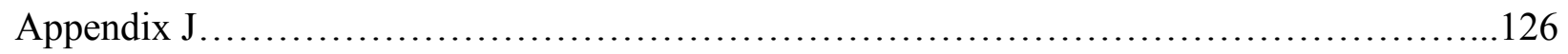

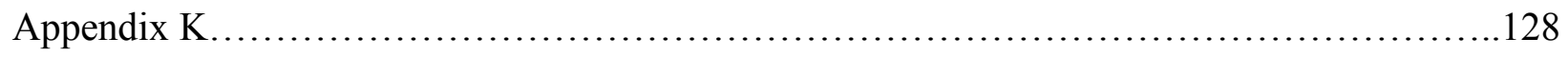

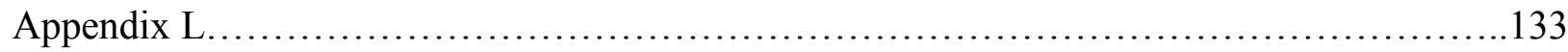

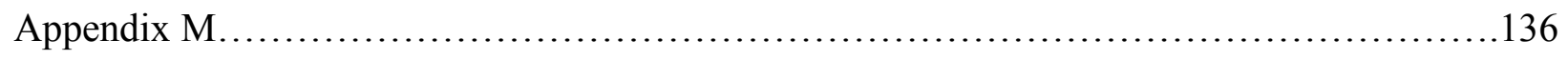

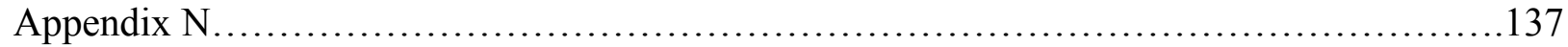

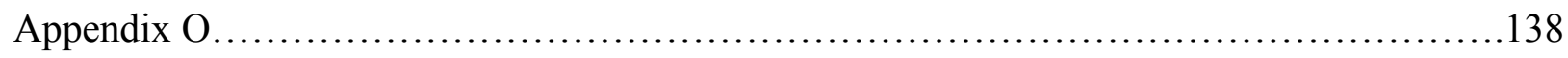

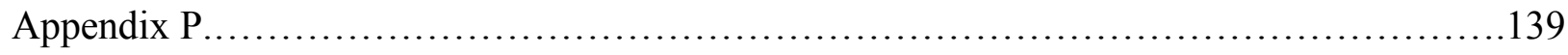

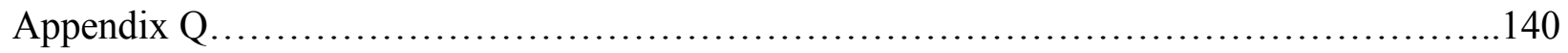

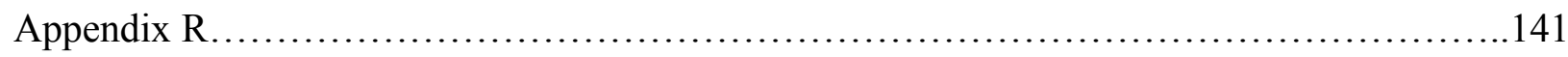

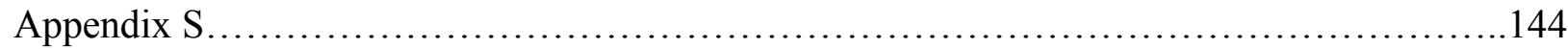

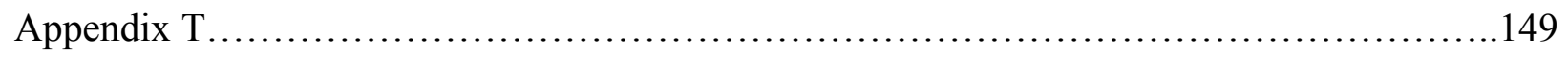

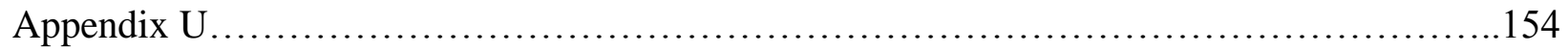

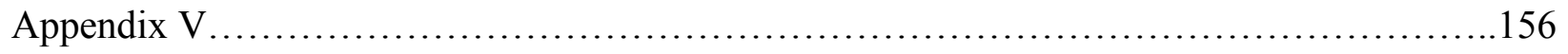

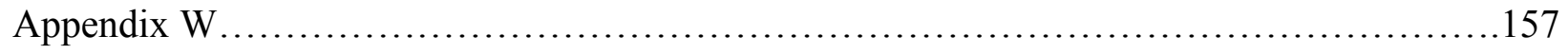

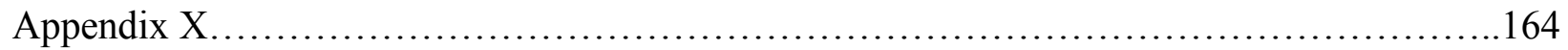

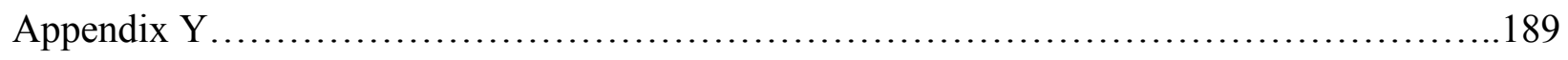

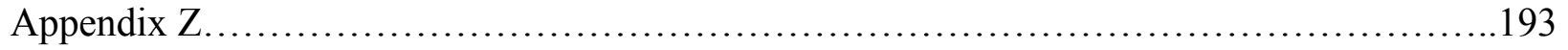




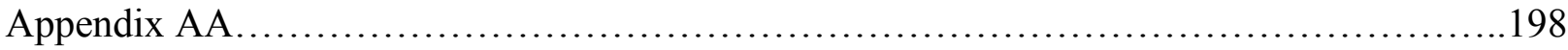

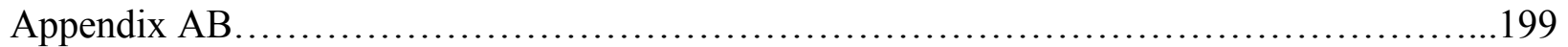

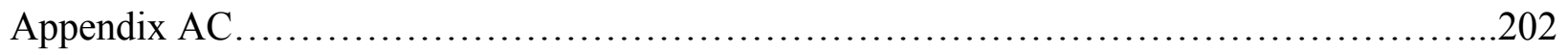

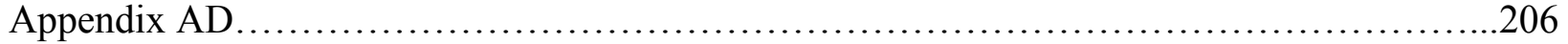

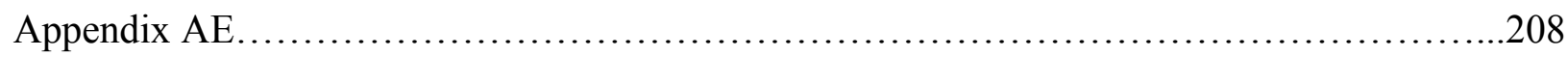

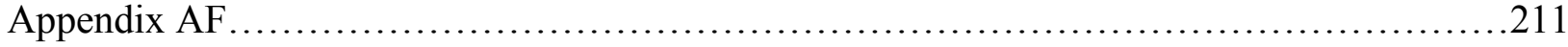

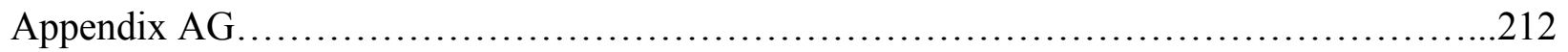

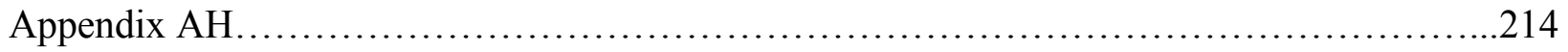

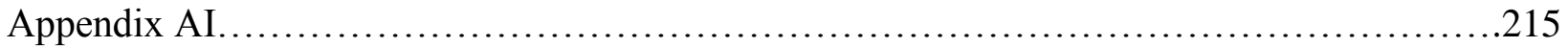

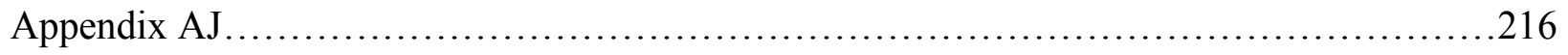




\section{CHAPTER I INTRODUCTION}

Osteoporosis is the most commonly diagnosed bone disease today, and is defined as "a skeletal disorder characterized by compromised bone strength, predisposing to an increased risk of fracture" (National Institutes of Health, 2000, p. 9). This disease, which is considered preventable, is often under-diagnosed and under-treated. With increased risk for an osteoporotic fracture, there is an increase in the risk for preventable morbidity and mortality (National Osteoporosis Foundation (NOF), 2010). The purpose of this project is to evaluate a communitybased osteoporosis educational program led by a nurse practitioner and conducted at a health and fitness center. The program focused on enhancing knowledge of the disease and bone healthy behaviors for the participants. The population focus was for those at high risk for osteoporosis; men aged 50 years old and older and post-menopausal women (NOF, 2010).

\section{CHAPTER II BACKGROUND AND SIGNIFICANCE}

\section{Pathophysiology of Osteoporosis/Osteopenia}

Bones are continually being both torn down and rebuilt. The human skeleton is almost completely rebuilt every ten years (U. S. Department of Health and Human Services, 2004). An individual's peak bone density or mass is typically achieved between the ages of 18 to 25 years old. Bone strength is usually maintained until the late 30 s to early 40 s. At that time, an imbalance between bone buildup and bone destruction begins to occur with more bone being resorbed than is rebuilt. For women, the onset of menopause worsens this imbalance, particularly during the first five years post-menopause. By age 65, both women and men are losing bone at the same rate (U. S. Department of Health and Human Services, 2004). The bone building and destructive process (remodeling process) can be affected by multiple factors such as certain medications, nutritional status, physical activity level, excess intake of alcoholic 
beverages, cigarette smoking, excess salt and caffeine intake, and specific diseases. With the loss of bone mineral density (BMD), there is a concurrent weakening of the bone's architecture and an increased risk for a fracture (NOF, 2010).

Osteoporosis can be diagnosed in one of two ways. The first is through the presence of a fragility type fracture (U. S. Department of Health and Human Services, 2004). These are fractures that occur in a situation where a fracture normally would not have occurred such as from a fall from standing height or less. The second is through measurement of the BMD. While there are numerous ways to measure BMD, the axial dual-energy X-ray densitometry (DXA) is the gold standard in conducting bone mineral density testing. This testing method creates the measurement unit of a T-score that is used in the World Health Organization's (1994) definition of osteoporosis and osteopenia. The T-score is obtained by comparing an individual's BMD to the mean BMD of a young normal reference group. A precursor to osteoporosis, low bone mass or osteopenia, is a DXA T-score between -1.0 and -2.5, while osteoporosis is defined as having a DXA T-score equal to or less than -2.5 (Kanis, Melton, Christiansen, Johnston, \& Khaltaev, 1994). With a decrease in BMD, the fracture risk is proportionally increased. While measurement of BMD is the single most important predictor of fractures, there are other risk factors that can affect an individual's risk for a fragility fracture. The Fracture Risk Assessment Tool (FRAX) algorithm developed through sponsorship by the World Health Organization takes into account the major risk factors on an individual basis. The algorithm provides calculations for an individual's likelihood over the next ten years of either a major fracture and/or a hip fracture due to low bone mass or osteoporosis (Kanis et al., 2005). 


\section{Prevalence and Morbidity of Osteopenia/Osteoporosis}

Internationally, an estimated 200 million people have osteoporosis (Cooper, Campion, \& Melton, 1992). In 2000, nine million osteoporotic fractures occurred worldwide with 1.6 million affecting the hip. The largest fracture prevalence (34.8\%) is in European countries. Of all fractures that occur worldwide, $15.7 \%$ of these occur in the Americas (Johnell \& Kanis, 2006). In North America and Europe, 30\% of postmenopausal women have osteoporosis with a $40 \%$ lifetime chance of a fragility fracture (Melton, Chrischilles, Cooper, Lane, \& Riggs, 1992).

In the United States, osteoporosis and osteopenia affected 55\% (44 million) of people aged 50 or older in 2002. In 2010, 52.4 million Americans had osteoporosis with a projected 61.4 million having the disease by 2020 (NOF, 2002). After the age of 50, current estimates are for one in two women and one in five men to have an osteoporosis-related fracture. Annually, 1.5 million people have a fracture due to osteoporosis (U. S. Department of Health and Human Services, 2004). Compared to the combined lifetime risk of developing ovarian, breast and uterine cancer, a woman is more likely to suffer an osteoporotic-related hip fracture (NOF, 2002).

While osteoporosis can lead to fractures in any of the bones, the most common fracture sites are vertebral, hip, and forearm. Osteoporotic fractures are often associated with chronic pain, increased mortality, and can negatively impact one's ability to perform activities of daily living (U. S. Department of Health and Human Services, 2004). Hip fractures are associated with the worst morbidity and mortality rates (NOF, 2010). One year after a hip fracture, $60 \%$ are unable to return to their full pre-fracture ambulatory status (Greendale \& Barrett-Conner, 2001). Among older patients, $20 \%$ of older patients die within one year from health issues related to or worsened by the fracture (U.S. Department of Health and Human Services, 2004). 


\section{West Virginia Prevalence Data for Osteoporosis and Osteopenia}

In 1996, an estimated $60.4 \%$ of West Virginia (WV) female residents, aged 50 years old or older, had either osteopenia or osteoporosis with an increase in 2002 to $77.5 \%(251,300)$. For males aged 50 years old or older, the prevalence of both osteopenia and osteoporosis increased from $17 \%$ in 1996 to $44.4 \%(118,600)$ in 2002 . In $2010,285,500 \mathrm{WV}$ women and 139,300 men,

aged 50 years and older, had either osteoporosis or osteopenia. This will increase to an estimated 311,600 women and 154,700 men in 2020 (NOF, 2002).

In a study of women aged 50 years old or older living in rural WV, peripheral DXA testing of the radius was used to evaluate 1,321 women. Of those screened, $317(26.6 \%)$ were found to have osteoporosis. Of those aged 65 years old and older, 251 (56.3\%) were osteoporotic (Pfister, Helmick, Saville, Welch, \& Emmett, 2008).

In WV, during 2001, there were 23,394 hospitalizations due to a fracture with an estimated hospital cost of $\$ 41.5$ million for those aged 45 years old or older. Of these fractures, 65.4\% were confirmed due to osteoporosis. Between 1995 and 2015, projections are for 8,400 WV women 50 years old and older to die within the first year after a hip fracture (West Virginia Department of Health and Human Resources, 2004).

\section{CHAPTER III RISK FACTORS FOR OSTEOPOROSIS/OSTEOPENIA}

Advancing age is highly correlated with the development of osteoporosis or osteopenia (NOF, 2010). In the 2010 population census, 16\% of WV's population was 65 years or older (U. S. Census Bureau, 2012). Other risk factors include: being Caucasian, cigarette smoking, low physical activity, and excess alcohol intake (NOF, 2010). Census estimates for 2010 for racial diversity in WV indicated $93.9 \%$ of the population statewide was Caucasian with Kanawha County's population being $89.1 \%$ Caucasian. African Americans made up $3.4 \%$ of the state's 
racial diversity and $7.3 \%$ of Kanawha County's population. The remaining populations $(2.7 \%$ statewide and 3.6\% Kanawha County wide) were composed of other minority groups (U. S. Census Bureau, 2012). Those residents who reported not getting any exercise included $25.8 \%$ of Kanawha County residents. Among county residents, 24.9\% smoked cigarettes. In 2006, 3.2\% of all WV residents reported heavy consumption of alcoholic beverages (more than one drink a day for a female and more than two drinks a day for a male) (WV Department of Health and Human Services, 2009).

\section{CHAPTER IV OSTEOPOROSIS AND HEALTH BELIEFS}

Studies have investigated osteoporosis knowledge and health beliefs of both genders and those considered at high risk for osteoporosis. Johnson, McLeod, Kennedy, and McLeod (2008) evaluated osteoporosis health beliefs between the genders and among three different age groups (aged 18 to 25 years old, 30 to 50 years old and older than 50 years old). Women scored higher on susceptibility concerns than did males, especially males aged 18 to 25 years old. Women aged 30 years or older felt they were more susceptible to the disease than younger women and males of various ages. Higher susceptibility scores were found in those women older than 50 years. No differences were found between the age groups or the genders in terms of health motivating factors or the perceived seriousness of osteoporosis (Johnson et al., 2008).

A study of women aged 40 to 95 years old found $89 \%$ perceived osteoporosis as a serious condition. However, only $29 \%$ believed they were likely to develop the disease. A recommendation from their physician was felt to be important to $90 \%$ of the women in initiating osteoporosis prevention behaviors. Participation in bone healthy behaviors to help prevent osteoporosis were found in $40 \%$ of the subjects, but $90 \%$ of the participants was willing to exercise, take calcium, and multivitamin supplementation. A positive correlation was found 
between those who noted concern about developing osteoporosis and those who engaged in bone healthy behaviors ( $\mathrm{p}=.03$ ) (Hsieh, Novielli, Diamond, \& Cheruva, 2001).

Several studies have found a positive correlation with lower levels of osteoporosis knowledge and poorer adherence to bone healthy behaviors. A study of residents, 65 years and older, living in retirement communities found $83.7 \%$ had inadequate daily dietary calcium intake. The vast majority, 95.9\%, were not getting the daily recommended amount of vitamin D. On a test of osteoporosis knowledge, $64 \%$ gave the incorrect answer to more than half of the questions. There was an association found between higher osteoporosis knowledge, reduced risk of falls, a higher self-efficacy, and greater strength of the lower extremities (Burke-Doe, Hudson, Werth, \& Riordan, 2008). Chang, Chen, Chen, and Chung (2003) found low levels of osteoporosis knowledge were associated with low dietary intake of calcium, perception of barriers to improved bone healthy behaviors, and intent to change the behaviors. A high positive correlation was found between one's intent to change the bone healthy behaviors and one's osteoporosis knowledge.

Terrio and Auld (2002) studied the differences among three age groups of women (25 to 35 years old, 36 to 46 years old, and 50 years old and older) regarding osteoporosis knowledge, calcium intake and physical activity levels. All three groups were found to have low levels of osteoporosis knowledge. Physical activity measures were similar among the three groups. Most subjects did not meet the daily recommended intake of calcium, and this was found to worsen with advancing age (Terrio \& Auld, 2002).

In a descriptive study, Sedlak, Doheny, \& Estok (2000) evaluated the osteoporosis knowledge, bone healthy behaviors, and health beliefs of males older than 65 years old. Low levels of osteoporosis knowledge were found (mean score of $50 \%$ on the osteoporosis knowledge 
test) as well as a low perceived susceptibility to osteoporosis. While a moderate level of confidence in performing the bone healthy behaviors was observed, the men were noted to engage in few bone healthy behaviors. The mean intake of daily calcium was well below the recommended level. One-third of the subjects participated in some form of weight bearing exercise (Sedlak, Doheny, \& Estok, 2000).

\section{CHAPTER V BONE HEALTHY BEHAVIORS}

The NOF (2010) defines bone healthy behaviors as adequate daily calcium and vitamin D intake, fall prevention behaviors, use of weight-bearing exercise, and avoidance of cigarettes and excess alcohol intake (three or more drinks a day). Information is available on the bone healthy behaviors of WV residents. In 1999, 83.3\% of WV males and 85.7\% of WV women, 18 years old and older, were not consuming the three daily recommended servings of dairy foods. Those taking a calcium supplement on a regular basis were $7.5 \%$ of surveyed males and $29.2 \%$ of

females (WV Department of Health and Human Resources, 1999). A study of women aged 65 years and older who lived in southern WV found every subject $(n=184)$ consumed less than the recommended amount of calcium on a daily basis (Pfister, Wulu, \& Saville, 2001). Analyzing data from the Behavioral Risk Factor Survey of 1999, the WV Osteoporosis and Arthritis Program estimated seven out of ten post-menopausal women had at least three or more risk factors for osteoporosis (WV Department of Health and Human Resources, 2004). The 2006 WV Behavioral Risk Factor Survey found 25.4\% of West Virginians reported smoking (26.1\% males and $25.7 \%$ females), $21 \%$ did not exercise (29.9\% males and $25.6 \%$ females), and $4.8 \%$ reported high intake of alcoholic beverages (1.7\% males and 3.2\% females) (West Virginia Department of Health and Human Resources, 2009). 
Gordon, Newcomer, and Krummel (2001) found that, while many WV residents were aware of the bone healthy benefits of exercise, most did not engage in regular physical activities. More than $88 \%$ felt weight-bearing exercise was beneficial for osteoporosis, but only $20 \%$ engaged in this type of activity. No regular physical activity was reported in $18 \%$ of respondents ( $19 \%$ of males and $17 \%$ of females). Participation in regular physical activity was reported in $28 \%$ of respondents ( $26 \%$ of males and $29 \%$ of females). Subjects were asked if they endorsed physical activity as beneficial for their health. Of those who did endorse physical activities, $29.3 \%$ were regularly physically active. Males who endorsed physical activity were more likely to be active (29.2\%) than those who did not endorse physical activity (16.7\%). Among females, no significant difference was found in the amount of exercise among those who did and did not endorse exercise (Gordon et al., 2001).

Limited exposure to osteoporosis education from a healthcare provider has been found in WV. The 1999 WV Behavioral Risk Factor Survey of those aged 18 years old and older found $22.5 \%$ of those surveyed had received osteoporosis education from a healthcare professional (35.1\% of women and 9.5\% of men) (WV Department of Health and Human Resources, 1999). The 2004 WV Behavioral Risk Survey found an increase in women who had received osteoporosis education to $43.1 \%$, but for males this had decreased to $9.2 \%$ (WV Department of Health and Human Resources, 2007).

\section{CHAPTER VI COST OF OSTEOPOROSIS AND OSTEOPENIA}

Osteoporosis is associated with significant negative economic consequences. Yearly, osteoporosis-related fractures are estimated to account for 432,000 hospital admissions nationwide. Annually, 180,000 nursing home admissions and 2.5 million medical office visits occur due to osteoporotic fractures. In 2005, the projected healthcare cost for these fractures was 
\$17 billion (U. S. Department of Health and Human Services, 2004). In comparison to 2004 national data, experts predict data collected in 2010 will indicate the number of hip fractures has doubled or tripled in the United States (U. S. Department of Health and Human Services, 2004).

Healthcare costs should be improved with a reduction in fractures. During a five year period, a study done by eleven Kaiser Centers in California found increased use of DXA testing and treatment for osteoporosis correlated with a $37 \%$ reduction in the number of hip fractures. This translated to an annual $\$ 30.8$ million savings in healthcare costs (Dell, Greene, Schelkun, \& Williams, 2008). Due to a reduction in the number of fractures, Kelton and Pasquaqle (2009) found healthcare cost savings from $\$ 13,932$ to $\$ 18,256$, depending on the fracture type, from adherence to osteoporosis drugs. In analyzing data from the five year period after starting their comprehensive osteoporosis management program, the Geisinger Health Plan found a \$7.8 million dollar healthcare cost savings due to a reduction in post-menopausal hip fractures (Newman, Ayoub, Starkey, Diehl, \& Wood, 2003).

Pfister, Sale, and Shaukat (2009) projected the cost of osteoporotic fractures for West Virginians over a five year period. Direct medical costs were estimated to be $\$ 105$ million. Taking into account proper diagnosis and subsequent adherent treatment of osteoporosis in every fracture case, a $\$ 45$ million savings was calculated. Considering the current under-diagnosis of the disease and subsequent under-treatment, the authors estimated less than $\$ 1$ million to $\$ 3.1$ million of these cost savings were being achieved (Pfister et al., 2009).

\section{CHAPTER VII TREATMENT RECOMMENDATIONS FOR OSTEOPOROSIS AND OSTEOPENIA}

Treatment recommendations for osteoporosis and osteopenia are composed of both nonpharmacological and pharmacological interventions. Limited adherence to pharmaceutical 
interventions for osteoporosis has been found. After one year, adherence with oral bisphosphonates, the most commonly recommended prescription drug class for the disease, varied in one systematic review from $17.9 \%$ to $78 \%$ (Cramer, Gold, Silverman, \& Lewiecki, 2007). Another systematic review found one-third to one-half of patients did not take their osteoporosis medications as ordered with many discontinuing therapy shortly after it was prescribed (Kothawala, Badamgarav, Ryu, Miller, \& Halbert, 2007).

In considering non-pharmacological treatment options, the National Osteoporosis Foundation's Clinician's Guide to Prevention and Treatment of Osteoporosis (2010) contends that all those with, or at risk for, osteoporosis should receive education on the physiology of bone loss, factors which affect the disease's development, and use of bone healthy behaviors. The bone healthy behavior recommendations are based upon a literature review and synthesis of the body of osteoporosis research by a panel of experts. These behaviors include: weight-bearing exercises, fall prevention behaviors, adequate daily calcium and vitamin D intake, and avoiding smoking and excess alcohol intake (three or more drinks a day) (NOF, 2010).

A concurrent reduction in fracture risk and the incidence of fractures should be seen with an increase in bone healthy behaviors. A study of the effects of a community-based osteoporosis and fall prevention program was conducted in a rural Swedish community. Comparing the five years before and the ten years after the initiation of the program to the fracture rates of a similar control community, a significant decrease in the number of trochanteric hip and forearm fractures was found in the intervention group (Grahn Kronhed et al., 2005).

\section{CHAPTER VIII LITERATURE REVIEW}

Inclusion criteria for the literature search included a community-based educational intervention for those with osteoporosis/osteopenia or at high risk for the disease in comparison 
to either usual care or no intervention. The population defined as being at high risk for osteopenia/osteoporosis included males aged 50 years or older and/or post-menopausal females. The role of educator could be filled by either a healthcare professional, such as a pharmacist or professional nurse, or a multi-disciplinary healthcare professional team. To be included in the literature synthesis, the educational intervention had to have pre-intervention and postintervention measurements regarding one or more of the bone healthy behaviors.

Databases searched included the Cochrane Library, National Guidelines Clearinghouse, CINAHL, PubMed, Health and Psychosocial Instruments, Complete Biological Abstracts from 1969-present, HealthSource: Nursing/Academic, International Pharmaceutical Abstracts, Academic Search, and Medline. Searching for the keyword "osteoporosis" resulted in over 123,890 hits. Searching with the addition of the keywords "education" and "community" reduced this to 730 hits. Further searches were conducted using the keywords and combinations of keywords, including osteoporosis, osteoporosis prevention, teaching, health education, nurse, patient, and community, which reduced the number of hits. No limits were placed on the type of evidence, population, setting, or geographic location, but studies were limited to the English language. No time limits were placed on the searches and included studies up to June, 2012. Reference lists were hand-searched for further relevant studies. No meta-analyses or clinical practice guidelines were found in regards to community-based osteoporosis educational interventions.

Sixteen studies were found which met all of the inclusion criteria. There was one systematic review, seven randomized controlled trials (RCTs), four quasi-experimental trials, and four descriptive longitudinal studies (Brecher et al., 2002; Chan \& Ko, 2006; Chan, Ko, \& Day, 2005; Davis, White, \& Yang, 2006; Driskell, Pohlman, \& Naslund, 2003; Gaines, Narrett, 
\& Parrish, 2010; Newman \& Hanus, 2001; Nielsen et al., 2008; Pearson, Burkhart, Pifalo, Palaggo-Toy, \& Krohn, 2005; Ribeiro \& Blakeley, 2001; Rolnick, Kopher, Jackson, Fischer, \& Compo, 2001; Schousboe et al., 2005; Sedlak, Doheny, Estok, \& Zeller, 2005; Smith, 2010; White, 2008; Yuskel, Majunder, Biggs, \& Tsuyoki, 2010). The systematic review was written by the author, and included ten of the studies noted above (Smith, 2010). This literature synthesis is an extension of that review with inclusion of five additional studies (Brecher et al., 2002; Driskell et al., 2003; Gains et al., 2010; White, 2008; Yuskel et al., 2010) found after publication.

Excluding the systematic review, all 15 studies were appraised using an appropriate evaluation form. The seven RCTs were individually appraised for study description, internal validity, and an overall assessment of the study using the Scottish Intercollegiate Guidelines Network (SIGN) RCT form as a guide (SIGN, 2008). The four quasi-experimental and four descriptive longitudinal comparative studies were analyzed using the quantitative literature review form found in Larrabee (2009).

\section{Randomized Controlled Trials}

In their randomized controlled trial, Rolnick, Kopher, Jackson, Fischer, and Compo (2001) assessed the impact of women's health nurse practitioner-led osteoporosis education, with and without BMD testing, on the initiation of bone healthy behaviors and pharmaceutical osteoporosis treatments in post-menopausal women not currently on osteoporosis therapy. The subjects were participants in a large managed care organization. The study had three groups; a control group, an education only group, and an education and BMD testing group. The educational session (two hours long) focused on osteoporosis, bone healthy behaviors, and treatment options. The BMD test was of the forearm with interpretation of the results given to 
the subjects at the time of the test. The subjects in the control group were matched to the subjects in both intervention groups. Measurements were taken pre-intervention and at six months post-intervention. There were a total of 695 subjects, all female. Ages ranged from 54 to 65 years. The education only group had 301 (43\%) subjects, the education group with BMD testing had 207 subjects (30\%), and 187 (27\%) were in the control group. Measurements were taken regarding the subject's potential risk of osteoporosis with the Simple Calculated Osteoporosis Risk Estimation instrument (Cadarett, Jaglal, \& Murray, 1999). The authors measured the bone healthy behaviors of diet/eating patterns, type and amount of exercise, calcium intake, vitamin D intake, HRT use, and use of other osteoporosis treatment medications (Rolnick et al., 2001).

Compared to the control group, both the education only group and the education with BMD group showed significant increases in bone healthy behaviors; improvement of nutrition $(\mathrm{p}<.001)$, increased calcium intake $(\mathrm{p}<0.01)$, and improved vitamin $\mathrm{D}$ intake $(\mathrm{p}<.0001)$. Of the $455(90 \%)$ intervention group participants completing the study, there were no group differences in bone healthy behaviors except for use of a pharmaceutical agent for osteoporosis. Subjects in the education and BMD testing group were three times more likely to start hormone replacement compared to those in the education only group $(\mathrm{p}=.004)$. Use of other types of osteoporosis medications was not significant. For those in the education and BMD intervention group, there was a positive association for low BMD scores and starting medication $(\mathrm{p}=.001)$ and for increasing vitamin D intake (p=.03) (Rolnick et al., 2001).

There are several strengths and limitations of this study. Strengths include randomization of the subjects with a sample size large enough to detect differences between groups. The control group subjects were matched with subjects in the intervention group for year of birth and 
home clinic. Limitations of the study include subjects' self reporting their bone healthy behaviors. No information on the validity and reliability of the questionnaires used to measure the bone healthy behaviors was noted. The non-blinding of the subjects and researchers may have impacted the results. The researchers noted many subjects reported disappointment at being assigned to the education only group as they had hoped to be in the education and BMD testing group. Those assigned to the education only group were more likely not to attend the educational activity compared to those in the education/BMD group (124 subjects or $29 \%$ versus 22 subjects or 10\%, $\mathrm{p}=<.001)$ (Rolnick el al., 2001).

In their randomized controlled trial, Schousboe and colleagues (2005) evaluated the impact of an osteoporosis education program held in a healthcare clinic on initiation and persistence with prescription osteoporosis treatment, calcium intake, and exercise for women at high risk for osteoporosis, independent of DXA testing. The study was composed of a nurse-led education group and a control group. Measurements were taken pre-intervention and at three months, six months, nine months, and twelve months post-intervention for those in the education group. Measurements were taken at pre-intervention and at twelve months post-intervention for the control group. There were 310 subjects, all female. In the nurse-led education group, there were 158 subjects (51\%) with a mean age of 71.8 years. The control group had 152 subjects (49\%) with a mean age of 73.1 years (Schousboe et al., 2005).

Those in the control group received the usual care which was the provision of two brochures on osteoporosis after their DXA testing. Those in the education group received the same two educational brochures along with a fifteen minute one-on-one osteoporosis educational session with a nurse immediately after the subject's DXA testing. The nurse educator also 
discussed calcium intake, exercise habits, and medication use at three, six, and nine months postintervention (Schousboe et al., 2005).

The Simple Calculated Osteoporosis Risk Estimation (SCORE) form was used to calculate risk of osteoporosis (Lydick et al., 1998). Questionnaires were used which asked about the subjects' use of calcium supplements/dairy products, use of hormone replacement, cigarette smoking history, exercise habits, personal and family history of fractures, and use of medications that may impact BMD. A script was used by the nurse educator in the telephone counseling sessions for the intervention group at three, six, and nine months post-intervention. The script included questions about the subjects' intake of calcium supplements and/or daily intake of calcium-rich foods, exercise frequency, and osteoporosis medication use. A script was also used when interviewing both groups at the twelve months post-intervention measurement interval. Questions were asked about the subjects' use of osteoporosis medication, changes in calcium intake, and use of weight bearing exercise. At the twelve month post-intervention measurement point, there were no significant differences between the groups for initiation and persistence with osteoporosis drug treatment. The nurse-led education group did show a significant difference for increased calcium intake $(\mathrm{p}<.05)$ and exercise frequency $(\mathrm{p}<0.05)($ Schousboe et al., 2005).

There are strengths and limitations of the study. One strength of the study is use of the randomized controlled design. Another is the large number of study participants. One limitation is the data collector was not blinded to group assignment. The subjects also self-reported their bone healthy behaviors. No information on the reliability and validity of the questionnaires used to measure the defined bone healthy behaviors was reported (Schousboe et al., 2005).

Nielsen et al. (2008) evaluated the effect of multidisciplinary-provider education program for patients with osteoporosis on knowledge. The multidisciplinary-provider team was 
comprised of physicians, dieticians, physiotherapists, and a nurse. The intervention group was provided with three educational classes on osteoporosis led by the education team. The intervention group was also given the opportunity to participate in a reinforcement program where they were called once a month and asked about issues such as pain intensity, quality of life, and physical activity level. The control group was given usual care. However, those in the control group with a history of fractures were offered instruction on exercise (Nielsen et al., 2008).

There were 300 subjects in Nielson et al.'s study (2008). The intervention group included 150 subjects $(50 \%)$ with an age range from 45 to 81 years old with a median age of 63 years old. The control group was composed of 150 subjects (50\%) with an age range from 48 to 80 years old with a median age of 64 years old. All of the subjects were patients with osteoporosis who had been started on medication for the disease within the past year. At three months follow-up, the intervention group had 141 subjects (127 women (90\%) and fourteen men (10\%)) with nine having dropped out. In the control group, 128 subjects remained with 22 having dropped out. Of those remaining, 115 were women (90\%), thirteen were men (10\%) (Nielsen et al., 2008).

Measurements were taken pre-intervention and at three months post-intervention. Measurements included: subjects' age, sex, educational level, and the time spent reading about health on a daily basis. Osteoporosis knowledge was measured with the Patients' Knowledge of Osteoporosis instrument (Ryg, Nissen, Nielsen, \& Brixen, 2005) given at the study's beginning and three months later. Baseline osteoporosis knowledge scores were significantly associated with sex $(\mathrm{p}=.000)$ with females having higher scores. Baseline osteoporosis knowledge scores were also significantly associated with level of education with higher educational levels having more osteoporosis knowledge (p<.001) (Nielsen et al., 2008). 
For the intervention group, there was an increase in osteoporosis knowledge postintervention compared to the control group $(\mathrm{p}<.001)$. A subject's level of education and baseline osteoporosis knowledge score were found to be significantly and positively correlated $(\mathrm{p}<.001)$. For the intervention group, there was a significant inverse correlation between educational level and the change in osteoporosis knowledge $(\mathrm{p}<.01)$. At baseline, there was a significant association between time spent reading about health issues and osteoporosis knowledge $(\mathrm{p}=.001)$. Post-intervention, there was no significant association between time spent reading about health and a change in the knowledge measurements for either group (Nielsen et al., 2008).

There are strengths and limitations of this study. A strength of the study is its randomized controlled trial design. Osteoporosis knowledge was measured with a previously validated and reliable instrument. A possible limitation is the undetermined influence of exercise instruction for an unknown number of control group subjects. Those in the control group who had a history of previous vertebral or hip fractures were offered instruction on exercise by a physiotherapist. The authors did not report how many in the control group took part in this instruction. A second limitation is that while the subjects were asked about bone healthy behaviors such as exercise, the authors did not discuss specific post-intervention measurements in regards to changes in these behaviors. Another limitation may have been the study's setting which was not discussed. The authors did report receiving funding from several groups in Scandinavia. As it is not known if the subjects were from a rural and/or urban setting, generalization of this study's findings to these groups and to those from other countries may be more difficult (Nielsen et al., 2008).

In their randomized controlled trial, Chan, Ko, and Day (2005) assessed the effects of a nurse-led educational program with phone call follow-ups on osteoporosis prevention behaviors 
and the subjects' attitude toward these behaviors. There were 41 subjects, all of whom were female, who had not been diagnosed with osteoporosis. The intervention group was composed of 20 subjects (49\%) with 21 participants $(51 \%)$ in the control group. Subjects were included if they were over 18 years old with the majority of recruits $(36.4 \%)$ being between 41 to 45 years old (Chan et al., 2005).

The intervention group received a 45 minute educational program on osteoporosis, the importance of calcium intake, and the calcium content of different kinds of foods. The bone health behaviors of consumption of soy foods, exposure to sunlight/vitamin D rich foods, and increased physical exercise were also discussed. Follow-up phone calls were placed three to seven days post-intervention and between days 14 to 20 post-intervention to addresses questions and/or concerns in regards to the intervention. Data was collected for the intervention group preintervention, immediately post-intervention, and one month later. Data for the control group was collected at pre-intervention and one month later (Chan et al., 2005).

The researchers used a survey for both groups that was adopted from another study (Pelletier, Kundrat, \& Hasler, 2003). They also used a Likert scale for attitude measurement and data regarding the four measured bone health behaviors. The immediate post-intervention survey was formatted by the researchers to be similar to the pre-survey. A frequency chart was used on which subjects marked presumed future consumption of calcium rich foods and/or supplements. The one month post-intervention survey was designed by the researchers to be similar to the pre-and immediate post-intervention surveys in questions and style (Chan et al., 2005).

At one month post-intervention, the education group had increased consumption of soy foods $(\mathrm{p}<.001)$, milk $(\mathrm{p}<.001)$, sunlight exposure/vitamin D food intake $(\mathrm{p}<.001)$, and increased 
exercise frequency $(\mathrm{p}=.003)$ in comparison to the control group. The control group had no significant change in attitude scores from baseline to one month post-intervention. The intervention group showed significant increases in positive attitudes toward consumption of soy foods $(\mathrm{p}=.005)$, milk $(\mathrm{p}=.001)$, and vitamin $\mathrm{D}$ foods/exposure to sunlight $(\mathrm{p}=.011)$. There was no significant difference between pre-intervention attitudes and one month follow up attitude for exercise $(\mathrm{p}=.779)$. There was a significant increase in positive attitudes when comparing preintervention and immediate post-intervention data for consumption of soy foods $(p=.010)$, milk $(\mathrm{p}=.011)$, and vitamin D/sunlight exposure $(\mathrm{p}=.013)($ Chan et al., 2005).

Strengths of this study include the randomized controlled design. The study also had a sample size large enough to detect differences between the groups. A survey used in another study was used in this one allowing for comparison. There are several limitations. As the subjects were clients of a beauty clinic, the site of the educational intervention, these subjects may have been more motivated to learn about osteoporosis than the general population due to a greater concern with their health and appearance. This concern would have made the intervention look more powerful than it was. The data collector and the subjects were not blinded. The subjects' self-reported their bone healthy behaviors. The authors noted modifying the survey for the post-intervention measurements which may have impacted the validity and reliability of the instrument as well as the comparison to the pre-intervention measurement. The setting of the study was noted to be in an urban setting in Hong Kong which may limit the generalization of these findings to rural residents and to those of other countries (Chan et al., 2005).

In a follow-up replication study using a randomized controlled trial design, Chan and Ko (2006) found similar results. The research question was, does a nurse-led educational 
program on osteoporosis prevention behaviors and two follow-up phone consultations lead to increased consumption of beneficial foods and supplements and an increased positive attitude for these behaviors? As in the 2005 study, the intervention group received the same 45 minute educational program on osteoporosis, the importance of calcium intake, and the calcium content of different kinds of foods. The bone health behaviors of consumption of soy foods, exposure to sunlight/vitamin D rich foods, and increased physical exercise were also discussed. Follow-up phone calls were placed on post-intervention days three to seven and between days 14 to 20 postintervention to address questions and/or concerns in regards to the intervention. The control group received no education or phone call follow-ups. Data was collected for the intervention group pre-intervention, immediately post-intervention, and one month later. Data for the control group was collected at pre-intervention and one month later. The same instruments (Pelletier et al., 2003) and surveys from the 2005 study were used. There were 76 subjects, all female. The majority of the subjects were between the ages of 18 to 30 years old. Both groups had 38 subjects (50\%) (Chan \& Ko, 2006).

At one month post-intervention, the education group showed significantly increased consumption of soy foods $(\mathrm{p}<.001)$, milk $(\mathrm{p}<.001)$, sunlight exposure/vitamin D food intake $(\mathrm{p}<.001)$, and increased exercise $(\mathrm{p}=.01)$ when compared to the control group. The control group had no significant change in attitude scores from baseline to one month post-intervention. The intervention group showed significant increases in positive attitudes toward consumption of soy foods ( $\mathrm{p}<.001)$, milk ( $\mathrm{p}=.001)$, exercise $(\mathrm{p}=.026)$, and vitamin $\mathrm{D}$ foods/exposure to sunlight $(\mathrm{p}=0.001)$. There was significant increased positive attitudes comparing pre-intervention and immediate post-intervention data for consumption of soy foods $(\mathrm{p}=.007)$, milk $(\mathrm{p}<.001)$, doing more exercise $(\mathrm{p}=.013)$, and vitamin $\mathrm{D} /$ sunlight exposure $(\mathrm{p}<.001)($ Chan \& Ko, 2006). 
There are strengths and limitations of this study. Strengths include the use of the randomized controlled trial design and a sample size large enough to detect differences between the groups. Another is the application of the earlier study's design which aids in validating the earlier findings. Limitations include the study setting of two beauty clinics in Hong Kong. As in the 2005 study, subject inclusion bias may have occurred as these participants may have been more motivated to learn about osteoporosis and bone healthy behaviors due an increased concern with their health and appearance. The data collector and the subjects were not blinded. The subjects' self-reported their bone healthy behaviors. It is noted that the majority of the women were younger than those in the previous study. An urban setting in Hong Kong was used which could make these findings less applicable to rural residents and/or those in other countries (Chan \& Ko, 2006).

The randomized controlled trial of Brecher et al. (2002) evaluated the impact of an osteoporosis educational program on knowledge of the disease, exercise frequency, and calcium intake. Assessment was also made of the participants' perceived ability and willingness to make behavior changes. The intervention was given one time, lasted three hours, and was led by a multidisciplinary healthcare team (Brecher et al., 2002).

The study population was women aged 25 to 75 years old. Of the 97 participants, 51 $(53 \%)$ were in the intervention group with $46(47 \%)$ in the control group. The mean age of the study participants was 53 years old. Those aged 45 years to 75 years made up $76 \%$ of the intervention group (mean age 55 years old) and $76 \%$ of the control group (mean age of 51 years old) (Brecher et al., 2002).

The study used four valid and reliable instruments; the Short Food Frequency Questionnaire (Blalock et al., 1998), Minnesota Leisure Time Physical Activity Questionnaire 
(Taylor et al., 1978), Osteoporosis Self-Efficacy Scale (Horan, Kim, Gendler, Froman, \& Patel, 1998), and Knowledge of Osteoporosis Questionnaire (Blalock et al., 1996). Measurements were taken pre-intervention, post-intervention (immediately afterwards for the intervention group and two weeks later for the control group), and three months later (Brecher et al., 2002).

Significantly improved osteoporosis knowledge was seen in the intervention group when compared to the control group $(\mathrm{p}=.005)$ immediately post-intervention $(\mathrm{p}<.001)$ and three months later $(\mathrm{p}<.001)$. At the first testing point after the intervention, a majority of both groups reported being in the process of changing their calcium intake (62\% treatment, $65 \%$ control). While this finding was not significant, a significant number of those in the intervention group who had not started changing their calcium intake were planning to do so $(p=.01)$. At three months post-intervention, $83 \%$ of the intervention group and $58 \%$ of the control group reported increasing their calcium intake $(\mathrm{p}=.05)$. No significant differences were found between the groups on the other measures (Brecher et al., 2002).

A strength of this study is its randomized controlled design. Another is the use of reliable and valid instruments. There are several limitations. While a large number of those in the intervention group reported increasing their calcium intake at three months post-intervention, evaluation of their Short Food Frequency Questionnaire did not bear this out. The participants were surveyed six weeks after the intervention for their thoughts on the program. This information is reported in brief anecdotal format with the author noting that overall the remarks were positive. Of concern, there is a discrepancy between the figures published with the study and the numbers of study participants noted in the body of the text. Table 1 of the study reports a total of 97 participants. The authors' note in the text indicated a total of 110 subjects with 96 (87\%) completing the post-intervention questionnaires and $86(78 \%)$ completing those at the 
three month measurement point. This discrepancy is not explained by the researchers (Brecher et al., 2002).

Another randomized controlled trial evaluated the effects of a pharmacist-led screening osteoporosis program for subjects older than 50 years old. The participants in the intervention group each received one thirty minute session. The session included a BMD heel ultrasound test and an individualized osteoporosis educational session with the provision of printed materials. The control group received only the printed materials. There were 262 subjects with 129 (49\%) in the intervention group and $133(51 \%)$ in the control group. The majority of the participants were female (n=175) (Yuksel, Majumder, Biggs, \& Tsuyuki, 2010).

While the primary outcome was on utilization of DXA post-intervention, secondary outcomes of changes in daily calcium, vitamin D intake, osteoporosis knowledge, and quality of life changes specific to osteoporosis were also measured. The Facts on Osteoporosis Quiz (Ailinger \& Emerson, 1998), the Osteoporosis-Specific Quality of Life questionnaire (Lydick et al., 1997), and the Changes in Generic Health Status questionnaire were used (Ware, Kosinski, \& Keller, 1996). The authors do not report how calcium and vitamin D were measured. At 16 weeks post-intervention, there were no changes in osteoporosis knowledge or osteoporosis quality of life measures between the two groups. While both calcium and vitamin D intake increased among the intervention group, only calcium intake increased significantly $(\mathrm{p}=.011)$ (Yuksel et al., 2010).

Strengths of the study include its randomized controlled design. The pharmacists involved in the study were all trained by the researchers. The pharmacists performed and discussed the results of the bone density test with each participant. The attrition rate was close to $19 \%$ (20\% in the intervention group and $17 \%$ in the control group) which may have impacted the 
findings. The researchers noted most dropouts occurred after randomization and before the intervention was given (Yuksel et al., 2010).

\section{Quasi-Experimental Studies}

In their quasi-experimental study, Ribeiro \& Blakeley (2001) evaluated the effects of an osteoporosis workshop on female subjects' osteoporosis knowledge and bone healthy practices. Bone healthy practices were defined as use of daily calcium supplements, daily vitamin D supplementation, frequent exercise use, limited caffeine intake, and use of hormone replacement. The intervention group received an educational workshop taught by a nutritionist, a rheumatologist, a natural health worker, two physiotherapists, and two nurses. The control group did not receive the educational workshop (Ribeiro \& Blakeley, 2001).

The study was conducted in various Canadian communities. There were 138 female subjects with $59(42.8 \%)$ in the intervention group, and $79(57.2 \%)$ in the control group. In the intervention group, $81 \%$ were between the ages of 45 and 69 years old . In the control group, $71 \%$ of participants were between the ages of 45 and 69 years old. The two groups did not differ significantly for age, educational background, exercise frequency, caffeine intake, and use of hormones. The instrument used was a researcher-created two part questionnaire. The first part focused on osteoporosis knowledge. The second part focused on subjects' practices regarding calcium and vitamin D use, exercise, use of hormone replacement, and alcohol and/or cigarette consumption. There was a significant difference between the groups for osteoporosis knowledge $(\mathrm{p}<.032)$, use of calcium $(\mathrm{p}<.011)$ and vitamin $\mathrm{D}$ supplements $(\mathrm{p}<.029)$ pre-intervention with the intervention group's scores being higher for all noted measures (Ribeiro \& Blakeley, 2001).

The educational intervention increased the subjects' osteoporosis knowledge six weeks $(\mathrm{p}<.000)$ and six months post-intervention $(\mathrm{p}<.003)$. Significant positive change regarding 
osteoporosis knowledge was also seen in the control group from baseline to six months postintervention $(\mathrm{p}<.002)$. In comparing the two groups, the intervention group scored $8 \%$ higher on osteoporosis knowledge than the control group six months post-intervention (Ribeiro \& Blakeley, 2001).

Regarding the bone healthy behaviors, there was a slight increase in calcium intake $(\mathrm{p}<.048)$ and hormone replacement $(\mathrm{p}<.032)$ for the intervention group six months postintervention compared to the control group. There were no significant differences between the two groups at six months post-intervention for exercise frequency, caffeine use, alcohol use, smoking, vitamin D, and calcium supplementation (Ribeiro \& Blakeley, 2001).

A strength of this study is its strong design with inclusion of a comparison control group. There are several limitations. There was no randomization. A convenience sample was used which may limit the generalizability of the findings. The subjects' self reported on their bone healthy behaviors which may have impacted the results. Compared to the intervention group who were members of the community at large, the control group was composed of members of the various branches of the Women's Institute (Canada) who volunteered to take part in the study. It was noted that osteoporosis knowledge also significantly increased for the control group post-intervention. While the reason for this increase is unknown, the researchers theorized this may have occurred because the members of the Women's Institute felt motivated to learn more about the disease. Pre-intervention, the intervention group already had significantly more osteoporosis knowledge $(\mathrm{p}<.032)$. Another factor which may have impacted validity of the data was that the control group follow-up measurement occurred eight months post-intervention instead of the six months measurement point used for the intervention group (Ribeiro \& Blakeley, 2001). 
Sedlak, Doheny, Estok, and Zeller (2005) evaluated the impact of tailored nursing interventions on subjects' osteoporosis knowledge, health beliefs, calcium intake, exercise frequency, smoking, and alcohol use. The subjects in the intervention group each received a tailored nursing intervention using the subject's DXA results and baseline osteoporosis preventing behaviors measurements that focused on osteoporosis knowledge and use of bone healthy behaviors. The intervention was delivered via phone by a nurse with a copy of the content later mailed to the subjects. The control group did not receive a telephone or written intervention, but did receive a DXA scan. Measurements were taken pre-intervention and six months post-intervention using the valid and reliable instruments of the Osteoporosis-Preventing Behaviors Survey (Doheny \& Sedlak, 2004), the Osteoporosis Knowledge Test (Kim, Horan, \& Gendler, 1991), the Osteoporosis Health Belief Scale (Kim, Horan, Gendler, \& Patel, 1991), and the Osteoporosis Self-Efficacy Scale (Horan, Kim, \& Gendler, 1993).

The subjects included 124 post-menopausal women between the ages of 50 and 65 years old with a median age of 56.2 years. The majority were Caucasian (90.3\%). The majority (73.4\%) had either some college education or were college graduates. There were 101 subjects (84\%) in the control group with 23 (16\%) in the intervention group (Sedlak et al., 2005).

Post-intervention, there was no significant difference between the two groups for increased osteoporosis knowledge. No significant differences were found for perceived osteoporosis susceptibility, seriousness of the disease, benefits of calcium, exercise benefits, osteoporosis self-efficacy, and motivation to change. There were more perceived barriers to calcium and to exercise in the intervention group than the control group (both $\mathrm{p}=.034)$. For calcium intake, there was a post-intervention increase for both groups $(\mathrm{p}=.00)$ but no significant difference for the increased amount. Post-intervention weight-bearing exercises significantly 
decreased in the intervention group $(\mathrm{p}<.030)$ and increased in the control group but not significantly $(\mathrm{p}<.425)$. There were no differences found for smoking and alcohol use between the two groups (Sedlak et al., 2005).

Two strengths of this study include its quasi-experimental design and use of valid and reliable instruments. Limitations of the study include lack of randomization and the unequal sample size of the two groups. Each subject in the intervention group received individualized osteoporosis counseling after having had a BMD test. However, most of the subjects, $84 \%$, were in the control group compared to the $16 \%$ in the intervention group. This may have impacted the strength of the statistical analysis to detect change. Post intervention, significant increases in perceived barriers to calcium intake and significant decreases in exercise frequency were reported by the subjects. The authors conjectured these findings may have occurred as women in the intervention group, having become more aware of their osteoporosis risk, felt the need to justify their lack of behavior change. Additionally, the subjects' individual data regarding prior bone healthy behaviors was not factored into the intervention which may have limited its usefulness to subjects (Sedlak et al., 2005).

Gaines, Narratt, and Parrish (2010) evaluated the impact of adding an osteoporosis educational program to a screening bone density program for adults 62 years old and older. The educational intervention led by a nurse was composed of a one hour session at baseline and a half hour refresher session one year later. The 376 participants (62 men and 314 women) were all residents of two retirement communities. With a mean age of 81.4 years, there were 193 subjects in the education and screening group and 183 in the control group. The Facts on Osteoporosis Quiz (Ailinger, Lasus, \& Braun, 2003) was used to assess osteoporosis knowledge. Exercise frequency and use of calcium supplementation was self-reported (Gains et al., 2010). 
Measurements were taken pre-intervention, immediately post-intervention, one year, and two years post-intervention. The education class was attended by 21 men (62\%) and 116 women (73\%). The one year refresher education class was attended by 72 women and 18 men.

Increases in osteoporosis knowledge $(\mathrm{p}<.001)$ were found for both the intervention and control group at two years' post-intervention. Significant improvement in calcium intake $(\mathrm{p}=.041)$ was seen at one year post-intervention for the education and BMD screening group, but not at the two year post-intervention point. No changes in aerobic or strength training exercise were seen in either group (Gaines et al., 2010).

A strength of this study is its longitudinal design, which involved measurements out to two years post-intervention. There was a control group to allow for comparison. Limitations of this study include the loss over the two years of the study of $30.5 \%$ of the screening with education group and $17 \%$ of the control group. Attrition also occurred before the educational offering. Osteoporosis knowledge was noted to significantly increase for both groups even though the control group had no educational intervention (Gaines et al., 2010).

White (2008) assessed the effects of three different educational interventions on the osteoporosis knowledge and bone healthy behaviors of adults 65 years old and older. Bone healthy behaviors were defined as adequate calcium intake, use of dietary supplements, fall prevention measures, and use of exercise. There were four groups with a total of 85 participants all of whom had been recruited from eight senior centers. There were 69 women and 16 men with an age range of 65 to 95 years. All participants received a screening BMD test with every group except the control group receiving this test pre-intervention. The first group, composed of 21 people, acted as a control group with no intervention. The control group received the BMD test at the final post-intervention measurement point. The second group with 21 subjects 
received two brochures on bone healthy behaviors. The third group, comprised of 19 people, was given the same two brochures along with two educational sessions on osteoporosis with two phone call follow-ups afterwards. The fourth group with 24 subjects received the same interventions as the third group but had individual attention in developing personal bone healthy goals.

Four valid and reliable instruments were used. These included the Osteoporosis Knowledge Questionnaire (Davis, 1999), Short Food Questionnaire (Blalock et al., 2003), Index of Readiness (Fleury \& Cameron, 2003), and the Osteoporosis Self-Management Index-Revised (Davis, Jimenez, \& Rubin, 1995). The researcher also created a fracture risk assessment questionnaire (White, 2008).

Measurements were taken pre-intervention and seven weeks post-intervention. Postintervention, a significant difference was found for improved osteoporosis knowledge in groups three and four (both $\mathrm{p}<.001$ ). In addition, bone healthy behaviors were significantly improved in group four $(\mathrm{p}<.001)$ (White, 2008).

There are several strengths and limitations of this study. One strength is its quasiexperimental design which allowed for the testing of the educational intervention in different formats. Four valid and reliable instruments were used. A limitation of the study is the small number of subjects in each group (White, 2008).

\section{Longitudinal Studies}

Pearson, Burkhart, Pifalo, Palaggo-Toy, and Krohn (2005) used a longitudinal repeated measures design in evaluating the effectiveness of a multidisciplinary educational and exercise program for individuals with osteopenia or osteoporosis. The educational intervention was composed of bi-weekly classes lasting $2 \frac{1}{2} 2$ hours each for a total of eight weeks. The sessions 
covered topics relevant to osteoporosis such as exercise and proper body mechanics designed to reduce falls. The subjects were offered individualized counseling by healthcare providers which included a pharmacist-led counseling session on medication appropriateness. In-home safety assessments were also offered and conducted (Pearson et al., 2005).

At baseline, there were 429 subjects with 375 having osteopenia or osteoporosis. The median age was 67 years with a range from 44 to 90 years old. The majority of participants, $98 \%$, were Caucasian. At the beginning of the study, $62 \%$ of participants were on medication for osteoporosis. Of those completing the eight week program, $98 \%$ were female $(n=367)$ and 8 were males $(2 \%)$. Measurements were taken pre-intervention, at the conclusion of the eight week program, and six months and two years post-intervention. A total of 231 participants completed the six month post-intervention instruments with 157 completing the two years postintervention. Gender percentages were not noted (Pearson et al., 2005).

Several instruments were used including the Center for Epidemiologic Studies Depression Scale (Radloff, 1977) and the Functional Fitness Test Battery (Rikli \& Jones, 1999). A researcher created, twenty item, multiple-choice test for osteoporosis knowledge was given. A two day food diary log with a structured interview by a dietician regarding calcium and vitamin D rich food consumption was completed. Using the diary, a nutritionist calculated the amount of calcium the subjects consumed from food and supplements. A weekly log on exercise and nutrition kept by the subjects was assessed. A structured interview with an exercise physiologist about exercise habits was also conducted (Pearson et al., 2005).

At eight weeks post-intervention, there were significant improvements over baseline measurements for osteoporosis knowledge $(\mathrm{p}<.0001)$, depression $(\mathrm{p}<.0001)$, and nutrition adherence for calcium and vitamin D (both at $\mathrm{p}<.0001)$. Fitness measurements showed 
improvements in upper body strength $(\mathrm{p}<.0001)$, lower body strength $(\mathrm{p}<.0001)$, upper body flexibility ( $\mathrm{p}<.0001)$, lower body flexibility $(\mathrm{p}<.0001)$, and balance $(\mathrm{p}<.0001)$. There was a significant increase in fitness adherence for strength training and aerobic exercise (both $\mathrm{p}<.0001$ ) (Pearson et al., 2005).

The actual time period for the six month post-intervention measurement varied from five to fifteen months as the researchers were experimenting with the best intermediate measurement period while the study was ongoing. At two years' post-intervention, continued significant improvements were found for exercise frequency, calcium and vitamin D intake (all significant to at least $\mathrm{p}<.05)$. A significant improvement in DXA bone mineral density measurements for the spine was also found ( $\mathrm{p}<.0001)$ (Pearson et al., 2005).

One strength of this study is its design which measured change at several testing intervals. Another strength is that two of the instruments had validity and reliability data. Structured interviews were used by the exercise physiologist and the nutritionist. There were also multiple healthcare providers of different disciplines involved in designing and implementing this intervention. The intervention was continually assessed for areas that needed improvement (Pearson et al., 2005).

There are several limitations of this study. There was no control group. Bone healthy behaviors were self-reported by the participants. Not all of the instruments used were valid and reliable. Post-intervention testing, scheduled to be done at the six month mark, varied from five to nineteen months as the researchers were experimenting with what would be the most appropriate post-intervention measurement period. This variation in the time of measurement may have affected the results (Pearson et al., 2005). 
In their longitudinal study, Newman and Hanus (2001) evaluated the impact of pharmacist-led classes about osteoporosis on subjects' bone health behaviors. A standardized educational presentation with a pre-defined patient education information packet was used by the community-based pharmacists. Bone health behaviors were defined as adequate calcium intake, seeking advice of healthcare providers, having a bone density test done, and beginning osteoporosis medication if indicated. With a median age of 54 years (range 21 to 86 years old), there were 350 subjects who were participants of the Geisinger Health System in central Pennsylvania. The participants were all female and 99.4\% Caucasian. Measurements were taken pre-intervention and at four to six weeks post-intervention (Newman \& Hanus, 2001). Measurements were obtained with four questionnaires. A baseline demographic questionnaire was used, which included questions on exercise frequency, use of calcium supplements, use of osteoporosis treatment medication, and previous bone density testing. The Simple Calculated Osteoporosis Risk Estimation (SCORE) (Lydick et al., 1998) form was used to calculate osteoporosis risk. The third questionnaire, also researcher created, allowed the participants to evaluate the class. The fourth component was a telephone interview, using a script, conducted four to six months post-intervention (Newman \& Hanus, 2001).

At four to six weeks post-intervention, $58 \%$ of subjects who had not been taking calcium supplements had started to do so. Thirty-two percent exercised more. Fifty percent sought the advice of a health care provider. Twenty-nine percent had obtained a bone density test. For those with a finding of osteoporosis on DXA testing, 33\% had started on medication therapy (Newman \& Hanus, 2001).

There are several strengths of this study. The educational intervention was created by a multidisciplinary team with an in-depth analysis of the educational intervention. Participants 
were asked to rate the intervention. Ranking the intervention as "excellent" was $74 \%$ of participants with 26\% rating it as "good" (Newman \& Hanus, 2001).

There are several limitations of this study. One is the lack of a control group. Selfreporting of the bone healthy behaviors was done by the participants. The educational intervention was performed at several different sites and with several different educators with no analysis for potential differences between the educators and/or the sites. In the mathematical analysis of the study, percentages only were used with no other statistical analyses reported (Newman \& Hanus, 2001).

Davis, White, and Yang (2006) assessed the effects of a nurse-led educational intervention for older adults living in a residential setting on osteoporosis knowledge and bone healthy behaviors. The educational intervention was composed of six, one hour, nurse-led educational sessions on osteoporosis, physical activity, fall prevention measures, nutrition/nutritional supplements, use of calcium, and medications. The dependent variable included measurements of fall prevention, independent functioning, and bone healthy behaviors. The bone healthy behaviors included: use of physical activity, fall prevention measures, adequate nutrition, and medication and/or supplement adherence (Davis et al., 2006).

A longitudinal repeated measures (pre- and post-test) design was used with measurements taken at baseline and one week, six weeks, and 9 1/2 months post-intervention. The settings were five residential communities for older adults. There were 54 participants with 41 completing the entire study. The mean age was 79.36 years old. The majority of subjects were female ( $85.1 \%$ female, $14.9 \%$ male). At the beginning of the study, $38.3 \%$ of subjects selfreported having osteoporosis (Davis et al., 2006). 
There were several instruments used. These included the Osteoporosis Knowledge Questionnaire (Davis, 1999), Osteoporosis Self-Management Index, Revised (Davis, Jimenez, \& Rubin, 1995), Short Food Questionnaire (Blalock et al., 2003), and the Falls Efficacy Scale (Tinetti, Richman, \& Powell, 1990). The Timed Up and Go test measured basic mobility (Podsiadlo \& Richardson, 1991).

There was a significant increase in osteoporosis knowledge from baseline to $91 / 2$ months post-intervention $(\mathrm{p}<.001)$. The greatest knowledge gain was seen between baseline and week one $(\mathrm{p}<.001)$ with some loss occurring between the week one and week six post-intervention period $(\mathrm{p}<.04)$. The greatest loss of knowledge occurred between week six and $91 / 2$ months post intervention period $(\mathrm{p}=.03)$. For bone healthy behaviors, the subjects showed improvement between baseline and $91 / 2$ months post-intervention $(\mathrm{p}=.01)$. The greatest increase in these behaviors was between baseline and one week post intervention $(\mathrm{p}<.01)$. Behaviors showing significant improvement from baseline to one week post-intervention $(\mathrm{p}<.05)$ included; eating high calcium foods, taking calcium supplements, using fall precautions, and exercising to improve strength, balance, and flexibility. At $9 \frac{1}{2}$ months post-intervention, the authors reported a continued significant improvement for fall precautions, exercising for strength and balance (p not reported). Taking a multi-vitamin, which was not significant at one week post-intervention, was found to be significant at $91 / 2$ months ( $p$ not reported). The behaviors of eating foods high in vitamin $\mathrm{D}$ and doing weight bearing exercise were found to not significantly change during the study (Davis et al., 2005).

Strengths of this study include its design and use of reliable and valid instruments. There are limitations of this study. One is the lack of a control group. Being limited to one community 
setting may make generalization to other more diverse settings more difficult. Another limitation was the use of subjects' self-reported bone healthy behaviors (Davis et al., 2005).

In their longitudinal study, Driskell, Pohlman, and Naslund (2003) assessed the effects of a healthcare team-led community-based educational intervention on osteoporosis. Members of the Cooperative Extension System had initiated the program with the program held in the area's Research and Extension Center. The objectives of the osteoporosis program were developed by a team composed of registered dieticians, physicians, public health employees, extension educators, and extension specialists. The educational intervention was one session long and was given twice to a total of 92 participants. The educational sessions were led by healthcare professionals with a physician being the primary presenter. No information was provided on the gender and age range of the participants.

Measurements were obtained pre-intervention and one month post-intervention with a $59 \%$ return rate $(n=54)$. A researcher created questionnaire was used, which included questions regarding subject perception of osteoporosis knowledge (rated as either a little, some or a lot), calcium supplement usage (rated as either a little, some or a lot), eating of a calcium-rich diet (rated as either a little, some or a lot), and partaking of weight-bearing exercise at least three times a week (rated as never, sometimes, or always). Subjects were asked additional questions regarding their age (specified in categories) and if they had had a bone density test done before and/or after the intervention.

At one month post-intervention, $82 \%$ of subjects felt they knew "a lot" about osteoporosis, an improvement from $24 \%$ pre-intervention $(\mathrm{p}<.05)$. Of those who had a bone density test before the educational session, there was an improvement from $21 \%$ perceiving knowing "a lot" about osteoporosis to $86 \%$ post-intervention. Of those who had not had a bone 
density scan previous to the intervention, an improvement from $27 \%$ to $55 \%$ was seen in those participants perceiving they had "a lot" of osteoporosis knowledge. A significance at $\mathrm{p}<.05$ was seen for improvements in usage of calcium supplements, consuming a calcium-rich diet, and partaking of weight-bearing exercise at least three times a week. Evaluation of the measured categories was conducted by age group with significant increases seen in those over 30 years of age and those aged 50 to 59 years old.

A strength of this study includes its development by a multidisciplinary healthcare team. There are several limitations of this study. One limitation is the self-reporting of the bone healthy behaviors by the subjects. Another is the lack of a control group. There was a $41 \%$ attrition rate. The questionnaire used had no reliability or validity data. As limited demographic information on the subjects was presented, generalization to other more diverse samples may be difficult.

\section{Synthesis}

Evidence from seven randomized controlled trials (RCTs), three quasi-experimental studies, and four descriptive, longitudinal, comparative studies were unanimous in strongly supporting the effectiveness of healthcare professional-led education on adherence to nonpharmacologic treatment recommendations for osteoporosis patients, or those at high risk for the disease, in comparison to usual care or no intervention (Brecher et al., 2002; Chan \& Ko, 2006; Chan et al., 2005; Davis et al., 2006; Driskell et al., 2003; Gaines et al., 2010; Newman \& Hanus, 2001; Nielsen et al., 2008; Pearson et al., 2005; Ribeiro \& Blakeley, 2001; Rolnick et al., 2001; Schousboe et al., 2005; White, 2008; Yuskel et al., 2010). One study did find significant increases to perceived barriers to calcium intake $(\mathrm{p}=0.034)$, in intent to exercise $(\mathrm{p}<0.030)$, and decreases in exercise frequency $(\mathrm{p}=0.034)$ post-intervention. Increases in 
calcium intake and use of exercise were observed in the control group, but these were not significant (Sedlak et al., 2005).

The bone healthy behaviors studied differed among the studies. This may be due in part to the evolution of understanding of which behaviors are bone healthy. In comparison to the National Osteoporosis Foundation's current recommendations (2010) regarding patient osteoporosis education, only three studies specifically noted incorporating and measuring for all of the recommended parameters (Davis et al., 2006; Pearson et al., 2005; White, 2008). Studies varied in their setting from senior centers to churches. No studies reported being conducted in a fitness center. Instruments measuring the bone healthy behaviors varied among the studies. Several did not mention the questionnaires used, used researcher created questionnaires and/or did not report the validity and reliability of the instruments (Driskel et al., 2003; Gaines et al., 2010; Newman \& Hanus, 2001; Pearson et al., 2005; Ribeiro \& Blakeley, 2001; Rolnick et al., 2001; Schousboe et al., 2005; Yuskel et al., 2010). Eight of the studies were conducted with a nurse as the educator, which supports the use of nurses as the healthcare professional in this role (Chan \& Ko, 2006; Chan et al., 2005; Davis et al., 2006; Gaines et al., 2010; Rolnick et al., 2001; Schousboe et al., 2005; Sedlak et al., 2005; White, 2008).

The amount of education varied from a onetime educational intervention to biweekly classes for eight weeks. The evidence suggests a onetime intervention, used in ten of the fifteen assessed studies, is effective (Brecher et al., 2002; Chan \& Ko, 2006; Chan et al., 2005; Driskell et al., 2003; Newman \& Hanus, 2001; Ribeiro \& Blakeley, 2001; Rolnick et al., 2001; Schousboe et al., 2005; Sedlak et al., 2005; Yuskel et al., 2010). When reported, the amount of time the educational intervention took varied among the onetime interventions. The shortest lasted 15 minutes (Schousboe et al., 2005); the longest was three hours (Brecher et al., 2002). 
Of the six studies including both genders, one had enough male subjects to allow for statistical analysis based upon gender (Davis et al., 2006; Gaines et al., 2010; Nielsen et al., 2008; Pearson et al., 2005; White, 2008; Yuskel et al., 2010). Pre-intervention, the osteoporosis knowledge scores of female subjects were found to be significantly higher when compared to male subjects $(\mathrm{p}<0.01)$. After the intervention, there were no significant differences between the genders (Nielsen et al., 2008). In a study specifically addressing osteoporosis knowledge in males aged 65 or older, subjects were found to have low levels of osteoporosis knowledge and did not perceive themselves as being susceptible to developing osteoporosis (Sedlak, Doheny, \& Estok., 2000). These findings warrant further research as it appears that males have a higher than anticipated need for osteoporosis knowledge, and their inclusion in future educational endeavors should be encouraged.

\section{Statewide Osteoporosis Programs}

Of note, discussion was found in the literature of statewide osteoporosis programs. Many of these programs have had a large number of participants. They were excluded from the literature review as there was limited published data analysis available for these programs. At present, 35 states have laws in place regarding osteoporosis issues. Many of these states have programs to improve public awareness and osteoporosis knowledge (National Conference of State Legislatures, 2009). There is evidence that a statewide osteoporosis educational intervention based in the community setting can be helpful.

The Bone Builders Osteoporosis Prevention Program based in Arizona began in 1998. It uses volunteers to provide lectures to community members regarding osteopenia and osteoporosis. The volunteers are not necessarily healthcare professionals. The program has trained over 320 volunteers and staff members statewide. Education is provided on the disease, 
use of a bone density scan, and the bone healthy behaviors of appropriate calcium intake and weight-bearing type exercises. In 2000, the program was expanded to include older men and women of all ages. In 2003, the program was further expanded with the addition of the Bone Builders Physical Activity Program. The goal of this nine week program is incorporation of physical exercise and fall prevention measures into the daily lives of older inactive adults (Day \& Block, 2006).

Two published evaluations have been done of this program. A survey of 2,000 participants measured for change in osteoporosis knowledge using a scale from one to five with five being the highest. There was an improvement in osteoporosis knowledge from 2.5 preeducational offering to 4.5 post-intervention (Day \& Block, 2006). In a survey of 211 participants, $79 \%$ planned to make some type of change regarding their bone health. Preintervention, $16 \%$ of attendees had routinely performed some type of weight bearing exercise. Four to six months post-offering, this had improved to $36 \%$ with $39 \%$ increasing their calcium intake (Stanford et al., 2005).

Due in part to their ranking as fifth in the nation with the number of residents with osteoporosis, the state of Pennsylvania has been particularly involved in osteoporosis research (NOF, 2002). The state of Pennsylvania's Osteoporosis and Education Program has multiple osteoporosis programs in place which address osteoporosis concerns across the lifespan. One program, Strong Women, is part of a larger national program. This program provides education on weight-bearing exercises as well as educational and dietary information for women at mid-life or older (Pennsylvania Department of Health, 2008). In 2003, the Penn State Cooperative Extension and Penn State Public Broadcasting collaborated to develop the Creating Health: Osteoporosis Prevention Program. This well received program uses extension educators 
throughout the state to provide osteoporosis education in a community setting (Corbin, Trainor, Liu, \& Gueldner, 2008).

The "Tone Your Bones" program was developed at the University of Alabama at Birmingham Health Services Foundation. This community-based program is carried out through a multidisciplinary osteoporosis clinic. Two bi-weekly group educational sessions are presented for four weeks on osteoporosis, treatment options, and the bone healthy behaviors. Positive changes for participants' balance, flexibility, and strength have been noted immediately following the four week educational period. The long term effects of this program are not known. The original design of the program was one session per week for eight weeks, but the attendance was poor. Evaluation of the program revealed many participants wanted a shorter length of time between the sessions (Peel, Lein, Kitchin, \& Morgan, 2001).

Started in 1997, Project Healthy Bones is a joint collaboration between the Rutgers Cooperative Extension of the State University of New Jersey, the New Jersey Department of Health and Senior Services, the Association of Retired and Senior Volunteer Program Directors, and the Saint Barnabas Center for Health and Wellness. It uses older adults as both peer advocates and trainers who perform the 24 week group sessions. While the focus of the sessions is on physical activity, there is education provided on other bone healthy behaviors. In an evaluation of 217 participants, improvements in the amount of weight that could be lifted and the amount of exercise that could be done was seen at the end of the last session. After completing a calcium diary, $68 \%$ of those surveyed were found to have increases in calcium intake. As of 2001, the program had enrolled over 1400 participants (Klotzbach-Shimomura, 2001). 


\section{CHAPTER IX CAPSTONE SITE}

The health and fitness center at which this educational offering was given is the largest of its kind in Kanawha County, WV. Administrators from the fitness center have given their support to the project (See Appendix A). Membership in the fitness center is open to the community at large which includes all ages and income levels with a sliding scale available for those with limited financial means. The center is open seven days a week with both early morning and late evening hours. The facility is composed, in part, of a six lane indoor pool, free weight room, fitness equipment area, two gymnasiums, a multipurpose gym, exercise studio, cycling studio, tennis courts, racquetball courts, and outdoor recreational fields for sports such as soccer and softball. The health and fitness center offers a variety of classes for all ages and interests. For example, there is a beginning free weight training course seven weeks long designed for adult females. There is also a series of classes on healthy eating. For older adults,

there are programs designed with them in mind (see Appendix B). There are monthly luncheons for seniors offering both educational and socialization opportunities. The Silver Sneakers programs in yoga and strength/muscle strength training are available as are several fitness classes tailored for the older adult (YMCA of the Kanawha Valley, 2012).

\section{CHAPTER X CAPSTONE PROJECT DESIGN}

The project is a onetime educational offering lasting approximately two and a half hours. The workshop addresses the pathophysiology of osteoporosis, risk factors for the disease, and non-pharmacological and pharmacological treatment options. The educational offering particularly focuses on non-pharmacological treatment recommendations as defined by the National Osteoporosis Foundation (2010): ideal daily intake of calcium and Vitamin D, weight- 
bearing exercise, fall prevention behaviors, avoidance of cigarette smoking and limiting alcohol intake to two drinks or less per day.

The evaluation of the osteoporosis workshop is a one group repeated measures design with measurements taken pre-intervention, immediately post-intervention and one month postintervention. One objective of the evaluation is to collect basic information on those attending the osteoporosis workshop including: gender, menopausal status if female, fitness center membership status, if diagnosed with osteoporosis or osteopenia, and use of medications for osteoporosis or osteopenia, both past and current. A second objective is to enhance knowledge about osteoporosis and bone healthy behaviors for participants. A third objective is to improve the participants' perception of meeting personal bone healthy behavior goals. A fourth objective is to improve participants' daily calcium and vitamin D intake. A fifth objective is to improve subjects' physical activity levels and decrease the time attendees spent sitting on a typical weekday.

The educational offering was held in the fitness center and was led by the project director, a nurse practitioner. The population for the project was those considered at high risk for osteoporosis; post-menopausal women and men aged 50 years old and older (NOF, 2010). The recruitment goal for this project was 50 participants. Two workshops were held on the same day with a third workshop later added to reach this recruitment goal.

\section{Theoretical Foundation of the Capstone Project}

Considering the diversity of previously used theoretical foundations in regards to osteoporosis education, the Integrated Theory of Health Behavior Change (ITHBC) (Ryan, 2009) was chosen as the theoretical model for this population. The ITHBC is a midrange nursing theory which integrates elements from multiple theories. It addresses health behavior change, 
self-regulation behaviors, chronic disease management, and social support. The ITHBC is currently being used as the theoretical framework in two studies. One of these studies involves an individualized osteoporosis educational intervention (Ryan, Pumilia, Henak, \& Chang, 2009).

The ITHBC theory is divided into two main parts. The first part is composed of three segments; knowledge/beliefs, self-regulation skill/ability, and social facilitation. In the first segment (knowledge and beliefs), the participant's personal goals, self-efficacy, and expectations of the intervention are assessed. Specific knowledge for a chronic condition is shared (Ryan, 2009). The educational offering utilized in this project focused on knowledge regarding osteoporosis and bone healthy behaviors. Before the workshop, the participants' knowledge regarding osteoporosis was assessed using the Osteoporosis Knowledge Assessment Tool (OKAT) instrument (see Appendix C) (Winzenberg, Oldenburg, Frendin, \& Jones, 2003). Preworkshop, the participants were encouraged to explore areas of knowledge deficit and what each attendee hoped to achieve from participating in the class. Subjects were encouraged to share these objectives before the class began. Immediately post-intervention and one month postintervention, the participants' osteoporosis knowledge was reassessed using the OKAT.

The second segment of the ITHBC (social facilitation) involves the influence and support of others in regards to the desired health behavior change. One component of social facilitation is the influence a healthcare provider could have in changing a subject's thinking and knowledge. Another component of social facilitation is the influence of one's social support system such as friends and family (Ryan, 2009). The ITHBC further posits that social facilitation can involve "emotional, instrumental, or informational support" (Ryan, 2009, p. 165). The workshops were led by a family nurse practitioner. The subjects in the group-based educational intervention could have drawn social support from each other. Reliable sources of 
information about osteoporosis were reviewed with the participants to further meet their current and future learning needs. Multiple handouts regarding osteoporosis and bone healthy behaviors were given to the subjects in their workbook (see Appendix D).

The third segment of the first part of the ITHBC theory (self-regulation skills and ability) is affected by both social facilitation and knowledge/beliefs. In this segment, there is a focus on decision-making and setting goals. A plan is created which is then carried out and later evaluated by the participant (Ryan, 2009). Pre-intervention, the participants were asked to rate their perception of meeting their bone healthy goals (see Appendix E). A workbook was given to each participant before the educational offering began, and was utilized throughout the presentation. The workbook contained a copy of the PowerPoint presentation used to educate participants, sources of reliable information about osteoporosis, and handouts about bone healthy behaviors (see Appendices D \& F). At the conclusion of the educational intervention, participants were encouraged to create a list of personalized goals and a plan by which to achieve these goals, with space for documentation provided in the workbooks. The instructor aided in facilitating this process as needed. One month post-intervention, participants were asked to rate where they currently perceived meeting their bone healthy goals (see Appendix G).

The second portion of the ITHBC is composed of two parts, both of which deal with outcomes. The first part focuses on early outcomes. An example of an early outcome is the initiation and maintenance of healthy behaviors. At pre-educational offering and at one month post-intervention, measurements regarding the bone healthy behaviors of adequate daily calcium and vitamin D intake and use of physical activity were obtained to evaluate for change. Vitamin D and calcium intake were measured with the Short Instrument for Assessing Dietary Intake of Calcium/Vitamin D (also referred to as the Short Food Questionnaire) (See Appendix H) 
(Blalock et al., 2003). Physical activity measurements were obtained through use of the International Physical Activity Questionnaire: Short Last 7 Days Self-Administered Format (See Appendix I) (Craig et al., 2003).

The second part of the ITHBC deals with long term outcomes. In maintaining healthy behaviors, there should be a positive impact upon a participant's long term health status (Ryan, 2009). In the case of osteoporosis, this would be improvement in bone density and/or risk reduction for fractures. Because each participant's involvement in the project was for four to six weeks, the potential long term health impact this project could have was not measurable during this project's time frame. Consideration could be given for future projects using this educational offering with longer follow-up measurement intervals.

The project, its design, and objectives were explained in detail to the potential subjects following a script (see Appendix J). Written consent from those willing to participate in the workshop's evaluation was obtained with each participant receiving a copy (see Appendix K). Demographic and basic bone heath information was obtained pre-intervention (see Appendix E). To make sure that the educational offering helped meet the immediate needs of the participants, participants were asked to complete an anonymous survey regarding their opinions and their suggestions for improvement of the program (see Appendix L).

At one month post-intervention, the subjects were mailed a letter about the one month post-educational offering evaluation and the instruments/questionnaires regarding their perception of meeting bone healthy goals, calcium/vitamin D dietary and supplement use, osteoporosis knowledge, and physical activity levels (see Appendix M). A postage paid selfaddressed envelope for the instruments/questionnaires' return as well as a gift card (\$5) for a popular local store was included. For those participants whose instruments were not returned, a 
follow-up letter was sent two weeks later along with copies of the instruments/questionnaires and a self-addressed postage paid envelope (see Appendix N).

\section{Ethical Considerations}

Approval of the project through the author's Capstone committee and the Institutional Review Board of West Virginia University (Tracking Number: H-23559) was obtained before the project was implemented. An informational letter describing the project was given to the participants before the osteoporosis workshop (see Appendix O). Participants were able to attend the osteoporosis workshop without participating in the project's evaluation. Consent to participate in the project's evaluation was obtained from the participants (see Appendix K). The subjects were advised they could skip any question that they did not wish to answer and could stop participation at any time. Each attendee's involvement was kept as confidential as legally possible. Each participant was given a unique identification number with the identifying information reported on a separate form (see Appendix P). All obtained materials from the participants were kept in a locked filing cabinet in the author's home for which she has the only key. All participant information will be shredded at the conclusion of the project's evaluation.

\section{CHAPTER XI INSTRUMENTS/QUESTIONNAIRES}

\section{Osteoporosis Knowledge}

Osteoporosis knowledge was measured by the Osteoporosis Knowledge Assessment Tool (OKAT) (see Appendix C) (Winzenberg et al., 2003). It is composed of twenty statements that are to be marked by the participant in one of three categories; true, false or don't know. Scoring is done by giving one point for each correct answer and zero points for each incorrect answer or those marked don't know (Tania Winzenberg, personal communication, September 12, 2010). This instrument has been shown to be reliable and valid (Ferguson's sigma 0.96 and Cronbach's 
alpha of 0.70 ). It is noted that instrument was designed for use by Australian women aged 25 to 44 years. To facilitate use in the United States of America, the words "in Australia" was removed from question \#20. Permission for its use has been obtained from the lead author, Dr. Winzenberg (see Appendix C).

\section{Calcium and Vitamin D Intake}

To measure calcium and vitamin D intake, the Short Instrument for Assessing Dietary Intakes of Calcium and Vitamin D was used (see Appendix H) (Blalock et al., 2003). This instrument is composed of a listing of 22 high calcium and vitamin D rich foods. The participant marks how often he or she consumes each of these foods in a one month time period. This data provides an estimate of daily dietary intake of calcium and vitamin D.

When the creators of the instrument compared it to seven day food diaries and the BlockNational Cancer Institute Health Habits and History Questionnaire (Block, Hartman, \& Naughton, 1990), a reliability of 0.72 and 0.66 was found respectively ( $p<.001)$. Predictive measurements for calcium intake were found to be $91.7 \%$ and $100 \%$ for vitamin D. The instrument was found to be more acceptable to participants than the seven day food diaries as it could typically be completed in five minutes. Drawbacks to use of this instrument include the exclusion of calcium and vitamin D fortified foods such as orange juice and some yogurts. Use of calcium and vitamin D supplements are also not queried (Blalock et al., 2003). Additional questions were asked about the consumption of calcium and vitamin D supplements to ensure accuracy of the participants' responses (see Appendices E \& G). Permission to use this instrument has been obtained from the lead author, Dr. Blalock (see Appendix H). 


\section{Weight-Bearing Exercise}

For evaluation of weight-bearing exercise, the International Physical Activity

Questionnaire: Short Last 7 Days Self-Administered Format was used (see Appendix I) (Craig et al., 2003). While there are four versions of the International Physical Activity Questionnaire (IPAQ), two long and two short, the IPAQ Short Last 7 Days Self-Administered Format (Craig et al., 2003) was chosen for its ease of use. The population for which the questionnaire was designed included people from 18 to 65 years old. The IPAQ: Short Last 7 Days SelfAdministered Format is composed of seven questions that measures the amount of time spent sitting, walking and doing vigorous and moderate level activities (Craig et al., 2003). The questionnaire is available for use in research/evaluation studies at no charge from the website, http://www.ipaq.ki.se/ipaq.htm.

Reliability and validity studies have been done using this instrument. A key reliability and validity study comparing the four versions of the IPAQ was conducted among several international sites. For the United States, the short forms reliability correlation coefficients ranged from 0.66 to 0.88 . The median criterion validity was 0.3 (Craig et al., 2003). Brown, Trost, Bauman, Mummery, and Owen (2004) compared the IPAQ Short Last 7 Days SelfAdministered Questionnaire to the Behavioral Risk Factor Surveillance System, the Australian National Health Survey, and the Active Australia Survey. The population of the study was Australian residents of both genders aged 18 to 75 years with approximately two-thirds of participants being older than 45 years old. They found agreement among the four surveys in categorizing activity level with the IPAQ questionnaire having the highest score of 79\%. Kappa statistics for this instrument were noted to be 0.47 (range $0.29-0.66$ ). 


\section{CHAPTER XII RESOURCES}

There were multiple resources available which facilitated the completion of this project. The author, a nurse practitioner, led the participants through the educational offering. In terms of content expertise, Ronald Hamdy, MD, a clinical expert in the field of osteoporosis reviewed the educational offering and provided guidance.

There were multiple sources of handouts and information used in the participant workbook that are non-copyrighted or available for a small fee (see Appendices D \& Q). The National Osteoporosis Foundation offers a set of handouts covering the bone healthy behaviors for $\$ 25$ that were duplicated for the event. The National Cancer Institute has non-copyrighted information on smoking cessation that was downloaded and copied. The National Institute on Health's National Institute on Aging, the Centers for Disease Control, and the National Institute on Alcohol Abuse and Alcoholism have several handouts regarding bone healthy behaviors available at no cost. Appendix D lists the handouts that were distributed to the participants during the workshops.

\section{CHAPTER XIII RESULTS}

Analysis using SPSS version 18 statistical software (SPSS, Chicago, IL, USA) to evaluate for change(s) between the testing intervals and the significance of these changes was done. A significance level of .05 was used. A total of three workshops were given. Two workshops were held on January 25, 2012. The first workshop was held from 1:00 PM to 3:30

PM. The second workshop was from 5:30 PM to 8:00 PM. A third workshop, from 1:00 PM to 3:30 PM, was added on March 20, 2012, to obtain the recruitment goal of 50 subjects. The IRB approved protocols were followed at each workshop. A total of 74 participants attended the workshops (workshop one: $n=34$; workshop two: $n=14$; workshop three: $n=26$ ). Of these 
participants, 67 consented to be in the study (workshop one: $n=34$; workshop two: $n=14$; workshop three: $\mathrm{n}=19)$.

While the workshop was attended by both genders, more women $(n=62)$ attended then men $(n=5)$. The men attended at the two different time offerings (workshop one: $n=0$; workshop two: $n=3$; workshop three: $n=2)$. The attendees were predominately Caucasian $(n=65(97 \%)$; 61 females, 4 males) with a minority being African American ( $n=2,(3 \%)$; one female, one male).

All but three potential participants who had registered for a workshop attended. These three participants did call to cancel the day of the program (two from the first workshop and one from the second). There were no cancellations from the third workshop. The vast majority of the participants stayed for the entire program. Two subjects had to leave early from the first workshop. All participants in the second workshop were able to complete the workshop. Three participants had to leave early during the third workshop.

During the first workshop, several potential participants asked if they could still join the workshop right before the program started. There were a total of 31 participants pre-registered with two of these cancelling the day of the workshop. An additional five participants who had not pre-registered were able to be accommodated for a total of 34 in the first workshop. There were at least four potential participants who could not be accommodated as the room had reached capacity. Most of the potential participants who were not able to be accommodated presented to the fitness center's main consumer service desk instead of the check-in point for the osteoporosis workshop to see if they could attend.

The third workshop's attendance and participation in the program's evaluation was limited in comparison to the other two workshops. There was an exercise class specifically for older adults being offered at the exact time of the third workshop that many of the potential 
attendees for the osteoporosis workshop wanted to attend also. This class was being offered the one time with no future classes scheduled. Of the three participants who left early, two had voiced they were planning on going to the other class. In addition, several of the participants reported having attended another program that morning. As a result of feeling tired and not sure how long they could attend the osteoporosis workshop, many of these participants did not want to participate in the workshop's evaluation portion.

\section{Instrument/Questionnaire Return Rates}

Analysis was conducted on the return rate for the instruments/questionnaires (see Appendix R). Of the 67 subjects, $67.2 \%(n=45)$ completed the instruments/questionnaires preintervention, immediately post-intervention, and one month post-intervention. Comparisons were made between those subjects completing the instruments/questionnaire at all three measurements points and those that had not (see Appendices S \& T).

Table 1

Comparison of Subjects Completing Data Collection at All Three Measurements Points Versus Those Subjects Who Had Not

\begin{tabular}{|l|l|l|}
\hline & Those Completing Forms & Those Not Completing All Forms \\
\hline Age & $\mathrm{M}=64.39$ years (SD: 9.138) & $\mathrm{M}=67.68$ years (SD: 8.420) \\
\hline Years of Education & $\mathrm{M}=14.70$ years (SD: 2.651) & $\mathrm{M}=14.26$ years (SD: 2.182) \\
\hline Gender & Female: $\mathrm{n}=42(93.3 \%)$ & Female: $\mathrm{n}=19(90.5 \%)$ \\
& Male: $\mathrm{n}=3(6.7 \%)$ & Male: $\mathrm{n}=2(9.5 \%)$ \\
\hline
\end{tabular}




\begin{tabular}{|c|c|c|}
\hline Menopause Status & $\begin{array}{l}\text { Menopausal: } \mathrm{n}=40(88.9 \%) \\
\text { Non-Menopausal: } \mathrm{n}=2(4.4 \%) \\
\text { Not Applicable: } \mathrm{n}=3(6.7 \%)\end{array}$ & $\begin{array}{l}\text { Menopausal: } \mathrm{n}=19(90.5 \%) \\
\text { Non-Menopausal: } \mathrm{n}=0 \\
\text { Not Applicable: } \mathrm{n}=2(9.5 \%)\end{array}$ \\
\hline Fitness Center Member & $\begin{array}{l}\text { Yes: } n=21(46.7 \%) \\
\text { No: } n=24(53.3 \%)\end{array}$ & $\begin{array}{l}\text { Yes: } 15(71.4 \%) \\
\text { No: } 6(28.6 \%)\end{array}$ \\
\hline $\begin{array}{l}\text { Diagnosed with } \\
\text { Osteoporosis/Osteopenia }\end{array}$ & $\begin{array}{l}\text { Yes: } n=25(55.6 \%) \\
\text { No: } n=20(44.4 \%)\end{array}$ & $\begin{array}{l}\text { Yes: } n=13(61.9 \%) \\
\text { No: } n=8(38.1 \%)\end{array}$ \\
\hline $\begin{array}{l}\text { If Diagnosed, Whether } \\
\text { Osteoporosis or } \\
\text { Osteopenia }\end{array}$ & $\begin{array}{l}\text { Yes: } n=16(35.6 \%) \\
\text { No: } n=9(20 \%) \\
\text { Not Applicable: } n=20(44.4 \%)\end{array}$ & $\begin{array}{l}\text { Yes: } \mathrm{n}=8(38.1 \%) \\
\text { No: } \mathrm{n}=5(23.8 \%) \\
\text { Not Applicable: } \mathrm{n}=8(38.1 \%)\end{array}$ \\
\hline $\begin{array}{l}\text { Past Medication Use for } \\
\text { Osteoporosis or } \\
\text { Osteopenia }\end{array}$ & $\begin{array}{l}\text { Yes: } n=23(51.5 \%) \\
\text { No: } n=22(48.9 \%)\end{array}$ & $\begin{array}{l}\text { Yes: } n=10(47.6 \%) \\
\text { No: } n=11(52.4 \%)\end{array}$ \\
\hline $\begin{array}{l}\text { If Prescribed } \\
\text { Medications, if Still } \\
\text { Taking }\end{array}$ & $\begin{array}{l}\text { Yes: } n=11(24.4 \%) \\
\text { No: } n=12(26.7 \%) \\
\text { Not Applicable: } n=22(48.9 \%)\end{array}$ & $\begin{array}{l}\text { Yes: } n=4(19 \%) \\
\text { No: } n=8(38.1 \%) \\
\text { Not Applicable: } n=9(42.9 \%)\end{array}$ \\
\hline
\end{tabular}

The mean age of those with a complete data set was 64.39 years (SD: 9.138) compared to 67.68 (SD: 8.420$)$ among non-completers. The educational level was similar with a grade school level of 14.70 years (SD: 2.65) for those completing the instruments and 14.26 years (SD: 2.18) for those who had not. Among subjects returning the forms at all three measurement points, the majority were not members of the fitness center $(n=24(53.3 \%))$ compared to $28.6 \%$ $(n=6)$ of those not returning the forms at all measurement points. 
The completion rates for the instruments/questionnaires varied among the three workshops for the three different measurement periods.

Table 2

Completion Rates for the Instruments at All Three Measurements Points by Workshop

\begin{tabular}{|l|l|l|l|l|}
\hline & Workshop One & Workshop Two & Workshop Three & $\begin{array}{l}\text { Total for All } \\
\text { Three } \\
\text { Workshops }\end{array}$ \\
\hline $\begin{array}{l}\text { Osteoporosis } \\
\text { Workshop Form } \\
\text { pre-intervention) }\end{array}$ & $97.1 \%(\mathrm{n}=33)$ & $100 \%(\mathrm{n}=14)$ & $100 \%(\mathrm{n}=19)$ & $98.5 \%(\mathrm{n}=66)$ \\
\hline $\begin{array}{l}\text { Osteoporosis } \\
\text { Workshop Follow- } \\
\text { Up Form (one } \\
\text { month post- } \\
\text { intervention) }\end{array}$ & $91.2 \%(\mathrm{n}=31)$ & $92.9 \%(\mathrm{n}=13)$ & $68.4 \%(\mathrm{n}=13)$ & $85.1 \%(\mathrm{n}=57)$ \\
\hline $\begin{array}{l}\text { OKAT (Pre- } \\
\text { Intervention) }\end{array}$ & $94.1 \%(\mathrm{n}=32)$ & $92.9 \%(\mathrm{n}=13)$ & $100 \%(\mathrm{n}=19)$ & $95.5 \%(\mathrm{n}=64)$ \\
\hline $\begin{array}{l}\text { OKAT } \\
\text { Immediately Post- } \\
\text { Intervention) }\end{array}$ & $85.3 \%(\mathrm{n}=29)$ & $100 \%(\mathrm{n}=14)$ & $52.6 \%(\mathrm{n}=10)$ & $79.1 \%(\mathrm{n}=53)$ \\
\hline $\begin{array}{l}\text { OKAT (One Month } \\
\text { Post-Intervention) }\end{array}$ & $91.2 \%(\mathrm{n}=31)$ & $92.9 \%(\mathrm{n}=13)$ & $68.4 \%(\mathrm{n}=13)$ & $85.1 \%(\mathrm{n}=57)$ \\
\hline $\begin{array}{l}\text { Short Food } \\
\text { Questionnaire (Pre- } \\
\text { Intervention) }\end{array}$ & $94.1 \%(\mathrm{n}=32)$ & $92.9 \%(\mathrm{n}=13)$ & $94.7 \%(\mathrm{n}=18)$ & $94 \%(\mathrm{n}=63)$ \\
\hline $\begin{array}{l}\text { Short Food } \\
\text { Questionnaire }(O n) \\
\text { Month Post- } \\
\text { Intervention) }\end{array}$ & $91.2 \%(\mathrm{n}=31)$ & $92.9 \%(\mathrm{n}=13)$ & $68.4 \%(\mathrm{n}=13)$ & $85.1 \%(\mathrm{n}=57)$ \\
\hline $\begin{array}{l}\text { IPAQ: Short Last } 7 \\
\text { Days (Pre- } \\
\text { Intervention }\end{array}$ & $91.2 \%(\mathrm{n}=31)$ & $92.9 \%(\mathrm{n}=13)$ & $100 \%(\mathrm{n}=19)$ & $94 \%(\mathrm{n}=63)$ \\
\hline $\begin{array}{l}\text { IPAQ: Short Last } 7 \\
\text { Days (One Month } \\
\text { Post-Intervention) }\end{array}$ & $91.2 \%(\mathrm{n}=31)$ & $92.9 \%(\mathrm{n}=13)$ & $68.4 \%(\mathrm{n}=13)$ & $85.1 \%(\mathrm{n}=57)$ \\
\hline
\end{tabular}

The timing of when the one month post-intervention mailings were returned was assessed. For workshops one and two, the majority of mailings were returned within the first two weeks $(\mathrm{n}=36(75 \%))$. An additional twelve mailings were sent out two weeks later with 
eight subjects $(16.7 \%)$ returning the materials. Four participants $(8.3 \%)$ of workshops one and two did not return their materials (see Appendix U). For the third workshop, less than half of subjects $(n=9(47.4 \%))$ returned their questionnaires in the two week period after the one month post-intervention mailing. Two weeks later, an additional ten mailings were sent out. Of these mailings, four attendees $(21 \%)$ returned the mailing. Six participants $(31.6 \%)$ from the third workshop did not return their materials (see Appendix V).

\section{Demographics}

While there were male participants $(n=5(7.6 \%)$,$) , the majority of subjects were female$ $(n=61(92.4 \%))$. The mean age of participants was 65.38 years $(n=63$, range $40-87$ years, standard deviation $(\mathrm{SD})=8.990)$. The mean school grade completed was 14.56 years $(\mathrm{n}=62$, range $12-20$ years, $\mathrm{SD}=2.507)$.

The majority of female subjects $(96.7 \%)$ were menopausal $(n=59)$. While the participants were typically members of the fitness center $(n=36(54.5 \%), 45.5 \%(n=30)$ of attendees were not members. The majority of subjects had been diagnosed with either osteopenia or osteoporosis $(n=38(57.6 \%))$ with osteoporosis being the prevalent diagnosis $(n=24(63.2 \%))$. Regarding medication use for osteoporosis and/or osteopenia, $50 \%$ of the participants had previously been prescribed these medications $(n=33)$ with $22.7 \%(n=15)$ reporting they were currently on this type of medication (see Appendix W).

\section{Meeting Personal Bone Healthy Goals}

A Wilcoxon Signed Rank Test was used to evaluate the impact of the osteoporosis workshop on the participant's perception of meeting personal bone healthy goals (scale: always meeting goals $=5$, usually meeting goals $=4$, meeting goals about half the time $=3$, seldom meeting goals=2, never meeting goals=1) (see Appendices $\mathrm{E} \& \mathrm{G})$. There was a significant increase in the 
subjects' perception of meeting bone healthy goals from pre-intervention (median $=3$ ) and one month post-intervention (median=4), $\mathrm{z}=-3.148, \mathrm{p}=.002$ (two-tailed). There was a small to medium effect size (r=.28) (see Appendix W).

\section{Osteoporosis Knowledge}

A one-way repeated measures analysis of variance (ANOVA) was conducted to compare scores on the Osteoporosis Knowledge Assessment Tool (OKAT) at Time 1 (pre-intervention), Time 2 (immediately post-intervention), and Time 3 (one month post-intervention). The means and standard deviation are presented in Table 2. There was a significant effect for time, Wilks' Lambda $=0.394, \mathrm{~F}(2,46)=35.41, \mathrm{p}<.0005$. With the multivariate partial eta squared of 0.61 , a large effect size is suggested.

Table 3

Descriptive Statistics for Confidence in Osteoporosis Knowledge Assessment Tool Test Scores for Time One, Time Two, and Time Three.

\begin{tabular}{|l|r|r|r|}
\hline & Mean & \multicolumn{1}{|c|}{$\begin{array}{c}\text { Std. } \\
\text { Deviation }\end{array}$} & \multicolumn{1}{|c|}{$\mathrm{N}$} \\
\hline $\begin{array}{l}\text { OKAT Pre- } \\
\text { Intervention Total }\end{array}$ & $\mathbf{1 0 . 4 0}$ & $\mathbf{3 . 3 3 1}$ & $\mathbf{4 8}$ \\
\hline $\begin{array}{l}\text { OKAT Immediately } \\
\text { Post-Intervention } \\
\text { Total }\end{array}$ & $\mathbf{1 4 . 2 3}$ & $\mathbf{3 . 8 9 9}$ & $\mathbf{4 8}$ \\
\hline $\begin{array}{l}\text { OKAT One-Month } \\
\text { Post-Intervention } \\
\text { Total }\end{array}$ & $\mathbf{1 4 . 0 6}$ & $\mathbf{2 . 5 1 3}$ & $\mathbf{4 8}$ \\
\hline
\end{tabular}

A significant improvement was seen from OKAT scores pre-intervention (mean (M) $=10.40, \mathrm{SD}=0.48)$ and immediately post-intervention $(\mathrm{M}=14.23, \mathrm{SD}=0.56), \mathrm{p}<.0005 . \mathrm{A}$ significant improvement in OKAT scores was also seen pre-intervention $(\mathrm{M}=10.40, \mathrm{SD}=0.48)$ 
and one month post-intervention $(\mathrm{M}=14.06, \mathrm{SD}=0.36), \mathrm{p}<.0005$. There was no significance between the immediately post-intervention OKAT scores $(\mathrm{M}=14.23, \mathrm{SD}=0.56)$ and those from one month post-intervention $(\mathrm{M}=14.06, \mathrm{SD}=0.36), \mathrm{p}=1.00$.

The scores for the individual questions on the OKAT were assessed at the preintervention, immediately post-intervention and one month post-intervention measurement point for those a majority of the participants (50\% or more) had answered incorrectly (see Appendix X). The range of scores on the pre-intervention OKAT was from zero to sixteen (highest possible score was 20). The range of scores on the immediately post-intervention OKAT was from one to twenty. The range of scores for the one month post-intervention OKAT was seven to twenty. At all three measurement points, questions 11 and 19 were missed by a majority of subjects (see Appendix X).

\section{Calcium and Vitamin D Intake}

A paired-samples t-test was conducted to evaluate the impact of the osteoporosis workshop on calcium and vitamin D intake (dietary calcium in milligrams (mg) and vitamin D intake in international units (IU) using the Short Instrument for Assessing Dietary Intake of Calcium/Vitamin D, supplemental calcium (mg) and vitamin D (IU) intake, total calcium (mg) and vitamin D (IU) intake). Dietary calcium intake (pre-intervention: $\mathrm{M}=886.15 \mathrm{mg}$, $\mathrm{SD}=493.59$ ) was slightly decreased at one month post-intervention, but the decrease was not significant $(\mathrm{M}=862.55 \mathrm{mg}, \mathrm{SD}=394.95), \mathrm{t}(54)=-0.41, \mathrm{p}=.68$ (two-tailed). There was a significant increase in supplemental calcium intake from pre-intervention $(\mathrm{M}=520.93 \mathrm{mg}$, $\mathrm{SD}=598.76)$ to one month post-intervention $(\mathrm{M}=762.45 \mathrm{mg}, \mathrm{SD}=618.56), \mathrm{t}(54)=3.86$, $\mathrm{p}<.0005$ (two-tailed). The mean change in supplemental calcium intake was $241.53 \mathrm{mg}$ with a 95\% confidence interval ranging from 116.163 to 366.89 . Total calcium intake from both 
dietary and supplemental sources also increased significantly (pre-intervention: M=1358.73 mg, $\mathrm{SD}=805.1$; one month post-intervention: $\mathrm{M}=1597.44 \mathrm{mg}, \mathrm{SD}=725.87), \mathrm{t}(55)=2.76, \mathrm{p}=.008$ (two-tailed). The mean change in total calcium intake was $238.7 \mathrm{mg}$ with a $95 \%$ confidence interval ranging from 65.23 to 412.17 . Dietary vitamin D intake decreased slightly posteducational offering, but not significantly (pre-intervention: $M=192.93 \mathrm{IU}, \mathrm{SD}=141.06$, one month post-intervention: $\mathrm{M}=181.8 \mathrm{IU}, \mathrm{SD}=115.06), \mathrm{t}(54)=-0.6, \mathrm{p}=.551$ (two-tailed). An increase in supplemental vitamin D intake one month post-intervention was found which reached significance (pre-intervention: $\mathrm{M}=2003.6 \mathrm{IU}, \mathrm{SD}=2284.9$; one month post-intervention: $\mathrm{M}=2730.51 \mathrm{IU}, \mathrm{SD}=3138.4), \mathrm{t}(54)=2.13, \mathrm{p}=.04$ (two-tailed). The mean change in supplemental vitamin D intake was 726.91 IU with a $95 \%$ confidence interval ranging from 42.33 to 1411.5 . Total vitamin D intake, one month post-intervention also significantly improved (preintervention: $M=2029.93$ IU, SD=2170.22; one month post-intervention: $M=2749.44 \mathrm{IU}$, $\mathrm{SD}=3122.31), \mathrm{t}(55)=2.12, \mathrm{p}=.04$ (two-tailed). The mean change was $719.51 \mathrm{IU}$ with a $95 \%$ confidence interval ranging from 37.67 to 1401.36 (see Appendix Y).

\section{Activity Levels}

Paired-samples t-tests were conducted to evaluate the impact of the osteoporosis workshop on amount (number of days of the week and time spent exercising on a typical day (in minutes) and type of exercise (vigorous, moderate, and walking)). A paired-samples t-test was also conducted to evaluate for changes in the amount of time spent sitting on a typical weekday. The number of days of the week spent in vigorous exercise did increase one month postintervention, but not significantly (pre-intervention: $\mathrm{M}=1.89$ days, $\mathrm{SD}=2.24$; one month postintervention: $\mathrm{M}=1.96$ days, $\mathrm{SD}=2.18), \mathrm{t}(54)=0.227, \mathrm{p}=.82$ (two-tailed). The amount of time spent engaging in vigorous exercise also increased post-intervention, but not significantly (pre- 
intervention: $\mathrm{M}=45.18$ minutes, $\mathrm{SD}=59.96$; one month post-intervention: $\mathrm{M}=50.55$ minutes, $\mathrm{SD}=69.63), \mathrm{t}(54)=0.54, \mathrm{p}=.59$ (two-tailed). The number of days per week engaging in moderate physical activities increased significantly (pre-intervention: $\mathrm{M}=2.35$ days, $\mathrm{SD}=2.31$; one month post-intervention: $\mathrm{M}=3.38$ days, $\mathrm{SD}=2.56), \mathrm{t}(54)=3.32, \mathrm{p}=.002$ (two-tailed). The mean change was 1.04 days with a $95 \%$ confidence interval ranging from 0.41 to 1.66 . The amount of time spent engaged in moderate physical activities on a typical day also increased significantly (pre-intervention: $\mathrm{M}=51.36$ minutes, $\mathrm{SD}=57.47$; one month post-intervention: $\mathrm{M}=82.18$ minutes, $\mathrm{SD}=87.41, \mathrm{t}(54)=2.41, \mathrm{p}=.019$ (two-tailed). The mean change was 30.82 minutes with a $95 \%$ confidence interval of 5.19 to 56.44 . The number of days spent walking each week increased post-intervention, but not significantly (pre-intervention: $M=3.69$ days, $\mathrm{SD}=3.04$; one month post-intervention: $\mathrm{M}=4.16$ days, $\mathrm{SD}=2.7$ ), $\mathrm{t}(54)=1.25, \mathrm{p}=.217$ (twotailed). The amount of time spent walking on a typical day did increase significantly one month post-intervention (pre-intervention: $\mathrm{M}=42.91$ minutes, $\mathrm{SD}=45.28$; one month post-intervention: $\mathrm{M}=85.73$ minutes, $\mathrm{SD}=110.5), \mathrm{t}(54)=3, \mathrm{p}=.004$ (two-tailed). The mean change was 42.82 minutes with a $95 \%$ confidence interval ranging from 14.12 to 71.52 . The amount of time spent sitting on a typical weekday did decrease post-intervention, but not reach statistical significance (pre-intervention: $\mathrm{M}=338.64$ minutes, $\mathrm{SD}=157.3$; one month post-intervention: $\mathrm{M}=300$ minutes, $\mathrm{SD}=135.49), \mathrm{t}(54)=-1.73, \mathrm{p}=.0 .09$ (two-tailed) (see Appendix Z).

\section{Anonymous Surveys}

The participants were asked to complete an anonymous survey at the end of each osteoporosis workshop (see Appendices L \& AA). There were 57 returned surveys from the three workshops (85\% return rate) (see Appendix AA). There were 36 comments and/or suggestions given by the subjects (see Appendix AB). 
Of the 57 respondents, $100 \%$ reported the program as helpful with $98.2 \%(n=56)$

recommending the program to others (see Appendix AC). There were seventeen comments from respondents describing the workshop as helpful and/or informative. There were two comments recommending future workshops with one subject writing the "need to take this show on the road".

All subjects $(\mathrm{n}=57(100 \%))$ recorded the presenter as helpful (see Appendix AC). There were fourteen positive comments about the presenter. There was one negative comment with the attendee reporting the presenter was talking a little fast for him/her with the recommendation for a microphone (see Appendix AB).

The majority of attendees $(n=46(83.6 \%))$ felt they had learned everything they wanted to. Eight respondents $(14.5 \%)$ reported they had not learned everything they wanted to. In the comment portion of the survey, there were three comments made in regards to the subjects having learned everything they had wanted to and more. One subject noted almost learning everything he/she had wanted to. One attendee reported wanting to learn more about medications with another wanting to know more about diet and foods. Another wrote "can always learn more, but learned a lot of new things." Two participants who wrote they hadn't learned everything they wanted to also report they felt the handouts would be of aid to address learning deficits (see Appendix AB).

The workbook was felt to be helpful by $98.2 \%$ of respondents $(n=55)$ (see Appendix AC). Comments written about the workbook were overall positive $(n=6)$. One participant felt there were "too many handouts in one sitting". One participant noted he/she hadn't looked at the workbook yet (see Appendix AB). 
When asked if the length of the program was right, $96.4 \%(n=53)$ answered yes. Two subjects declined to answer the question (see Appendix AC). There were two participant comments regarding how quickly time went by or being able to listen longer. There were four comments that the length of the workshop was a little or too long with two adding comments about the program being informative and helpful for those with questions. There was one comment requesting questions be held until the end of the program. One participant requested the workshop be broken into shorter sessions given over two days.

\section{CHAPTER XIV BUDGET}

In creating an estimated budget for the osteoporosis workshop evaluation, the cost was projected to be $\$ 755.00$ (see Appendix AD). There was no cost to use the classroom, tables, and chairs available at the fitness center. There was access to a projector system. The recruitment goal for the evaluation portion of the osteoporosis workshop was 50 subjects. The initial design of the project was for two osteoporosis workshops to be held on the same day at two different times. As the recruitment goal was not meet (workshops one and two: $n=48$ ), a third workshop was added. The cost of the first two workshops was $\$ 1,007.90$. This total includes an additional $\$ 63.40$, not in the initial budget, spent on promotional mailings for the first two osteoporosis workshops (final cost without the promotional mailings: \$944.50). The cost of the third osteoporosis workshop was $\$ 472.95$. The cost for all three workshops was $\$ 1,475.85$.

There were several unanticipated or unplanned for factors which affected the final cost of the workshops. One factor was related to creation of the workbooks. Copying and paper supplies for the instruments and mailings were initially estimated at $\$ 50.00$ with an additional $\$ 30.00$ budgeted for the copying of the handouts. The projected cost for the workbooks was $\$ 100.00$ which included items such as folder, labels, and paper clips. The estimate had been 
based upon access to a copier. Due to a change in circumstances, access to a copier was not available. Copying had to be done instead via a home printer with an estimated cost of $\$ 0.05$ a page with each individual workbook costing $\$ 5.75$. Another unplanned budgetary item(s) were tablecloths at a total cost of $\$ 10.00$ (workshops one and two: $\$ 5.00$, workshop three: $\$ 5.00$ ). Incentives for participation in the follow-up measurements were utilized. As a third workshop was added, this was an additional cost of $\$ 95.00$ for the 19 subjects (see Appendix AE).

\section{CHAPTER XV DISCUSSION}

The purpose of this study was to evaluate potential changes in osteoporosis knowledge, participants' perception of meeting personal bone healthy behaviors, calcium/vitamin D intake, and physical activity levels before and after an osteoporosis workshop for individuals at high risk for the disease. The osteoporosis workshop was attended primarily by post-menopausal Caucasian females. The workshop appealed to both those with osteopenia or osteoporosis (57.6\%) and those not diagnosed with the disease $(42.4 \%)$. Of those who had been given pharmaceutical treatment $(\mathrm{n}=33)$, a majority $(54.5 \%)$ were no longer taking the medication. The reasons for this warrants further evaluation.

An improvement in osteoporosis knowledge was seen with a significant improvement immediately post-intervention with continued significant improvement maintained at one month post-intervention. These improvements are consistent with other research findings on the effect of a onetime community-based osteoporosis workshop on osteoporosis knowledge (Brecher et al., 2002; Gaines et al., 2010; Riberio \& Blakeley, 2001). There have been studies which found no improvement in osteoporosis knowledge after a onetime educational offering. No change was seen in osteoporosis knowledge measured 16 weeks post-intervention in a study by Yuksel et al. (2010). Sedlak et al. (2005) also found no improvement in osteoporosis knowledge six months 
post-intervention. As this study also found significant increased barriers to calcium intake and decreased exercise frequency post-intervention, the authors theorized incorporating the subjects' individual data and goals may be of aid in overcoming these barriers. A consideration for future evaluation of this workshop is additional measurement points beyond the one month postintervention period to evaluate for a sustained improvement in osteoporosis knowledge.

Analysis of incorrectly answered questions on the OKAT revealed a majority had missed questions eleven and nineteen at all three measurement points (see Appendix C). Question 11 asked about the ability to determine risk of osteoporosis by assessing one's risk factors. Question 19 asked about the use of post-menopausal hormone therapy in regards to bone loss. As these questions were missed at all three measurement periods, additional information on these two subjects should be provided to participants in future workshops.

There was significant improvement in subjects' personal perception of meeting bone healthy behaviors one month post-intervention. The majority $(91.4 \%)$ perceived meeting their bone healthy behavior goals at least half the time. As this finding may not persist beyond the one month post-intervention period, consideration for future evaluation would include a longer post-intervention measurement period (see Appendix W).

Participants' supplemental and total daily calcium intake increased significantly one month post-intervention. For those aged 50 and older, the National Osteoporosis Foundation (NOF) recommends a daily calcium intake of 1200 milligrams (NOF, 2010). Dietary calcium intake, both pre- and post-intervention, was below the NOF's recommended daily intake. Dietary calcium intake was slightly decreased one month post-intervention, but not significantly. Pfister, Wulu, and Saville (2001) found in their study, of southern WV women aged 65 years and older, every subject $(n=184)$ consumed less than the recommended daily amount of calcium. 
Shea et al. (2011) found a median daily calcium intake of $739 \mathrm{mg}$ in Caucasians and $681 \mathrm{mg}$ in African Americans aged 70 to 81 years old.

While supplemental calcium intake in this study did significantly increase one month post-intervention, the calcium intake from supplements alone at both measurement periods was also below the NOF's recommended daily intake. The total calcium intake from both dietary and supplemental sources increased significantly one month post-intervention. At both measurement points, the total calcium intake exceeded the NOF's daily minimum calcium intake. As the preferred method of obtaining calcium is through the diet, focus in future osteoporosis workshops should be on providing additional information on ways to improve dietary calcium intake. To aid the participants in understanding their individual dietary calcium and vitamin D intake and the potential need for improvement, the subjects could be provided with their pre-intervention calculated dietary calcium and vitamin D intakes to aid in these efforts.

For those aged 50 and older, the NOF recommends a daily vitamin D intake of 800 to 1000 international units (IU) (NOF, 2010). Dietary vitamin D intake at both pre- and one month post-intervention was below the NOF's recommendations. Dietary vitamin D intake was slightly decreased post-educational offering, but not significantly. Shea et al. (2011) found 92\% of Caucasians and $90 \%$ of African Americans aged 70 to 81 years old had a dietary vitamin D intake of less than 400 IU a day. The median daily vitamin D intake for Caucasians was 198 IU and for African Americans was 159 IU (Shea et al., 2011). At both pre- and one month postintervention, the supplemental and total vitamin D intake was found to exceed the NOF's daily recommended intake of 800 to 1000 IU. Supplemental and total vitamin D intake postintervention did increase significantly. 
Physical activity levels improved in the days of the week and time spent doing moderate physical activities and the time spent when walking. Due to the possibility of a fracture from more strenuous types of exercise, more moderate physical activities and walking are encouraged for those with osteoporosis (NOF, 2010). The number of days a week of vigorous exercise did slightly increase from 1.89 days a week to 1.96 days post-intervention albeit not significantly. The amount of time spent engaging in vigorous exercise also increased from 45.18 minutes to 50.55 minutes post-intervention, but not significantly. A significant increase was seen in the number of days per week and the time spent on a typical day engaging in moderate physical activities. Pre-intervention, participants engaged in moderate exercise 2.35 days a week for 51.36 minutes at a time with an increase to 3.38 days post-intervention for 82.18 minutes at a time. While the increase in number of days from 3.69 to 4.16 spent walking each week did not increase significantly, the amount of time spent walking on a typical day did increase significantly from 42.91 minutes to 85.73 minutes. While the amount of time spent sitting on a typical weekday did decrease from 338.645 minutes to 300 minutes, this was not significant.

Overall, the majority of participants found the workshop helpful and learned everything he/she had wanted. The location, the comfort of the room, and the time(s) of the workshop were acceptable to a majority of subjects. The length of the program was perceived by most to be appropriate with the majority recommending the workshop to others. The workbook and presenter were reported to be helpful to a preponderance of attendees. The cost of the workbook was a large part of the budget, and could be a hindrance to holding future programs (see Appendix AE). Further evaluation of the workshop could be done without the workbook to evaluate the benefit of its incorporation. 


\section{Limitations}

There are limiting factors in regards to this study. The instruments were self-report which may have limited the findings. Since the creation of the Short Instrument for Assessing Dietary Intake of Calcium/Vitamin D, additional high calcium and vitamin D foods are available which the participants may have had access to. For example, calcium and vitamin D fortified orange juice and breakfast bars are available at many local grocery stores as is calcium fortified bread. Many of these food items were discussed in the osteoporosis workshop, but their use would not have been captured by the Short Instrument for Assessing Dietary Intake of Calcium/Vitamin D (see Appendix H).

As the participants were primarily post-menopausal Caucasian females who were fairly well educated and members of the fitness center, the findings of this study may not be generalizable to males and to other more diverse populations. Another possible limiting factor is the one month post-intervention measurements were completed at the subjects' convenience which may have impacted the findings. While the majority of returned instruments/questionnaires $(67 \%)$ were returned within two weeks at the one month postintervention measurement point, $33 \%$ were not (see Appendices U \& V). There was a $15 \%$ attrition rate at the one month post-intervention.

Personal circumstances of the attendees may have affected the outcomes. Two of the participants wrote unsolicited remarks on the returned instruments/questionnaires regarding reduced activity levels at the one month post-intervention measurement point (see Appendix AJ). During the osteoporosis workshops, several participants reported health conditions such as hypercalcemia, hyperparathryodisim, and vitamin D deficiency requiring prescription treatment which may have impacted their calcium and/or vitamin D intake. Information on health 
conditions which could impact calcium and/or vitamin D intake could be collected at future osteoporosis workshop evaluations. There were two unsolicited comments written on the preintervention forms describing them as "unreliable". Both of these participants partially completed the pre-intervention and immediately post-intervention questionnaires/instruments. Neither returned the one month post-intervention mailings at either mailing period. As the workshops were held in a fitness center and the majority of attendees were members of the fitness center, the subjects may have been more motivated to learn about osteoporosis and change their bone healthy behaviors.

\section{CHAPTER XVI CONCLUSION}

Osteoporosis is a preventable and prevalent disease seen nationally and among the residents of West Virginia. To aid in the care of those with the disease and to improve the bone health of the surrounding community, a Capstone project was proposed and evaluated. This project was a onetime community-based educational offering regarding osteoporosis knowledge and bone healthy behavior led by a nurse practitioner, and held in a fitness center. The focus of the intervention was on those at high risk for osteoporosis; post-menopausal women and men aged 50 and older (NOF, 2010). The participants were followed up to one month posteducational offering to evaluate for changes in osteoporosis knowledge and the bone healthy behaviors of adequate daily calcium/vitamin $\mathrm{D}$ intake and being physically active. The majority of the subjects reported the workshop as helpful and would recommend it to others. Significant increases in osteoporosis knowledge, daily supplemental calcium intake, total daily calcium intake, daily supplemental vitamin D intake, and total daily vitamin D intake were seen one month post-intervention. Significant improvements were also seen in the days of the week and time spent on a typical day engaging in moderate physical activities and the time spent walking 
on a typical day. The effectiveness of this type of intervention needs to be replicated with a more diverse sample of participants. 


\section{References}

Ailinger, R. L., \& Emerson, J. (1998). Women's knowledge of osteoporosis. Applied Nursing Research, 11 (3), 111-114.

Ailinger, R. L., Lasus, H., \& Braun, M. A. (2003). Revision of the facts on osteoporosis quiz. Nursing Research, 52, 198-201.

Bartlett, E. (2012, February 19). Exercise, education may stem bone loss. Sunday GazetteMail, Outlook Section on Health and Medicine, p. 11J.

Blalock, S. J., Currey, S. S., DeVillis, R. F., Anderson, J. J., Gold, D. T., \& Dooley, M. A. (1998). Using a Short Food Frequency Questionnaire to estimate dietary calcium intake consumption: A tool for patient education. Arthritis Care \& Research, 11, 479-484.

Blalock, S. J., DeVellis, R. F., Giorgino, K. B., DeVillis, B. M., Gold., D. T., Dooley, M. A., Anderson, J. J., \& Smith, S. L. (1996). Osteoporosis prevention in premenopausal women: Using a stage model approach to examine the predictors of behavior. Health Psychology, 15 (2), 84-93.

Blalock, S. J., Norton, L. L., Patel, R. A., Cabral, K., \& Thomas, C. L. (2003). Development and assessment of a short instrument for assessing dietary intakes of calcium and vitamin D. Journal of the American Pharmacists Association, 43 (6), 685-693.

Block, G., Hartman, A. M., \& Naughton, D. (1990). A reduced dietary questionnaire: Development and validation. Epidemiology, 1, 38-64.

Brecher, L. S., Pomerantz, S. C., Snyder, B. A., Jenora, D. M., Klotzbach-Shimomura, K. M., \& Cavalieri, T. A. (2002). Osteoporosis prevention project: A multi-disciplinary educational intervention. Journal of the American Osteopathic Association, 102 (6), 327$335,354-355$. 
Brown, W. J., Trost, S G., Bauman, A., Mummery, K., \& Owen, N. (2004). Test-retest reliability of four physical activity measures used in population surveys. Journal of Science and Medicine in Sports, 7 (2), 205-215.

Burke-Doe, A., Hudson, A., Werth, H., \& Riordan, D. G. (2008). Knowledge of osteoporosis risk factors and prevalence of risk factors for osteoporosis, falls, and fracture in functionally independent older adults. Journal of Geriatric Physical Therapy, 31 (1), 11 17.

Cadarett, S. M., Jaglal, S. B., \& Murray, T. M. (1999). Validation of the simple calculated osteoporosis risk estimation (SCORE) for patient selection for bone densitometry. Osteoporosis International, $10(1), 85-90$.

Chan, M. F., Ko, C. Y., \& Day, M. C. (2005). The effectiveness of an osteoporosis prevention education programme for women in Hong Kong: A randomized controlled trial. Journal of Clinical Nursing, 14 (9), 1112-1123.

Chan, M. F., \& Ko, C. Y. (2006). Osteoporosis prevention education programme for women. Journal of Advanced Nursing, 54 (2), 159-170.

Chang, S. F., Chen, C. M., Chen, P. L., \& Chung, U. L. (2003). Predictors of community women's osteoporosis prevention intention-A pilot study. Journal of Nursing Research, $11(4), 231-239$.

Cooper, C., Campion, G., \& Melton, L. J. (1992). Hip fractures in the elderly: A world-wide projection. Osteoporosis International, 2 (6), 285-289. 
Corbin, M. A., Trainor, J., Liu, C., \& Gueldener, S. H. (2008). A model for community outreach: Cooperative extension osteoporosis prevention and screening programs. In S.

H. Gueldner, T. N. Grabo, E. D. Newman, \& D. R. Cooper (Eds.), Osteoporosis: Clinical guidelines for prevention, diagnosis, and management (pp. 187-200). New York: Springer Publishing Company.

Craig, C. L., Marshall, A. L., Sjostrom, M., Bauman, A. E., Booth, M. L., Ainsworth, B. E., Prat, M., Ekelund, U., Yngve, A., Sallis, J. F., \& Oja, P. (2003). International physical activity questionnaire: 12-country reliability and validity. Medicine \& Science in Sports \& Exercise, 35 (8), 1381-1395.

Cramer, J. A., Gold, D. T., Silverman, S. L., \& Lewiecki, E. M. (2007). A systematic review of persistence and compliance with bisphosphonates for osteoporosis. Osteoporosis International, 18, 1023-1031.

Davis, G. C. (1999). Development of the osteoporosis knowledge questionnaire. Unpublished manuscript, College of Nursing, Texas Women's University, Denton, Texas.

Davis, G. C., Jimenez, C. A., \& Rubin, B. R. (1995). Health status measurement in osteoporosis. [Supplemental material]. Arthritis \& Rheumatism, 38 (9), S222.

Davis, G. C., White, T. L., \& Yang, A. (2006). A bone health intervention for older adults living in residential settings. Research in Nursing \& Health, 29, 566-575.

Day, S. H., \& Block, L. (2006). Extension program builds on UA research. Journal of Family and Consumer Sciences, 98 (2), 62-63.

Dell, R., Greene, D., Schelkun, S. R., \& Williams, K. (2008). Osteoporosis disease management: The role of the orthopaedic surgeon. The Journal of Bone and Joint Surgery, 90, 188-194. 
Doheny, M., \& Sedlak, C. (2004). Osteoporosis preventing behavior survey. Unpublished manuscript, Department of Nursing, Kent State University, Kent, Ohio.

Driskell, J. A., Pohlman, H. D., \& Naslund, M. M. (2003). Value of an educational program on osteoporosis. Journal of Extension, 41 (5). Retrieved November 5, 2009 from http://www.joe.org/joe/2003october/rb6.php

Fleury, J., \& Cameron, K. (2003). The index of readiness. In O. L. Strickland, \& C. Dilonio (Eds.). Measurement of Nursing Outcomes: Self Care and Coping. (2 ${ }^{\text {nd }}$ ed., Vol. 3, pp. 265-275). New York: Springer.

Gaines, J. M., Narratt, M., \& Parrish, J. M. (2010). The effect of the addition of osteoporosis education to a bone health screening for older adults. Geriatric Nursing, 31 (5), 348-360.

Gordon, P. M., Newcomer, R. R., \& Krummel, D. A. (2001). Physical activity and osteoporosis: Disparities between knowledge and practice. The West Virginia Medical Journal, 97, 153-156.

Grahn Kronhed, A. C., Blomberg, C., Karlsson, N., Lofman, O., Timpka, T., \& Moller, M. (2005). Impact of a community-based osteoporosis and fall prevention program on fracture incidence. Osteoporosis International, 16, 700-706.

Greendale, G. A., \& Barrett-Conner, E. (2001). Outcomes of osteoporotic fractures. In R. Marcus, D. Feldman, \& J. Kelsey (Eds), Osteoporosis ( $2^{\text {nd }}$ ed., Vol 1) (pp. 819-829). San Diego: Academic Press.

Horan, M. L., Kim, K. K., \& Gendler, P. (1993, March). Development and evaluation of osteoporosis self-efficacy scale. Paper presented at the meeting of the Midwest Nursing Research Society Conference, Cleveland, Ohio. 
Horan, M. L., Kim, K. K., Gendler, P., Froman, R. D., \& Patel, M. D. (1998). Development and evaluation of the Osteoporosis Self-Efficacy Scale. Research in Nursing and Health, 21 (5), 395-403.

Hsieh, C., Novielli, K.D., Diamond, J. J., \& Cheruva, D. (2001). Health beliefs and attitudes toward the prevention of osteoporosis in older women. Menopause, 8 (5), 372-376.

Johnell, O., \& Kanis, J. A. (2006). An estimate of the worldwide prevalence and disability associated with osteoporotic fractures. Osteoporosis International, 17, 1726-1733.

Johnson, C. S., McLeod, W., Kennedy, L., \& McLeod, K. (2008). Osteoporosis health beliefs among younger and older men and women. Health Education \& Behavior, 35 (5), 721 733.

Kanis, J. A., Borgstrom, F., De Laet, C., Johansson, H., Johnell, O., Jonsson, B., Oden, A., Zethraeus, N., Pfleger, B., \& Khaltaev, N. (2005). Assessment of fracture risk. Osteoporosis International, 16, 581-589.

Kanis , J., Melton, L., Christiansen, C., Johnston, C., \& Khaltaev, N. (1994). The diagnosis of osteoporosis. Journal of Bone Mineral Research, 9 (8), 1137-1141.

Kelton, C. M. L., \& Pasquale, M. K. (2009). Evaluating the claim of enhanced persistence: The case of osteoporosis and implications for payers. Medical Decision Making, 29, 690-706.

Kim, K. K., Horan, M. L., \& Gendler, P. (1991). Osteoporosis knowledge test, osteoporosis health belief scale, and osteoporosis self-efficacy scale. Archives of Grand Valley State University, Allendale, MI.

Kim, K. K., Horan, M. L., Gendler, P., \& Patel, M. K. (1991). Development and evaluation of the osteoporosis health belief scale. Research in Nursing and Health, 14, 155-163. 
Klotzbach-Shimomura, K. (2001). Project healthy bones: An osteoporosis prevention program for older adults. Journal of Extension, 39 (3). Retrieved June 13, 2010 from http://www.joe.org.www.libproxy.wvu.edu/joe/2001june/iw6.php

Kothawala, P., Badamgarav, E., Ryu, S., Miller, R. M., \& Halbert, R. J. (2007). Systematic review and meta-analysis of real-world adherence to drug therapy for osteoporosis. Mayo Clinic Proceedings, 82 (12), 1493-1501.

Larrabeee, J. H. (2009). Nurse to nurse evidence-based practice. New York: McGraw-Hill.

Lydick, E., Cook, K., Turpin, J., Melton, M., Stine, R., \& Byrnes, C. (1998). Development and validation of a simple questionnaire to facilitate identification of women likely to have low bone density. The American Journal of Managed Care, 4, 37-48.

Lydick, E., Zimmerman, S. I., Yawn, B., Love, B., Kleerekoper, M., Ross, P., Martin, A., \& Holmes, R. (1997). Development and validation of a discriminative quality of life questionnaire for osteoporosis (the OPTQoL). Journal of Bone and Mineral Research, $12(3), 456-463$.

Melton, L. J., Chrischilles, E. A., Cooper, C., Lane, A. W., \& Riggs, B. L. (1992). Perspective: How many women have osteoporosis. Journal of Bone Mineral Research, 7, 1005-1010. National Conference of State Legislatures. (2009). Osteoporosis: State laws. Washington, D. C.: Author. [on-line]. Retrieved September 29, 2010 from http://www.ncsl.org/programs/health/whosteo.htm

National Conference of State Legislatures. (2009). Osteoporosis: State Laws.

Washington, D. C.: Author. [on-line]. Retrieved Febuary 28, 2010, from http://www.ncsl.org/programs/health/whosteo.htm 
National Institutes of Health. (2000). Osteoporosis prevention, diagnosis, and therapy. NIH Consensus Statement Online 2000 [on-line]. Retrieved September 29, 2010 from http://consensus.nih.gov/2000/2000Osteoporosis111html.htm

National Osteoporosis Foundation. (2002). America's bone health: The state of osteoporosis and low bone mass in our nation. Washington, D. C.: National Osteoporosis Foundation.

National Osteoporosis Foundation. (2010). Clinician's guide to prevention and treatment of osteoporosis. Washington, D. C.: National Osteoporosis Foundation.

Newman, E. D., Ayoub, W. T., Starkey, R. H., Diehl, J. M., \& Wood, G. C. (2003). Osteoporosis disease management in a rural health care population: Hip fracture reduction and reduced costs in postmenopausal women after 5 years. Osteoporosis International, 14, 146-151.

Newman, E. D., \& Hanus, P. (2001). Improved bone health behavior using community pharmacists as educators: The Geisinger health system community pharmacist osteoporosis education program. Disease Management \& Health Outcomes, 9 (6), 329335.

Nielsen, D., Ryg, J., Nissen, N., Nielsen, W., Knold, B., \& Brixen, K. (2008). Multidisciplinary patient education in groups increases knowledge on osteoporosis: A randomized controlled trial. Scandinavian Journal of Public Health, 36 (4), 346-352.

Pearson, J. A., Burkhart, E., Pifalo, B., Palaggo-Toy, T., \& Krohn, K. (2005). A lifestyle modification intervention for the treatment of osteoporosis. American Journal of Health Promotion, 20 (1), 28-33. 
Peel, C., Lein, D., Kitchin, B., \& Morgan, S. (2001). "Tone your bones": A model for health education for older adults. Journal of Physical Therapy Education, 15 (2), 23-28.

Pelletier, S., Kundrat, S., \& Hasler, C. M. (2003). Effects of a functional foods nutrition education program with cardiac rehabilitation patients. Journal of Cardiopulmonary Rehabilitation, 23, 334-340.

Pennsylvania Department of Health. (2008). Annual Report to the General Assembly. Harrisburg, PA: Osteoporosis Prevention and Education Program.

Pfister, A. K., Wulu, J. T., \& Saville, P. D. (2001). Factors determining calcium intake in elderly women of Appalachia. Southern Medical Journal, 94 (10), 1006-1012.

Pfister, A. K., Helmick, K. P., Saville, P. D., Welch, C. A., \& Emmett, M. K. (2008). OST risk index with forearm densitometry. Journal of Clinical Denistometry, 11 (4), 590-591.

Pfister, A. K., Sale, W. G., \& Shaulkat, S. (2009). The economics of fragility fractures in West Virginia. West Virginia Medical Journal, 105, 10-13.

Podsiadlo, D., \& Richardson, S. (1991). The timed "up \& go": A test of basic function mobility for frail elderly persons. Journal of the American Geriatrics Society, 39, 142-148.

Radloff, L. S. (1977). The CES-D scale: A self-report depression scale for research in the general population. Applied Psychology Measures, 1, 385-401.

Ribeiro,V., \& Blakeley, J. A. (2001). Evaluation of an osteoporosis workshop for women. Public Health Nursing, 18, (3), 186-193.

Rikli, R. E., \& Jones, C. J. (1999). Development and validation of a functional fitness test for community-residing older adults. Journal of Aging and Physical Activity, 7, 129-161. 
Rolnick, S. J., Kopher, R., Jackson, J., Fischer, L. R., \& Compo, R. (2001). What is the impact of osteoporosis education and bone mineral density testing for postmenopausal women in a managed care setting. Menopause, 8, (2), 141-148.

Ryan, P. (2009). Integrated theory of health behavior change: Background and intervention development. Clinical Nurse Specialist, 23 (3), 161-170.

Ryan, P., Pumilia, N. J., Henak, B., \& Chang. T. (2009). Development and performance usability of a theory-based, computerized, tailored intervention. Computers, Informatics, Nursing, 27 (5), 288-298.

Ryg, J., Nissen, N., Nielsen, D., \& Brixen, K. T. (2005). Patients' and population's knowledge of osteoporosis. Ugeskr Kaeger, 167, 282-285.

Schousboe, J. T., DeBold, R. C., Kuno, L. S., Weiss, T. W., Chen, Y., \& Abbott, T. A. (2005). Education and phone follow-up in postmenopausal women at risk for osteoporosis: effects on calcium intake, exercise frequency, and medication use. Disease Management \& Health Outcomes, $13(6), 395-404$.

Scottish Intercollegiate Guidelines Network. (2008). Critical appraisal: Notes and checklists. [on-line]. Available: www.sign.ac.uk/methodology/checklists.html

Sedlak, C. A., Doheny, M. O., \& Estok, P. J. (2000). Osteoporosis in older men: Knowledge and health beliefs. Orthopaedic Nursing, 19 (3), 44-46.

Sedlak, C. A., Doheny, M. O., Estok, P. J., \& Zeller, R. A. (2005). Tailored interventions to enhance osteoporosis prevention in women. Orthopaedic Nursing, 24 (4), 270-278. 
Shea, M. K., Houston, D. K., Tooze, J. A., Davis, C. C., Johnson, M. A., Hausman, D. B., Cauley, J. A., Bauer, D. C., Tylavsky, F., Harris, T. B., \& Kritchevsky, S. B. (2011). Correlates and prevalence of insufficient 25-hydroxyvitamin D status in black and white older adults. Journal of the American Geriatrics Society,59 (7), 1165-1174.

Smith, C. (2010). A systematic review of healthcare professional-led education for osteoporosis patients or those at high risk for the disease. Orthopaedic Nursing, 29 (2), 119-132.

Stanford, V. A., Hoelscher Day, S., Houtkooper, L. B., Block, L., Harris, R., Larkey, L., Metcalfe, L., Going, S., \& Lohman, T. (2005, April). Bone Builders Osteoporosis Prevention Education Program. Poster session presented at the annual meeting of the National Osteoporosis Foundation, Washington, D. C.

Taylor, H. L., Jacobs, D. R., Schucker, B., Knudsen, J., Leon, A. S., \& Debacker, G. (1978). A questionnaire for the assessment of leisure time activities. Journal of Chronic Disease, $31,741-755$.

Terrio, K., \& Auld, G. W. (2002). Osteoporosis knowledge, calcium intake, and weight-bearing physical activity in three age groups of women. Journal of Community Health, 27 (5), 307-320.

Tinetti, M. E., Richman, D., \& Powell, L. (1990). Falls efficacy as a measure of fear of falling. Journal of Gerontology, 45, 239-243.

United States Census Bureau (2012). American Fact Finder.

Washington, D. C., Author [on-line]. Retrieved June 4, 2012, from http://factfinder2.census.gov/faces/nav/jsf/pages/index.xhtml 
U. S. Department of Health and Human Services. (2004). Bone health and osteoporosis: A report of the Surgeon General. U. S. Department of Health and Human Services: Office of the Surgeon General.

Ware, J., Kosinski, M., \& Keller, S. D. (1996). A 12-item short-form health survey: Construction of scales and preliminary tests of reliability and validity. Medical Care, 29, 602-608.

West Virginia Department of Health and Human Resources. (1999). 1999 Behavioral risk factor survey report. Charleston, WV: Health Statistics Center.

West Virginia Department of Health and Human Resources. (2004). The burden of osteoporosis in West Virginia. Charleston, WV: West Virginia Osteoporosis Prevention Education Program.

West Virginia Department of Health and Human Resources. (2007). 2004-2005 Behavioral risk factor survey report. Charleston, WV: WV Health Statistics Center.

West Virginia Department of Health and Human Resources. (2009). 2006 Behavioral risk factor survey report. Charleston, WV: WV Health Statistics Center.

White, T. L. (2008). Improving osteoporosis knowledge and healthy bone habits of ruraldwelling older adults. Unpublished doctoral dissertation, Texas Woman's University.

Winzenberg, T. M., Oldenburg, B., Frendin, S., \& Jones, G. (2003). The design of a valid and reliable questionnaire to measure osteoporosis knowledge in women: The osteoporosis knowledge assessment tool (OKAT). BMC Musculoskeletal Disorders, 4, 17-24.

World Health Organization. (1994). Assessment of fracture risk and its application to screening for postmenopausal osteoporosis: Report of a WHO Study Group. (WHO Technical Report Series, No. 843). Geneva: Author. 
YMCA of the Kanawha Valley (2012). The YMCA winter/spring 2011-2012 membership

program guide [brochure]. Retrieved January 1, 2012 from http://www.ymcawv.org/PDFs/YMCA-WinterSpringProgram2011.pdf.

Yuksel, N., Majumder, S. R., Biggs, C., \& Tsuyuki, R. T. (2010). Community pharmacistinitiated screening program for osteoporosis: Randomized controlled trial. Osteoporosis International, 21, 391-398. 


\section{Appendix A}

\section{Letter of Support for Capstone Project from YMCA of the Kanawha Valley}

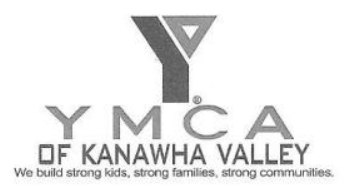

July 20, 2011

West Virginia University - School of Nursing

Attention: Nan Leslie, PhD, RN, CRNP

Health Promotion

PO Box 9600

Morgantown, WV 26506-9600

Dear Dr. Leslie and members of the West Virginia University Institutional Review Board,

The YMCA of Kanawha Valley is pleased to support Cynthia A. Smith, doctoral of nursing practice student, at West Virginia University School of Nursing, and director of Pars Osteoporosis Clinic. The YMCA of Kanawha Valley realizes the importance of health education for all age groups, in particular, older adults which is our fastest growing membership. We value programs that provide information to these older adults with regard to health issues they may be facing including osteoporosis. Given the incidence of osteoporosis among this age group and given the need to educate them on ways to preserve skeletal health, we would welcome the opportunity to assist you in this project.

Sincerely,

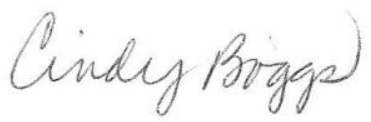

Cindy Boggs

Fitness Coordinator

YMCA of Kanawha Valley

100 YMCA Drive

Charleston, WV 25311

304-340-3527

www.ymcawv.org

\footnotetext{
YMCA of Kanawha Valley • 100 YMCA Drive • Charleston, West Virginia 25311

304-340-3527•Fax 304-340-3528 • Email: info@ymcawv.org • www.ymcawv.org

YMCA Mission: To put Christian principles into practice through programs that build healthy spirit, mind, and body for all.

Caring • Honesty - Respect - Responsibility
} 


\section{Appendix B}

Senior Classes Offered at the YMCA of the Kanawha Valley

\section{CHARLESTON FAMILY YMCA \\ Senior Class Schedule 2012 \\ Bone Building class $=\mathrm{BB}$ \\ Y'S SENIORS IN MOTION \\ Monday \& Wednesday at 11:00am \\ (Cardio and Strength) BB \\ MEET THE MACHINES \\ Wednesday in the Fitness Center BB \\ Anytime between 10:00am and 10:50am \\ (Not a class but rather a Personal Orientation to Fitness Center) \\ SilverSneakers MSROM \\ Monday at 9:30am; Tuesday and \\ Thursday at 1:00pm; Friday at 11:00am \\ (Muscular Strength \& Range of Movement) BB}

\section{SilverSneakers YogaStretch}

Wednesday at 9:30am

(Balance and Flexibility)

\section{SENIOR SPIRIT}

$2^{\text {nd }}$ Wednesday of each month at noon

(Pot luck luncheon with speaker)

\section{SENIOR GAME DAY}

$2^{\text {nd }}$ Friday of each month at noon

(Variety of board games with snacks)

We offer one SS class each day Monday through Friday plus a weekly orientation to fitness center and a cardio class!

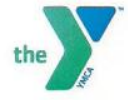

These classes are free with your SilverSneakers or Y membership. Please call 304-340-3527 for more information or visit our web site www.ymcawv.org 


\section{Senior Specific Classes with Descriptions

(Designed for Older Adults or for those with limitations) $\quad B B=$ Bone Building

Y's Seniors in Motion (formerly Senior Fit) Ready, Set, GO for this comprehensive fitness class, which encompasses the major components of a well-balanced fitness regimen: cardio, strength, flexibility, and balance/agility. This is a low impact class especially designed for older adults, with modifications given to allow for musculoskeletal differences and issues. Healthy lifestyles are emphasized, and current updates from well-known medical centers are distributed regularly. Free to members! Mon and Wed BB

Meet the Machines (formerly Senior Power) Feel intimidated by the machines in the Fitness Center? This instructional time will help put you at ease, and provide an introduction to the machines in an informal, one-onone setting. The instructor will be in the Fitness Center each Wednesday from 10:00 to 10:50 to facilitate orientation and to ensure good form and provide tips geared to seniors. Free to members! Wed BB

SilverSneakers MSROM- Muscular Strength and Range of Movement-Have fun and move to the music through a variety of exercises designed to increase bone density, muscular strength, range of movement and activity for daily living skills. Hand-held weights, elastic tubing with handles and a ball are used for resistance, and a chair is provided for seated or standing support. Bring water. Free to members! Mon, Tu, Th, Fri BB

SilverSneakers Yogastretch- This class enhances flexibility, balance, and posture, using a chair for seated or standing support. Various stretches are combined with restorative breathing to improve individual's energy and sense of well-being. A perfect complement to the SilverSneakers MSROM classes, SS Yoga Stretch moves the joints and stretches the muscles without weights or resistance. Bring water. Free to Members! Wed

Senior Spirit- Calling all older adult $Y$ members: Do you like to hear stimulating speakers, learn, laugh, eat good food, and share in camaraderie? If so, join a group of fun-loving, interesting people for a monthly potluck luncheon in the Noffsinger Room at 12:00 noon. The seniors meet the second Wednesday of each month (except in January and during the summer) to hear speakers on various topics and to enjoy food, fun, and fellowship. Please join us! Free to members.

Senior Game Day- Enjoy a variety of board games and plenty of fun and fellowship for Senior Game Day. Held the second Friday of each month at noon following SilverSneakers MSROM. You don't have to have participated in SilverSneakers to join us for the fun. Light snacks will be provided but feel free to pack a sandwich and bring it to Senior Game Day. Free to members. 


\section{Appendix C \\ Information on the Osteoporosis Knowledge Assessment Tool}

\section{Appendix One: The Osteoporosis Knowledge Assessment Tool (OKAT)}

\section{Please answer each of the following questions with True, False or Don't Know.}

1. Osteoporosis leads to an increased risk of bone fractures.

2. Osteoporosis usually causes symptoms ( e.g. pain) before fractures occur.

3. Having a higher peak bone mass at the end of childhood gives no protection against the development of osteoporosis in later life.

4. Osteoporosis is more common in men.

5. Cigarette smoking can contribute to osteoporosis.

6. White women are at highest risk of fracture as compared to other races.

7. A fall is just as important as low bone strength in causing fractures.

8. By age 80 , the majority of women have osteoporosis.

9. From age 50, most women can expect at least one fracture before they die.

10. Any type of physical activity is beneficial for osteoporosis.

11. It is easy to tell whether I am at risk of osteoporosis by my clinical risk factors.

12. Family history of osteoporosis strongly predisposes a person to osteoporosis.

13. An adequate calcium intake can be achieved from two glasses of milk a day.

14. Sardines and broccoli are good sources of calcium for people who cannot take dairy products.

15. Calcium supplements alone can prevent bone loss.

16. Alcohol in moderation has little effect on osteoporosis.

17. A high salt intake is a risk factor for osteoporosis.

18. There is a small amount of bone loss in the ten years following the onset of menopause.

19. Hormone therapy prevents further bone loss at any age after menopause.

20. There are no effective treatments for osteoporosis available in Australia. $\square$ True $\square$ False $\square$ Don't know

$\square$ True $\square$ False $\square$ Don't know

$\square$ True $\square$ False $\square$ Don't know

$\square$ True $\square$ False $\square$ Don’t know

$\square$ True $\square$ False $\square$ Don't know

$\square$ True $\square$ False $\square$ Don't know

$\square$ True $\square$ False $\square$ Don't know

$\square$ True $\square$ False $\square$ Don't know

$\square$ True $\square$ False $\square$ Don't know

$\square$ True $\square$ False $\square$ Don't know

$\square$ True $\square$ False $\square$ Don't know

$\square$ True $\square$ False $\square$ Don't know

$\square$ True $\square$ False $\square$ Don't know

$\square$ True $\square$ False $\square$ Don't know

$\square$ True $\square$ False $\square$ Don't know

$\square$ True $\square$ False $\square$ Don't know

$\square$ True $\square$ False $\square$ Don't know

$\square$ True $\square$ False $\square$ Don't know

$\square$ True $\square$ False $\square$ Don't know

$\square$ True $\square$ False $\square$ Don't know 
Dear Cynthia

Thank you for your interest in our work. We are happy for the OKAT to be used by others, provided the use is acknowledged and our BMC Musculoskeletal validation paper is cited in any publications resulting from its use. I would also be pleased to receive a copy of your results.

You can download the questionnaire from BMC Musculoskeletal: http://www.biomedcentral.com/1471-2474/4/17. The OKAT is located in the methods section as an additional file, which you can click on to download. If you have any problems, let me know.

We have only used the OKAT as described in Caucasian premenopausal women. While I can see no reason why it should not be effective in other populations, as with all these sorts of questionnaires, you can really only confidently state its validity for use in populations similar to that in which it was studied. So if I were using the OKAT in other populations, I would include some validation in whatever publication results if the population were very different from ours.

The answers to the OKAT are given below. We scored 1 for correct, 0 for incorrect or don't know.

Please let me know if I can be of more help

Tania

Dr Tania Winzenberg

Musculoskeletal Epidemiologist

Menzies Research Institute

Private Bag 23

Hobart TAS 7001 
Dear Cynthia

Thank you for your interest in our work. We are happy for the OKAT to be used by others, provided the use is acknowledged and our BMC Musculoskeletal validation paper is cited in any publications resulting from its use. I would also be pleased to receive a copy of your results.

You can download the questionnaire from BMC Musculoskeletal: http://www.biomedcentral.com/1471-2474/4/17. The OKAT is located in the methods section as an additional file, which you can click on to download. If you have any problems, let me know.

We have only used the OKAT as described in Caucasian premenopausal women. While I can see no reason why it should not be effective in other populations, as with all these sorts of questionnaires, you can really only confidently state its validity for use in populations similar to that in which it was studied. So if I were using the OKAT in other populations, I would include some validation in whatever publication results if the population were very different from ours.

The answers to the OKAT are given below. We scored 1 for correct, 0 for incorrect or don't know.

Please let me know if I can be of more help

Tania

Dr Tania Winzenberg

Musculoskeletal Epidemiologist

Menzies Research Institute

Private Bag 23

Hobart TAS 7001 
Ph: 0362267770

Fax; 0362267704

tania.winzenberg@utas.edu.au

The correct answers to the questionnaire as we used it are:

1. $\mathrm{T}$

2. $\mathrm{F}$

3. F

4. F

5. T

6. T

7. $T$

8. $\mathrm{T}$

9. T

10. $\mathrm{F}$

11. $\mathrm{F}$

12. $T$

13. F

14. $T$

15. F 
16. $T$

17. $\mathrm{T}$

18. $\mathrm{F}$

19. $T$

20. $F$

From: Cynthia Smith [mailto:csmit120@mix.wvu.edu]

Sent: Monday, 13 September 2010 6:59 AM

To: Tania Winzenberg

Subject: Request From a Student About the OKAT

Dr. Winzenberg,

Hello! My name is Cynthia Smith, and I am a doctoral of nursing practice student in the United States of America at West Virginia University School of Nursing. I am currently working on my Capstone project which is part of a practice change for an osteoporosis clinic. The project is a onetime community-based group educational intervention for those with or at risk for osteoporosis led by a registered nurse. Thirty to fifty participants will be recruited. Measurements will be taken pre-, immediately post-, one month, and three months post-intervention on the effect on osteoporosis knowledge, calcium/vitamin D intake, physical activity levels, fear of falling, and use of tobacco and alcoholic products.

In researching instruments I could use to assess osteoporosis knowledge, I came across your article describing the Osteoporosis Knowledge Assessment Tool (OKAT) in the 2003 BMC Musculoskeletal Disorders. As the lead author, I was writing to request permission to use this instrument in my Capstone project. Any information you could supply me with how to interpret this instrument and how to obtain copies would also be greatly appreciated. Thank you for taking the time to consider my request as I truly appreciate it. Please do not hesitate to call on me with any questions and/or concerns.

Sincerely,

Cynthia A. Smith, FNP-BC, RN, MSN, CCD 


\section{Appendix D}

Handouts Given in Participant Workbook

\begin{tabular}{|c|c|c|}
\hline Name of Organization & Type/Name of Handouts & Cost \\
\hline $\begin{array}{l}\text { National Osteoporosis } \\
\text { Foundation }\end{array}$ & $\begin{array}{l}\text { Calcium Sources in Food } \\
\text { Fall Prevention Checklist } \\
\text { Handouts used from the Bone } \\
\text { Basics for Osteoporosis Kit: } \\
\text { Top } 10 \text { Myths About } \\
\text { Osteoporosis } \\
\text { Bone Density Testing } \\
\text { What You Should Know } \\
\text { About Calcium } \\
\text { Diagnosing Osteoporosis } \\
\text { Tips for Fall Prevention } \\
\text { Frotecting the Spine From } \\
\text { Kyphosis } \\
\text { Osteopenia-What Does it } \\
\text { Mean? }\end{array}$ & $\begin{array}{l}\$ 10 \text { for } 50 \\
\$ 10 \text { for } 50 \\
\$ 25.00 \text { (Items available NOF } \\
\text { website (NOF.org)) }\end{array}$ \\
\hline
\end{tabular}




\begin{tabular}{|c|c|c|}
\hline & $\begin{array}{l}\text { Balance, Posture and } \\
\text { Functional Exercises } \\
\text { Vitamin D and Bone Health } \\
\text { Can People Regain Bone } \\
\text { Density? } \\
\text { How The Food You Eat Can } \\
\text { Affect Your Bones } \\
\text { Exercise for Your Bone } \\
\text { Health } \\
\text { The Use of Exercise Machines } \\
\text { Top } 25 \text { Ways to Prevent Falls }\end{array}$ & \\
\hline National Cancer Institute & $\begin{array}{l}\text { Fact Sheet: Harms of } \\
\text { Smoking and Health Benefits } \\
\text { of Quitting } \\
\text { You Can Quit Smoking: A } \\
\text { Personalized Quit Plan } \\
\text { Fact Sheet: Where to Get } \\
\text { Help When You Decide to } \\
\text { Quit Smoking } \\
\text { How to Handle Withdrawal } \\
\text { Symptoms and Triggers When } \\
\text { You Decide to Quit Smoking }\end{array}$ & No Cost \\
\hline
\end{tabular}




\begin{tabular}{|c|c|c|}
\hline $\begin{array}{l}\text { National Institute on Alcohol } \\
\text { Abuse and Alcoholism }\end{array}$ & $\begin{array}{l}\text { Rethinking Drinking: Alcohol } \\
\text { and Your Health }\end{array}$ & No Cost \\
\hline $\begin{array}{l}\text { National Institute of Health: } \\
\text { National Institute on Aging }\end{array}$ & $\begin{array}{l}\text { Exercise and Physical } \\
\text { Activity: Your Everyday } \\
\text { Guide from the National } \\
\text { Institute on Aging } \\
\text { Age Page: Falls and Fractures } \\
\text { Age Page: Healthy Eating } \\
\text { After } 50 \\
\text { Age Page: Medicines Use } \\
\text { Them Safely } \\
\text { Age Page: Exercise and } \\
\text { Physical Activity: Getting Fit } \\
\text { for Life } \\
\text { Age Page: Osteoporosis: The } \\
\text { Bone Thief } \\
\text { Age Page: Alcohol Use in } \\
\text { Older People }\end{array}$ & No Cost \\
\hline $\begin{array}{l}\text { U. S. Department of Health } \\
\text { and Human Services } \\
\text { Centers for Disease Control } \\
\text { and Prevention }\end{array}$ & $\begin{array}{l}\text { What You Can Do to Prevent } \\
\text { Falls } \\
\text { Check for Safety: A Home } \\
\text { Fall Prevention Checklist for } \\
\text { Older Adults }\end{array}$ & No Cost \\
\hline
\end{tabular}


Appendix E

Osteoporosis Workshop Information Form

ID Number:

\section{Osteoporosis Workshop Information Form}

Age:

Last Grade Completed:

Please circle appropriate answer:

\begin{tabular}{|c|c|c|}
\hline Gender & Male & Female \\
\hline If Female: & Not menopausal & Post-menopausal \\
\hline YMCA Member & Yes & No \\
\hline $\begin{array}{c}\text { Diagnosed with } \\
\text { Osteoporosis or } \\
\text { Osteopenia? }\end{array}$ & Yes & \\
\hline $\begin{array}{c}\text { If diagnosed with } \\
\text { Osteoporosis or }\end{array}$ & & No \\
Osteopenia, which one? & Osteoporosis & Osteopenia \\
\hline $\begin{array}{c}\text { Have you been } \\
\text { for Osteoporosis or } \\
\text { Osteopenia? }\end{array}$ & & No \\
\hline
\end{tabular}




\begin{tabular}{|c|c|c|}
\hline $\begin{array}{c}\text { If you have been } \\
\text { prescribed medication } \\
\text { for Osteoporosis or } \\
\text { osteopenia, are you }\end{array}$ & Yes & No \\
currently taking it? & & \\
\hline
\end{tabular}

How do you feel you are doing meeting your goals for your bone health?

Please circle appropriate answer:

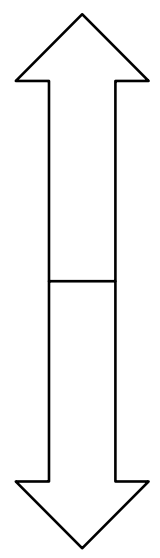
Always meet goals
Usually meet goals
Meeting goals about half the time

Seldom meeting goals

Never meeting goals

If you take calcium and/or vitamin D supplements, how much and how often: 
Appendix F

\section{Osteoporosis Workshop Power Point Presentation}
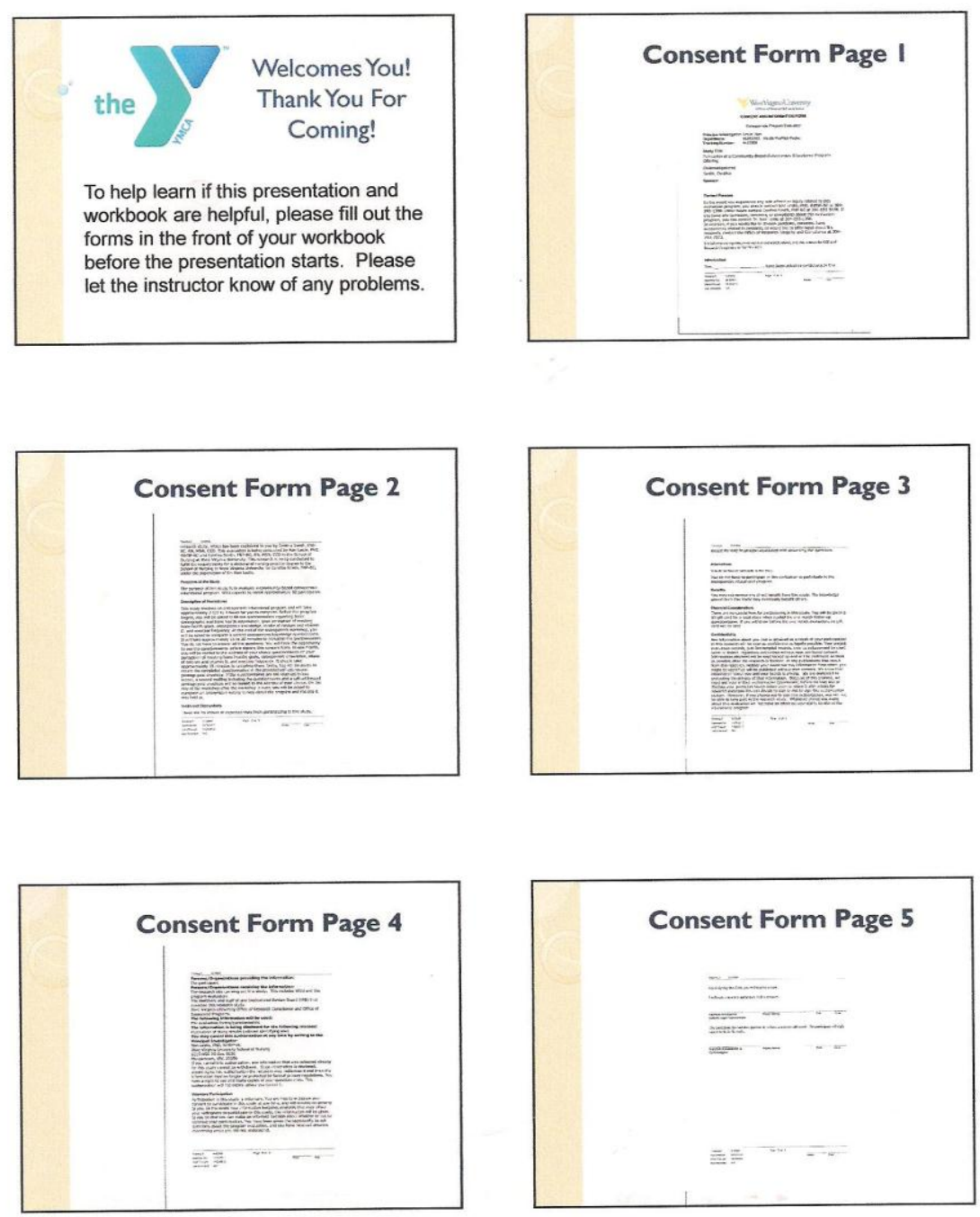


\section{Osteoporosis: The Bone} Thief

Cindy Smith, FNP-BC, RN, MSN, CCD Doctoral of Nursing Practice StudentWest Virginia University School of Nursing

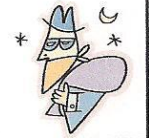

\section{Some Thoughts:}

- Think about what you would like to learn today, and don't hesitate to let the instructor know!

- What are your bone healthy behaviors goal(s)?

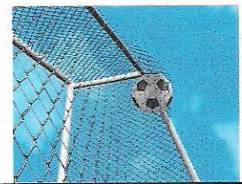

Top 10 Myths About Osteoporosis

- Handout in workbook (National Osteoporosis Foundation)

1. Most people don't need to worry about osteoporosis.

2. Osteoporosis is only a problem for older Caucasian women.

3. You don't need to worry about osteoporosis if you break a bone from a serious fall or accident.

\section{Top 10 Myths Continued}

4. People with osteoporosis can feel their bones getting weaker.

5. An osteoporosis test is painful and exposes you to a lot of radiation.

6. Children and teens do not need to worry about their bone health.

\section{Top 10 Myths Continued}

7. If you drink a lot of milk and exercise, you are not at risk for osteoporosis.

8. Osteoporosis isn't serious.

9. Taking extra calcium supplementation can help prevent osteoporosis.

10. Most people do not need to take a vitamin D supplement.

\section{Bone Facts}

- Bones are a living growing tissue that is made mostly of collagen and calcium phosphate.

Collagen is a protein that provides a soft

frame.

Calcium phosphate is a mineral that provides strength and hardens the frame. 
Calcium in the Body

. $99 \%$ of the body's calcium is in the bones.

- $1 \%$ is in the blood.

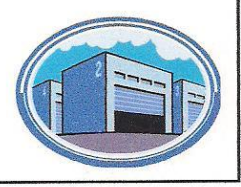

\section{Types of Bone}

- Cancellous (trabecular) bone (20\% of the skeleton)

"shock absorbing bone" found in the

vertebrae of the spine, femoral neck/total

femoral region, and at the end of long bones.

\section{Types of Bone}

- Cortical bone ( $80 \%$ of the skeleton)

Makes up the shaft of the long bones and makes up the outer shell of all bones.

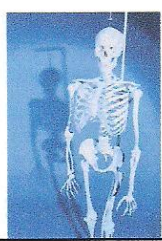

\section{Cortical and Trabecular Bone}
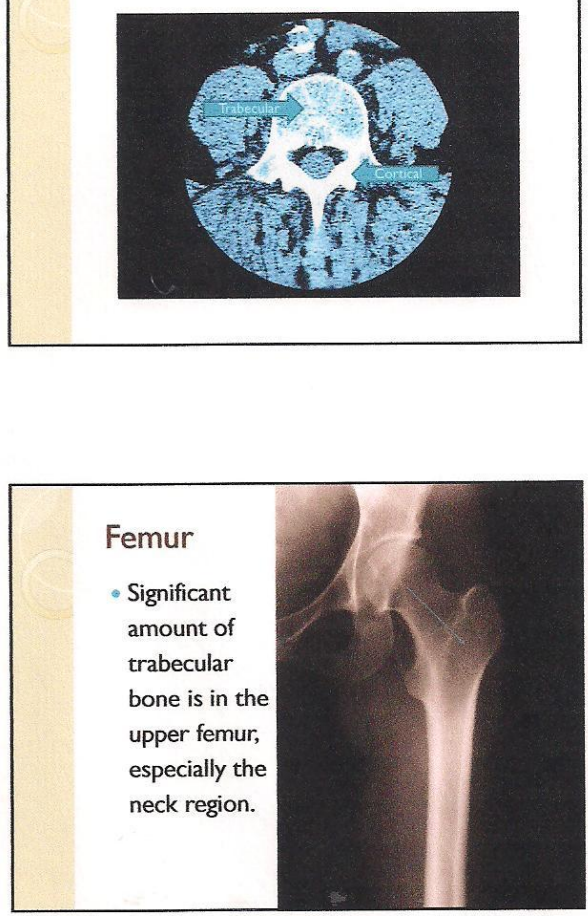
Bone Growth and Development

- Bone is a living tissue that is continuously being both built up and torn down (remodeling cycle).

- Every ten years, most of the skeleton has been remodeled.

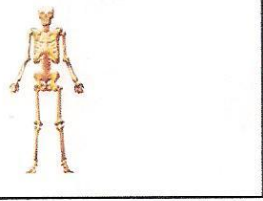

\section{Peak Bone Mass}

- More bone is built up than destroyed for most individuals until their early 20's.

- At this point, peak bone mass is

reached or the strongest the bones will be.

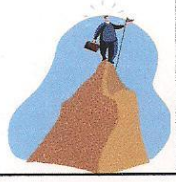

Influences on Peak Bone Mass

- Lifestyle Influences (20-30\%)

- Smoking

- Excess intake of ETOH

Exercise

- Fall prevention behaviors

- Nutritional (calcium and vitamin D)

\section{Bone Growth and Development}

- Involvement of two types of bone cells in the remodeling process:

Osteoclasts-remove old bone.

Osteoblasts-build bone.

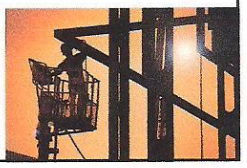

Influences on Peak Bone Mass

- Hereditary Influences (70-80\%)

- Gender

- Race

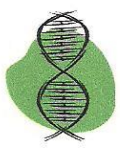

\section{Changes in Bone OverTime}

- Bone is significantly built up during the teenage years.

- Bone mass remains essentially the same until the late 30 's to 40 's.

Bone loss starts to occur as more bone is broken down than is built up.

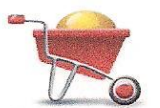




\section{Changes in Bone Over Time}

- For women, with the onset of menopause, bone loss is accelerated.

- This acceleration can last 5-10 years.

- Some women can lose as much bone during the 5 years after menopause as they gained during their teen years.

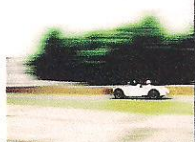

\section{Bone Changes}

While women lose bone rapidly in the years following menopause, by age 65-70, men and women lose

bone at the same rate.

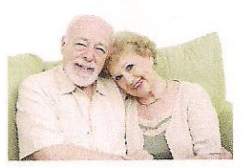

\section{Handout}

- Can People Regain Bone Density? (National Osteoporosis Foundation)

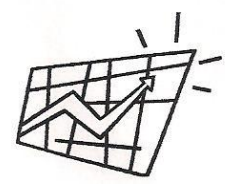

Effect of Age on Bone Mass

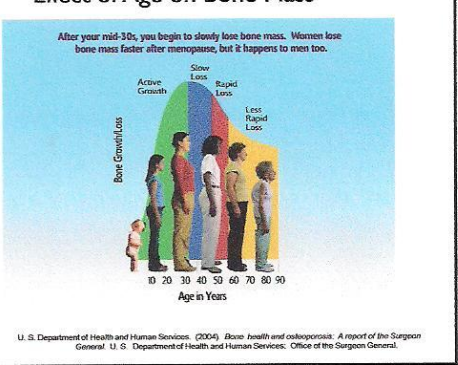

\section{Changes in Bone}

$1 / 2$ of all people over the age of 75 have osteoporosis.

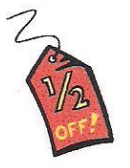

\section{Osteoporosis:}

- Osteoporosis is a skeletal disorder characterized by compromised bone strength predisposing to an increased risk of fracture.

- Bone strength reflects the integration of two main features: bone density and bone quality.

U.S. Department of Health and Human Services. (2000). NiH consensus
statement- OSteoporosis prevention, diagnosis. and therapy Bethesda, statement: Asthor. 


\section{Handout}

- Age Page: Osteoporosis-The Bone Thief

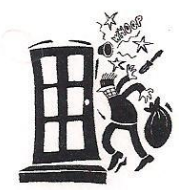

NormalVs. Osteoporotic Bone

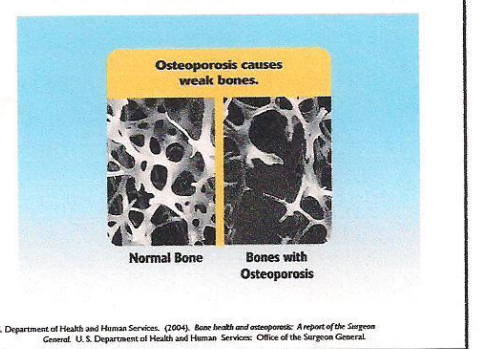

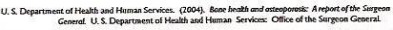

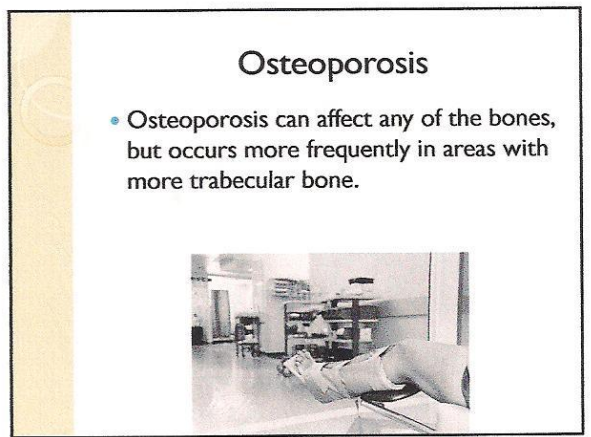

The Most Common OsteoporoticFracture Sites

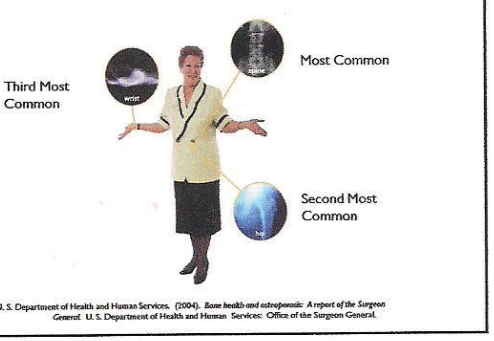

\section{Fracture Rates}

- An estimated 2 million fractures a year occur due to osteoporosis/osteopenia

for those aged 50 years old and older.

550,000-700,000 vertebral

250,000-400,000 wrist

- 300,000 hip

250,000-810,000 other sites 


\section{- $90 \%$ of hip fractures are associated with osteoporosis.}
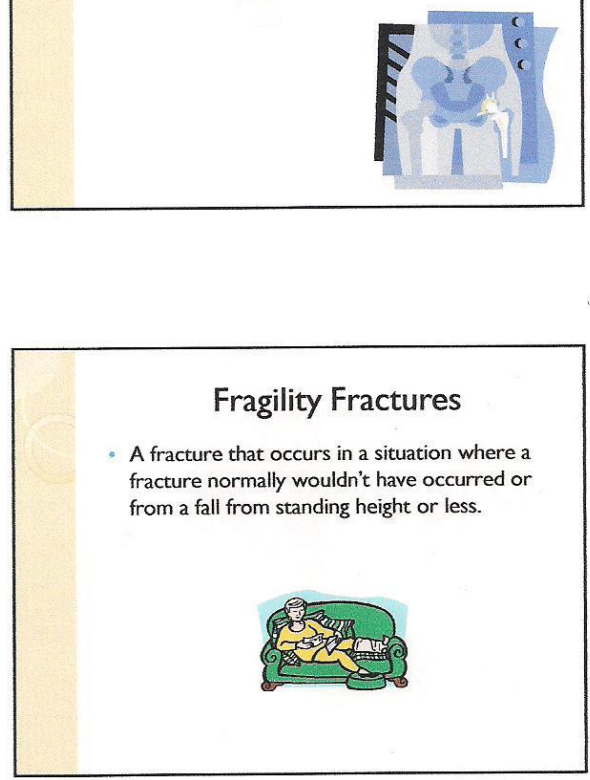

More Types of Bone Density Tests

Radiographic absorptiometry-x-ray technique of hand which requires specialized equipment

Radiogrammetry-x-ray technique of the hand.

Single $x$-ray absorptiometry-peripheral site measurement requiring the heel or forearm to be immersed in water.

Peripheral energy dual $x$-ray absorptiometry (PDXA)focused on forearm or heel.

\section{Diagnosis:}

- Use of the World Health Organization Classification (1994)

OR

- Having a fragility fracture (low trauma)
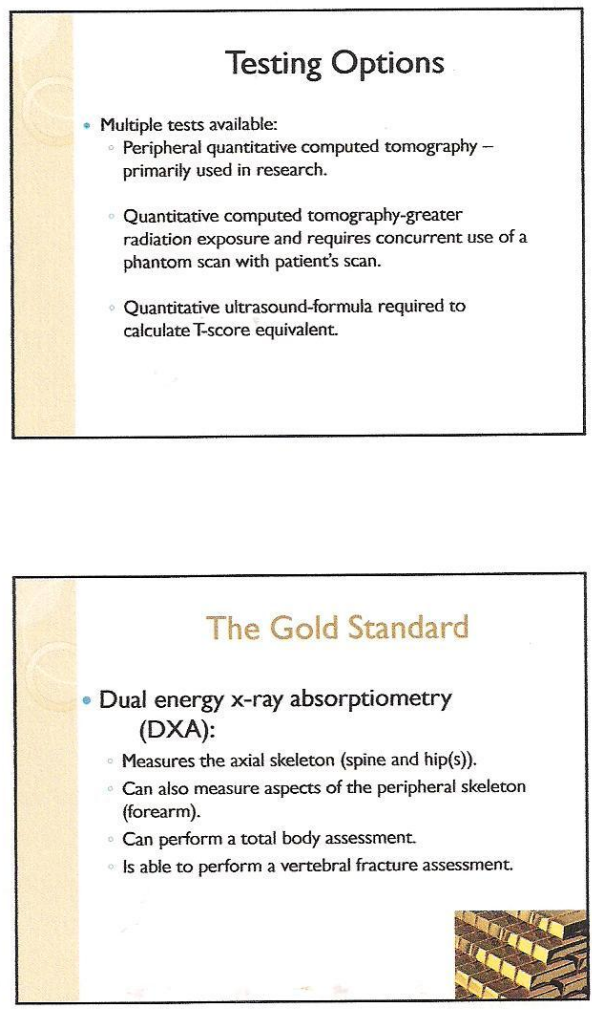

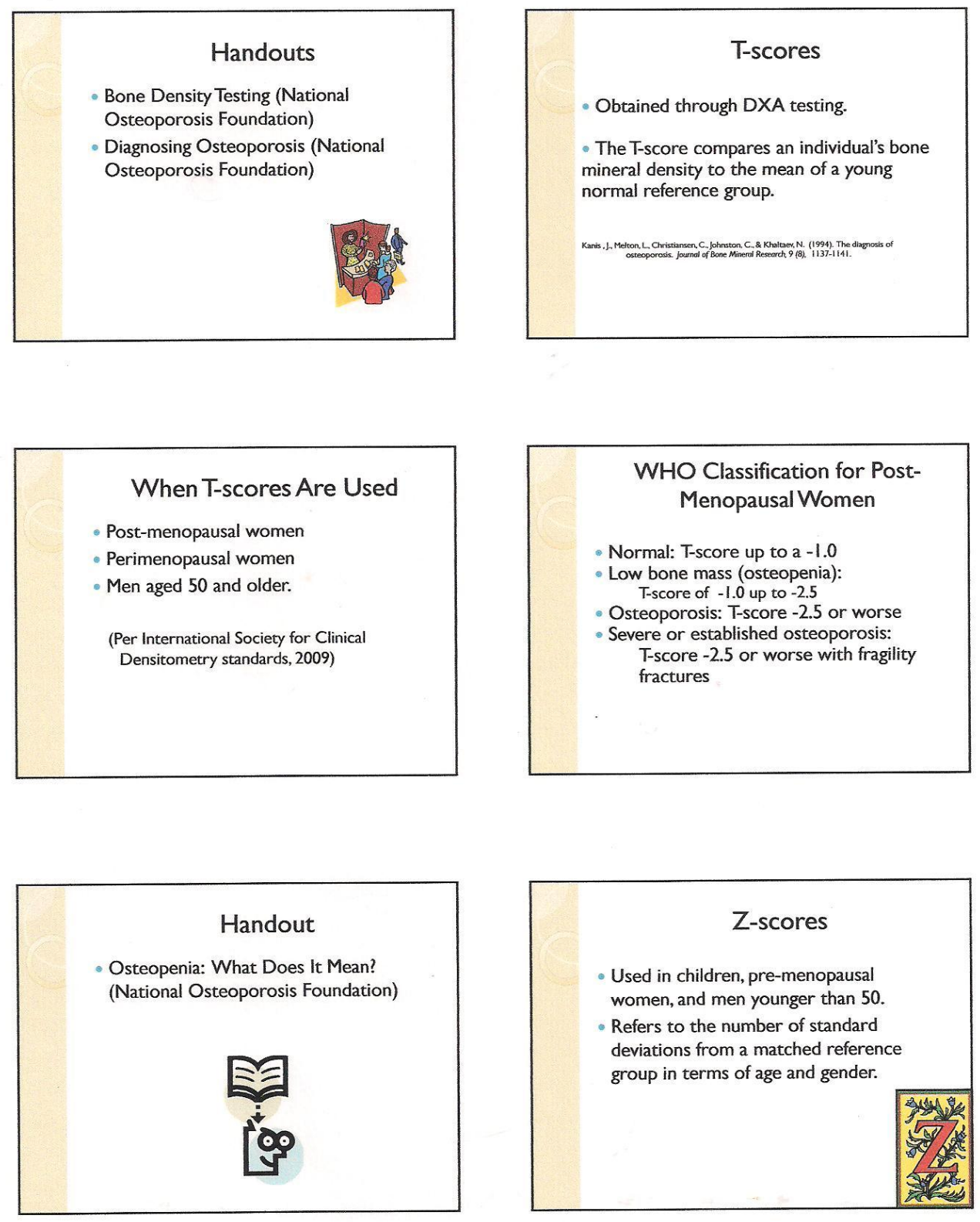


\section{Fracture Risk}

- Osteopenia increases the risk of a fracture two-fold while osteoporosis increases fracture risk four- to five-fold.

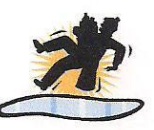

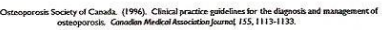
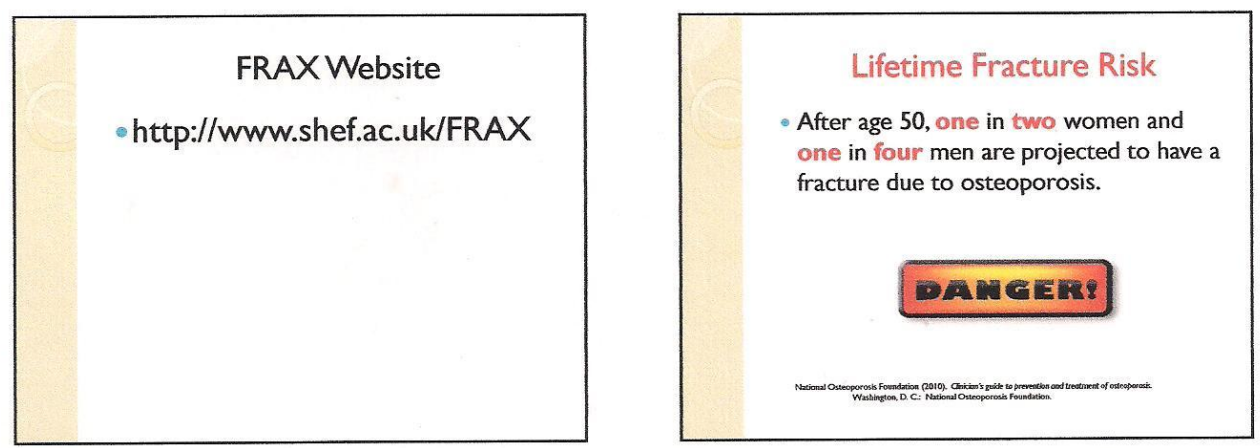

WHO Fracture Risk Assessment Tool (FRAX)

- Came out in 2008

- Provides guidance for patients with osteopenia to help determine if pharmacological treatment should be recommended

- Takes into account major risk factors that contribute to fracture risk one in four men are projected to have a acture due to osteoporosis.
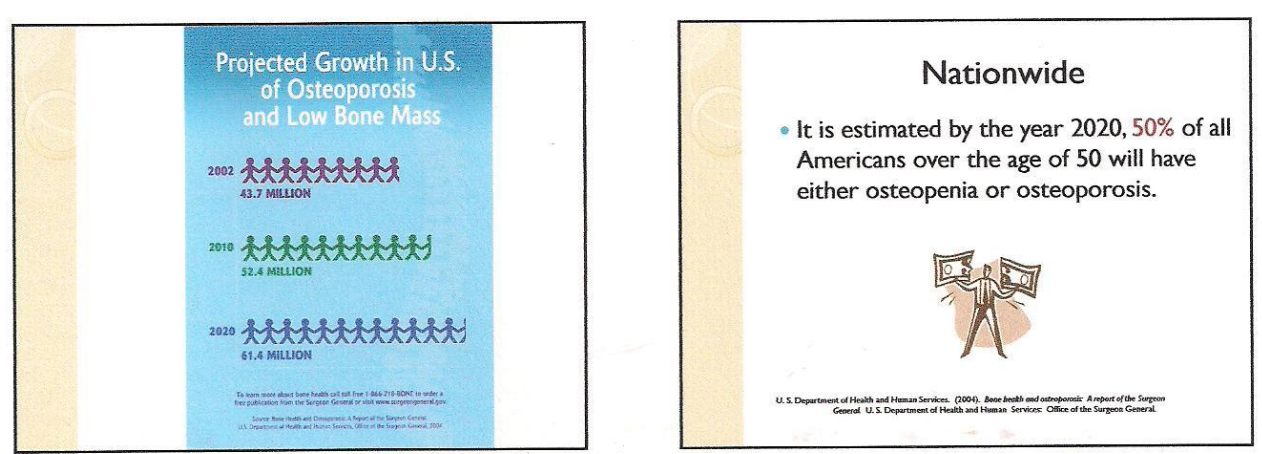


\section{Prevalence Nationally}

- Nationally, ten million people have osteoporosis.

- Thirty four million have osteopenia.

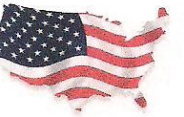

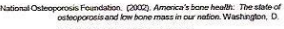

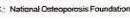

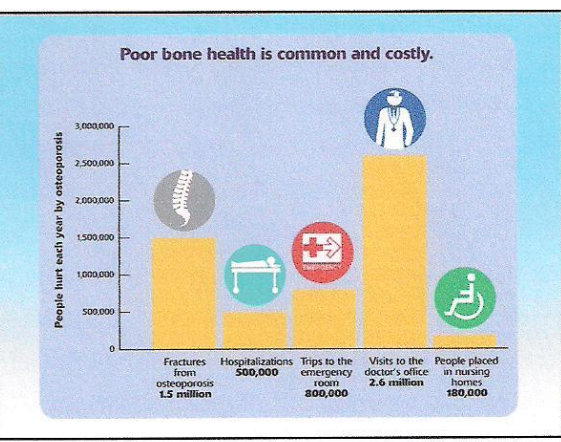

\section{Fracture Consequences}

- 20-24\% of patients with a hip fracture die within a year of the fracture.

- One year after the fracture, $40 \%$ of patients have trouble walking without help. - $60 \%$ have trouble doing necessary ADLs.

- 15-20\% of hip fracture patients will still be in a long term care facility one year after the

fracture.

\section{Reality Check}

A woman's risk of a hip fracture is equal to the combined risk of developing breast, uterine, and ovarian cancer.

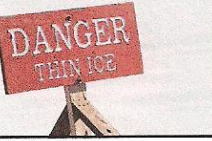

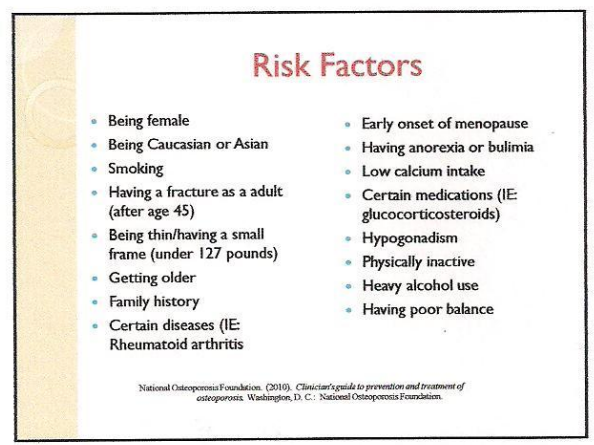

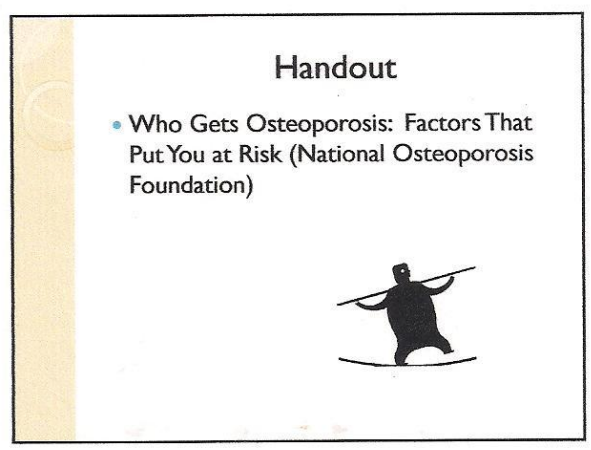




\section{Concerns for WestVirginians}

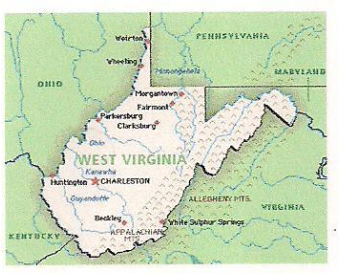

\section{Prevalence of Osteoporosis and Osteopenia in WV in 2002}

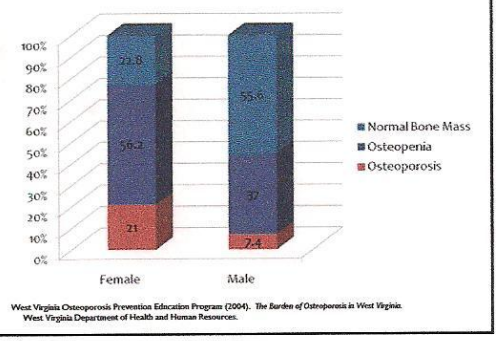

Prevalence of Osteoporosis and Osteopenia for WV Residents in 2010

-Men with

-Osteoporosis: 23,200

-Osteopenia: 139,300

-Women with

- Osteoporosis: 78,400

-Osteopenia: 206,600

-Total: 424,300

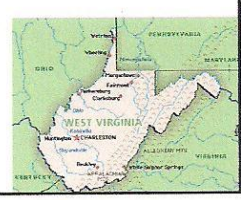

Prevalence of Osteoporosis and Osteopenia for WV Residents in 2020

-Men with

-Osteoporosis: 25,800

-Osteopenia: 128,900

-Women with

- Osteoporosis: 85,600

- Osteopenia: 226,000

-Total: 466,300
Select Osteoporosis Risk Factors for WV Residents, 1999

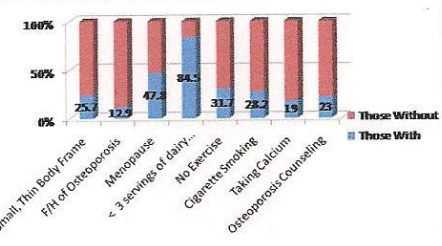

\section{Osteoporosis Treatment Options}

- Pharmacological

- Non-Pharmacological:

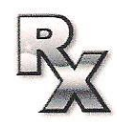




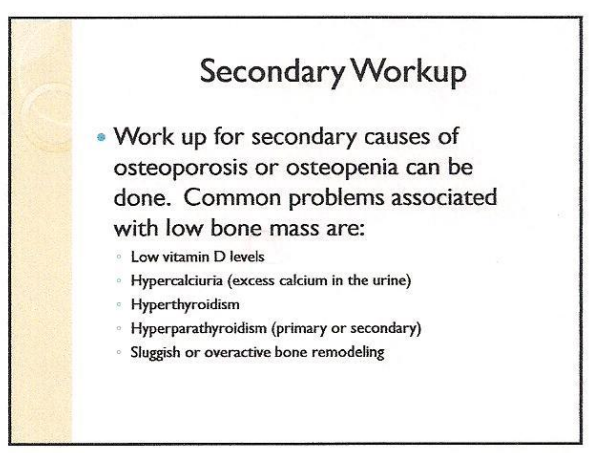

\section{Hormone Therapy}

- Use of estrogen and if needed progestional agent for post-menopausal women.

- Spine fracture protective.

Concern for increasing stroke, blood clot and breast cancer risk.

- Use of testosterone for low testosterone in males.

\section{Pharmacologic Treatment}

- Two types:

- Antiresorptives

Anabolics

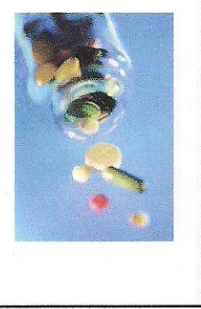

\section{Antiresorptives}

- Work by slowing bone loss.

- Affect the bone destroyers

(osteoclasts).

- Most widely used.

- Several options available.

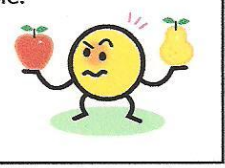

\section{Calcitonin}

\section{Evista (Raloxifene)}

Available in nasal spray or injection. Generic or brand as Miacalcin or Fortical Beneficial for improving bone density in the spine.

Side effects: nasal irritation, headaches.

For some people, can improve back pain from a fracture.

Drug class: Selective estrogen receptor modulator.

- Benefits of estrogen with less drawbacks.

- Improves spine bone density and can decrease the risk of breast cancer.

- Concern for increased risk of blood clots, leg cramps, swelling and hot flashes. 

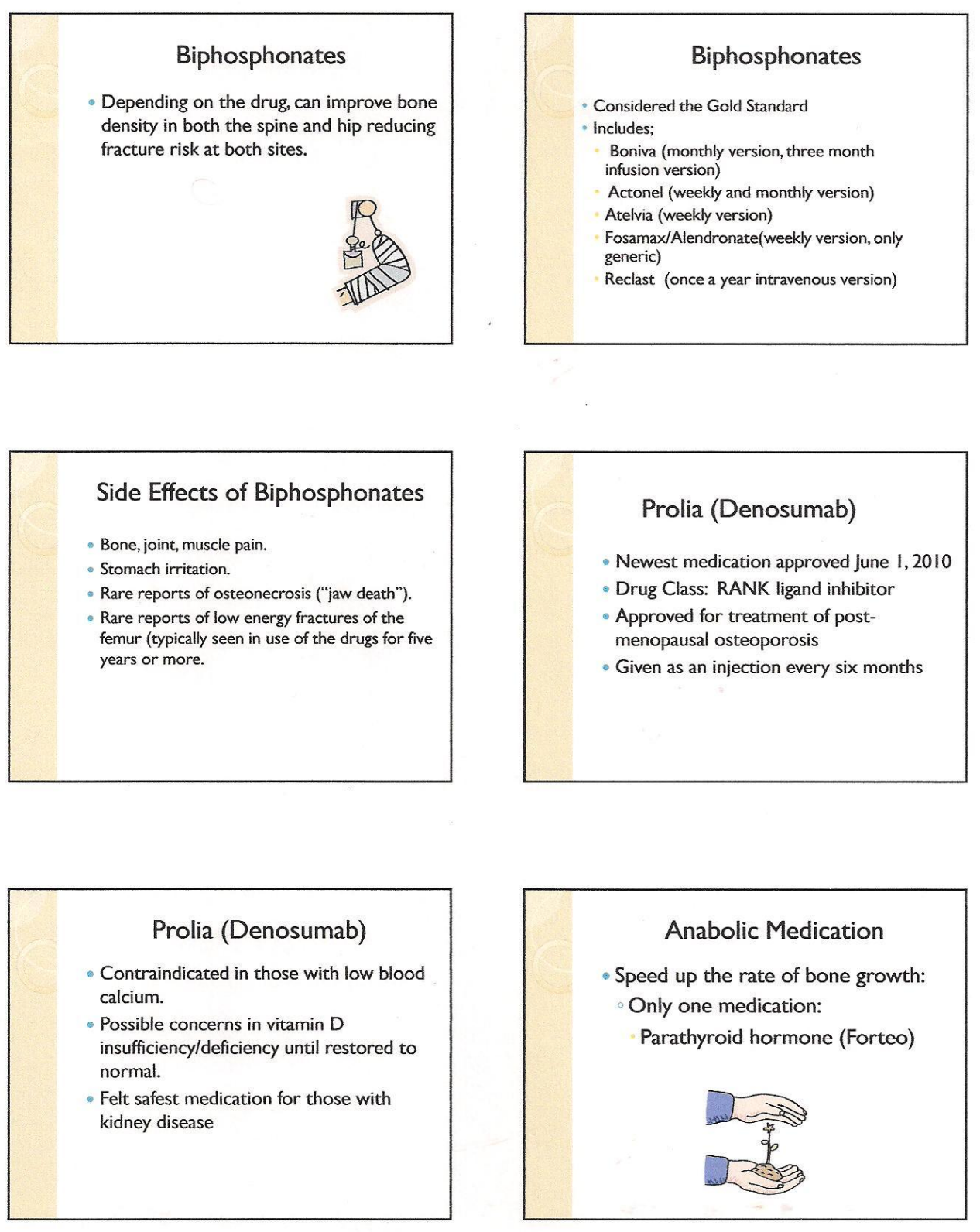

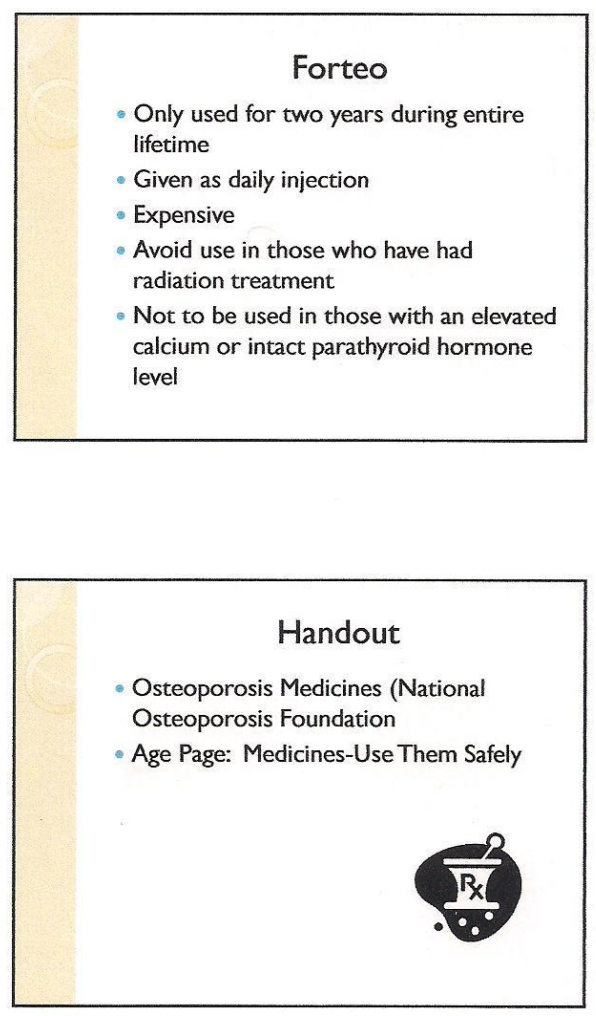

Bone Healthy Behaviors

- Adequate daily calcium

- Adequate daily vitamin D intake

- Weight bearing exercise

- Fall prevention behaviors

- Avoiding tobacco use

- Avoiding excess alcohol intake (more

than two drinks a day)

\section{Non-FDA Approved Medications}

- Hydrochlorothiazide

- Sodium fluoride

- Etidronate

- Pamidronate

- Strontium ranelate

- Potassium chloride
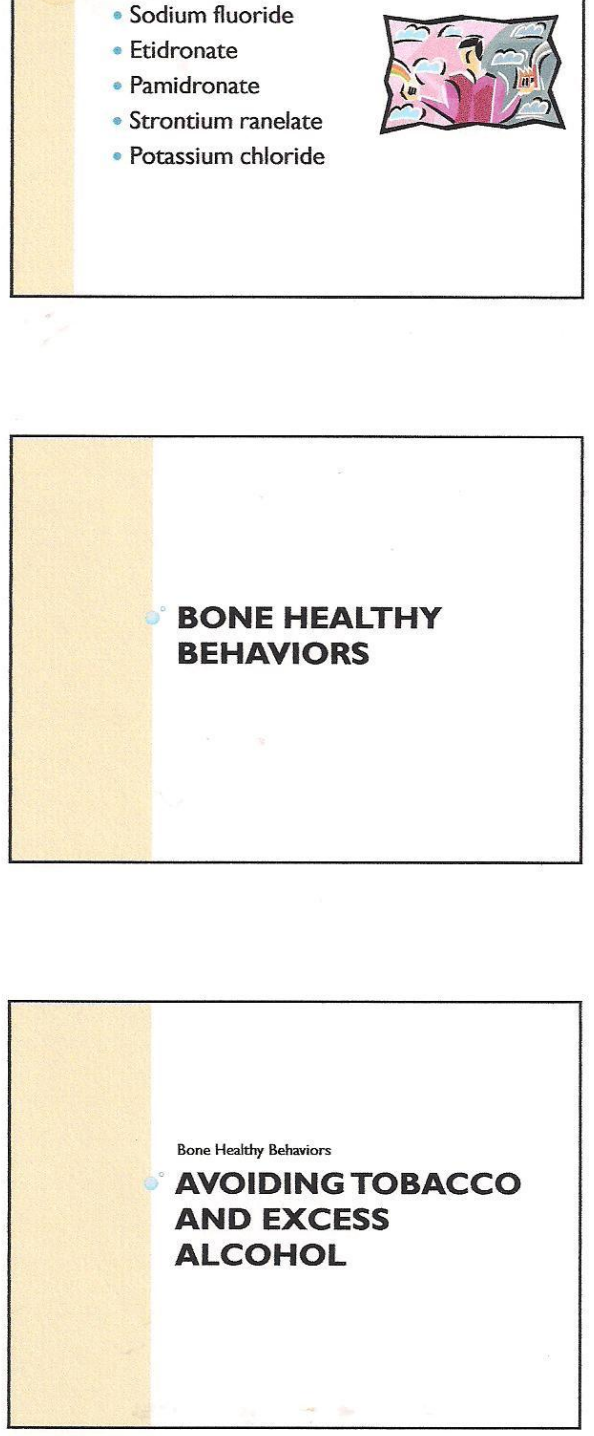

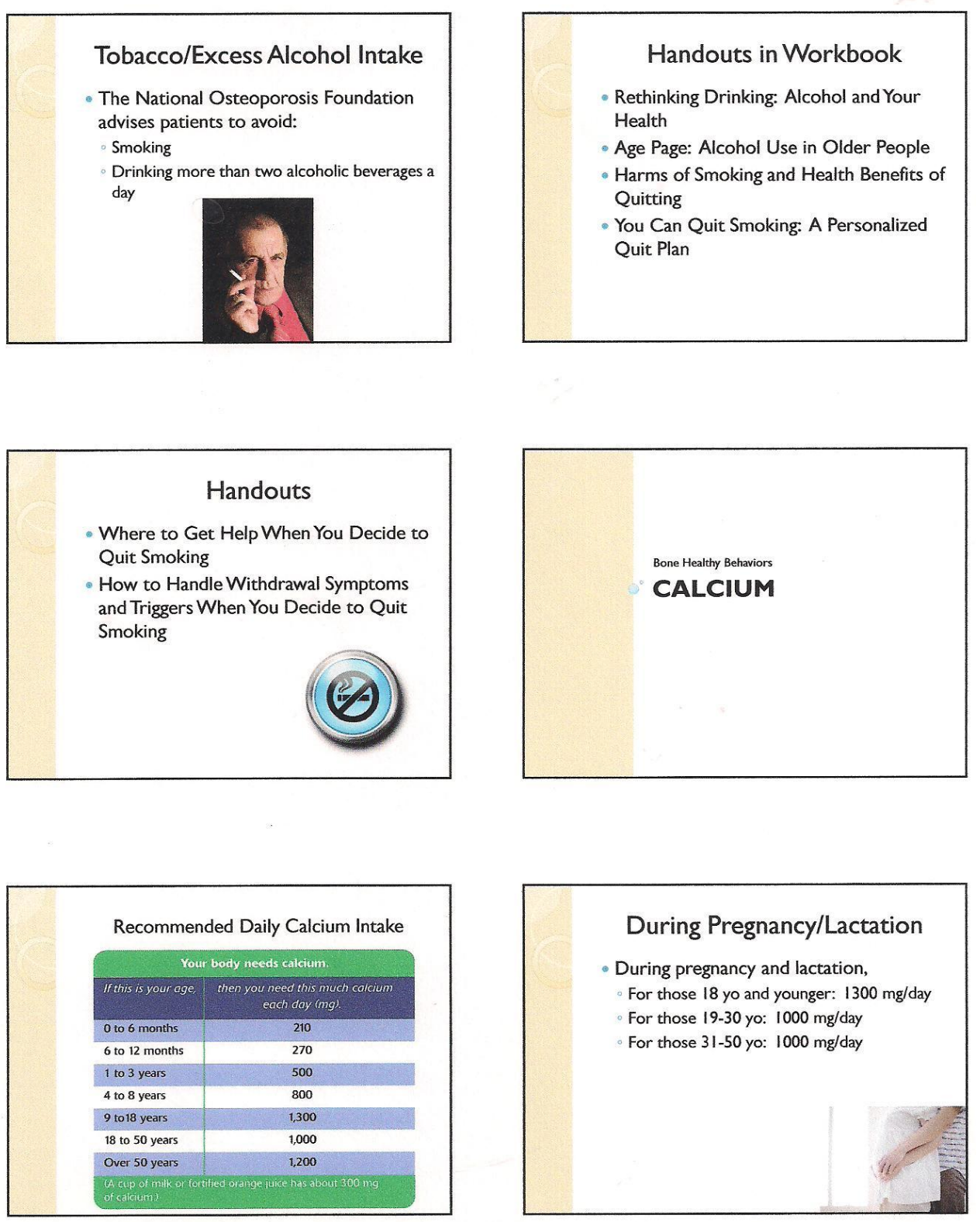


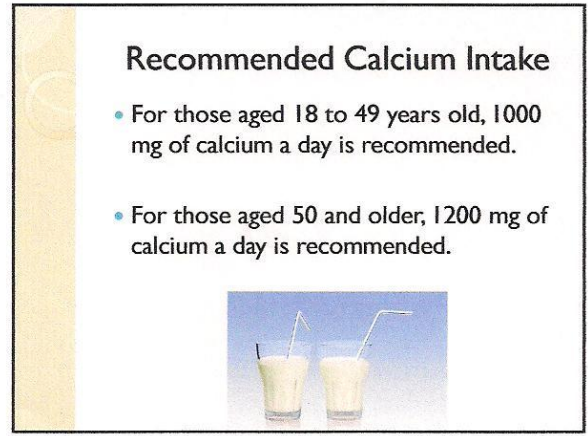

\section{Food Labels}

- Daily value of calcium is based upon recommendation for $1000 \mathrm{mg}$ a day.

- If daily value is listed at $40 \%$, that means there is $400 \mathrm{mg}$ of calcium.

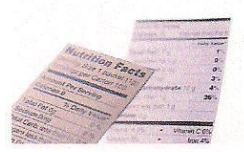

\section{Calcium Pearls}

- For those with normal serum calcium, don't want to exceed $2000-2500 \mathrm{mg}$ of calcium a day.

- The body absorbs about 500-600 mg at a time.

- If on an acid suppressing medication and a supplement needed, calcium citrate supplementation a better choice.

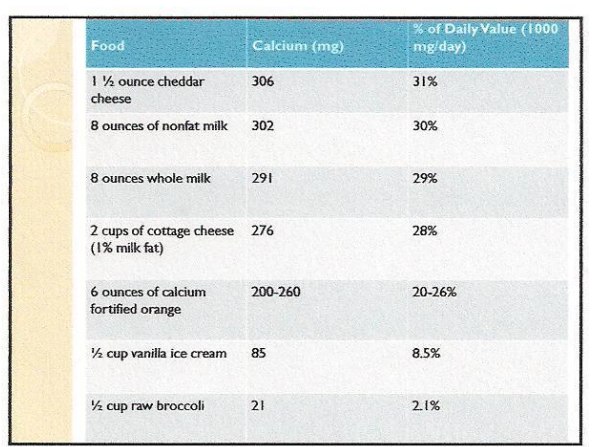

\section{Handout}

- Calcium Sources in Food (National Osteoporosis)

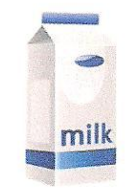

\section{Calcium Pearls}

- One tablespoon of non-fat powdered milk contains about $50 \mathrm{mg}$ of calcium and can be added to:

Casseroles

Cookies

Muffins or bread

Pudding 

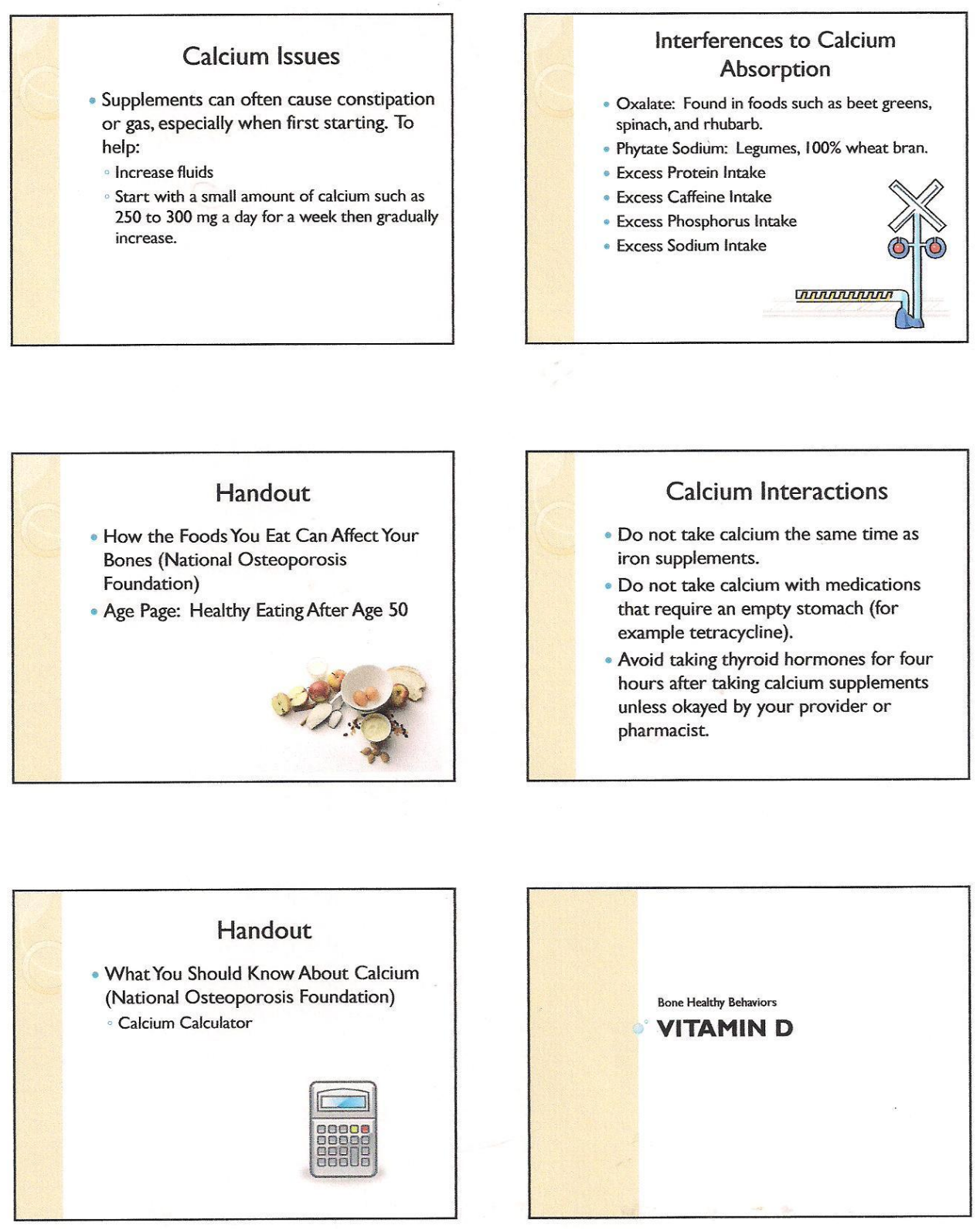

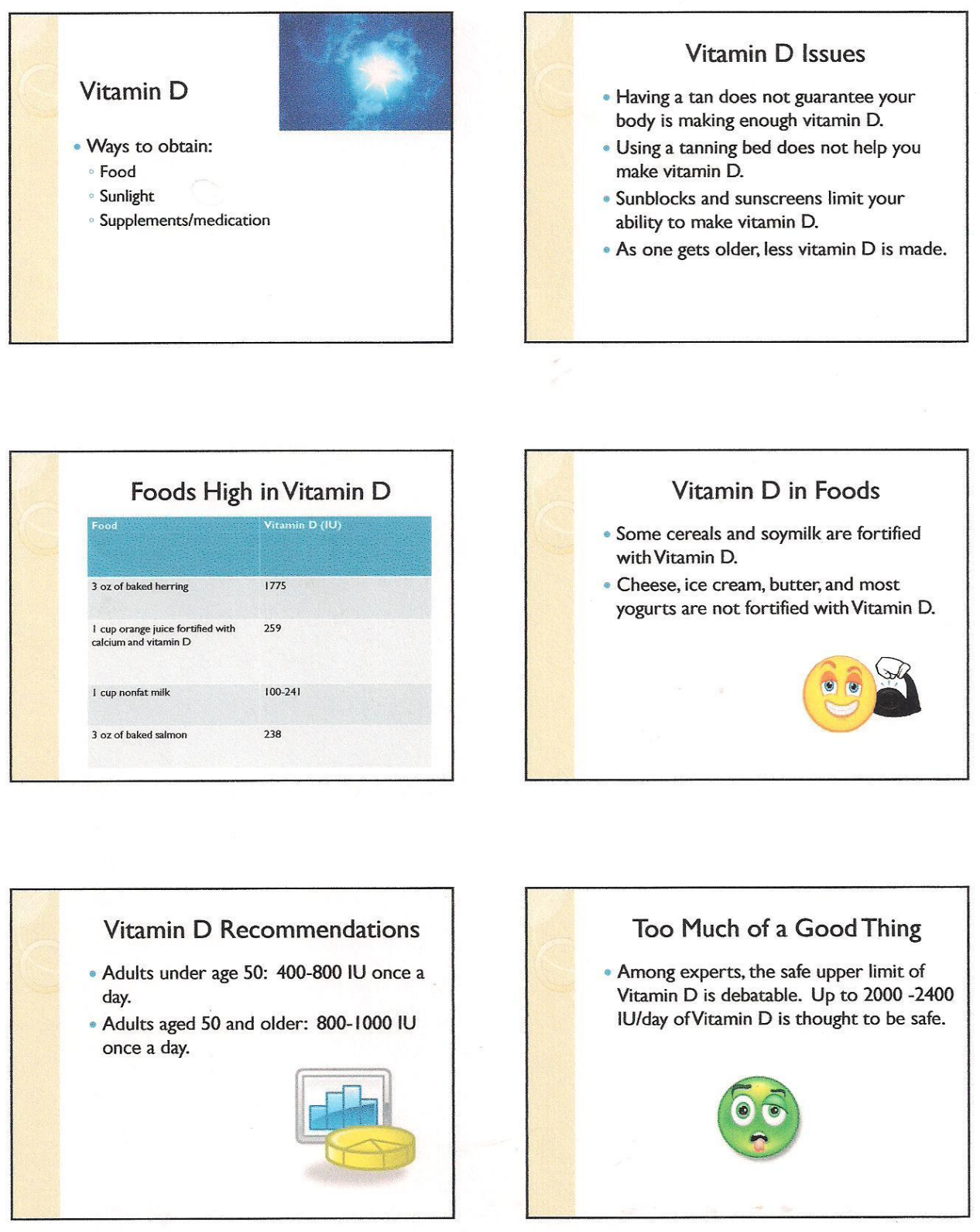

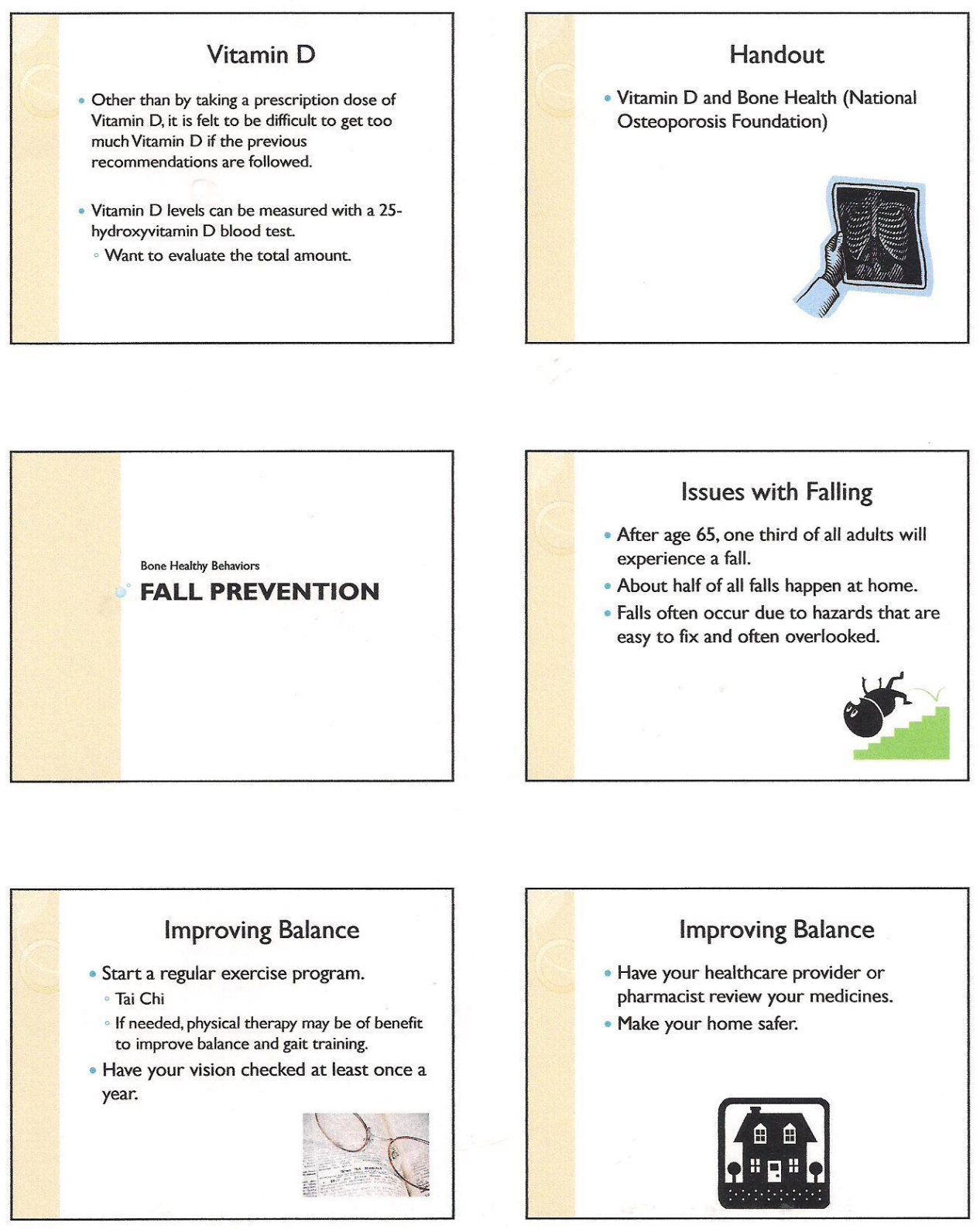

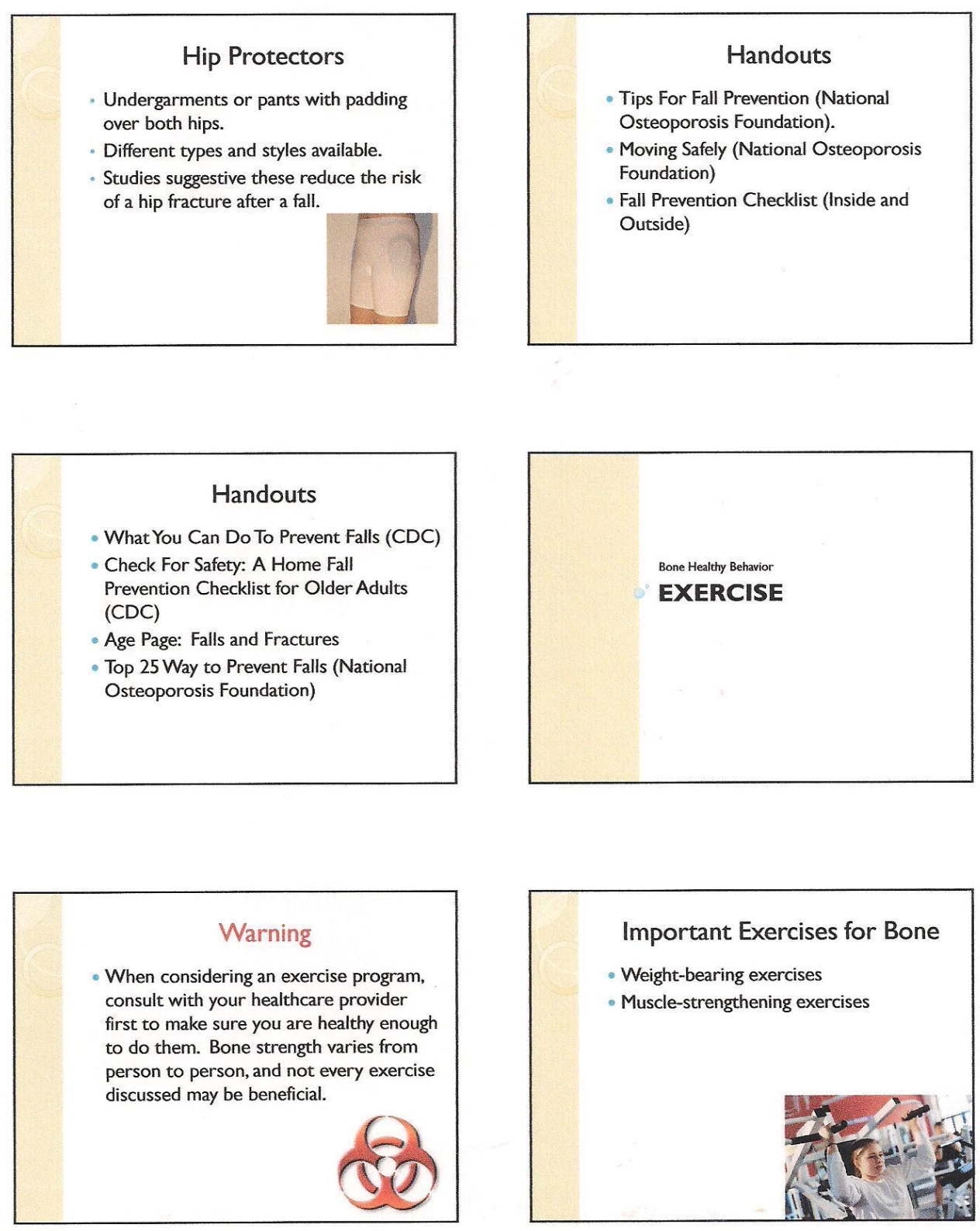


\section{Weight-Bearing Exercises}

\section{- Two Groups:}

High Impact (best for keeping bones strong)

- Low Impact (better for those with

osteoporosis, who are frail or fall easily.

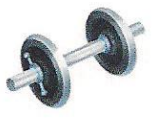

Low Impact Weight-Bearing Exercise

- Walking

- Stair-step machines

- Downhill and cross

- Cross-country ski country skiing

machines

- Low impact aerobics

- Elliptical exercise

- Treadmill walking

\section{How Much to Do?}

- For weight bearing exercises, recommendations are for 30 minutes a day five to seven days a week.

- Okay to break it up such as 2 sessions of 15 minutes a piece.

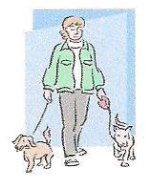

\section{How Much to Do?}

- For muscle-strengthening exercises, do two to three times a week.

- Need at least one day of rest inbetween

- Exercise each major muscle group for one to two sets of 8 to 10 repetitions.

- If bones are frail, consider using lighter weights for 10 to 15 repetitions. 

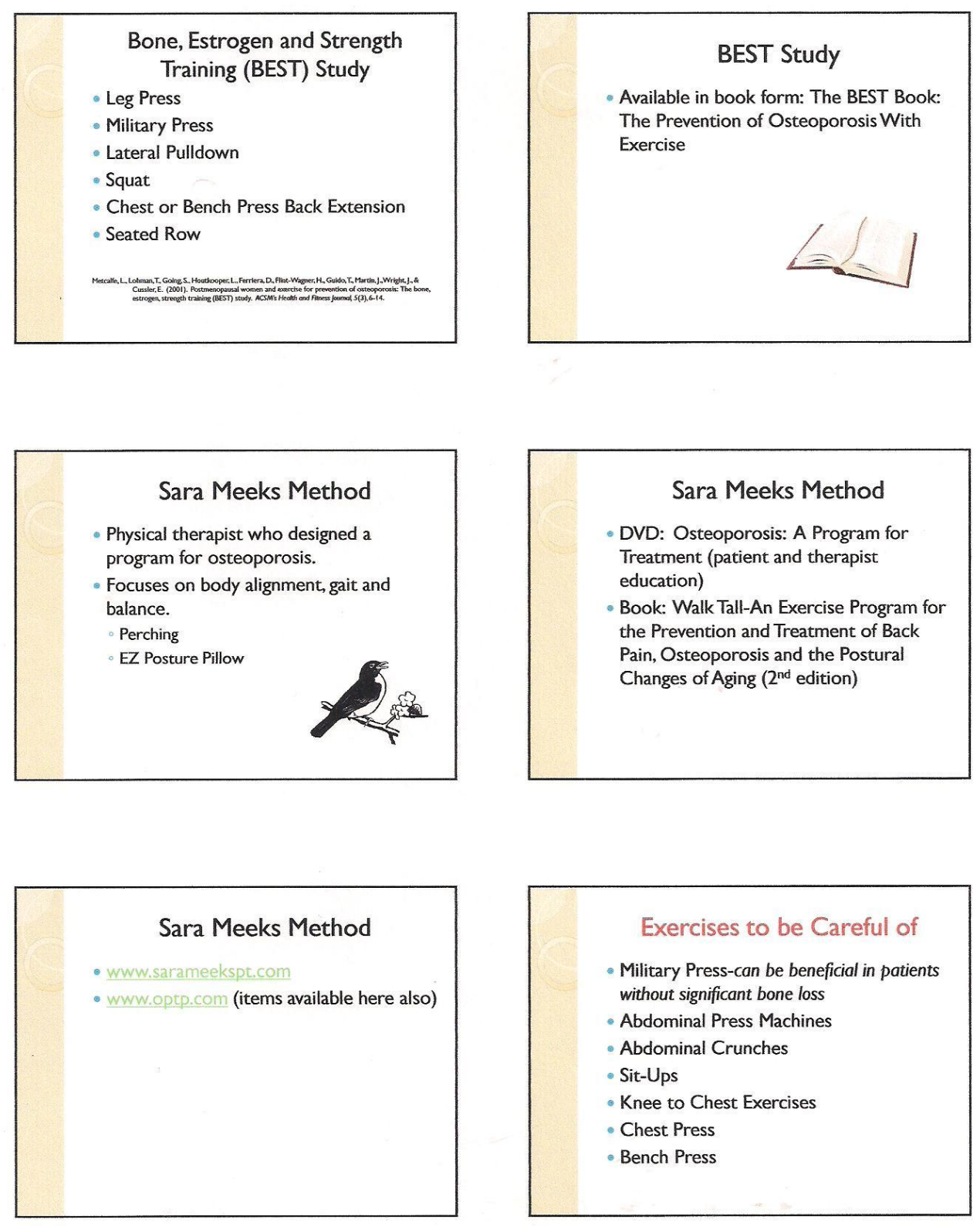

\section{Exercises to be Careful of}

- Military Press-can be beneficial in patients without significant bone loss

- Abdominal Press Machines

- Abdominal Crunches

- Sit-Ups

- Knee to Chest Exercises

- Chest Press

- Bench Press 


\section{Exercises to be Careful of}

- Seated or Standing Toe Touches

- Straight Leg Raising (except when advised

by a healthcare provider)

- Raising of both legs at the same time

- Side Bending Exercises

- Hip Abductor Machines-can be beneficial

for patients without severe bone loss
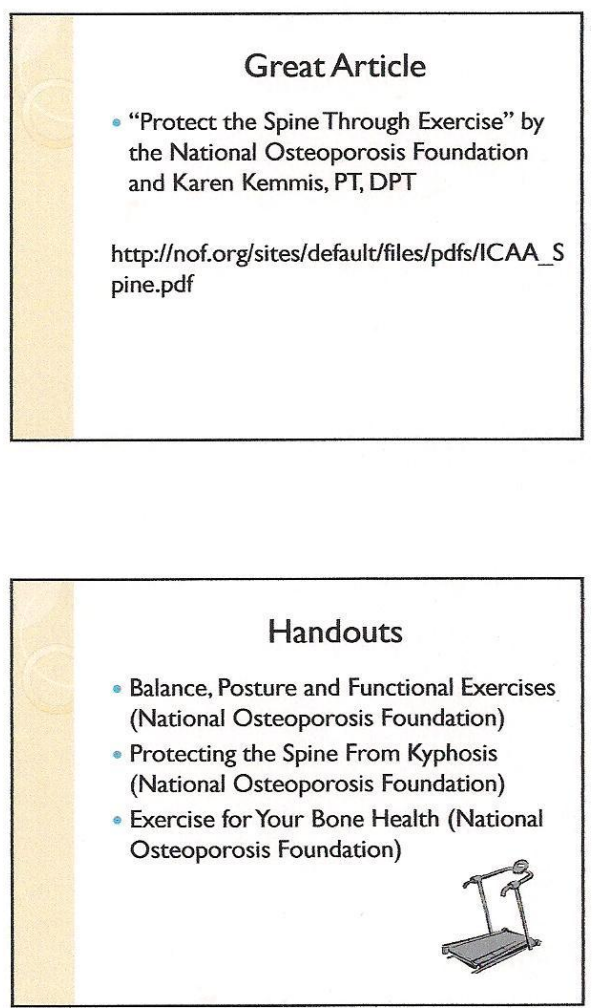

\section{Other Exercise DVDs}

- Be BoneWise Exercise (through National Osteoporosis Foundation)

- Skeletal Fitness (through National

Osteoporosis Foundation)

- Exercise for Individuals with

Osteoporosis or Arthritis (West Virginia

Osteoporosis and Arthritis Program)
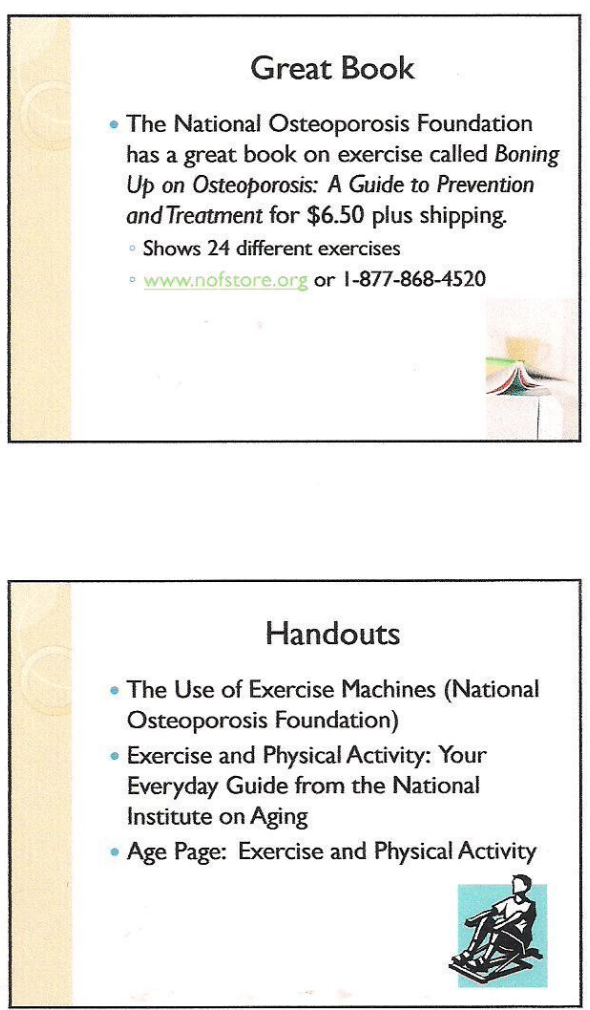

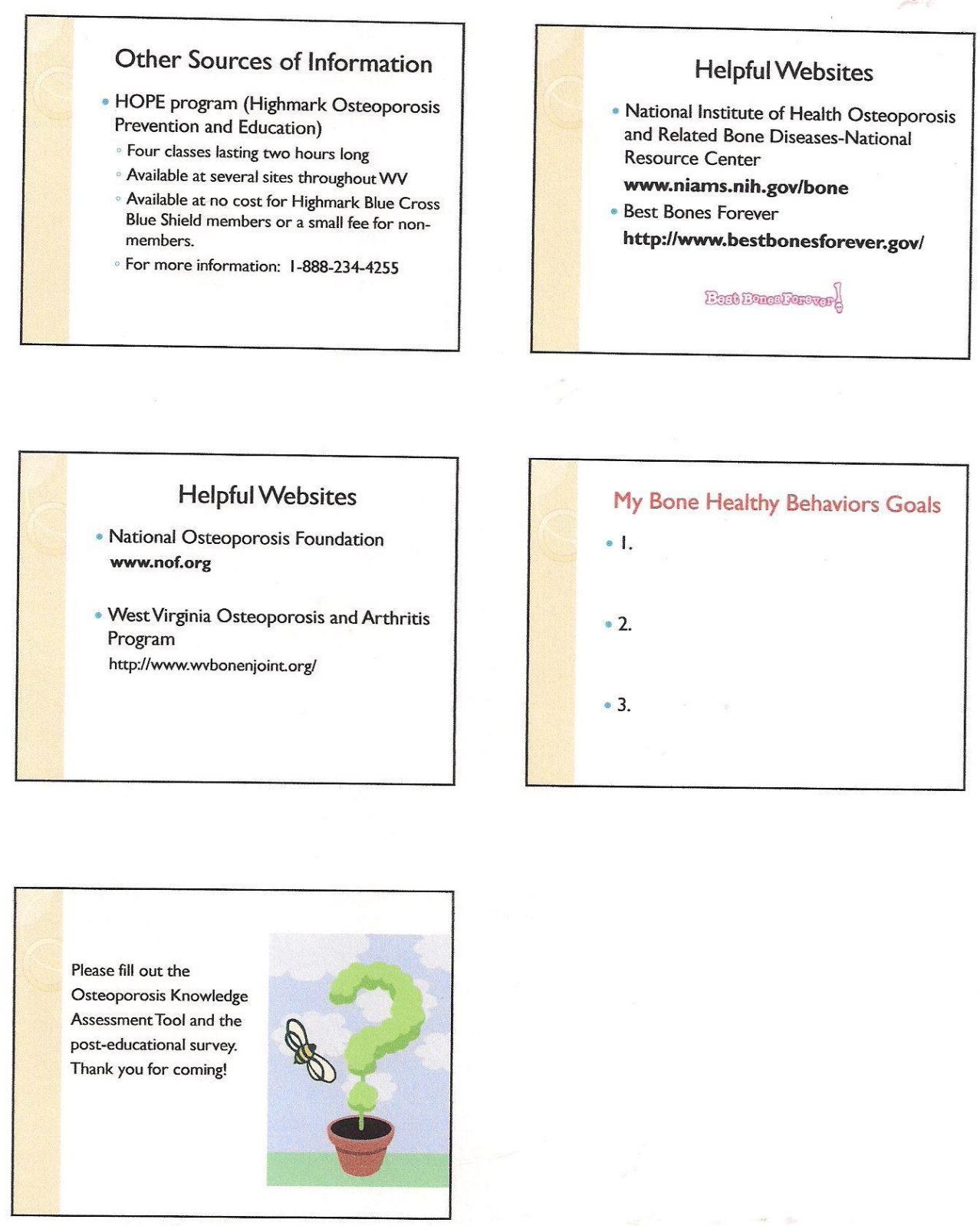


\section{Appendix G \\ Osteoporosis Workshop Follow-Up Form}

Since the osteoporosis workshop, how do you feel you are doing meeting your goals for your bone health? Please circle appropriate answer:

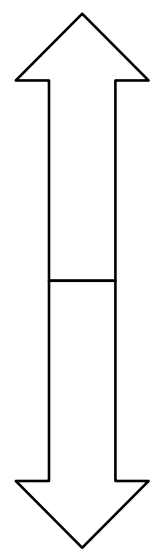
Always meet goals
Usually meet goals
Meeting goals about half the time
Seldom meeting goals
Never meeting goals

If you take calcium and/or vitamin D supplements, how much and how often:

ID: 


\section{Appendix $\mathrm{H}$}

Information on the Short Food Questionnaire

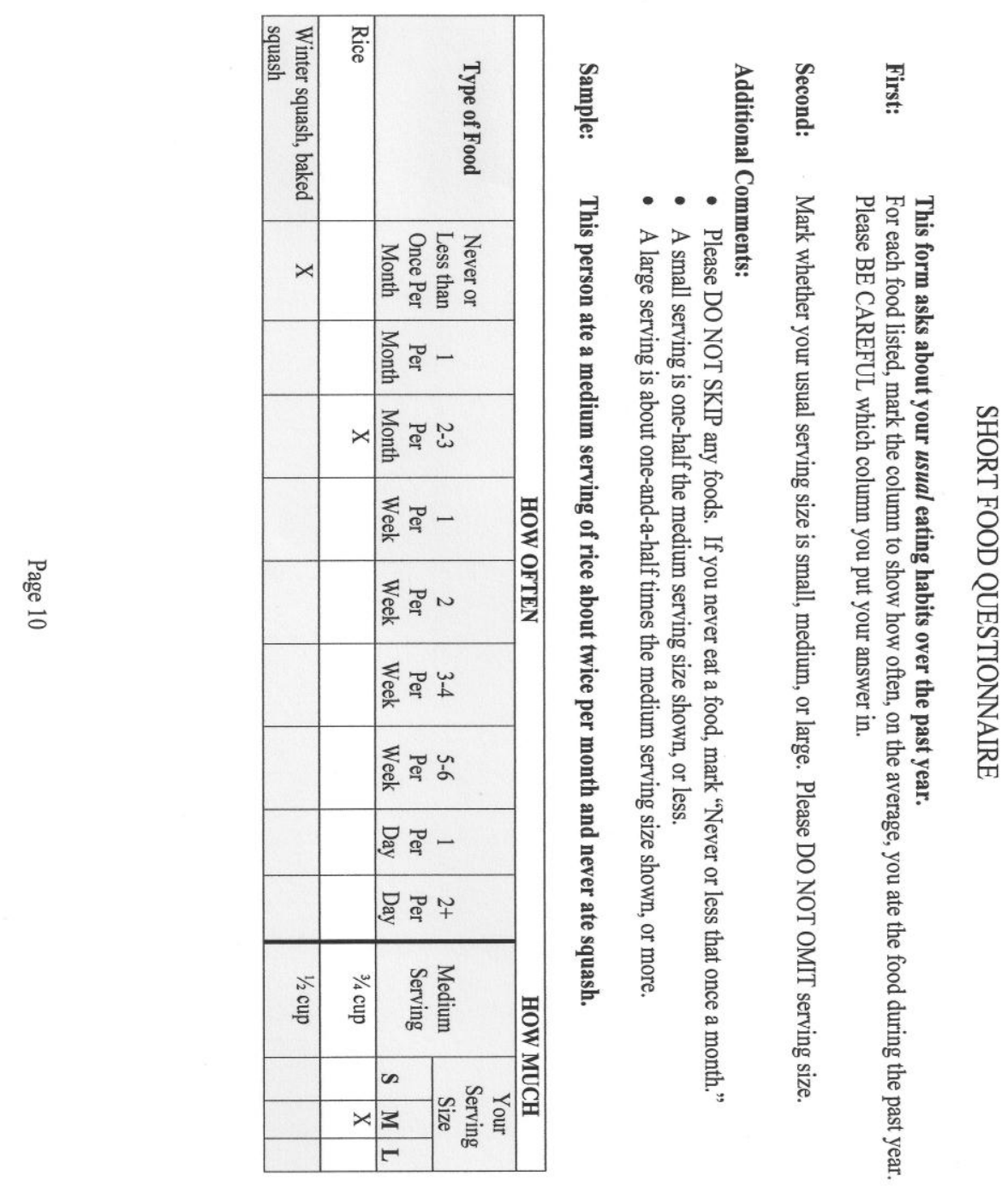




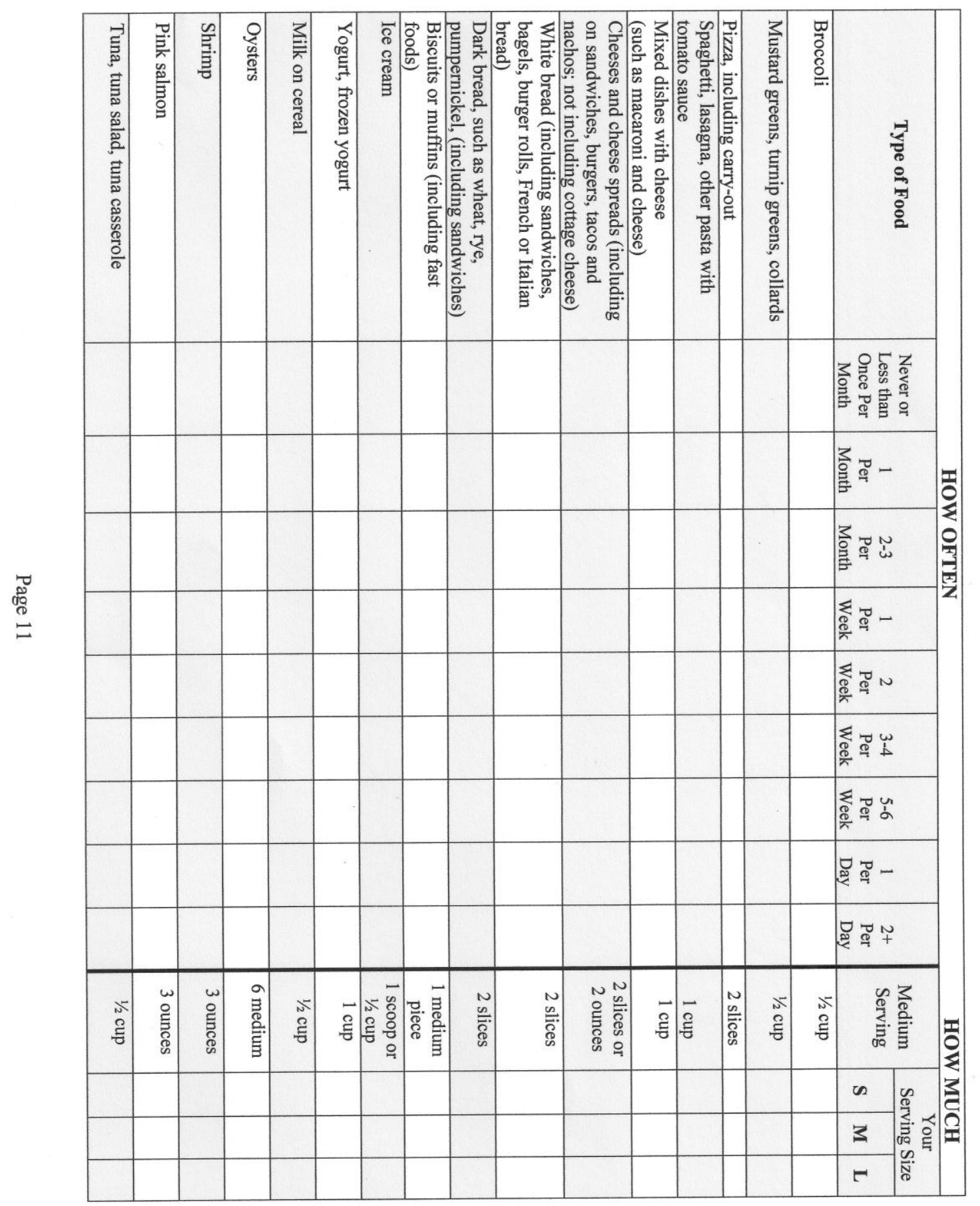



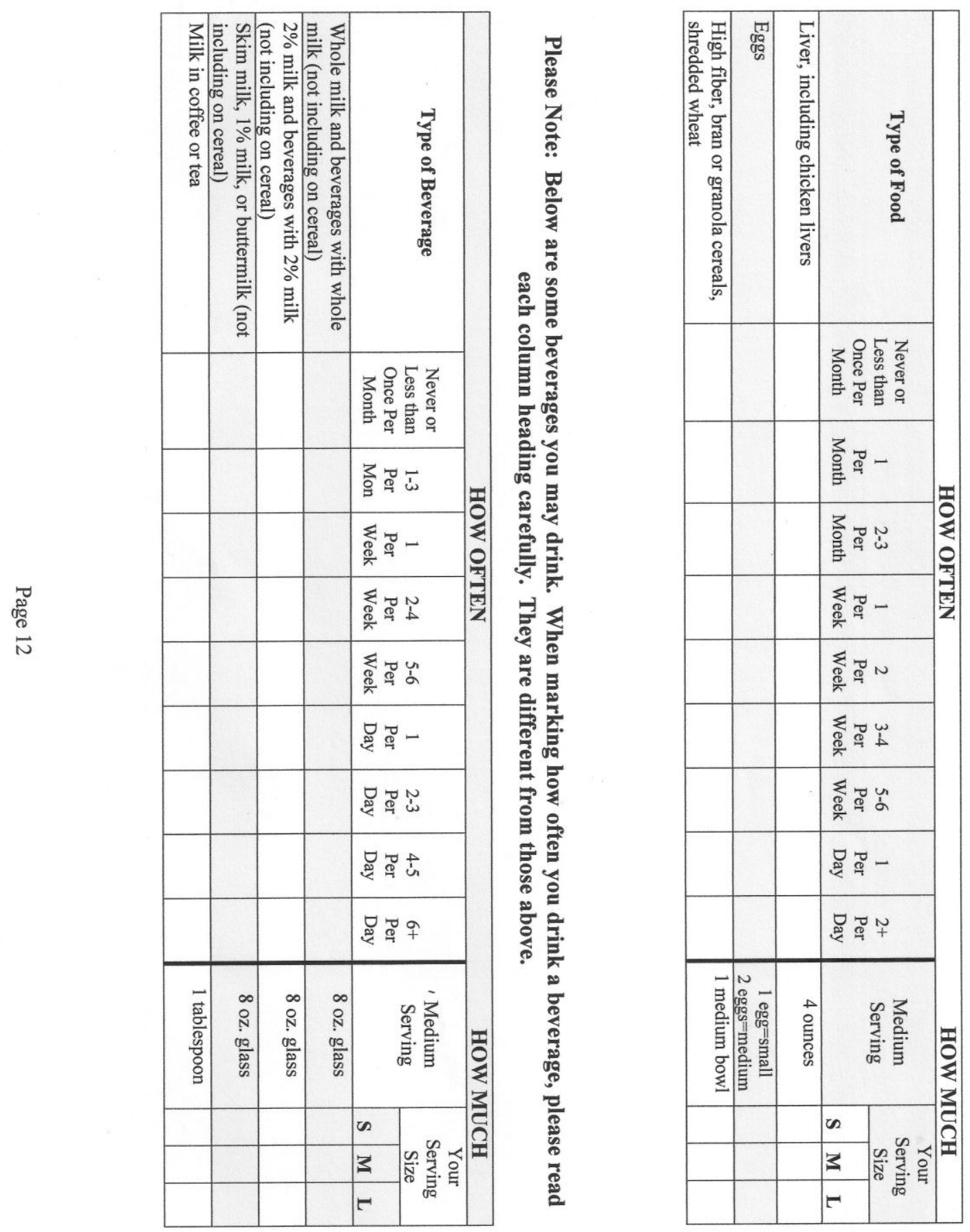
Page 1 of 1

Subject: Re: Request from a DNP Student

To: Cynthia Smith <csmit120@mix.wvu.edu>
Date: 03:25 PM

From: Sue Blalock <blalocks@email.unc.edu>

Spreadsheet and Questionnaire.zip (162kB)

Hi Cynthia, You have my permission to use the instrument. I have attached a copy of an Access database that performs the calcium and vitamin D calculations. It is fairly large, so it is attached as a zip file. Let me know if you have trouble opening it. The database is fairly selfexplanatory, but unfortunately. I do not have separate documentation that explains how the calculations are made. (All of the tables are embedded in the Access database.)

Hope you find it useful.

Sue

Cynthia Smith wrote:

$>$ $>$ Dr. Blalock,

$>$ Hello! My name is Cynthia Smith. I am a doctoral of nursing practice student at West Virginia University School of Nursing. I am currently working on my Capstone project which is part of a practice change for an osteoporosis clinic. The project is a onetime community-based group educational intervention for those with or at risk for osteoporosis led by a registered nurse. Thirty to fifty participants will be recruited. Measurements will be taken pre-, immediately postintervention, one month, and three months post-intervention on the effect on osteoporosis knowledge, calcium/vitamin D intake, physical activity levels, fear of falling, and use of tobacco and alcoholic products.

$>$

>In researching instruments I could use to assess intake of vitamin D and calcium, I came across your article describing the Short Instrument for Assessing Dietary Intakes of Calcium and Vitamin D in the 2003 /Journal of the American Pharmacists Association/. As the lead author, I was writing to request permission to use this instrument in my Capstone project. Any information you could supply me with how to interpret this instrument and, if possible, how to obtain copies would also be greatly appreciated. Thank you for taking the time to consider my request as I truly appreciate it. Please do not hesitate to call on me with any questions and/or concerns.

$>$

$>$ Sincerely,

$>$

$>$ Cynthia A. Smith, FNP-BC, RN, MSN, CCD

$>5011$ Renard Street

$>$

>Sissonville, WV 25320

$>$

>Home Phone: 304-988-1986

$>$

>Work Phone: 740-315-5706

$>$

$>$ Fax: $\quad 304-865-3700$

$>$ E-mail: csmit120@mix.wvu.edu

$--$

Susan J. Blalock, Ph.D.

Associate Professor

Division of Pharmaceutical Outcomes and Policy Eshelman School of Pharmacy

University of North Carolina

Chapel Hill, NC 27599-7573

Phone $919-962-0080$

https://mix.wvu.edu/iwc_static/layout/shell.html?lang=en-US\&11.01_204835 


\title{
Appendix I
}

Information on the International Physical Activity Questionnaire: Short Last 7 Days Self-

\author{
Administered
}

\section{INTERNATIONAL PHYSICAL ACTIVITY QUESTIONNAIRES}

\section{IPAQ: SHORT LAST 7 DAYS SELF-ADMINISTERED FORMAT}

\section{FOR USE WITH YOUNG AND MIDDLE-AGED ADULTS}

\begin{abstract}
The International Physical Activity Questionnaires (IPAQ) comprises a set of 4 questionnaires. Long ( 5 activity domains asked independently) and short (4 generic items) versions for use by either telephone or self-administered methods are available. The purpose of the questionnaires is to provide common instruments that can be used to obtain internationally comparable data on healthrelated physical activity.
\end{abstract}

\section{Background on IPAQ}

The development of an international measure for physical activity commenced in Geneva in 1998 and was followed by extensive reliability and validity testing undertaken in 12 countries (14 sites) across 6 continents during 2000 . The final results suggest that these measures have acceptable measurement properties for use in many settings and in different languages. IPAQ is suitable for use in regional, national and international monitoring and surveillance systems and for use in research projects and public health program planning and evaluation. International collaboration on IPAQ is on-going and an international prevalence study is under development.

\section{Using IPAQ}

Worldwide use of the IPAQ instruments for monitoring and research purposes is encouraged.

It is strongly recommended, to ensure data quality and comparability and to facilitate the development of an international database on health-related physical activity, that

- no changes be made to the order or wording of the questions as this will affect the psychometric properties of the instruments,

- if additional questions on physical activity are needed they should follow the IPAQ items,

- translations are undertaken using the prescribed back translation methods (see website)

- new translated versions of IPAQ be made available to others via the web site to avoid duplication of effort and different versions in the same language,

- a copy of IPAQ data from representative samples at national, state or regional level be provided to the IPAQ data storage center for future collaborative use (with permission) by those who contribute.

\section{More Information}

Two scientific publications presenting the methods and the pooled results from the IPAQ reliability and validity study are due out in 2002.

More detailed information on the IPAQ process, the research methods used in the development of the IPAQ instruments, the use of IPAQ, the published papers and abstracts and the on-going international collaboration is available on the IPAQ web-site.

\section{www.ipaq.ki.se}




\section{INTERNATIONAL PHYSICAL ACTIVITY QUESTIONNAIRE}

IPAQ: SHORT LAST 7 DAYS SELF-ADMINISTERED FORMAT

FOR USE WITH YOUNG AND MIDDLE-AGED ADULTS

NOTE: EXAMPLES OF ACTIVITIES MAY BE REPLACED BY CULTURALLY RELEVANT EXAMPLES WITH THE SAME METS VALUES (SEE AINSWORTH ET AL., 2000). 


\section{INTERNATIONAL PHYSICAL ACTIVITY QUESTIONNAIRE}

We are interested in finding out about the kinds of physical activities that people do as part of their everyday lives. This is part of a large study being conducted in many countries around the world. Your answers will help us to understand how active we are compared with people in other countries.

The questions are about the time you spent being physically active in the last 7 days. They include questions about activities you do at work, as part of your house and yard work, to get from place to place, and in your spare time for recreation, exercise or sport.

Your answers are important.

Please answer each question even if you do not consider yourself to be an active person.

THANK YOU FOR PARTICIPATING.

In answering the following questions,

- vigorous physical activities refer to activities that take hard physical effort and make you breathe much harder that normal.

- moderate activities refer to activities that take moderate physical effort and make you breathe somewhat harder that normal. 
1a. During the last 7 days, on how many days did you do vigorous physical activities like heavy lifting, digging, aerobics, or fast bicycling,?

Think about only those physical activities that you did for at least 10 minutes at a time.

days per week $\Rightarrow \quad$ 1b. $\begin{aligned} & \text { How much time in total did you usually } \\ & \text { spend on one of those days doing } \\ & \text { vigorous physical activities? }\end{aligned}$

or

hours minutes

none

2a. Again, think only about those physical activities that you did for at least 10 minutes at a time. During the last 7 days, on how many days did you do moderate physical activities like carrying light loads, bicycling at a regular pace, or doubles tennis? Do not include walking.

days per week $\Rightarrow$

or

none 2b. How much time in total did you usually spend on one of those days doing moderate physical activities?

hours minutes

3a. During the last 7 days, on how many days did you walk for at least 10 minutes at a time? This includes walking at work and at home, walking to travel from place to place, and any other walking that you did solely for recreation, sport, exercise or leisure.

days per week $\Rightarrow$

or 3b. How much time in total did you usually spend walking on one of those days?

hours minutes

none

The last question is about the time you spent sitting on weekdays while at work, at home, while doing course work and during leisure time. This includes time spent sitting at a desk, visiting friends, reading traveling on a bus or sitting or lying down to watch television.

4. During the last 7 days, how much time in total did you usually spend sitting on a week.day?

hours minutes

This is the end of questionnaire, thank you for participating. 


\section{Appendix J}

\section{Script to Group for Consent Form Review}

Hello! My name is Cynthia Smith, and I am a family nurse practitioner and a doctoral of nursing practice student in the School of Nursing at West Virginia University. I am here to conduct a study that will look at the effects of a community-based osteoporosis educational program on knowledge of the disease and bone healthy behaviors.

Before we begin, I would like to take a minute to explain why I am inviting you to participate and what I will be doing with the information you provide to me. Please stop me at any time if you have any questions. After I have told you a bit more about my project, you can decide whether or not you would like to participate in the evaluation of the program. You do not have to participate in the evaluation to participate in the program.

I am doing this research as part of my studies in the Department of Health Promotion/Risk Reduction at West Virginia University. The principal investigator and my Capstone chair is Dr. Nan Leslie with West Virginia University's School of Nursing. I will be collecting data on age, gender, education level, for women, if you are menopausal, if osteoporosis/osteopenia medications have been taken and/or still being taken, osteoporosis knowledge, calcium and vitamin D intake, exercise frequency, and how you feel you are doing reaching your bone health goals. A minimum of 50 participants will be recruited. I will use this information as the basis for my doctoral Capstone project. I may also use this information in articles that might be published, as well as in academic presentations.

The osteoporosis educational program is expected to last two and a half hours. Participation in the evaluation should take about 15 to 20 minutes to complete the questionnaires. Participation is on a purely voluntary basis. You will be asked to fill out four questionnaires before the program starts and one questionnaire immediately after the program. You will be given an anonymous survey after the program ends where you can list any comments and/or suggestions. One month from now, four questionnaires 
along with a $\$ 5$ gift card to Target as well as a post-paid self-addressed envelope for the questionnaires’ return will be mailed to the address of your choosing. For those questionnaires not yet returned two weeks later, a second set of questionnaires with a postage paid self-addressed envelope will be mailed to you. The foreseeable risk to participating in the evaluation is minimal discomfort associated in filling out the questionnaires. All data obtained will be kept in a locked filing cabinet in my home office for which I have the only key. All data will be kept as confidential as possible.

If at any time and for any reason, you would prefer not to answer any questions, please feel free not to. If at any time you would like to stop participating, please tell me. You will not be penalized in any way for deciding to stop participation at any time.

If you have questions, you are free to ask them now or you prefer I can meet with you in private. If you have questions later, you may contact me or Dr. Leslie. If you have any questions about your rights as a participant in this research, you can contact the Compliance Office at West Virginia University. This information is listed on the consent form of which you will be given a copy.

If you are interested in participating in this study, open your workbook. In the front, there is a consent form. I will now put up slides of the consent form and read the consent form to you. Please do not hesitate to let me know of any questions/concerns.

(Putting up the PowerPoint Slides of the IRB approved consent form, and reading it verbatim to the participants). 


\title{
Appendix K
}

\section{Consent Form for Osteoporosis Workshop}

\section{West VirginiaUniversity. \\ Office of Research Compliance \\ CONSENT AND INFORMATION FORM}

Osteoporosis Program Evaluation

\author{
Principal Investigator: Leslie, Nan \\ Department: NURSING - Health Pro/Rick Reduc. \\ Tracking Number: $\quad \mathrm{H}-23559$
}

Study Title:

Evaluation of a Community-Based Osteoporosis Educational Program Offering

Co-Investigator(s):

Smith, Cynthia

Sponsor

\section{Contact Persons}

In the event you experience any side effects or injury related to this evaluation program, you should contact Nan Leslie, PhD, WHNP-BC at 304293-1390. (After hours contact Cynthia Smith, FNP-BC at 304-553-5436. If you have any questions, concerns, or complaints about this evaluation program, you can contact Dr. Nan Leslie at 304-293-1390.

In addition, if you would like to discuss problems, concerns, have suggestions related to research, or would like to offer input about the research, contact the Office of Research Integrity and Compliance at 304293-7073.

For information regarding your rights as a research subject, you may contact the Office of Research Compliance at 304/293-7073.

Introduction

You, __ have been asked to participate in this

\begin{tabular}{llll}
\hline Tracking \#: & $\mathrm{H}-23559$ & Page 1 of 5 & \\
Approved On: & $11 / 30 / 2011$ & & Initials \\
Valid Through: & $11 / 29 / 2012$ & & \\
Last Amended: & N/A & &
\end{tabular}


Tracking \#: $\quad \mathrm{H}-23559$

research study, which has been explained to you by Cynthia Smith, FNP$B C, R N, M S N, C C D$. This evaluation is being conducted by Nan Leslie, PhD, WHNP-BC and Cynthia Smith, FNP-BC, RN, MSN, CCD in the School of Nursing at West Virginia University. This research is being conducted to fulfill the requirements for a doctoral of nursing practice degree in the School of Nursing at West Virginia University for Cynthia Smith, FNP-BC, under the supervision of Dr. Nan Leslie.

\section{Purposes of the Study}

The purpose of this study is to evaluate a community-based osteoporosis educational program. WVU expects to enroll approximately 50 participants.

\section{Description of Procedures}

This study involves an osteoporosis educational program and will take approximately $21 / 2$ to 3 hours for you to complete. Before the program begins, you will be asked to fill out questionnaires regarding basic demographic and bone health information, your perception of meeting bone health goals, osteoporosis knowledge, intake of calcium and vitamin $D$, and exercise frequency. At the end of the osteoporosis workshop, you will be asked to complete a second osteoporosis knowledge questionnaire. It will take approximately 15 to 20 minutes to complete the questionnaires. You do not have to answer all the questions. You will have the opportunity to see the questionnaires before signing this consent form. In one month, you will be mailed to the address of your choice questionnaires on your perception of meeting bone healthy goals, osteoporosis knowledge, intake of calcium and vitamin $\mathrm{D}$, and exercise frequency. It should take approximately 15 minutes to complete these forms. You will be asked to return the completed questionnaires in the provided self-addressed, postage paid envelope. If the questionnaires are not returned in two weeks, a second mailing including the questionnaires and a self-addressed postage paid envelope will be mailed to the address of your choice. On the day of the workshop after the workshop is over, you will be asked to complete an anonymous survey survey about the program and the site it was held in.

\section{Risks and Discomforts}

There are no known or expected risks from participating in this study,

\begin{tabular}{lll}
\hline Tracking \#: & H-23559 & Page 2 of 5 \\
Approved On: & $11 / 30 / 2011$ & \\
Valid Through: & $11 / 29 / 2012$ & \\
Last Amended: & N/A
\end{tabular}


Tracking \#: $\quad \mathrm{H}-23559$

except for mild frustration associated with answering the questions.

\begin{abstract}
Alternatives
You do not have to participate in this study.

You do not have to participate in this evaluation to participate in the osteoporosis educational program.
\end{abstract}

\title{
Benefits
}

You may not receive any direct benefit from this study. The knowledge gained from this study may eventually benefit others.

\section{Financial Considerations}

There are no special fees for participating in this study. You will be given a $\$ 5$ gift card for a local store when mailed the one month follow-up questionnaires. If you withdraw before the one month evaluation, no gift card will be sent.

\section{Confidentiality}

Any information about you that is obtained as a result of your participation in this research will be kept as confidential as legally possible. Your project evaluation records, just like hospital records, may be subpoenaed by court order or federal regulatory authorities without your additional consent. Information obtained will be kept locked up and will be destroyed as soon as possible after the research is finished. In any publications that result from this research, neither your name nor any information from which you might be identified will be published without your consent. We know that information about you and your health is private. We are dedicated to protecting the privacy of that information. Because of this promise, we must get your written authorization (permission) before we may use or disclose your protected health information or share it with others for research purposes. You can decide to sign or not to sign this authorization section. However, if you choose not to sign this authorization, you will not be able to take part in the research study. Whatever choice you make about this evaluation will not have an effect on your ability to attend the educational program.

\begin{tabular}{lllll}
\hline Tracking \#: & $\mathrm{H}-23559$ & Page 3 of 5 & \\
Approved On: & $11 / 30 / 2011$ & & & \\
Valid Through: & $11 / 29 / 2012$ & & & \\
Last Amended: & N/A & & &
\end{tabular}


Tracking\#: H-23559
Persons/Organizations providing the information:
The participant

Persons/Organizations receiving the information:

The research site carrying out this study. This includes WVU and the program evaluators.

The members and staff of any Institutional Review Board (IRB) that oversees this research study.

West Virginia University Office of Research Compliance and Office of Sponsored Programs.

The following information will be used:

The evaluation forms/questionnaires.

The information is being disclosed for the following reasons: Publication of study results (without identifying you)

You may cancel this authorization at any time by writing to the Principal Investigator:

Nan Leslie, PhD, WHNP-BC

West Virginia University School of Nursing

6515 HSS PO Box 9630

Morgantown, WV, 26506

If you cancel this authorization, any information that was collected already for this study cannot be withdrawn. Once information is disclosed, according to this authorization the recipient may redisclose it and then the information may no longer be protected by federal privacy regulations. You have a right to see and make copies of your questionnaires. This authorization will not expire unless you cancel it.

\section{Voluntary Participation}

Participation in this study is voluntary. You are free to withdraw your consent to participate in this study at any time, and will involve no penalty to you. In the event new information becomes available that may affect your willingness to participate in this study, this information will be given to you so that you can make an informed decision about whether or not to continue your participation. You have been given the opportunity to ask questions about the program evaluation, and you have received answers concerning areas you did not understand.

\begin{tabular}{lll}
\hline Tracking \#: & H-23559 & Page 4 of 5 \\
Approved On: & $11 / 30 / 2011$ & \\
Valid Through: & $11 / 29 / 2012$ & \\
Last Amended: & N/A &
\end{tabular}


Tracking \#: $\quad$ H-23559

Upon signing this form, you will receive a copy.

I willingly consent to participate in this research.

$\begin{array}{lll}\begin{array}{l}\text { Signature of Subject or } \\ \text { Subjects Legal Representative }\end{array} & \overline{\text { Printed Name }} & \overline{\text { Time }}\end{array}$

The participant has had the opportunity to have questions addressed. The participant willingly agrees to be in the study.

$\begin{array}{llll}\begin{array}{l}\text { Signature of Investigator or } \\ \text { Co-Investigator }\end{array} & \text { Date } & \text { Time }\end{array}$

\begin{tabular}{lllll}
\hline Tracking H: & $\mathrm{H}-23559$ & Page 5 of 5 & & \\
Approved On: & $11 / 30 / 2011$ & & & Date \\
Valid Through: & $11 / 29 / 2012$ & & & \\
Last Amended: & N/A & & &
\end{tabular}


Appendix L

\section{Osteoporosis Workshop Survey}

To help us with future workshops like this one, we would like to know your thoughts and suggestions to help improve it. Thank you for attending today's osteoporosis educational workshop and for taking the time to complete this survey. Please put your response in the appropriate boxes below.

\begin{tabular}{|l|l|l|l|}
\hline & Yes & No & Don't Want to \\
\hline program helpful? & & & \\
\hline Did you find the & & & \\
\hline recommend it to & & & \\
someone else? & & & \\
\hline Was it offered at a & & & \\
time convenient & & & \\
for you? & & & \\
\end{tabular}




\begin{tabular}{|l|l|l|l|}
\hline & Yes & No & Answer \\
\hline everything you had & & & \\
\hline wanted to learn? & & & \\
\hline about right? & & & \\
\hline Was the length & & & \\
\hline Wace convenient & & & \\
for you? & & & \\
\hline helpful? & & & \\
\hline Was the room & & & \\
\hline comfortable? & & & \\
\hline Was the workbook & & & \\
\hline
\end{tabular}


Please feel free to offer any comments and/or suggestions you have for this program: 


\section{Appendix M}

\section{One Month Post-Educational Offering Letter}

\section{WestVhrginiaUniversity}

School of Nursing

Dear Participant,

One month ago you attended an osteoporosis workshop held at the Charleston Family YMCA. As you may recall, this workshop is being evaluated by Cynthia Smith, FNP-BC, RN, MSN,

CCD, as part of a Doctorate of Nursing Practice (DNP) degree at West Virginia University School of Nursing, Department of Health Promotion/Risk Reduction. Your participation in this workshop and in filling out the pre-workshop and post-workshop questionnaires is greatly appreciated. I am enclosing the one month questionnaires along with a postage-paid envelope for their return. As a token of appreciation for your time and attention, I am enclosing a $\$ 5$ gift card for Target.

Your participation is completely voluntary. You may skip any question that you do not wish to answer and you may stop participation at any time. Your involvement in this project will be kept as confidential as legally possible. All data will be reported as a group. West Virginia University's Institutional Review Board's approval of this project is on file at the West Virginia University Research Corporation at 886 Chestnut Ridge Road, PO Box 6845, West Virginia University, Morgantown, WV 26506-6845.

I hope that you will be able to complete and return these questionnaires as it could be very beneficial in understanding how best to educate participants regarding osteoporosis and bone healthy behaviors. Thank you very much for your time. Should you have any questions about this letter or the evaluation project, please feel free to contact me (Co-Investigator) at csmit120@mix.wvu.edu or my Capstone Project Chair (Principal Investigator), Dr. Nan Leslie, at nleslie@hsc.wvu.edu or (304) 293-1390. If you have questions about your rights as a research subject, you can contact the West Virginia University Office of Research Compliance of the IRB at 304-293-7073.

Sincerely,

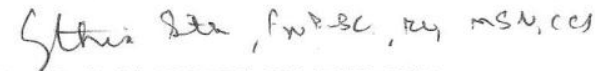

Cynthia Smith, FNP-BC, RN, MSN, CCD

DNP Student

Enclosures

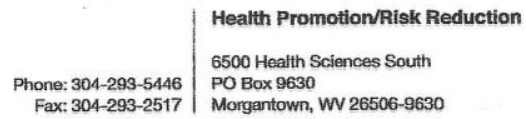

Equal Opportunity/Afflmative Action Institution 


\section{Appendix $\mathrm{N}$}

\section{Follow-Up Letter for Non-Returned Instruments/Questionnaires}

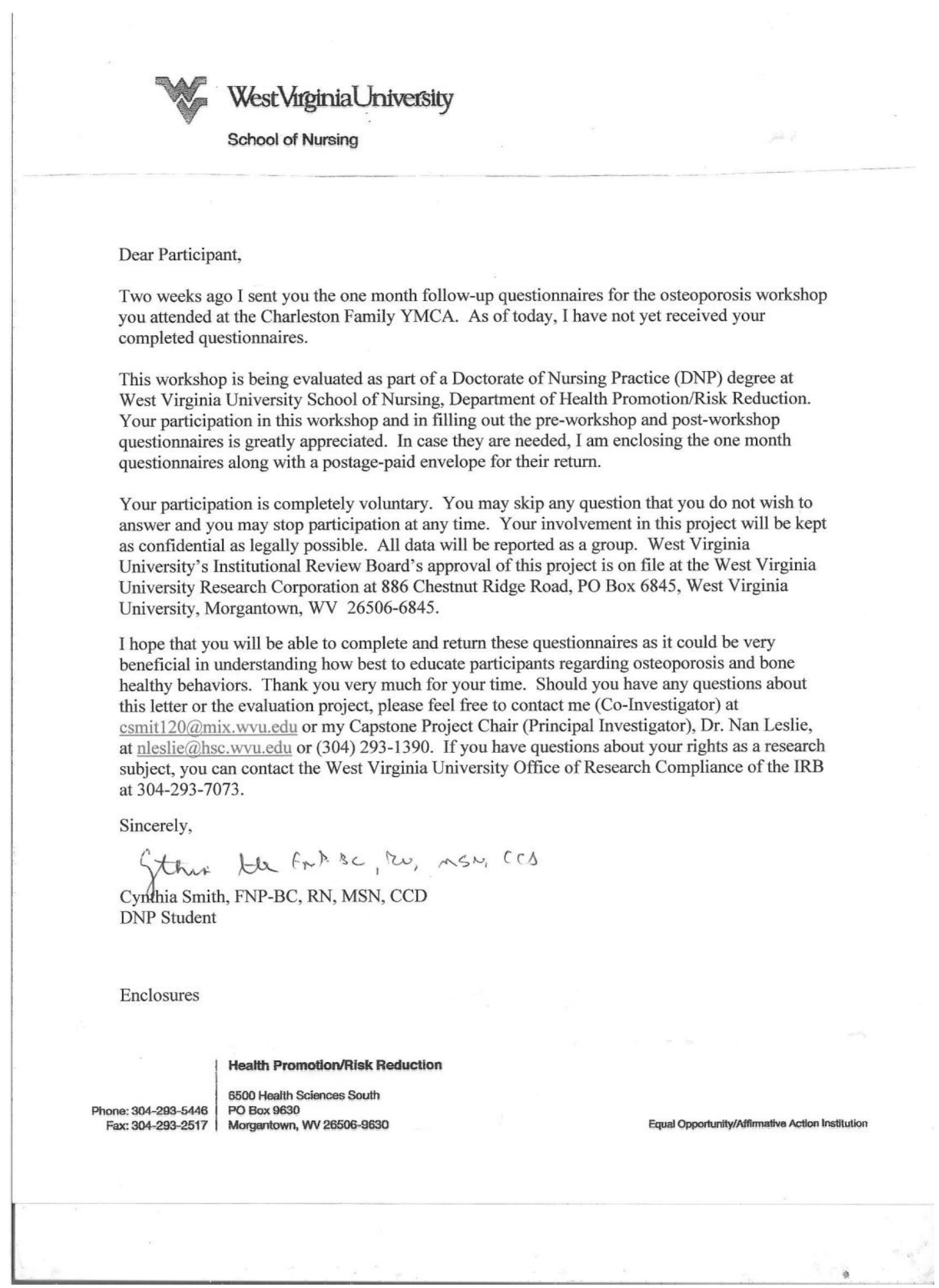




\section{Appendix $\mathrm{O}$}

\section{Informational Letter}

\section{West VirginiaUniversity}

School of Nursing

Dear Participant,

This letter is a request for you to take part in an evaluation project of a community-based onetime osteoporosis workshop led by a nurse practitioner. This project is being conducted by Cynthia Smith, FNP-BC, RN, MSN, CCD, as part of a Doctorate of Nursing Practice (DNP) degree at West Virginia University School of Nursing, Department of Health Promotion/Risk Reduction. Your participation in the project is greatly appreciated, and will hopefully improve osteoporosis education. Your time commitment will include attendance at the osteoporosis workshop and about fifteen minutes to fill out pre- and post-program questionnaires at the end of the project in one month.

Your involvement in this project will be kept as confidential as legally possible. All data will be reported as a group. You must be at least 18 years old or older to participate. Your participation is completely voluntary. You may skip any question that you do not wish to answer and you may discontinue at any time. West Virginia University's Institutional Review Board acknowledgement of this project is on file at the West Virginia University Research Corporation at 886 Chestnut Ridge Road, PO Box 6845, West Virginia University, Morgantown, WV 265066845.

I hope that you will participate in this project as it could be very beneficial in understanding how best to educate participants regarding osteoporosis and bone healthy behaviors. Thank you very much for your time. Should you have any questions about this letter or the evaluation project, please feel free to contact me at csmit120@mix.wvu.edu or my Capstone Project Chair, Dr. Nan Leslie, at nleslie@hsc.wvu.edu or (304) 293-1390. If you have any questions about your rights as a research subject, you can contact the West Virginia University Office of Research Compliance of the IRB at 304-293-7073.

Sincerely,

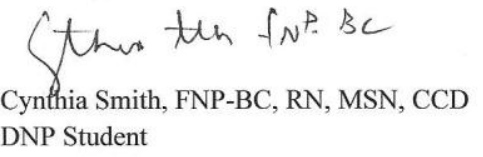

Health Promotion/Risk Reduction

\begin{tabular}{l|l} 
Phone: 304-293-5446 & PO Box 9630
\end{tabular} 
Appendix P

Osteoporosis Workshop Sign In Sheet

Name:

Address:

Phone:

ID: 


\title{
Appendix Q
}

Terms of Use for Handouts

\section{Reproducing NOF's Educational Handouts}

\author{
Terms of Use Agreement \\ IMPORTANT - READ CAREFULLY:
}

This agreement is between you and the National Osteoporosis Foundation (NOF) for reproducing any of NOF's educational materials included with this letter 1) for the NOF Professional Partners Network; 2) for NOF Support Group Leaders; and 3) that were purchased from NOF. If you reproduce (copy) these handouts, you agree to be bound by the terms in this letter.

\section{TERMS AND CONDITIONS:}

The National Osteoporosis Foundation grants you the right to reproduce the educational handouts provided with this letter under the following conditions:

1. You are hereby given the rights to reproduce the articles to promote the health and well-being of the people you serve. You may reproduce them in handouts, employee education materials, client health education materials and posted on your facility bulletin boards in order to reach the individuals you serve.

2. You agree to reproduce any item in its entirety including the copyright notice and the author name and/or sources listed at the end of the article.

3. Any change in the text of the items reprinted from the National Osteoporosis Foundation is strictly prohibited without written consent from NOF.

4. You are restricted from the sale or transfer of the copyright held by NOF.

5. You are restricted from reproducing any of the articles from NOF in any media that is for sale.

DISCLAIMER OR WARRANTY:

NOF does not make any express or implied warranties, representations or endorsements whatsoever (including without limitation warranties of title or noninfringement, or the implied warranties of merchantability or appropriateness for a particular purpose) with regard to the information provided through its educational materials.Y ou hereby accept NOF's educational handouts as is." NOF does not warrant the accuracy, completeness or correctness, timeliness, or usefulness of any opinions, advice, or other information provided through these articles that are provided by NOF for the purpose of

disseminating health information to its members, Support Group Leaders and others to use in service to their patients or clients.

National Osteoporosis Foundation

1150 17th Street, NW, Suite 850 Washington, DC 20036

- Phone: (202) 223-2226 E-mail Request@nof.org $\downarrow$ Website: www.NOF.org 


\section{Appendix R}

Returned Instruments/Questionnaires

\begin{tabular}{|c|c|c|c|c|c|c|c|c|c|}
\hline ID & $\begin{array}{l}\text { Info } \\
\text { Pre- }\end{array}$ & $\begin{array}{c}\text { Follow- } \\
\text { Up }\end{array}$ & $\begin{array}{c}\text { OKAT } \\
\text { Pre- }\end{array}$ & $\begin{array}{c}\text { OKAT } \\
\text { IP* }^{*}\end{array}$ & $\begin{array}{l}\text { OKAT } \\
1 \mathrm{MP}^{* *}\end{array}$ & $\begin{array}{c}\mathrm{Ca} / \mathrm{VitD} \\
\text { Pre- }\end{array}$ & $\begin{array}{c}\mathrm{Ca} / \mathrm{VitD} \\
1 \mathrm{MP}^{*} *\end{array}$ & $\begin{array}{c}\text { IPAQ } \\
\text { Pre- }\end{array}$ & $\begin{array}{c}\text { IPAQ } \\
1 \mathrm{MP}^{* *}\end{array}$ \\
\hline 1 & + & - & + & - & - & - & - & - & - \\
\hline 2 & + & + & + & + & + & + & + & + & + \\
\hline 3 & + & + & + & + & + & + & + & + & + \\
\hline 4 & + & + & + & + & + & + & + & + & + \\
\hline 5 & + & + & + & + & + & + & + & + & + \\
\hline 6 & + & + & + & + & + & + & + & + & + \\
\hline 7 & + & + & + & + & + & + & + & + & + \\
\hline 8 & + & - & + & + & - & + & - & + & - \\
\hline 9 & + & + & + & - & + & + & + & + & + \\
\hline 10 & + & + & + & + & + & + & + & + & + \\
\hline 11 & + & - & + & + & - & - & - & - & - \\
\hline 12 & + & + & + & + & + & + & + & + & + \\
\hline 13 & + & + & + & + & + & + & + & + & + \\
\hline 14 & + & + & + & + & + & + & + & + & + \\
\hline 15 & + & + & + & + & + & + & + & + & + \\
\hline 16 & + & + & + & + & + & + & + & + & + \\
\hline 17 & + & + & + & + & + & + & + & + & + \\
\hline 18 & + & + & + & + & + & + & + & + & + \\
\hline 19 & + & + & + & - & + & + & + & + & + \\
\hline 20 & + & + & + & + & + & + & + & + & + \\
\hline 21 & + & + & + & + & + & + & + & + & + \\
\hline 22 & + & + & + & + & + & + & + & + & + \\
\hline 23 & + & + & + & + & + & + & + & + & + \\
\hline 24 & + & + & - & + & + & + & + & + & + \\
\hline 25 & + & + & + & + & + & + & + & + & + \\
\hline 26 & - & + & - & + & + & + & + & - & + \\
\hline 27 & + & + & + & + & + & + & + & + & + \\
\hline 28 & + & + & + & + & + & + & + & + & + \\
\hline 29 & + & + & + & + & + & + & + & + & + \\
\hline 30 & + & + & + & + & + & + & + & + & + \\
\hline 31 & + & + & + & + & + & + & + & + & + \\
\hline 32 & + & + & + & - & + & + & + & + & + \\
\hline 33 & + & + & + & - & + & + & + & + & + \\
\hline 34 & + & + & + & + & + & + & + & + & + \\
\hline $\begin{array}{c}\text { Totals } \\
\text { Workshop } \\
\text { One }\end{array}$ & 33 & 31 & 32 & 29 & 31 & 32 & 31 & 31 & 31 \\
\hline
\end{tabular}




\begin{tabular}{|c|c|c|c|c|c|c|c|c|c|}
\hline $\begin{array}{c}\text { Return } \\
\text { Rate } \\
\text { Workshop } \\
\text { One }\end{array}$ & $97.1 \%$ & $91.2 \%$ & $94.1 \%$ & $85.3 \%$ & $91.2 \%$ & $94.1 \%$ & $91.2 \%$ & $91.2 \%$ & $91.2 \%$ \\
\hline 35 & + & + & + & + & + & + & + & + & + \\
\hline 36 & + & + & + & + & + & + & + & + & + \\
\hline 37 & + & + & + & + & + & + & + & + & + \\
\hline 38 & + & + & + & + & + & + & + & + & + \\
\hline 39 & + & + & + & + & + & + & + & + & + \\
\hline 40 & + & + & + & + & + & - & + & - & + \\
\hline 41 & + & + & + & + & + & + & + & + & + \\
\hline 42 & + & + & + & + & + & + & + & + & + \\
\hline 43 & + & + & + & + & + & + & + & + & + \\
\hline 44 & + & + & + & + & + & + & + & + & + \\
\hline 45 & + & + & + & + & + & + & + & + & + \\
\hline 46 & + & - & - & + & - & + & - & + & - \\
\hline 47 & + & + & + & + & + & + & + & + & + \\
\hline 48 & + & + & + & + & + & + & + & + & + \\
\hline $\begin{array}{c}\text { Totals } \\
\text { Workshop } \\
\text { Two }\end{array}$ & 14 & 13 & 13 & 14 & 13 & 13 & 13 & 13 & 13 \\
\hline $\begin{array}{c}\text { Return } \\
\text { Rate } \\
\text { Workshop } \\
\text { Two }\end{array}$ & $100 \%$ & $92.9 \%$ & $92.9 \%$ & $100 \%$ & $92.9 \%$ & $92.9 \%$ & $92.9 \%$ & $92.9 \%$ & $92.9 \%$ \\
\hline 51 & + & + & + & + & + & + & + & + & + \\
\hline 52 & + & + & + & + & + & + & + & + & + \\
\hline 54 & + & + & + & + & + & + & + & + & + \\
\hline 55 & + & - & + & - & - & + & - & + & - \\
\hline 56 & + & - & + & - & - & + & - & + & - \\
\hline 57 & + & + & + & + & + & + & + & + & + \\
\hline 59 & + & + & + & + & + & + & + & + & + \\
\hline 60 & + & + & + & - & + & + & + & + & + \\
\hline 61 & + & + & + & + & + & + & + & + & + \\
\hline 63 & + & + & + & - & + & + & + & + & + \\
\hline 64 & + & + & + & + & + & + & + & + & + \\
\hline 65 & + & + & + & + & + & + & + & + & + \\
\hline 66 & + & - & + & + & - & + & - & + & - \\
\hline 68 & + & - & + & - & - & + & - & + & - \\
\hline 69 & + & + & + & - & + & + & + & + & + \\
\hline 71 & + & + & + & - & + & + & + & + & + \\
\hline 72 & + & - & + & + & - & + & - & + & - \\
\hline 73 & + & - & + & - & - & + & - & + & - \\
\hline 75 & + & + & + & - & + & - & + & + & + \\
\hline
\end{tabular}




\begin{tabular}{|c|c|c|c|c|c|c|c|c|c|}
\hline $\begin{array}{c}\text { Totals } \\
\text { Workshop } \\
\text { Three }\end{array}$ & 19 & 13 & 19 & 13 & 13 & 18 & 13 & 19 & 13 \\
\hline $\begin{array}{c}\text { Return } \\
\text { Rate } \\
\text { Workshop } \\
\text { Three }\end{array}$ & $100 \%$ & $68.4 \%$ & $100 \%$ & $68.4 \%$ & $68.4 \%$ & $94.7 \%$ & $68.4 \%$ & $100 \%$ & $68.4 \%$ \\
\hline $\begin{array}{c}\text { Totals } \\
\text { For } \\
\text { All } \\
\text { Workshops }\end{array}$ & 66 & 57 & 64 & 56 & 57 & 63 & 57 & 63 & 57 \\
\hline $\begin{array}{c}\text { Total } \\
\text { Return } \\
\text { Rate } \\
\text { All } \\
\text { Workshops }\end{array}$ & $98.5 \%$ & $85.1 \%$ & $95.5 \%$ & $83.6 \%$ & $85.1 \%$ & $94 \%$ & $85.1 \%$ & $94 \%$ & $85.1 \%$ \\
\hline
\end{tabular}

(+ Returned Instrument/Questionnaire)

(- Non-Returned Instrument/Questionnaire)

(* Immediately Post-Intervention)

(**One Month Post-Intervention) 
Appendix $S$

Information on Subjects Completing Questionnaires/Instruments at All Measurement Points

Table 1

Statistics on Ages of Subjects Completing Instruments at All Measurement Points

\begin{tabular}{|c|c|c|c|c|c|}
\hline & & $\begin{array}{c}\text { Freque } \\
\text { ncy }\end{array}$ & Percent & Valid Percent & Cumulative Percent \\
\hline \multirow[t]{25}{*}{ Valid } & 40 & 1 & 2.2 & 2.3 & 2.3 \\
\hline & 48 & 1 & 2.2 & 2.3 & 4.5 \\
\hline & 52 & 1 & 2.2 & 2.3 & 6.8 \\
\hline & 53 & 1 & 2.2 & 2.3 & 9.1 \\
\hline & 55 & 1 & 2.2 & 2.3 & 11.4 \\
\hline & 56 & 2 & 4.4 & 4.5 & 15.9 \\
\hline & 57 & 2 & 4.4 & 4.5 & 20.5 \\
\hline & 58 & 1 & 2.2 & 2.3 & 22.7 \\
\hline & 59 & 2 & 4.4 & 4.5 & 27.3 \\
\hline & 60 & 4 & 8.9 & 9.1 & 36.4 \\
\hline & 61 & 5 & 11.1 & 11.4 & 47.7 \\
\hline & 63 & 1 & 2.2 & 2.3 & 50.0 \\
\hline & 64 & 1 & 2.2 & 2.3 & 52.3 \\
\hline & 65 & 2 & 4.4 & 4.5 & 56.8 \\
\hline & 66 & 1 & 2.2 & 2.3 & 59.1 \\
\hline & 67 & 1 & 2.2 & 2.3 & 61.4 \\
\hline & 68 & 5 & 11.1 & 11.4 & 72.7 \\
\hline & 70 & 2 & 4.4 & 4.5 & 77.3 \\
\hline & 71 & 1 & 2.2 & 2.3 & 79.5 \\
\hline & 72 & 1 & 2.2 & 2.3 & 81.8 \\
\hline & 74 & 2 & 4.4 & 4.5 & 86.4 \\
\hline & 76 & 1 & 2.2 & 2.3 & 88.6 \\
\hline & 77 & 1 & 2.2 & 2.3 & 90.9 \\
\hline & 79 & 3 & 6.7 & 6.8 & 97.7 \\
\hline & 87 & 1 & 2.2 & 2.3 & 100.0 \\
\hline
\end{tabular}




\begin{tabular}{|l|l|r|r|r|r|}
\hline & Total & $\mathbf{4 4}$ & $\mathbf{9 7 . 8}$ & $\mathbf{1 0 0 . 0}$ & \\
\hline Missing & System & $\mathbf{1}$ & $\mathbf{2 . 2}$ & & \\
\hline Total & $\mathbf{4 5}$ & $\mathbf{1 0 0 . 0}$ & & \\
\hline
\end{tabular}

Table 2

Information on Grade Completed for Subjects Completing Forms at All Measurement Points

\begin{tabular}{|c|c|c|c|c|c|}
\hline & & Frequency & Percent & Valid Percent & Cumulative Percent \\
\hline \multirow[t]{10}{*}{ Valid } & 12 & 15 & 33.3 & 34.9 & 34.9 \\
\hline & 13 & 3 & 6.7 & $\mathbf{7 . 0}$ & 41.9 \\
\hline & 14 & 7 & 15.6 & 16.3 & 58.1 \\
\hline & 15 & 2 & 4.4 & 4.7 & 62.8 \\
\hline & 16 & 3 & 6.7 & 7.0 & 69.8 \\
\hline & 17 & 1 & 2.2 & 2.3 & 72.1 \\
\hline & 18 & 9 & 20.0 & 20.9 & 93.0 \\
\hline & 19 & 2 & 4.4 & 4.7 & 97.7 \\
\hline & 20 & 1 & 2.2 & 2.3 & $\overline{100.0}$ \\
\hline & Total & 43 & 95.6 & 100.0 & \\
\hline Missing & System & 2 & 4.4 & & \\
\hline \multicolumn{2}{|c|}{ Total } & 45 & 100.0 & & \\
\hline
\end{tabular}

Table 3

Descriptive Statistics on Age and Grade Completed for Subjects Completing Forms at All Measurement Points

\begin{tabular}{|l|r|r|r|r|r|r|r|}
\hline & \multicolumn{1}{|c|}{ N } & Range & Minimum & Maximum & Sum & \multicolumn{1}{c|}{ Mean } & Std. Deviation \\
\hline Age & $\mathbf{4 4}$ & $\mathbf{4 7}$ & $\mathbf{4 0}$ & $\mathbf{8 7}$ & $\mathbf{2 8 3 3}$ & $\mathbf{6 4 . 3 9}$ & $\mathbf{9 . 1 3 8}$ \\
\hline $\begin{array}{l}\text { Grade } \\
\text { Completed }\end{array}$ & $\mathbf{4 3}$ & $\mathbf{8}$ & $\mathbf{1 2}$ & $\mathbf{2 0}$ & $\mathbf{6 3 2}$ & $\mathbf{1 4 . 7 0}$ & $\mathbf{2 . 6 5 1}$ \\
\hline $\begin{array}{l}\text { Valid N } \\
\text { (listwise) }\end{array}$ & $\mathbf{4 3}$ & & & & & & \\
\hline
\end{tabular}


Table 4

Gender Data of Those Subjects Completing Forms at All Measurement Points

\begin{tabular}{|l|l|r|r|r|r|}
\hline \multicolumn{2}{|c|}{} & Frequency & Percent & Valid Percent & \multicolumn{2}{c|}{ Cumulative Percent } \\
\hline \multirow{3}{*}{ Valid } & Female & $\mathbf{4 2}$ & $\mathbf{9 3 . 3}$ & $\mathbf{9 3 . 3}$ & $\mathbf{9 3 . 3}$ \\
\cline { 2 - 6 } & Male & $\mathbf{3}$ & $\mathbf{6 . 7}$ & $\mathbf{6 . 7}$ & $\mathbf{1 0 0 . 0}$ \\
\cline { 2 - 6 } & Total & $\mathbf{4 5}$ & $\mathbf{1 0 0 . 0}$ & $\mathbf{1 0 0 . 0}$ & \\
\hline
\end{tabular}

Table 5

Menopause Status of Those Subjects Completing Forms at All Measurement Points

\begin{tabular}{|c|l|r|r|r|r|}
\hline \multicolumn{2}{|c|}{} & Frequency & Percent & Valid Percent & Cumulative Percent \\
\hline \multirow{6}{*}{ Valid } & Menopausal & $\mathbf{4 0}$ & $\mathbf{8 8 . 9}$ & $\mathbf{8 8 . 9}$ & $\mathbf{8 8 . 9}$ \\
\cline { 2 - 7 } & $\begin{array}{l}\text { Non- } \\
\text { menopausal }\end{array}$ & $\mathbf{2}$ & $\mathbf{4 . 4}$ & $\mathbf{4 . 4}$ & $\mathbf{9 3 . 3}$ \\
\cline { 2 - 7 } & NA & 3 & $\mathbf{6 . 7}$ & $\mathbf{6 . 7}$ & $\mathbf{1 0 0 . 0}$ \\
\cline { 2 - 6 } & Total & $\mathbf{4 5}$ & $\mathbf{1 0 0 . 0}$ & $\mathbf{1 0 0 . 0}$ & \\
\hline
\end{tabular}

Table 6

Membership Status of Those Subjects Completing Forms at All Measurement Points

\begin{tabular}{|c|c|c|c|c|c|}
\hline & & Frequency & Percent & Valid Percent & Cumulative Percent \\
\hline \multirow[t]{3}{*}{ Valid } & Yes & 21 & 46.7 & 46.7 & 46.7 \\
\hline & No & 24 & 53.3 & 53.3 & 100.0 \\
\hline & Total & 45 & 100.0 & 100.0 & \\
\hline
\end{tabular}


Table 7

Descriptive Statistics Regarding Osteoporosis or Osteopenia Status among Subjects Completing

Forms at All Measurement Points

\begin{tabular}{|l|l|r|r|r|r|}
\hline \multicolumn{2}{|c|}{} & Frequency & Percent & Valid Percent & \multicolumn{2}{c|}{ Cumulative Percent } \\
\hline \multirow{3}{*}{ Valid } & Yes & $\mathbf{2 5}$ & $\mathbf{5 5 . 6}$ & $\mathbf{5 5 . 6}$ & $\mathbf{5 5 . 6}$ \\
\cline { 2 - 6 } & No & $\mathbf{2 0}$ & $\mathbf{4 4 . 4}$ & $\mathbf{4 4 . 4}$ & $\mathbf{1 0 0 . 0}$ \\
\cline { 2 - 6 } & Total & $\mathbf{4 5}$ & $\mathbf{1 0 0 . 0}$ & $\mathbf{1 0 0 . 0}$ & \\
\hline
\end{tabular}

Table 8

Descriptive Statistics for if Diagnosed, Whether Osteoporosis or Osteopenia among Subjects

Completing Forms at All Measurement Points

\begin{tabular}{|l|l|r|r|r|r|}
\hline \multicolumn{2}{|c|}{} & Frequency & Percent & Valid Percent & \multicolumn{2}{c|}{ Cumulative Percent } \\
\hline \multirow{3}{*}{ Valid } & Osteoporosis & $\mathbf{1 6}$ & $\mathbf{3 5 . 6}$ & $\mathbf{3 5 . 6}$ & $\mathbf{3 5 . 6}$ \\
\cline { 2 - 6 } & Osteopenia & $\mathbf{9}$ & $\mathbf{2 0 . 0}$ & $\mathbf{2 0 . 0}$ & $\mathbf{5 5 . 6}$ \\
\cline { 2 - 6 } & NA & $\mathbf{2 0}$ & $\mathbf{4 4 . 4}$ & $\mathbf{4 4 . 4}$ & $\mathbf{1 0 0 . 0}$ \\
\cline { 2 - 6 } & Total & $\mathbf{4 5}$ & $\mathbf{1 0 0 . 0}$ & $\mathbf{1 0 0 . 0}$ & \\
\hline
\end{tabular}

Table 9

Descriptive Statistics for Past Osteoporosis/Osteopenia Medication Use for Those Subjects

Completing Forms at All Measurement Points

\begin{tabular}{|l|l|r|r|r|r|}
\hline \multicolumn{2}{|c|}{} & Frequency & Percent & Valid Percent & \multicolumn{2}{c|}{ Cumulative Percent } \\
\hline \multirow{2}{*}{ Valid } & Yes & $\mathbf{2 3}$ & $\mathbf{5 1 . 1}$ & $\mathbf{5 1 . 1}$ & $\mathbf{5 1 . 1}$ \\
\cline { 2 - 6 } & No & $\mathbf{2 2}$ & $\mathbf{4 8 . 9}$ & $\mathbf{4 8 . 9}$ & $\mathbf{1 0 0 . 0}$ \\
\cline { 2 - 6 } & Total & $\mathbf{4 5}$ & $\mathbf{1 0 0 . 0}$ & $\mathbf{1 0 0 . 0}$ & \\
\hline
\end{tabular}


Table 10

Descriptive Statistics for Those Prescribed Medications for Osteoporosis/Osteopenia, if They

Are Still Being Taken for Those Subjects Completing Forms All Measurement Points

\begin{tabular}{|l|l|r|r|r|r|}
\hline \multicolumn{2}{|c|}{} & Frequency & \multicolumn{1}{c|}{ Percent } & Valid Percent & Cumulative Percent \\
\hline \multirow{3}{*}{ Valid } & Yes & $\mathbf{1 1}$ & $\mathbf{2 4 . 4}$ & $\mathbf{2 4 . 4}$ & $\mathbf{2 4 . 4}$ \\
\cline { 2 - 6 } & No & 12 & $\mathbf{2 6 . 7}$ & $\mathbf{2 6 . 7}$ & $\mathbf{5 1 . 1}$ \\
\cline { 2 - 6 } & NA & $\mathbf{2 2}$ & $\mathbf{4 8 . 9}$ & $\mathbf{4 8 . 9}$ & $\mathbf{1 0 0 . 0}$ \\
\cline { 2 - 6 } & Total & $\mathbf{4 5}$ & $\mathbf{1 0 0 . 0}$ & $\mathbf{1 0 0 . 0}$ & \\
\hline
\end{tabular}




\section{Appendix T}

Information on Those Subjects Not Returning Questionnaires/Instruments at All Tested Points

Table 1

Statistics on Ages of Subjects Not Completing Forms at All Measurement Points

\begin{tabular}{|c|c|c|c|c|c|}
\hline & & Frequency & Percent & Valid Percent & Cumulative Percent \\
\hline \multirow[t]{16}{*}{ Valid } & 53 & 1 & 4.5 & 5.3 & 5.3 \\
\hline & 57 & 1 & 4.5 & 5.3 & $\mathbf{1 0 . 5}$ \\
\hline & 59 & 1 & 4.5 & 5.3 & 15.8 \\
\hline & 61 & 1 & 4.5 & 5.3 & 21.1 \\
\hline & 63 & 1 & 4.5 & 5.3 & 26.3 \\
\hline & 64 & 2 & 9.1 & 10.5 & 36.8 \\
\hline & 65 & 2 & 9.1 & 10.5 & $\mathbf{4 7 . 4}$ \\
\hline & 66 & 2 & 9.1 & 10.5 & 57.9 \\
\hline & 68 & 2 & 9.1 & 10.5 & 68.4 \\
\hline & 69 & 1 & 4.5 & 5.3 & 73.7 \\
\hline & 75 & 1 & 4.5 & 5.3 & 78.9 \\
\hline & 78 & 1 & 4.5 & 5.3 & 84.2 \\
\hline & 80 & 1 & 4.5 & 5.3 & 89.5 \\
\hline & 81 & 1 & 4.5 & 5.3 & 94.7 \\
\hline & 84 & 1 & 4.5 & 5.3 & 100.0 \\
\hline & Total & 19 & 86.4 & 100.0 & \\
\hline Missing & System & 3 & 13.6 & & \\
\hline Total & & 22 & 100.0 & & \\
\hline
\end{tabular}


Table 2

Information on Grade Completed for Those Subjects Not Completing Forms at All Measurement

Points

\begin{tabular}{|c|c|c|c|c|c|}
\hline & & Frequency & Percent & Valid Percent & Cumulative Percent \\
\hline \multirow[t]{8}{*}{ Valid } & 12 & 6 & 27.3 & 31.6 & 31.6 \\
\hline & 13 & 1 & 4.5 & 5.3 & 36.8 \\
\hline & 14 & 6 & 27.3 & 31.6 & 68.4 \\
\hline & 16 & 3 & 13.6 & 15.8 & 84.2 \\
\hline & 17 & 1 & 4.5 & 5.3 & 89.5 \\
\hline & 18 & 1 & 4.5 & 5.3 & 94.7 \\
\hline & 19 & 1 & 4.5 & 5.3 & 100.0 \\
\hline & Total & 19 & 86.4 & 100.0 & \\
\hline Missing & System & 3 & 13.6 & & \\
\hline \multicolumn{2}{|l|}{ Total } & 22 & 100.0 & & \\
\hline
\end{tabular}

Table 3

Descriptive Statistics on Age and Grade Completed for Subjects Not Completing Forms at All

Measurement Points

\begin{tabular}{|l|r|r|r|r|r|r|}
\hline & N & Range & \multicolumn{1}{c|}{ Minimum } & \multicolumn{1}{c|}{ Maximum } & Mean & \multicolumn{1}{c|}{ Std. Deviation } \\
\hline Age & $\mathbf{1 9}$ & $\mathbf{3 1}$ & $\mathbf{5 3}$ & $\mathbf{8 4}$ & $\mathbf{6 7 . 6 8}$ & $\mathbf{8 . 4 2 0}$ \\
\hline $\begin{array}{l}\text { Grade } \\
\text { Completed }\end{array}$ & $\mathbf{1 9}$ & $\mathbf{7}$ & $\mathbf{1 2}$ & $\mathbf{1 9}$ & $\mathbf{1 4 . 2 6}$ & $\mathbf{2 . 1 8 2}$ \\
\hline $\begin{array}{l}\text { Valid N (list } \\
\text { wise) }\end{array}$ & $\mathbf{1 9}$ & & & & & \\
\hline
\end{tabular}


Table 4

Gender Data of Those Subjects Not Completing Forms at All Measurement Points

\begin{tabular}{|l|l|r|r|r|r|}
\hline \multicolumn{2}{|c|}{} & Frequency & Percent & $\begin{array}{c}\text { Valid } \\
\text { Percent }\end{array}$ & Cumulative Percent \\
\hline \multirow{3}{*}{ Valid } & Female & $\mathbf{1 9}$ & $\mathbf{8 6 . 4}$ & $\mathbf{9 0 . 5}$ & $\mathbf{9 0 . 5}$ \\
\cline { 2 - 6 } & Male & $\mathbf{2}$ & $\mathbf{9 . 1}$ & $\mathbf{9 . 5}$ & $\mathbf{1 0 0 . 0}$ \\
\cline { 2 - 6 } & Total & $\mathbf{2 1}$ & $\mathbf{9 5 . 5}$ & $\mathbf{1 0 0 . 0}$ & \\
\hline Missing & System & $\mathbf{1}$ & $\mathbf{4 . 5}$ & & \\
\hline \multicolumn{2}{|l|}{ Total } & $\mathbf{2 2}$ & $\mathbf{1 0 0 . 0}$ & & \\
\hline
\end{tabular}

Table 5

Menopause Status of Those Subjects Not Completing Forms at All Measurement Points

\begin{tabular}{|l|l|r|r|r|r|}
\hline \multicolumn{2}{|c|}{} & Frequency & Percent & $\begin{array}{c}\text { Valid } \\
\text { Percent }\end{array}$ & Cumulative Percent \\
\hline \multirow{3}{*}{ Valid } & Menopausal & $\mathbf{1 9}$ & $\mathbf{8 6 . 4}$ & $\mathbf{9 0 . 5}$ & $\mathbf{9 0 . 5}$ \\
\cline { 2 - 7 } & NA & 2 & $\mathbf{9 . 1}$ & $\mathbf{9 . 5}$ & $\mathbf{1 0 0 . 0}$ \\
\cline { 2 - 7 } & Total & $\mathbf{2 1}$ & $\mathbf{9 5 . 5}$ & $\mathbf{1 0 0 . 0}$ & \\
\hline Missing & System & $\mathbf{1}$ & $\mathbf{4 . 5}$ & & \\
\hline Total & $\mathbf{2 2}$ & $\mathbf{1 0 0 . 0}$ & & & \\
\hline
\end{tabular}

Table 6

Membership Status of Those Subjects Not Completing Forms at All Measurement Points

\begin{tabular}{|l|l|r|r|r|r|}
\hline \multicolumn{2}{|c|}{} & Frequency & \multicolumn{1}{c|}{ Percent } & $\begin{array}{c}\text { Valid } \\
\text { Percent }\end{array}$ & Cumulative Percent \\
\hline \multirow{3}{*}{ Valid } & Yes & $\mathbf{1 5}$ & $\mathbf{6 8 . 2}$ & $\mathbf{7 1 . 4}$ & $\mathbf{7 1 . 4}$ \\
\cline { 2 - 7 } & No & $\mathbf{6}$ & $\mathbf{2 7 . 3}$ & $\mathbf{2 8 . 6}$ & $\mathbf{1 0 0 . 0}$ \\
\cline { 2 - 7 } & Total & $\mathbf{2 1}$ & $\mathbf{9 5 . 5}$ & $\mathbf{1 0 0 . 0}$ & \\
\hline Missing & System & $\mathbf{1}$ & $\mathbf{4 . 5}$ & & \\
\hline \multicolumn{2}{|l|}{ Total } & $\mathbf{2 2}$ & $\mathbf{1 0 0 . 0}$ & & \\
\hline
\end{tabular}


Table 7

Descriptive Statistics Regarding Osteoporosis or Osteopenia Status among Subjects Not

Returning Forms at All Measurement Points

\begin{tabular}{|l|l|r|r|r|r|}
\hline \multicolumn{2}{|c|}{} & Frequency & Percent & Valid Percent & \multicolumn{2}{c|}{ Cumulative Percent } \\
\hline \multirow{3}{*}{ Valid } & Yes & $\mathbf{1 3}$ & $\mathbf{5 9 . 1}$ & $\mathbf{6 1 . 9}$ & $\mathbf{6 1 . 9}$ \\
\cline { 2 - 6 } & No & $\mathbf{8}$ & $\mathbf{3 6 . 4}$ & $\mathbf{3 8 . 1}$ & $\mathbf{1 0 0 . 0}$ \\
\cline { 2 - 6 } & Total & $\mathbf{2 1}$ & $\mathbf{9 5 . 5}$ & $\mathbf{1 0 0 . 0}$ & \\
\hline Missing & System & $\mathbf{1}$ & $\mathbf{4 . 5}$ & & \\
\hline \multicolumn{2}{|l|}{ Total } & $\mathbf{2 2}$ & $\mathbf{1 0 0 . 0}$ & & \\
\hline
\end{tabular}

Table 8

Descriptive Statistics for if Diagnosed, Whether Osteoporosis or Osteopenia among Subjects Not Completing Forms at All Measurement Points.

\begin{tabular}{|l|l|r|r|r|r|}
\hline \multicolumn{2}{|c|}{} & Frequency & Percent & Valid Percent & Cumulative Percent \\
\hline \multirow{3}{*}{ Valid } & Osteoporosis & $\mathbf{8}$ & $\mathbf{3 6 . 4}$ & $\mathbf{3 8 . 1}$ & $\mathbf{3 8 . 1}$ \\
\cline { 2 - 6 } & Osteopenia & $\mathbf{5}$ & $\mathbf{2 2 . 7}$ & $\mathbf{2 3 . 8}$ & $\mathbf{6 1 . 9}$ \\
\cline { 2 - 7 } & NA & $\mathbf{8}$ & $\mathbf{3 6 . 4}$ & $\mathbf{3 8 . 1}$ & $\mathbf{1 0 0 . 0}$ \\
\cline { 2 - 7 } & Total & $\mathbf{2 1}$ & $\mathbf{9 5 . 5}$ & $\mathbf{1 0 0 . 0}$ & \\
\hline Missing & System & $\mathbf{1}$ & $\mathbf{4 . 5}$ & & \\
\hline Total & & $\mathbf{2 2}$ & $\mathbf{1 0 0 . 0}$ & & \\
\hline
\end{tabular}


Table 9

Descriptive Statistics for Past Osteoporosis/Osteopenia Medication Use for Those Subjects Completing Forms at All Measurement Points

\begin{tabular}{|l|l|r|r|r|r|}
\hline \multicolumn{2}{|c|}{} & Frequency & Percent & \multicolumn{1}{c|}{$\begin{array}{c}\text { Valid } \\
\text { Percent }\end{array}$} & Cumulative Percent \\
\hline \multirow{3}{*}{ Valid } & Yes & $\mathbf{1 0}$ & $\mathbf{4 5 . 5}$ & $\mathbf{4 7 . 6}$ & $\mathbf{4 7 . 6}$ \\
\cline { 2 - 6 } & No & $\mathbf{1 1}$ & $\mathbf{5 0 . 0}$ & $\mathbf{5 2 . 4}$ & $\mathbf{1 0 0 . 0}$ \\
\cline { 2 - 6 } & Total & $\mathbf{2 1}$ & $\mathbf{9 5 . 5}$ & $\mathbf{1 0 0 . 0}$ & \\
\hline Missing & System & $\mathbf{1}$ & $\mathbf{4 . 5}$ & & \\
\hline \multicolumn{2}{|l|}{ Total } & $\mathbf{2 2}$ & $\mathbf{1 0 0 . 0}$ & & \\
\hline
\end{tabular}

Table 10

Descriptive Statistics for Those Prescribed Medications for Osteoporosis/Osteopenia, if They Are Still Being Taken for Those Subjects Not Completing Forms at All Measurement Points

\begin{tabular}{|l|l|r|r|r|r|}
\hline \multicolumn{2}{|c|}{} & Frequency & Percent & \multicolumn{1}{c|}{$\begin{array}{c}\text { Valid } \\
\text { Percent }\end{array}$} & Cumulative Percent \\
\hline \multirow{3}{*}{ Valid } & Yes & $\mathbf{4}$ & $\mathbf{1 8 . 2}$ & $\mathbf{1 9 . 0}$ & $\mathbf{1 9 . 0}$ \\
\cline { 2 - 6 } & No & $\mathbf{8}$ & $\mathbf{3 6 . 4}$ & $\mathbf{3 8 . 1}$ & $\mathbf{5 7 . 1}$ \\
\cline { 2 - 7 } & NA & $\mathbf{9}$ & $\mathbf{4 0 . 9}$ & $\mathbf{4 2 . 9}$ & $\mathbf{1 0 0 . 0}$ \\
\cline { 2 - 7 } & Total & $\mathbf{2 1}$ & $\mathbf{9 5 . 5}$ & $\mathbf{1 0 0 . 0}$ & \\
\hline Missing & System & $\mathbf{1}$ & $\mathbf{4 . 5}$ & & \\
\hline Total & & $\mathbf{2 2}$ & $\mathbf{1 0 0 . 0}$ & & \\
\hline
\end{tabular}


Appendix U

Mailing Information for Workshops One and Two

\begin{tabular}{|c|c|c|c|c|}
\hline ID Number & $\begin{array}{l}\text { Date First } \\
\text { Mailing }\end{array}$ & $\begin{array}{l}\text { When } \\
\text { Received }\end{array}$ & $\begin{array}{l}\text { Date Second } \\
\text { Mailing }\end{array}$ & $\begin{array}{l}\text { When } \\
\text { Received }\end{array}$ \\
\hline 1 & $2 / 24 / 12$ & $\mathrm{n} / \mathrm{a}$ & $3 / 12 / 12$ & $\mathrm{n} / \mathrm{a}$ \\
\hline 2 & $2 / 24 / 12$ & $3 / 02 / 12$ & $\mathrm{n} / \mathrm{a}$ & $\mathrm{n} / \mathrm{a}$ \\
\hline 3 & $2 / 24 / 12$ & $2 / 27 / 12$ & $\mathrm{n} / \mathrm{a}$ & $\mathrm{n} / \mathrm{a}$ \\
\hline 4 & $2 / 24 / 12$ & $3 / 02 / 12$ & $\mathrm{n} / \mathrm{a}$ & $\mathrm{n} / \mathrm{a}$ \\
\hline 5 & $2 / 24 / 12$ & $2 / 28 / 12$ & $\mathrm{n} / \mathrm{a}$ & $\mathrm{n} / \mathrm{a}$ \\
\hline 6 & $2 / 24 / 12$ & $\mathrm{n} / \mathrm{a}$ & $3 / 12 / 12$ & $3 / 15 / 12$ \\
\hline 7 & $2 / 24 / 12$ & $2 / 27 / 12$ & $\mathrm{n} / \mathrm{a}$ & $\mathrm{n} / \mathrm{a}$ \\
\hline 8 & $2 / 24 / 12$ & $\mathrm{n} / \mathrm{a}$ & $3 / 12 / 12$ & $\mathrm{n} / \mathrm{a}$ \\
\hline 9 & $2 / 24 / 12$ & $\mathrm{n} / \mathrm{a}$ & $3 / 12 / 12$ & $3 / 16 / 12$ \\
\hline 10 & $2 / 24 / 12$ & $3 / 05 / 12$ & $\mathrm{n} / \mathrm{a}$ & $\mathrm{n} / \mathrm{a}$ \\
\hline 11 & $2 / 24 / 12$ & $\mathrm{n} / \mathrm{a}$ & $3 / 12 / 12$ & $\mathrm{n} / \mathrm{a}$ \\
\hline 12 & $2 / 24 / 12$ & $\mathrm{n} / \mathrm{a}$ & $3 / 12 / 12$ & $\begin{array}{l}/ 24 / 12 \\
\text { (postmarked } \\
\text { date-was } \\
\text { delayed in } \\
\text { mail) }\end{array}$ \\
\hline 13 & $2 / 24 / 12$ & $2 / 27 / 12$ & $\mathrm{n} / \mathrm{a}$ & $\mathrm{n} / \mathrm{a}$ \\
\hline 14 & $2 / 24 / 12$ & $2 / 29 / 12$ & $\mathrm{n} / \mathrm{a}$ & $\mathrm{n} / \mathrm{a}$ \\
\hline 15 & $2 / 24 / 12$ & $3 / 07 / 12$ & $\mathrm{n} / \mathrm{a}$ & $\mathrm{n} / \mathrm{a}$ \\
\hline 16 & $2 / 24 / 12$ & $2 / 28 / 12$ & $\mathrm{n} / \mathrm{a}$ & $\mathrm{n} / \mathrm{a}$ \\
\hline 17 & $2 / 24 / 12$ & $2 / 28 / 12$ & $\mathrm{n} / \mathrm{a}$ & $\mathrm{n} / \mathrm{a}$ \\
\hline 18 & $2 / 24 / 12$ & $2 / 29 / 12$ & $\mathrm{n} / \mathrm{a}$ & $\mathrm{n} / \mathrm{a}$ \\
\hline 19 & $2 / 24 / 12$ & $3 / 08 / 12$ & $\mathrm{n} / \mathrm{a}$ & $\mathrm{n} / \mathrm{a}$ \\
\hline 20 & $2 / 24 / 12$ & $2 / 28 / 12$ & $\mathrm{n} / \mathrm{a}$ & $\mathrm{n} / \mathrm{a}$ \\
\hline 21 & $2 / 24 / 12$ & $\mathrm{n} / \mathrm{a}$ & $3 / 12 / 12$ & $3 / 19 / 12$ \\
\hline 22 & $2 / 24 / 12$ & $2 / 29 / 12$ & $\mathrm{n} / \mathrm{a}$ & $\mathrm{n} / \mathrm{a}$ \\
\hline 23 & $2 / 24 / 12$ & $\mathrm{n} / \mathrm{a}$ & $3 / 12 / 12$ & $3 / 13 / 12$ \\
\hline 24 & $2 / 24 / 12$ & $2 / 28 / 12$ & $\mathrm{n} / \mathrm{a}$ & $\mathrm{n} / \mathrm{a}$ \\
\hline
\end{tabular}




\begin{tabular}{|c|c|c|c|c|}
\hline 25 & $2 / 24 / 12$ & $2 / 28 / 12$ & $\mathrm{n} / \mathrm{a}$ & $\mathrm{n} / \mathrm{a}$ \\
\hline 26 & $2 / 24 / 12$ & $3 / 05 / 12$ & $\mathrm{n} / \mathrm{a}$ & $\mathrm{n} / \mathrm{a}$ \\
\hline 27 & $2 / 24 / 12$ & $\mathrm{n} / \mathrm{a}$ & $3 / 12 / 12$ & $3 / 24 / 12$ \\
\hline 28 & $2 / 24 / 12$ & $\mathrm{n} / \mathrm{a}$ & $3 / 12 / 12$ & $3 / 19 / 12$ \\
\hline 29 & $2 / 24 / 12$ & $3 / 03 / 12$ & $\mathrm{n} / \mathrm{a}$ & $\mathrm{n} / \mathrm{a}$ \\
\hline 30 & $2 / 24 / 12$ & $2 / 28 / 12$ & $\mathrm{n} / \mathrm{a}$ & $\mathrm{n} / \mathrm{a}$ \\
\hline 31 & $2 / 24 / 12$ & $3 / 10 / 12$ & $\mathrm{n} / \mathrm{a}$ & $\mathrm{n} / \mathrm{a}$ \\
\hline 32 & $2 / 24 / 12$ & $3 / 01 / 12$ & $\mathrm{n} / \mathrm{a}$ & $\mathrm{n} / \mathrm{a}$ \\
\hline 33 & $2 / 24 / 12$ & $\mathrm{n} / \mathrm{a}$ & $3 / 12 / 12$ & $3 / 17 / 12$ \\
\hline 34 & $2 / 24 / 12$ & $2 / 29 / 12$ & $\mathrm{n} / \mathrm{a}$ & $\mathrm{n} / \mathrm{a}$ \\
\hline 35 & $2 / 24 / 12$ & $3 / 06 / 12$ & $\mathrm{n} / \mathrm{a}$ & $\mathrm{n} / \mathrm{a}$ \\
\hline 36 & $2 / 24 / 12$ & $2 / 28 / 12$ & $\mathrm{n} / \mathrm{a}$ & $\mathrm{n} / \mathrm{a}$ \\
\hline 37 & $2 / 24 / 12$ & $3 / 02 / 12$ & $\mathrm{n} / \mathrm{a}$ & $\mathrm{n} / \mathrm{a}$ \\
\hline 38 & $2 / 24 / 12$ & $3 / 02 / 12$ & $\mathrm{n} / \mathrm{a}$ & $\mathrm{n} / \mathrm{a}$ \\
\hline 39 & $2 / 24 / 12$ & $2 / 27 / 12$ & $\mathrm{n} / \mathrm{a}$ & $\mathrm{n} / \mathrm{a}$ \\
\hline 40 & $2 / 24 / 12$ & $2 / 27 / 12$ & $\mathrm{n} / \mathrm{a}$ & $\mathrm{n} / \mathrm{a}$ \\
\hline 41 & $2 / 24 / 12$ & $3 / 10 / 12$ & $\mathrm{n} / \mathrm{a}$ & $\mathrm{n} / \mathrm{a}$ \\
\hline 42 & $2 / 24 / 12$ & $3 / 10 / 12$ & $\mathrm{n} / \mathrm{a}$ & $\mathrm{n} / \mathrm{a}$ \\
\hline 43 & $2 / 24 / 12$ & $2 / 27 / 12$ & $\mathrm{n} / \mathrm{a}$ & $\mathrm{n} / \mathrm{a}$ \\
\hline 44 & $2 / 24 / 12$ & $3 / 08 / 12$ & $\mathrm{n} / \mathrm{a}$ & $\mathrm{n} / \mathrm{a}$ \\
\hline 45 & $2 / 24 / 12$ & $2 / 27 / 12$ & $\mathrm{n} / \mathrm{a}$ & $\mathrm{n} / \mathrm{a}$ \\
\hline 46 & $2 / 24 / 12$ & $\mathrm{n} / \mathrm{a}$ & $3 / 12 / 12$ & $\mathrm{n} / \mathrm{a}$ \\
\hline 47 & $2 / 24 / 12$ & $2 / 28 / 12$ & $\mathrm{n} / \mathrm{a}$ & $\mathrm{n} / \mathrm{a}$ \\
\hline \multirow[t]{2}{*}{48} & $2 / 24 / 12$ & $2 / 28 / 12$ & $\mathrm{n} / \mathrm{a}$ & $\mathrm{n} / \mathrm{a}$ \\
\hline & & $\begin{array}{l}\text { Total } \\
\text { Returned } \\
\text { First } \\
\text { Mailing: } 36\end{array}$ & & $\begin{array}{l}\text { Total } \\
\text { Returned } \\
\text { Second } \\
\text { Mailing: } 8\end{array}$ \\
\hline
\end{tabular}


Appendix V

Mailing Information for Workshop Three

\begin{tabular}{|c|c|c|c|c|}
\hline ID Number & $\begin{array}{l}\text { Date First } \\
\text { Mailing }\end{array}$ & $\begin{array}{l}\text { When } \\
\text { Received }\end{array}$ & $\begin{array}{l}\text { Date Second } \\
\text { Mailing }\end{array}$ & $\begin{array}{l}\text { When } \\
\text { Received }\end{array}$ \\
\hline 51 & $4 / 19 / 12$ & $\mathrm{n} / \mathrm{a}$ & $5 / 04 / 12$ & $5 / 09 / 12$ \\
\hline 52 & $4 / 19 / 12$ & $\mathrm{n} / \mathrm{a}$ & $5 / 04 / 12$ & $5 / 15 / 12$ \\
\hline 54 & $4 / 19 / 12$ & $4 / 23 / 12$ & $n / a$ & $\mathrm{n} / \mathrm{a}$ \\
\hline$\overline{55}$ & $4 / 19 / 12$ & $\mathrm{n} / \mathrm{a}$ & $5 / 04 / 12$ & $\mathrm{n} / \mathrm{a}$ \\
\hline 56 & $4 / 19 / 12$ & $\bar{n} / \mathrm{a}$ & $5 / 04 / 12$ & $\mathrm{n} / \mathrm{a}$ \\
\hline 57 & $4 / 19 / 12$ & $4 / 24 / 12$ & $\mathrm{n} / \mathrm{a}$ & $\mathrm{n} / \mathrm{a}$ \\
\hline 59 & $4 / 19 / 12$ & $4 / 27 / 12$ & $\mathrm{n} / \mathrm{a}$ & $\mathrm{n} / \mathrm{a}$ \\
\hline 60 & $4 / 19 / 12$ & $4 / 28 / 12$ & $\mathrm{n} / \mathrm{a}$ & $\mathrm{n} / \mathrm{a}$ \\
\hline 61 & $4 / 19 / 12$ & $\mathrm{n} / \mathrm{a}$ & $5 / 04 / 12$ & $5 / 09 / 12$ \\
\hline 63 & $4 / 19 / 12$ & $4 / 24 / 12$ & $\mathrm{n} / \mathrm{a}$ & $\mathrm{n} / \mathrm{a}$ \\
\hline 64 & $4 / 19 / 12$ & $4 / 24 / 12$ & $\mathrm{n} / \mathrm{a}$ & $\mathrm{n} / \mathrm{a}$ \\
\hline 65 & $4 / 19 / 12$ & $\mathrm{n} / \mathrm{a}$ & $5 / 04 / 12$ & $5 / 18 / 12$ \\
\hline 66 & $4 / 19 / 12$ & $\mathrm{n} / \mathrm{a}$ & $5 / 04 / 12$ & $\mathrm{n} / \mathrm{a}$ \\
\hline 68 & $4 / 19 / 12$ & $\mathrm{n} / \mathrm{a}$ & $5 / 04 / 12$ & $\mathrm{n} / \mathrm{a}$ \\
\hline 69 & $4 / 19 / 12$ & $4 / 22 / 12$ & $\mathrm{n} / \mathrm{a}$ & $\mathrm{n} / \mathrm{a}$ \\
\hline 71 & $4 / 19 / 12$ & $4 / 28 / 12$ & $\mathrm{n} / \mathrm{a}$ & $\mathrm{n} / \mathrm{a}$ \\
\hline 72 & $4 / 19 / 12$ & $\mathrm{n} / \mathrm{a}$ & $5 / 04 / 12$ & $\mathrm{n} / \mathrm{a}$ \\
\hline 73 & $4 / 19 / 12$ & $\mathrm{n} / \mathrm{a}$ & $5 / 04 / 12$ & $\mathrm{n} / \mathrm{a}$ \\
\hline \multirow[t]{2}{*}{75} & $4 / 19 / 12$ & $4 / 24 / 12$ & $\mathrm{n} / \mathrm{a}$ & $n / a$ \\
\hline & & $\begin{array}{l}\text { Total } \\
\text { Returned } \\
\text { First } \\
\text { Mailing: } 9\end{array}$ & & $\begin{array}{l}\text { Total } \\
\text { Returned } \\
\text { Second } \\
\text { Mailing: } 4\end{array}$ \\
\hline
\end{tabular}


Appendix W

Osteoporosis Workshop Information and Follow-Up Form Statistical Analysis

Table 1

Osteoporosis Workshop Information Form Valid and Missing

Data

\begin{tabular}{|c|c|c|c|c|c|c|}
\hline & & Gender & $\begin{array}{c}\text { Menopause } \\
\text { Status }\end{array}$ & $\begin{array}{l}\text { YMCA } \\
\text { Member }\end{array}$ & $\begin{array}{l}\text { Diagnosed } \\
\text { with } \\
\text { Osteoporosis/ } \\
\text { Osteopenia }\end{array}$ & $\begin{array}{l}\text { If Diagnosed, Whether } \\
\text { Osteoporosis or Osteopenia }\end{array}$ \\
\hline \multirow[t]{3}{*}{$\mathrm{N}$} & Valid & 66 & 66 & 66 & 66 & 66 \\
\hline & Missing & 1 & 1 & $\mathbf{1}$ & 1 & 1 \\
\hline & & & $\begin{array}{l}\text { Past } \\
\text { steoporosis/ } \\
\text { Osteopenia } \\
\text { Med Use }\end{array}$ & $\begin{array}{r}\text { If Prescribed } \\
\text { Tak }\end{array}$ & $\begin{array}{l}\text { Meds, Still } \\
\text { ing }\end{array}$ & \\
\hline \multirow[t]{2}{*}{$\mathrm{N}$} & Valid & & 66 & & 66 & \\
\hline & Missing & & 1 & & 1 & \\
\hline
\end{tabular}

Table 2

Gender Data for the Osteoporosis Workshop

\begin{tabular}{|l|l|r|r|r|r|}
\hline \multicolumn{2}{|c|}{} & Frequency & Percent & Valid Percent & Cumulative Percent \\
\hline \multirow{4}{*}{ Valid } & Female & $\mathbf{6 1}$ & $\mathbf{9 1 . 0}$ & $\mathbf{9 2 . 4}$ & $\mathbf{9 2 . 4}$ \\
\cline { 2 - 6 } & Male & $\mathbf{5}$ & $\mathbf{7 . 5}$ & $\mathbf{7 . 6}$ & $\mathbf{1 0 0 . 0}$ \\
\cline { 2 - 6 } & Total & $\mathbf{6 6}$ & $\mathbf{9 8 . 5}$ & $\mathbf{1 0 0 . 0}$ & \\
\hline Missing & System & $\mathbf{1}$ & $\mathbf{1 . 5}$ & & \\
\hline \multicolumn{2}{|l|}{ Total } & $\mathbf{6 7}$ & $\mathbf{1 0 0 . 0}$ & & \\
\hline
\end{tabular}


Table 3

Menopause Status for the Osteoporosis Workshop

\begin{tabular}{|l|l|r|r|r|r|}
\hline \multicolumn{2}{|c|}{} & Frequency & Percent & Valid Percent & Cumulative Percent \\
\hline Valid & Menopausal & $\mathbf{5 9}$ & $\mathbf{8 8 . 1}$ & $\mathbf{8 9 . 4}$ & $\mathbf{8 9 . 4}$ \\
\cline { 2 - 6 } & $\begin{array}{l}\text { Non- } \\
\text { menopausal }\end{array}$ & $\mathbf{2}$ & $\mathbf{3 . 0}$ & $\mathbf{3 . 0}$ & $\mathbf{9 2 . 4}$ \\
\cline { 2 - 7 } & NA & $\mathbf{5}$ & $\mathbf{7 . 5}$ & $\mathbf{7 . 6}$ & $\mathbf{1 0 0 . 0}$ \\
\cline { 2 - 7 } & Total & $\mathbf{6 6}$ & $\mathbf{9 8 . 5}$ & $\mathbf{1 0 0 . 0}$ & \\
\hline Missing & System & $\mathbf{1}$ & $\mathbf{1 . 5}$ & & \\
\hline \multicolumn{2}{l|}{ Total } & $\mathbf{6 7}$ & $\mathbf{1 0 0 . 0}$ & & \\
\hline
\end{tabular}

Table 4

Fitness Center Membership Status for the Osteoporosis Workshop

\begin{tabular}{|c|c|c|c|c|c|}
\hline & & Frequency & Percent & $\begin{array}{l}\text { Valid } \\
\text { Percent }\end{array}$ & Cumulative Percent \\
\hline \multirow[t]{3}{*}{ Valid } & Yes & 36 & 53.7 & 54.5 & $\begin{array}{rr}54.5 \\
\end{array}$ \\
\hline & No & 30 & 44.8 & 45.5 & 100.0 \\
\hline & Total & 66 & 98.5 & 100.0 & \\
\hline Missing & System & 1 & 1.5 & & \\
\hline Total & & 67 & 100.0 & & \\
\hline
\end{tabular}


Table 5

Those Diagnosed with Osteoporosis/Osteopenia Attending the Osteoporosis Workshop

\begin{tabular}{|c|c|c|c|c|c|}
\hline & & Frequency & Percent & $\begin{array}{c}\text { Valid } \\
\text { Percent }\end{array}$ & Cumulative Percent \\
\hline \multirow[t]{3}{*}{ Valid } & Yes & 38 & 56.7 & 57.6 & $\mathbf{5 7 . 6}$ \\
\hline & No & 28 & 41.8 & 42.4 & 100.0 \\
\hline & Total & 66 & 98.5 & 100.0 & \\
\hline \multicolumn{2}{|c|}{\begin{tabular}{|l|l} 
Missing & System \\
Total
\end{tabular}} & 1 & 1.5 & & \\
\hline Total & & 67 & 100.0 & & \\
\hline
\end{tabular}

Table 6

If Diagnosed, Whether Osteoporosis or Osteopenia

\begin{tabular}{|c|c|c|c|c|c|}
\hline & & $\begin{array}{c}\text { Frequenc } \\
\mathrm{y}\end{array}$ & Percent & $\begin{array}{l}\text { Valid } \\
\text { Percent }\end{array}$ & Cumulative Percent \\
\hline \multirow[t]{4}{*}{ Valid } & Osteoporosis & 24 & 35.8 & 36.4 & 36.4 \\
\hline & Osteopenia & 14 & 20.9 & 21.2 & 57.6 \\
\hline & NA & 28 & 41.8 & 42.4 & 100.0 \\
\hline & Total & 66 & 98.5 & 100.0 & \\
\hline Missing & System & 1 & 1.5 & & \\
\hline \multicolumn{2}{|c|}{ Total } & 67 & 100.0 & & \\
\hline
\end{tabular}

Table 7

Past Osteoporosis/Osteopenia Medication Use

\begin{tabular}{|c|c|c|c|c|c|}
\hline & & Frequency & Percent & $\begin{array}{c}\text { Valid } \\
\text { Percent }\end{array}$ & Cumulative Percent \\
\hline \multirow[t]{3}{*}{ Valid } & Yes & 33 & 49.3 & 50.0 & 50.0 \\
\hline & No & 33 & 49.3 & 50.0 & 100.0 \\
\hline & Total & 66 & 98.5 & 100.0 & \\
\hline Missing & System & 1 & 1.5 & & \\
\hline \multicolumn{2}{|c|}{ Total } & 67 & 100.0 & & \\
\hline
\end{tabular}


Table 8

If Prescribed Medications for Osteoporosis/Osteopenia, Are They Still Being Taken

\begin{tabular}{|l|l|r|r|r|r|}
\hline \multicolumn{2}{|c|}{} & Frequency & Percent & $\begin{array}{c}\text { Valid } \\
\text { Percent }\end{array}$ & Cumulative Percent \\
\hline \multirow{3}{*}{ Valid } & Yes & $\mathbf{1 5}$ & $\mathbf{2 2 . 4}$ & $\mathbf{2 2 . 7}$ & $\mathbf{2 2 . 7}$ \\
\cline { 2 - 6 } & No & $\mathbf{2 0}$ & $\mathbf{2 9 . 9}$ & $\mathbf{3 0 . 3}$ & $\mathbf{5 3 . 0}$ \\
\cline { 2 - 6 } & NA & $\mathbf{3 1}$ & $\mathbf{4 6 . 3}$ & $\mathbf{4 7 . 0}$ & $\mathbf{1 0 0 . 0}$ \\
\cline { 2 - 6 } & Total & $\mathbf{6 6}$ & $\mathbf{9 8 . 5}$ & $\mathbf{1 0 0 . 0}$ & \\
\hline Missing & System & $\mathbf{1}$ & $\mathbf{1 . 5}$ & & \\
\hline \multicolumn{2}{|l|}{ Total } & $\mathbf{6 7}$ & $\mathbf{1 0 0 . 0}$ & & \\
\hline
\end{tabular}

Table 9

Wilcoxon Signed Rank Test (Descriptive Statistics) for Meeting Personal Bone Healthy Goals

\begin{tabular}{|l|r|r|r|r|}
\hline \multirow{2}{*}{} & \multirow{2}{*}{} & \multicolumn{3}{|c|}{ Percentiles } \\
\cline { 2 - 5 } & $\mathrm{N}$ & 25 th & $\begin{array}{c}\text { 50th } \\
\text { (Median) }\end{array}$ & 75th \\
\hline $\begin{array}{l}\text { Meeting Personal Bone } \\
\text { Healthy Goals }\end{array}$ & $\mathbf{6 5}$ & $\mathbf{2 . 0 0}$ & $\mathbf{3 . 0 0}$ & $\mathbf{4 . 0 0}$ \\
\hline $\begin{array}{l}\text { One Month Post } \\
\text { Meeting Personal Bone } \\
\text { Healthy Goals }\end{array}$ & $\mathbf{5 8}$ & $\mathbf{3 . 0 0}$ & $\mathbf{4 . 0 0}$ & $\mathbf{4 . 0 0}$ \\
\hline
\end{tabular}


Table 10

Wilcoxon Signed Rank Test for Meeting Personal Bone Healthy Goals

\begin{tabular}{|l|l|r|r|r|}
\hline \multicolumn{2}{|l|}{} & $\mathrm{N}$ & \multicolumn{1}{c|}{$\begin{array}{c}\text { Rean } \\
\text { Rank }\end{array}$} & $\begin{array}{c}\text { Sum of } \\
\text { Ranks }\end{array}$ \\
\hline $\begin{array}{l}\text { One Month Post } \\
\text { Meeting Personal Bone }\end{array}$ & $\begin{array}{l}\text { Negative } \\
\text { Realthy Goals - } \\
\text { Reans } \\
\text { Meeting Personal Bone } \\
\text { Healthy Goals }\end{array}$ & $\mathbf{2 5}^{\mathbf{a}}$ & $\mathbf{1 7 . 0 8}$ & $\mathbf{4 2 7 . 0 0}$ \\
\cline { 2 - 5 } & Positive & $\mathbf{7}^{\mathbf{b}}$ & $\mathbf{1 4 . 4 3}$ & $\mathbf{1 0 1 . 0 0}$ \\
\cline { 2 - 5 } & Ranks & & & \\
\cline { 2 - 6 } & Ties & $\mathbf{2 4}^{\mathbf{c}}$ & & \\
\hline
\end{tabular}

a. One Month Post Meeting Personal Bone Healthy Goals < Meeting Personal Bone Healthy Goals

b. One Month Post Meeting Personal Bone Healthy Goals > Meeting Personal Bone Healthy Goals

c. One Month Post Meeting Personal Bone Healthy Goals = Meeting Personal Bone Healthy Goals

\begin{tabular}{|l|c|}
\hline & $\begin{array}{c}\text { One Month Post Meeting } \\
\text { Personal Bone Healthy Goals } \\
\text { - Meeting Personal Bone } \\
\text { Healthy Goals }\end{array}$ \\
\hline Z & \multicolumn{2}{|c|}{$\mathbf{- 3 . 1 4 8}$} \\
\hline $\begin{array}{l}\text { Asymp. Sig. } \\
\text { (2-tailed) }\end{array}$ & $\mathbf{. 0 0 2}$ \\
\hline
\end{tabular}

a. Based on negative ranks.

b. Wilcoxon Signed Ranks Test 
Table 11

Statistics for Meeting Personal Bone Healthy Goals Pre-Intervention

\begin{tabular}{|l|l|r|r|r|r|}
\hline \multicolumn{2}{|c|}{} & Frequency & Percent & $\begin{array}{c}\text { Valid } \\
\text { Percent }\end{array}$ & Cumulative Percent \\
\hline Valid & Never Meeting Goals & $\mathbf{2}$ & $\mathbf{3 . 0}$ & $\mathbf{3 . 1}$ & $\mathbf{3 . 1}$ \\
\cline { 2 - 6 } & $\begin{array}{l}\text { Seldom Meeting } \\
\text { Goals }\end{array}$ & $\mathbf{2 0}$ & $\mathbf{2 9 . 9}$ & $\mathbf{3 0 . 8}$ & $\mathbf{3 3 . 8}$ \\
\cline { 2 - 6 } & $\begin{array}{l}\text { Meeting Goals About } \\
\text { Half the Time }\end{array}$ & $\mathbf{1 8}$ & $\mathbf{2 6 . 9}$ & $\mathbf{2 7 . 7}$ & $\mathbf{6 1 . 5}$ \\
\cline { 2 - 7 } & $\begin{array}{l}\text { Usually Meeting } \\
\text { Goals }\end{array}$ & $\mathbf{1 9}$ & $\mathbf{2 8 . 4}$ & $\mathbf{2 9 . 2}$ & $\mathbf{9 0 . 8}$ \\
\cline { 2 - 7 } & $\begin{array}{l}\text { Always Meeting } \\
\text { Goals }\end{array}$ & $\mathbf{6}$ & $\mathbf{9 . 0}$ & $\mathbf{9 . 2}$ & $\mathbf{1 0 0 . 0}$ \\
\cline { 2 - 6 } & Total & $\mathbf{6 5}$ & $\mathbf{9 7 . 0}$ & $\mathbf{1 0 0 . 0}$ & \\
\hline Missing & System & $\mathbf{2}$ & $\mathbf{3 . 0}$ & & \\
\hline Total & & $\mathbf{6 7}$ & $\mathbf{1 0 0 . 0}$ & & \\
\hline
\end{tabular}


Table 12

Statistics for Meeting Personal Bone Healthy Goals One Month Post-Intervention

\begin{tabular}{|c|c|c|c|c|c|}
\hline & & Frequency & Percent & $\begin{array}{c}\text { Valid } \\
\text { Percent } \\
\end{array}$ & Cumulative Percent \\
\hline \multirow[t]{6}{*}{ Valid } & Never Meeting Goals & 1 & 1.5 & 1.7 & 1.7 \\
\hline & $\begin{array}{l}\text { Seldom Meeting } \\
\text { Goals }\end{array}$ & 4 & 6.0 & 6.9 & 8.6 \\
\hline & $\begin{array}{l}\text { Meeting Goals About } \\
\text { Half the Time }\end{array}$ & 14 & 20.9 & 24.1 & 32.8 \\
\hline & Usually Meet Goals & 34 & 50.7 & 58.6 & 91.4 \\
\hline & Always Meet Goals & 5 & 7.5 & 8.6 & 100.0 \\
\hline & Total & 58 & 86.6 & 100.0 & \\
\hline Missing & System & 9 & 13.4 & & \\
\hline \multicolumn{2}{|l|}{ Total } & 67 & 100.0 & & \\
\hline
\end{tabular}




\section{Appendix X}

Descriptive Statistics for the OKAT

Table 1

ANOVA Analysis for the OKAT within Subjects Factors

Measure:MEASURE_1

\begin{tabular}{|l|l|}
\hline OKAT & \multicolumn{1}{|c|}{ Dependent Variable } \\
\hline 1 & OKATBT \\
\hline 2 & OKATPT \\
\hline 3 & OKATOT \\
\hline
\end{tabular}

Table 2

ANOVA Analysis for the OKAT Descriptive Statistics

\begin{tabular}{|l|r|r|r|}
\hline & Mean & Std. Deviation & N \\
\hline $\begin{array}{l}\text { OKAT Pre- } \\
\text { Intervention Total }\end{array}$ & $\mathbf{1 0 . 4 0}$ & $\mathbf{3 . 3 3 1}$ & $\mathbf{4 8}$ \\
\hline $\begin{array}{l}\text { OKAT } \\
\text { Immediately-Post } \\
\text { Total }\end{array}$ & $\mathbf{1 4 . 2 3}$ & $\mathbf{3 . 8 9 9}$ & $\mathbf{4 8}$ \\
\hline $\begin{array}{l}\text { OKAT One-Month } \\
\text { Post Total }\end{array}$ & $\mathbf{1 4 . 0 6}$ & $\mathbf{2 . 5 1 3}$ & $\mathbf{4 8}$ \\
\hline
\end{tabular}


Table 3

ANOVA Analysis for the OKAT-Multivariate Tests

Multivariate Tests ${ }^{b}$

\begin{tabular}{|c|c|c|c|c|c|c|c|}
\hline \multicolumn{2}{|l|}{ Effect } & Value & $\mathrm{F}$ & $\begin{array}{c}\text { Hypothesis } \\
\text { df }\end{array}$ & Error df & Sig. & $\begin{array}{c}\text { Partial Eta } \\
\text { Squared }\end{array}$ \\
\hline \multirow{4}{*}{$\begin{array}{l}\text { OKA } \\
\mathrm{T}\end{array}$} & Pillai's Trace & .606 & $35.412^{a}$ & 2.000 & 46.000 & .000 & .606 \\
\hline & $\begin{array}{l}\text { Wilks' } \\
\text { Lambda }\end{array}$ & .394 & $35.412^{\mathrm{a}}$ & 2.000 & 46.000 & .000 & .606 \\
\hline & $\begin{array}{l}\text { Hotelling's } \\
\text { Trace }\end{array}$ & 1.540 & $35.412^{\mathrm{a}}$ & 2.000 & 46.000 & .000 & .606 \\
\hline & $\begin{array}{l}\text { Roy's Largest } \\
\text { Root }\end{array}$ & 1.540 & $35.412^{\mathrm{a}}$ & 2.000 & 46.000 & .000 & .606 \\
\hline
\end{tabular}

a. Exact statistic

b. Design: Intercept

Within Subjects Design: OKAT

Table 4

Mauchly's Test of Sphericity (b) for the OKAT

Measure:MEASURE_1

\begin{tabular}{|c|c|c|c|c|c|c|c|}
\hline \multirow{2}{*}{$\begin{array}{l}\text { Within Subjects } \\
\text { Effect }\end{array}$} & \multirow[b]{2}{*}{$\begin{array}{c}\text { Mauchly's } \\
\text { W }\end{array}$} & \multirow[b]{2}{*}{$\begin{array}{c}\text { Approx. Chi- } \\
\text { Square }\end{array}$} & \multirow[b]{2}{*}{ df } & \multirow[b]{2}{*}{ Sig. } & \multicolumn{3}{|c|}{ Epsilon $^{\mathrm{a}}$} \\
\hline & & & & & $\begin{array}{c}\text { Greenhouse- } \\
\text { Geisser }\end{array}$ & $\begin{array}{c}\text { Huynh- } \\
\text { Feldt }\end{array}$ & $\begin{array}{l}\text { Lower- } \\
\text { bound }\end{array}$ \\
\hline \begin{tabular}{r|l} 
dimensio & OKA \\
$\mathrm{n} 1$ & $\mathrm{~T}$
\end{tabular} & .826 & 8.767 & 2 & .012 & .852 & .881 & .500 \\
\hline
\end{tabular}

Tests the null hypothesis that the error covariance matrix of the orthonormalized transformed dependent variables is proportional to an identity matrix.

a. May be used to adjust the degrees of freedom for the averaged tests of significance. Corrected tests are displayed in the Tests of Within-Subjects Effects table.

b. Design: Intercept

Within Subjects Design: OKAT 
Table 5

Tests of Within-Subjects Effects for Osteoporosis Knowledge

Measure:MEASURE_1

\begin{tabular}{|c|c|c|c|c|c|c|c|}
\hline Source & & $\begin{array}{c}\text { Type III Sum } \\
\text { of Squares }\end{array}$ & Df & $\begin{array}{c}\text { Mean } \\
\text { Square }\end{array}$ & $\mathrm{F}$ & Sig. & $\begin{array}{c}\text { Partial Eta } \\
\text { Squared }\end{array}$ \\
\hline \multirow[t]{4}{*}{ OKAT } & $\begin{array}{l}\text { Sphericity } \\
\text { Assumed }\end{array}$ & 450.667 & 2 & 225.333 & 26.880 & .000 & .364 \\
\hline & $\begin{array}{l}\text { Greenhouse- } \\
\text { Geisser }\end{array}$ & 450.667 & 1.704 & 264.433 & 26.880 & .000 & .364 \\
\hline & Huynh-Feldt & 450.667 & 1.762 & 254.338 & 26.880 & .000 & .364 \\
\hline & Lower-bound & 450.667 & 1.000 & 450.667 & 26.880 & .000 & .364 \\
\hline \multirow[t]{4}{*}{$\begin{array}{l}\text { Error }(\mathrm{OK} \\
\mathrm{AT})\end{array}$} & $\begin{array}{l}\text { Sphericity } \\
\text { Assumed }\end{array}$ & 788.000 & 94 & 8.383 & & & \\
\hline & $\begin{array}{l}\text { Greenhouse- } \\
\text { Geisser }\end{array}$ & 788.000 & 80.101 & 9.838 & & & \\
\hline & Huynh-Feldt & 788.000 & 82.808 & 9.516 & & & \\
\hline & Lower-bound & 788.000 & 47.000 & 16.766 & & & \\
\hline
\end{tabular}

Table 6

Tests of Within-Subjects Contrast for the OKAT

Measure:MEASURE_1

\begin{tabular}{|c|c|c|c|c|c|c|c|}
\hline Source & OKAT & $\begin{array}{c}\text { Type III Sum of } \\
\text { Squares }\end{array}$ & $\mathrm{df}$ & $\begin{array}{l}\text { Mean } \\
\text { Square }\end{array}$ & $\mathrm{F}$ & Sig. & $\begin{array}{c}\text { Partial Eta } \\
\text { Squared }\end{array}$ \\
\hline \multirow[t]{2}{*}{ OKAT } & Linear & 322.667 & 1 & 322.667 & 65.274 & .000 & .581 \\
\hline & Quadratic & 128.000 & 1 & 128.000 & 10.827 & .002 & .187 \\
\hline \multirow{2}{*}{$\begin{array}{l}\text { Error }(\mathrm{OK} \\
\mathrm{AT})\end{array}$} & Linear & 232.333 & 47 & 4.943 & & & \\
\hline & Quadratic & 555.667 & 47 & 11.823 & & & \\
\hline
\end{tabular}


Table 7

Tests of Between-Subjects Effects for the OKAT

Measure:MEASURE_1

Transformed Variable: Average

\begin{tabular}{|l|r|r|c|c|r|r|}
\hline Source & $\begin{array}{c}\text { Type III Sum of } \\
\text { Squares }\end{array}$ & df & $\begin{array}{c}\text { Mean } \\
\text { Square }\end{array}$ & F & Sig. & Partial Eta Squared \\
\hline Intercept & $\mathbf{2 3 9 4 7 . 5 6 3}$ & $\mathbf{1}$ & $\mathbf{2 3 9 4 7 . 5 6}$ & $\mathbf{1 5 1 1 . 2 5 1}$ & $\mathbf{. 0 0 0}$ & $\mathbf{9 7 0}$ \\
\hline Error & & & & & & \\
\hline
\end{tabular}

Table 8

ANOVA-Estimates for the OKAT

Measure:MEASURE_1

\begin{tabular}{|c|c|c|c|c|}
\hline \multirow[t]{2}{*}{ OKAT } & \multirow[b]{2}{*}{ Mean } & \multirow[b]{2}{*}{ Std. Error } & \multicolumn{2}{|c|}{ 95\% Confidence Interval } \\
\hline & & & Lower Bound & Upper Bound \\
\hline 1 & 10.396 & 481 & 9.429 & 11.363 \\
\hline 2 & 14.292 & .563 & 13.097 & 15.361 \\
\hline 3 & 14.063 & .363 & 13.333 & 14.792 \\
\hline
\end{tabular}


Table 9

Pairwise Comparisons for the OKAT

Measure:MEASURE_1

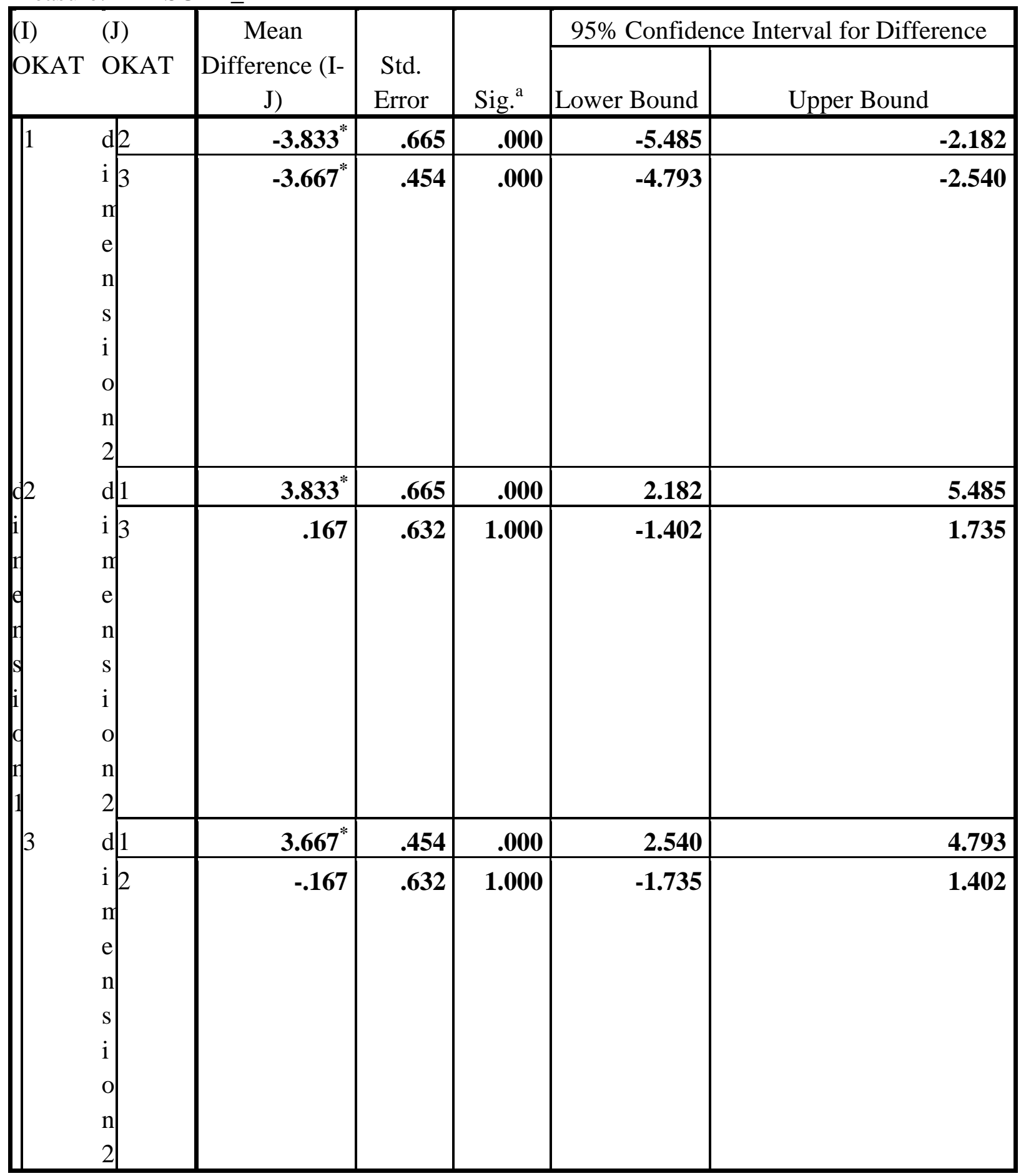

Based on estimated marginal means

*. The mean difference is significant at the .05 level. 
Measure:MEASURE_1

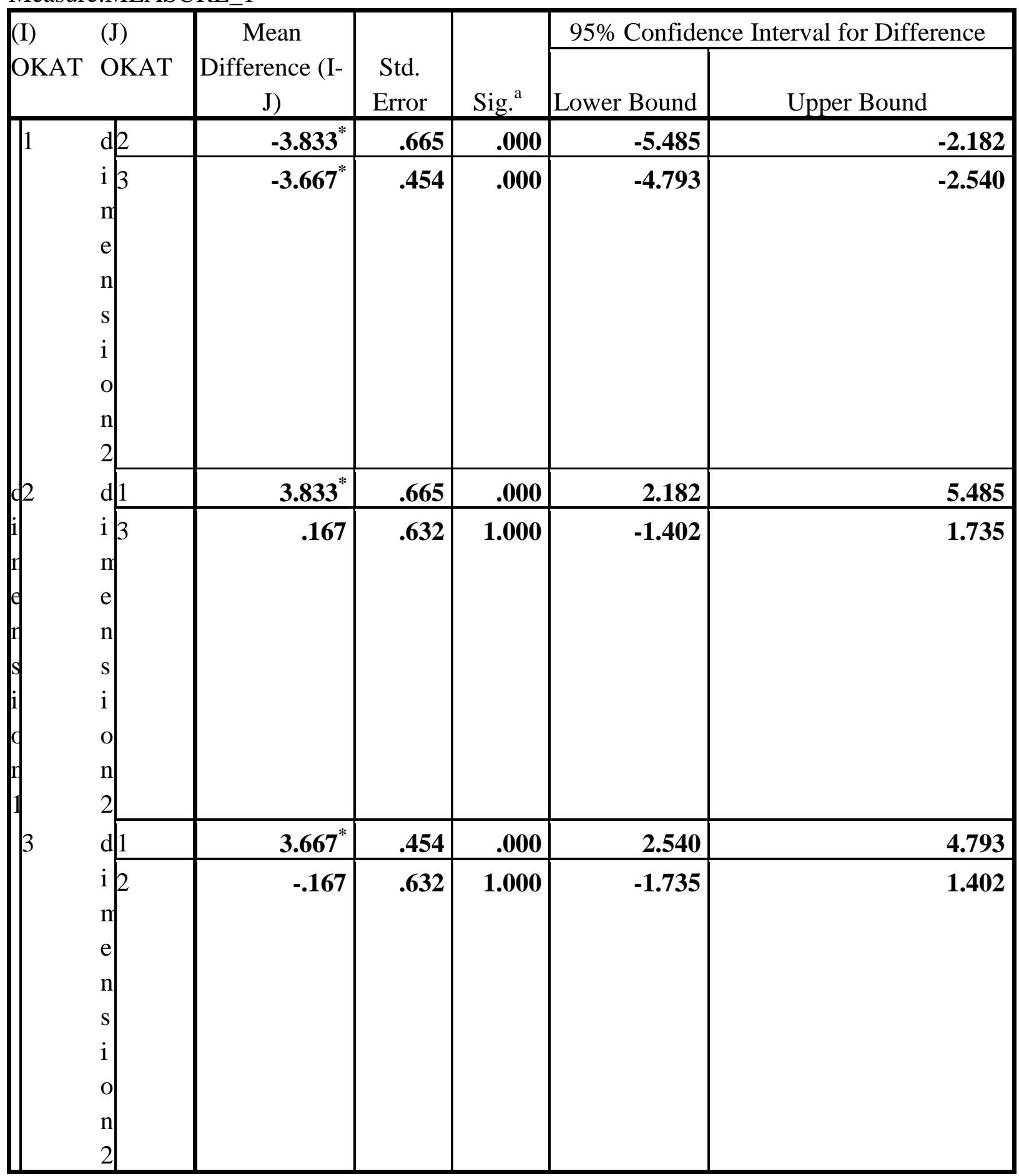

Based on estimated marginal means

*. The mean difference is significant at the .05 level.

a. Adjustment for multiple comparisons: Bonferroni. 
Table 10

Multivariate Tests for the OKAT

\begin{tabular}{|l|r|r|r|r|r|r|}
\hline & Value & \multicolumn{1}{|c|}{ F } & $\begin{array}{c}\text { Hypothesis } \\
\text { df }\end{array}$ & Error df & Sig. & \multicolumn{2}{|c|}{$\begin{array}{c}\text { Partial Eta } \\
\text { Squared }\end{array}$} \\
\hline Pillai's trace & $\mathbf{. 6 0 6}$ & $\mathbf{3 5 . 4 1 2}^{\mathrm{a}}$ & $\mathbf{2 . 0 0 0}$ & $\mathbf{4 6 . 0 0 0}$ & $\mathbf{. 0 0 0}$ & $\mathbf{. 6 0 6}$ \\
\hline $\begin{array}{l}\text { Wilks' } \\
\text { lambda }\end{array}$ & $\mathbf{. 3 9 4}$ & $\mathbf{3 5 . 4 1 2}$ & $\mathbf{2 . 0 0 0}$ & $\mathbf{4 6 . 0 0 0}$ & $\mathbf{. 0 0 0}$ & $\mathbf{. 6 0 6}$ \\
\hline $\begin{array}{l}\text { Hotelling's } \\
\text { trace }\end{array}$ & $\mathbf{1 . 5 4 0}$ & $\mathbf{3 5 . 4 1 2}$ & $\mathbf{2 . 0 0 0}$ & $\mathbf{4 6 . 0 0 0}$ & $\mathbf{. 0 0 0}$ & $\mathbf{. 6 0 6}$ \\
\hline $\begin{array}{l}\text { Roy's largest } \\
\text { root }\end{array}$ & $\mathbf{1 . 5 4 0}$ & $\mathbf{3 5 . 4 1 2}$ & $\mathbf{2 . 0 0 0}$ & $\mathbf{4 6 . 0 0 0}$ & $\mathbf{. 0 0 0}$ & $\mathbf{. 6 0 6}$ \\
\hline
\end{tabular}

Each F tests the multivariate effect of OKAT. These tests are based on the linearly independent pairwise comparisons among the estimated marginal means.

a. Exact statistic

Table 11

Valid and Missing Data for the OKAT at Pre-Intervention, Immediately Post-Intervention and One Month Post-Intervention

\begin{tabular}{|c|c|c|c|c|c|c|}
\hline & & $\begin{array}{c}\text { OKAT Q1 } \\
\text { Pre-Int }\end{array}$ & $\begin{array}{c}\text { OKAT } \\
\text { Q2 Pre- } \\
\text { Int }\end{array}$ & $\begin{array}{c}\text { OKAT Q3 Pre- } \\
\text { Int }\end{array}$ & $\begin{array}{c}\text { OKAT Q4 } \\
\text { Pre-Int } \\
\end{array}$ & OKAT Q5 Pre-Int \\
\hline \multirow[t]{2}{*}{$\mathrm{N}$} & Valid & 64 & 64 & 64 & 64 & 64 \\
\hline & Missing & 3 & 3 & 3 & 3 & 3 \\
\hline
\end{tabular}

\begin{tabular}{|c|l|r|r|r|r|r|}
\hline \multicolumn{2}{|c|}{} & $\begin{array}{c}\text { OKAT Q6 } \\
\text { Pre-Int }\end{array}$ & $\begin{array}{c}\text { OKAT Q7 } \\
\text { Pre-Int }\end{array}$ & $\begin{array}{l}\text { OKAT Q8 } \\
\text { Pre-Int }\end{array}$ & $\begin{array}{c}\text { OKAT Q9 } \\
\text { Pre-Int }\end{array}$ & OKAT Q10 Pre-Int \\
\hline \multirow{N}{*}{ P } & Valid & $\mathbf{6 4}$ & $\mathbf{6 4}$ & $\mathbf{6 4}$ & $\mathbf{6 4}$ & $\mathbf{6 4}$ \\
\cline { 2 - 8 } & Missing & $\mathbf{3}$ & $\mathbf{3}$ & $\mathbf{3}$ & $\mathbf{3}$ & $\mathbf{3}$ \\
\hline
\end{tabular}




\begin{tabular}{|l|l|r|r|r|r|r|}
\hline \multicolumn{2}{|c|}{} & $\begin{array}{l}\text { OKAT Q11 } \\
\text { Pre-Int }\end{array}$ & $\begin{array}{l}\text { OKAT Q12 } \\
\text { Pre-Int }\end{array}$ & $\begin{array}{l}\text { OKAT Q13 } \\
\text { Pre-Int }\end{array}$ & $\begin{array}{l}\text { OKAT Q14 } \\
\text { Pre-Int }\end{array}$ & $\begin{array}{l}\text { OKAT Q15 } \\
\text { Pre-Int }\end{array}$ \\
\hline \multirow{N}{*}{$\mathbf{N}$} & Valid & $\mathbf{6 4}$ & $\mathbf{6 4}$ & $\mathbf{6 4}$ & $\mathbf{6 4}$ & $\mathbf{6 4}$ \\
\cline { 2 - 7 } & Missing & $\mathbf{3}$ & $\mathbf{3}$ & $\mathbf{3}$ & $\mathbf{3}$ & $\mathbf{3}$ \\
\hline
\end{tabular}

\begin{tabular}{|l|l|r|r|r|r|r|}
\hline \multicolumn{2}{|c|}{} & $\begin{array}{l}\text { OKAT Q16 } \\
\text { Pre-Int }\end{array}$ & $\begin{array}{c}\text { OKAT Q17 } \\
\text { Pre-Int }\end{array}$ & $\begin{array}{c}\text { OKAT Q18 } \\
\text { Pre-Int }\end{array}$ & $\begin{array}{l}\text { OKAT Q19 } \\
\text { Pre-Int }\end{array}$ & $\begin{array}{l}\text { OKAT Q20 } \\
\text { Pre-Int }\end{array}$ \\
\hline \multirow{N}{*}{$\mathbf{N}$} & Valid & $\mathbf{6 4}$ & $\mathbf{6 4}$ & $\mathbf{6 4}$ & $\mathbf{6 4}$ & $\mathbf{6 4}$ \\
\cline { 2 - 7 } & Missing & $\mathbf{3}$ & $\mathbf{3}$ & $\mathbf{3}$ & $\mathbf{3}$ & $\mathbf{3}$ \\
\hline
\end{tabular}

\begin{tabular}{|l|l|r|r|r|r|r|}
\hline \multicolumn{2}{|c|}{} & $\begin{array}{c}\text { OKAT Pre- } \\
\text { Int Total }\end{array}$ & $\begin{array}{c}\text { OKAT Q1 } \\
\text { Immed-Post }\end{array}$ & $\begin{array}{c}\text { OKAT Q2 } \\
\text { Immed-Post }\end{array}$ & $\begin{array}{c}\text { OKAT Q3 } \\
\text { Immed-Post }\end{array}$ & $\begin{array}{c}\text { OKAT Q4 } \\
\text { Immed-Post }\end{array}$ \\
\hline \multirow{2}{*}{\begin{tabular}{l} 
Im \\
\cline { 2 - 7 }
\end{tabular}} & Valid & $\mathbf{6 4}$ & $\mathbf{5 4}$ & $\mathbf{5 4}$ & $\mathbf{5 4}$ & $\mathbf{5 4}$ \\
\cline { 2 - 7 } & Missing & $\mathbf{3}$ & $\mathbf{1 3}$ & $\mathbf{1 3}$ & $\mathbf{1 3}$ & $\mathbf{1 3}$ \\
\hline
\end{tabular}

\begin{tabular}{|l|l|r|r|r|r|r|}
\hline \multicolumn{2}{|c|}{} & $\begin{array}{c}\text { OKAT Q5 } \\
\text { Immed-Post }\end{array}$ & $\begin{array}{c}\text { OKAT Q6 } \\
\text { Immed-Post }\end{array}$ & $\begin{array}{c}\text { OKAT Q7 } \\
\text { Immed-Post }\end{array}$ & $\begin{array}{c}\text { OKAT Q8 } \\
\text { Immed-Post }\end{array}$ & $\begin{array}{c}\text { OKAT Q9 } \\
\text { Immed-Post }\end{array}$ \\
\hline \multirow{N}{*}{\begin{tabular}{l} 
Im \\
\cline { 2 - 7 }
\end{tabular}} & Valid & $\mathbf{5 4}$ & $\mathbf{5 4}$ & $\mathbf{5 4}$ & $\mathbf{5 4}$ & $\mathbf{5 4}$ \\
\cline { 2 - 7 } & Missing & $\mathbf{1 3}$ & $\mathbf{1 3}$ & $\mathbf{1 3}$ & $\mathbf{1 3}$ & $\mathbf{1 3}$ \\
\hline
\end{tabular}

\begin{tabular}{|l|l|r|r|r|r|r|}
\hline \multicolumn{2}{|c|}{} & $\begin{array}{l}\text { OKAT Q10 } \\
\text { Immed-Post }\end{array}$ & $\begin{array}{l}\text { OKAT Q11 } \\
\text { Immed-Post }\end{array}$ & $\begin{array}{l}\text { OKAT Q12 } \\
\text { Immed-Post }\end{array}$ & $\begin{array}{l}\text { OKAT Q13 } \\
\text { Immed-Post }\end{array}$ & $\begin{array}{l}\text { OKAT Q14 } \\
\text { Immed-Post }\end{array}$ \\
\hline \multirow{N}{*}{\begin{tabular}{l} 
Im \\
\cline { 2 - 7 }
\end{tabular}} & Valid & $\mathbf{5 4}$ & $\mathbf{5 4}$ & $\mathbf{5 4}$ & $\mathbf{5 4}$ & $\mathbf{5 4}$ \\
\cline { 2 - 7 } & Missing & $\mathbf{1 3}$ & $\mathbf{1 3}$ & $\mathbf{1 3}$ & $\mathbf{1 3}$ & $\mathbf{1 3}$ \\
\hline
\end{tabular}

\begin{tabular}{|c|c|r|r|r|r|r|}
\hline \multicolumn{2}{|c|}{} & $\begin{array}{c}\text { OKAT Q15 } \\
\text { Immed- } \\
\text { Post }\end{array}$ & $\begin{array}{c}\text { OKAT Q16 } \\
\text { Immed-Post }\end{array}$ & $\begin{array}{c}\text { OKAT Q17 } \\
\text { Immed-Post }\end{array}$ & $\begin{array}{c}\text { OKAT Q18 } \\
\text { Immed-Post }\end{array}$ & $\begin{array}{c}\text { OKAT Q19 } \\
\text { Immed-Post }\end{array}$ \\
\hline $\mathbf{N}$ & Valid & $\mathbf{5 4}$ & $\mathbf{5 4}$ & $\mathbf{5 4}$ & $\mathbf{5 4}$ & $\mathbf{5 4}$ \\
\cline { 2 - 8 } & Missing & $\mathbf{1 3}$ & $\mathbf{1 3}$ & $\mathbf{1 3}$ & $\mathbf{1 3}$ & $\mathbf{1 3}$ \\
\hline
\end{tabular}




\begin{tabular}{|l|r|r|r|r|r|r|}
\hline \multicolumn{2}{|c|}{} & $\begin{array}{c}\text { OKAT Q20 } \\
\text { Immed-Post }\end{array}$ & $\begin{array}{c}\text { OKAT } \\
\text { Immed-Post } \\
\text { Total }\end{array}$ & $\begin{array}{c}\text { OKAT Q1 } \\
\text { One-Month } \\
\text { Post }\end{array}$ & $\begin{array}{c}\text { OKAT Q2 } \\
\text { One-Month } \\
\text { Post }\end{array}$ & $\begin{array}{c}\text { OKAT Q3 } \\
\text { One-Month } \\
\text { Post }\end{array}$ \\
\hline $\mathbf{N}$ & Valid & $\mathbf{5 4}$ & $\mathbf{5 7}$ & $\mathbf{5 7}$ & $\mathbf{5 7}$ & $\mathbf{5 7}$ \\
\cline { 2 - 8 } & Missing & $\mathbf{1 3}$ & $\mathbf{1 0}$ & $\mathbf{1 0}$ & $\mathbf{1 0}$ & $\mathbf{1 0}$ \\
\hline
\end{tabular}

\begin{tabular}{|l|l|r|r|r|r|r|}
\hline \multicolumn{2}{|c|}{} & $\begin{array}{c}\text { OKAT Q4 } \\
\text { One-Month } \\
\text { Post }\end{array}$ & $\begin{array}{c}\text { OKAT Q5 } \\
\text { One-Month } \\
\text { Post }\end{array}$ & $\begin{array}{c}\text { OKAT Q6 } \\
\text { One-Month } \\
\text { Post }\end{array}$ & $\begin{array}{c}\text { OKAT Q7 } \\
\text { One-Month } \\
\text { Post }\end{array}$ & $\begin{array}{c}\text { OKAT Q8 } \\
\text { One-Month } \\
\text { Post }\end{array}$ \\
\hline $\mathbf{N}$ & Valid & $\mathbf{5 7}$ & $\mathbf{5 7}$ & $\mathbf{5 7}$ & $\mathbf{5 7}$ & $\mathbf{5 7}$ \\
\cline { 2 - 8 } & Missing & $\mathbf{1 0}$ & $\mathbf{1 0}$ & $\mathbf{1 0}$ & $\mathbf{1 0}$ & $\mathbf{1 0}$ \\
\hline
\end{tabular}

\begin{tabular}{|c|l|r|r|r|r|r|}
\hline \multicolumn{2}{|c|}{} & $\begin{array}{c}\text { OKAT Q9 } \\
\text { One-Month } \\
\text { Post }\end{array}$ & $\begin{array}{l}\text { OKAT Q10 } \\
\text { One-Month } \\
\text { Post }\end{array}$ & $\begin{array}{l}\text { OKAT Q11 } \\
\text { One-Month } \\
\text { Post }\end{array}$ & $\begin{array}{l}\text { OKAT Q12 } \\
\text { One-Month } \\
\text { Post }\end{array}$ & $\begin{array}{c}\text { OKAT Q13 } \\
\text { One-Month } \\
\text { Post }\end{array}$ \\
\hline \multirow{2}{*}{$\mathbf{5}$} & Valid & $\mathbf{5 7}$ & $\mathbf{5 7}$ & $\mathbf{5 7}$ & $\mathbf{5 7}$ & $\mathbf{5 7}$ \\
\cline { 2 - 8 } & Missing & $\mathbf{1 0}$ & $\mathbf{1 0}$ & $\mathbf{1 0}$ & $\mathbf{1 0}$ & $\mathbf{1 0}$ \\
\hline
\end{tabular}

\begin{tabular}{|l|l|r|r|r|r|r|}
\hline \multicolumn{2}{|c|}{} & $\begin{array}{l}\text { OKAT Q14 } \\
\text { One-Month } \\
\text { Post }\end{array}$ & $\begin{array}{l}\text { OKAT Q15 } \\
\text { One-Month } \\
\text { Post }\end{array}$ & $\begin{array}{l}\text { OKAT Q16 } \\
\text { One-Month } \\
\text { Post }\end{array}$ & $\begin{array}{l}\text { OKAT Q17 } \\
\text { One-Month } \\
\text { Post }\end{array}$ & $\begin{array}{l}\text { OKAT Q18 } \\
\text { One-Month } \\
\text { Post }\end{array}$ \\
\hline $\mathbf{N}$ & Valid & $\mathbf{5 7}$ & $\mathbf{5 7}$ & $\mathbf{5 7}$ & $\mathbf{5 7}$ & $\mathbf{5 7}$ \\
\cline { 2 - 8 } & Missing & $\mathbf{1 0}$ & $\mathbf{1 0}$ & $\mathbf{1 0}$ & $\mathbf{1 0}$ & $\mathbf{1 0}$ \\
\hline
\end{tabular}

\begin{tabular}{|l|l|r|r|r|}
\hline \multicolumn{2}{|c|}{} & $\begin{array}{l}\text { OKAT Q19 } \\
\text { One-Month } \\
\text { Post }\end{array}$ & $\begin{array}{l}\text { OKAT Q20 } \\
\text { One-Month } \\
\text { Post }\end{array}$ & $\begin{array}{l}\text { OKAT One- } \\
\text { Month Post } \\
\text { Total }\end{array}$ \\
\hline $\mathrm{N}$ & Valid & $\mathbf{5 7}$ & $\mathbf{5 7}$ & $\mathbf{5 7}$ \\
\cline { 2 - 5 } & Missing & $\mathbf{1 0}$ & $\mathbf{1 0}$ & $\mathbf{1 0}$ \\
\hline
\end{tabular}


Table 12

Frequency Data for OKAT Questions Pre-Intervention

OKAT Q1 Pre-Intervention

\begin{tabular}{|l|l|r|r|r|r|}
\hline \multicolumn{2}{|c|}{} & $\begin{array}{c}\text { Frequenc } \\
\text { y }\end{array}$ & Percent & Valid Percent & \multicolumn{2}{|c|}{ Cumulative Percent } \\
\hline \multirow{3}{*}{ Valid } & Incorrect & $\mathbf{4}$ & $\mathbf{6 . 0}$ & $\mathbf{6 . 3}$ & $\mathbf{6 . 3}$ \\
\cline { 2 - 7 } & Correct & $\mathbf{6 0}$ & $\mathbf{8 9 . 6}$ & $\mathbf{9 3 . 8}$ & $\mathbf{1 0 0 . 0}$ \\
\cline { 2 - 7 } & Total & $\mathbf{6 4}$ & $\mathbf{9 5 . 5}$ & $\mathbf{1 0 0 . 0}$ & \\
\hline Missing & System & $\mathbf{3}$ & $\mathbf{4 . 5}$ & & \\
\hline \multicolumn{2}{|l|}{ Total } & $\mathbf{6 7}$ & $\mathbf{1 0 0 . 0}$ & & \\
\hline
\end{tabular}

OKAT Q2 Pre-Intervention

\begin{tabular}{|l|l|r|r|r|r|}
\hline \multicolumn{2}{|c|}{} & $\begin{array}{c}\text { Frequenc } \\
\text { y }\end{array}$ & Percent & Valid Percent & Cumulative Percent \\
\hline \multirow{3}{*}{ Valid } & Incorrect & $\mathbf{2 5}$ & $\mathbf{3 7 . 3}$ & $\mathbf{3 9 . 1}$ & $\mathbf{3 9 . 1}$ \\
\cline { 2 - 6 } & Correct & $\mathbf{3 9}$ & $\mathbf{5 8 . 2}$ & $\mathbf{6 0 . 9}$ & $\mathbf{1 0 0 . 0}$ \\
\cline { 2 - 6 } & Total & $\mathbf{6 4}$ & $\mathbf{9 5 . 5}$ & $\mathbf{1 0 0 . 0}$ & \\
\hline Missing & System & $\mathbf{3}$ & $\mathbf{4 . 5}$ & & \\
\hline \multicolumn{2}{|l|}{ Total } & $\mathbf{6 7}$ & $\mathbf{1 0 0 . 0}$ & & \\
\hline
\end{tabular}

OKAT Q3 Pre-Intervention

\begin{tabular}{|l|l|r|r|r|r|}
\hline \multicolumn{2}{|c|}{} & $\begin{array}{r}\text { Frequenc } \\
\text { y }\end{array}$ & Percent & Valid Percent & Cumulative Percent \\
\hline \multirow{3}{*}{ Valid } & Incorrect & $\mathbf{4 8}$ & $\mathbf{7 1 . 6}$ & $\mathbf{7 5 . 0}$ & $\mathbf{7 5 . 0}$ \\
\cline { 2 - 6 } & Correct & $\mathbf{1 6}$ & $\mathbf{2 3 . 9}$ & $\mathbf{2 5 . 0}$ & $\mathbf{1 0 0 . 0}$ \\
\cline { 2 - 6 } & Total & $\mathbf{6 4}$ & $\mathbf{9 5 . 5}$ & $\mathbf{1 0 0 . 0}$ & \\
\hline Missing & System & $\mathbf{3}$ & $\mathbf{4 . 5}$ & & \\
\hline \multicolumn{2}{|l|}{ Total } & $\mathbf{6 7}$ & $\mathbf{1 0 0 . 0}$ & & \\
\hline
\end{tabular}


OKAT Q4 Pre-Intervention

\begin{tabular}{|l|l|r|r|r|r|}
\hline \multicolumn{2}{|c|}{} & Frequency & Percent & Valid Percent & Cumulative Percent \\
\hline Valid & Incorrect & $\mathbf{1 5}$ & $\mathbf{2 2 . 4}$ & $\mathbf{2 3 . 4}$ & $\mathbf{2 3 . 4}$ \\
& & & & & \\
\cline { 2 - 7 } & Correct & 49 & $\mathbf{7 3 . 1}$ & $\mathbf{7 6 . 6}$ & \\
\cline { 2 - 7 } & Total & $\mathbf{6 4}$ & $\mathbf{9 5 . 5}$ & $\mathbf{1 0 0 . 0}$ & \\
\hline Missing & System & $\mathbf{3}$ & $\mathbf{4 . 5}$ & & \\
\hline \multicolumn{1}{|l|}{ Total } & $\mathbf{6 7}$ & $\mathbf{1 0 0 . 0}$ & & \\
\hline
\end{tabular}

OKAT Q5 Pre-Intervention

\begin{tabular}{|c|c|c|c|c|c|}
\hline & Frequency & Percent & Valid Percent & Cumulative Percent \\
\hline \multirow[t]{3}{*}{ Valid } & Incorrect & 15 & 22.4 & 23.4 & 23.4 \\
\hline & Correct & 49 & 73.1 & 76.6 & 100.0 \\
\hline & Total & 64 & 95.5 & 100.0 & \\
\hline Missin & System & 3 & 4.5 & & \\
\hline \multicolumn{2}{|c|}{ Total } & 67 & 100.0 & & \\
\hline
\end{tabular}

OKAT Q6 Pre-Intervention

\begin{tabular}{|c|c|c|c|c|c|}
\hline & Frequency & Percent & Valid Percent & Cumulative Percent \\
\hline \multirow[t]{3}{*}{ Valid } & Incorrect & 31 & 46.3 & 48.4 & 48.4 \\
\hline & Correct & 33 & 49.3 & 51.6 & 100.0 \\
\hline & Total & 64 & 95.5 & 100.0 & \\
\hline Missin & System & 3 & 4.5 & & \\
\hline \multicolumn{2}{|c|}{ Total } & 67 & 100.0 & & \\
\hline
\end{tabular}

OKAT Q7 Pre-Intervention

\begin{tabular}{|l|l|r|r|r|r|}
\hline \multicolumn{2}{|c|}{} & Frequency & Percent & Valid Percent & Cumulative Percent \\
\hline Valid & Incorrect & $\mathbf{3 4}$ & $\mathbf{5 0 . 7}$ & $\mathbf{5 3 . 1}$ & $\mathbf{5 3 . 1}$ \\
\cline { 2 - 6 } & Correct & $\mathbf{3 0}$ & $\mathbf{4 4 . 8}$ & $\mathbf{4 6 . 9}$ & $\mathbf{1 0 0 . 0}$ \\
\cline { 2 - 6 } & Total & $\mathbf{6 4}$ & $\mathbf{9 5 . 5}$ & $\mathbf{1 0 0 . 0}$ & \\
\hline Missing & System & $\mathbf{3}$ & $\mathbf{4 . 5}$ & & \\
\hline \multicolumn{2}{|l|}{ Total } & $\mathbf{6 7}$ & $\mathbf{1 0 0 . 0}$ & & \\
\hline
\end{tabular}


OKAT Q8 Pre-Intervention

\begin{tabular}{|l|l|r|r|r|r|}
\hline \multicolumn{2}{|c|}{} & Frequency & Percent & Valid Percent & \multicolumn{2}{|c|}{ Cumulative Percent } \\
\hline Valid & Incorrect & $\mathbf{2 6}$ & $\mathbf{3 8 . 8}$ & $\mathbf{4 0 . 6}$ & $\mathbf{4 0 . 6}$ \\
\cline { 2 - 6 } & Correct & $\mathbf{3 8}$ & $\mathbf{5 6 . 7}$ & $\mathbf{5 9 . 4}$ & $\mathbf{1 0 0 . 0}$ \\
\cline { 2 - 7 } & Total & $\mathbf{6 4}$ & $\mathbf{9 5 . 5}$ & $\mathbf{1 0 0 . 0}$ & \\
\hline Missing & System & $\mathbf{3}$ & $\mathbf{4 . 5}$ & & \\
\hline \multicolumn{2}{|l|}{ Total } & $\mathbf{6 7}$ & $\mathbf{1 0 0 . 0}$ & & \\
\hline
\end{tabular}

OKAT Q9 Pre-Intervention

\begin{tabular}{|c|c|c|c|c|c|}
\hline & & Frequency & Percent & Valid Percent & Cumulative Percent \\
\hline \multirow[t]{3}{*}{ Valid } & Incorrect & 34 & 50.7 & 53.1 & 53.1 \\
\hline & Correct & 30 & 44.8 & 46.9 & 100.0 \\
\hline & Total & 64 & 95.5 & 100.0 & \\
\hline Missing & System & 3 & 4.5 & & \\
\hline Total & & 67 & 100.0 & & \\
\hline
\end{tabular}

OKAT Q10 Pre-Intervention

\begin{tabular}{|c|c|c|c|c|c|}
\hline & Frequency & Percent & Valid Percent & Cumulative Percent \\
\hline \multirow[t]{3}{*}{ Valid } & Incorrect & 47 & 70.1 & 73.4 & 73.4 \\
\hline & Correct & 17 & 25.4 & 26.6 & 100.0 \\
\hline & Total & 64 & 95.5 & 100.0 & \\
\hline \multicolumn{2}{|c|}{ Missing System } & 3 & 4.5 & & \\
\hline \multicolumn{2}{|l|}{ Total } & 67 & 100.0 & & \\
\hline
\end{tabular}

OKAT Q11 Pre-Intervention

\begin{tabular}{|l|l|r|r|r|r|}
\hline \multicolumn{2}{|c|}{} & $\begin{array}{r}\text { Frequenc } \\
\text { y }\end{array}$ & \multicolumn{1}{c|}{ Percent } & Valid Percent & \multicolumn{2}{|c|}{ Cumulative Percent } \\
\hline \multirow{3}{*}{ Valid } & Incorrect & $\mathbf{5 5}$ & $\mathbf{8 2 . 1}$ & $\mathbf{8 5 . 9}$ & $\mathbf{8 5 . 9}$ \\
\cline { 2 - 7 } & Correct & $\mathbf{9}$ & $\mathbf{1 3 . 4}$ & $\mathbf{1 4 . 1}$ & $\mathbf{1 0 0 . 0}$ \\
\cline { 2 - 7 } & Total & $\mathbf{6 4}$ & $\mathbf{9 5 . 5}$ & $\mathbf{1 0 0 . 0}$ & \\
\hline Missing & System & $\mathbf{3}$ & $\mathbf{4 . 5}$ & & \\
\hline \multicolumn{2}{|l|}{ Total } & $\mathbf{6 7}$ & $\mathbf{1 0 0 . 0}$ & & \\
\hline
\end{tabular}


OKAT Q12 Pre-Intervention

\begin{tabular}{|c|c|c|c|c|c|}
\hline & Frequency & Percent & Valid Percent & Cumulative Percent \\
\hline \multirow[t]{3}{*}{ Valid } & Incorrect & 20 & 29.9 & 31.3 & 31.3 \\
\hline & Correct & 44 & 65.7 & 68.8 & 100.0 \\
\hline & Total & 64 & 95.5 & 100.0 & \\
\hline \multirow{2}{*}{\multicolumn{2}{|c|}{$\begin{array}{ll}\text { Missing } & \text { System } \\
\end{array}$}} & 3 & 4.5 & & \\
\hline & & 67 & 100.0 & & \\
\hline
\end{tabular}

OKAT Q13 Pre-Intervention

\begin{tabular}{|c|c|c|c|c|c|}
\hline & Frequency & Percent & Valid Percent & Cumulative Percent \\
\hline \multirow[t]{3}{*}{ Valid } & Incorrect & 32 & 47.8 & $\mathbf{5 0 . 0}$ & 50.0 \\
\hline & Correct & 32 & 47.8 & 50.0 & 100.0 \\
\hline & Total & 64 & 95.5 & 100.0 & \\
\hline \multicolumn{2}{|c|}{ Missing System } & 3 & 4.5 & & \\
\hline \multicolumn{2}{|l|}{ Total } & 67 & 100.0 & & \\
\hline
\end{tabular}

OKAT Q14 Pre-Intervention

\begin{tabular}{|l|l|r|r|r|r|}
\hline \multicolumn{2}{|c|}{} & \multicolumn{1}{|c|}{ Frequency } & Percent & Valid Percent & \multicolumn{2}{|c|}{ Cumulative Percent } \\
\hline \multirow{3}{*}{ Valid } & Incorrect & $\mathbf{9}$ & $\mathbf{1 3 . 4}$ & $\mathbf{1 4 . 1}$ & $\mathbf{1 4 . 1}$ \\
\cline { 2 - 7 } & Correct & $\mathbf{5 5}$ & $\mathbf{8 2 . 1}$ & $\mathbf{8 5 . 9}$ & $\mathbf{1 0 0 . 0}$ \\
\cline { 2 - 7 } & Total & $\mathbf{6 4}$ & $\mathbf{9 5 . 5}$ & $\mathbf{1 0 0 . 0}$ & \\
\hline Missing & System & $\mathbf{3}$ & $\mathbf{4 . 5}$ & & \\
\hline \multicolumn{2}{|l|}{ Total } & $\mathbf{6 7}$ & $\mathbf{1 0 0 . 0}$ & & \\
\hline
\end{tabular}

OKAT Q15 Pre-Intervention

\begin{tabular}{|l|l|r|r|r|r|}
\hline \multicolumn{2}{|c|}{} & Frequency & Percent & Valid Percent & \multicolumn{2}{|c|}{ Cumulative Percent } \\
\hline \multirow{4}{*}{ Valid } & Incorrect & $\mathbf{1 8}$ & $\mathbf{2 6 . 9}$ & $\mathbf{2 8 . 1}$ & $\mathbf{2 8 . 1}$ \\
\cline { 2 - 7 } & Correct & $\mathbf{4 6}$ & $\mathbf{6 8 . 7}$ & $\mathbf{7 1 . 9}$ & $\mathbf{1 0 0 . 0}$ \\
\cline { 2 - 7 } & Total & $\mathbf{6 4}$ & $\mathbf{9 5 . 5}$ & $\mathbf{1 0 0 . 0}$ & \\
\hline Missing & System & $\mathbf{3}$ & $\mathbf{4 . 5}$ & & \\
\hline Total & $\mathbf{6 7}$ & $\mathbf{1 0 0 . 0}$ & & & \\
\hline
\end{tabular}


OKAT Q16 Pre-Intervention

\begin{tabular}{|l|l|r|r|r|rr|}
\hline \multicolumn{2}{|c|}{} & Frequency & Percent & Valid Percent & \multicolumn{2}{|c|}{ Cumulative Percent } \\
\hline \multirow{3}{*}{ Valid } & Incorrect & $\mathbf{4 3}$ & $\mathbf{6 4 . 2}$ & $\mathbf{6 7 . 2}$ & $\mathbf{6 7 . 2}$ \\
\cline { 2 - 7 } & Correct & $\mathbf{2 1}$ & $\mathbf{3 1 . 3}$ & $\mathbf{3 2 . 8}$ & $\mathbf{1 0 0 . 0}$ \\
\cline { 2 - 7 } & Total & $\mathbf{6 4}$ & $\mathbf{9 5 . 5}$ & $\mathbf{1 0 0 . 0}$ & \\
\hline Missing & System & $\mathbf{3}$ & $\mathbf{4 . 5}$ & & & \\
\hline \multicolumn{2}{|l|}{ Total } & $\mathbf{6 7}$ & $\mathbf{1 0 0 . 0}$ & & & \\
\hline
\end{tabular}

OKAT Q17 Pre-Intervention

\begin{tabular}{|c|c|c|c|c|c|}
\hline & & Frequency & Percent & Valid Percent & Cumulative Percent \\
\hline \multirow[t]{3}{*}{ Valid } & Incorrect & 53 & 79.1 & 82.8 & 82.8 \\
\hline & Correct & 11 & 16.4 & 17.2 & 100.0 \\
\hline & Total & 64 & 95.5 & 100.0 & \\
\hline Missing & System & 3 & 4.5 & & \\
\hline Total & & 67 & 100.0 & & \\
\hline
\end{tabular}

OKAT Q18 Pre-Intervention

\begin{tabular}{|c|c|c|c|c|c|}
\hline & Frequency & Percent & Valid Percent & Cumulative Percent \\
\hline \multirow[t]{3}{*}{ Valid } & Incorrect & 52 & 77.6 & 81.3 & 81.3 \\
\hline & Correct & 12 & 17.9 & 18.8 & 100.0 \\
\hline & Total & 64 & 95.5 & 100.0 & \\
\hline \multirow{2}{*}{\multicolumn{2}{|c|}{$\begin{array}{ll}\text { Missing } & \text { System } \\
\text { Total }\end{array}$}} & 3 & 4.5 & & \\
\hline & & 67 & 100.0 & & \\
\hline
\end{tabular}

OKAT Q19 Pre-Intervention

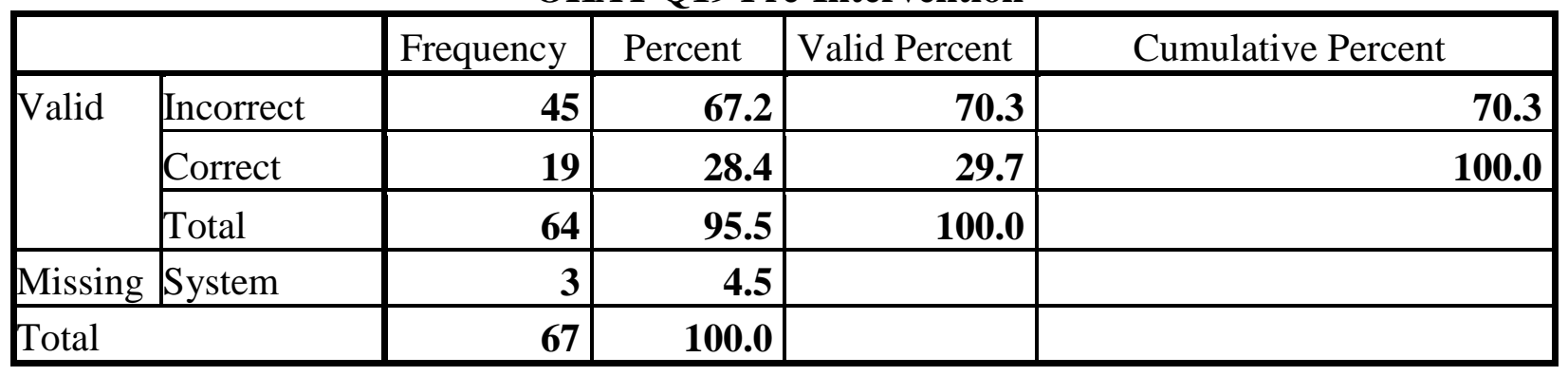


OKAT Q20 Pre-Intervention

\begin{tabular}{|c|c|c|c|c|c|}
\hline & Frequency & Percent & Valid Percent & Cumulative Percent \\
\hline \multirow[t]{3}{*}{ Valid } & Incorrect & 24 & 35.8 & 37.5 & 37.5 \\
\hline & Correct & 40 & 59.7 & 62.5 & 100.0 \\
\hline & Total & 64 & 95.5 & 100.0 & \\
\hline \multicolumn{2}{|c|}{\begin{tabular}{|l|l|} 
Missing & System \\
\end{tabular}} & 3 & 4.5 & & \\
\hline \multicolumn{2}{|l|}{ Total } & 67 & 100.0 & & \\
\hline
\end{tabular}

Table 14

Frequency Data for OKAT Immediately Post-Intervention

OKAT Q1 Immediately-Post Intervention

\begin{tabular}{|c|c|c|c|c|c|}
\hline & & Frequency & Percent & Valid Percent & Cumulative Percent \\
\hline \multirow[t]{3}{*}{ Valid } & Incorrect & 1 & 1.5 & \begin{tabular}{|r}
1.9 \\
\end{tabular} & 1.9 \\
\hline & Correct & 53 & 79.1 & 98.1 & 100.0 \\
\hline & Total & 54 & 80.6 & 100.0 & \\
\hline Missing & System & 13 & 19.4 & & \\
\hline Total & & 67 & 100.0 & & \\
\hline
\end{tabular}

OKAT Q2 Immediately-Post Intervention

\begin{tabular}{|c|c|c|c|c|c|}
\hline & & Frequency & Percent & Valid Percent & Cumulative Percent \\
\hline \multirow[t]{3}{*}{ Valid } & Incorrect & 12 & 17.9 & 22.2 & 22.2 \\
\hline & Correct & 42 & 62.7 & 77.8 & 100.0 \\
\hline & Total & 54 & 80.6 & 100.0 & \\
\hline \multicolumn{2}{|c|}{ Missing System } & 13 & 19.4 & & \\
\hline Total & & 67 & 100.0 & & \\
\hline
\end{tabular}

OKAT Q3 Immediately-Post Intervention

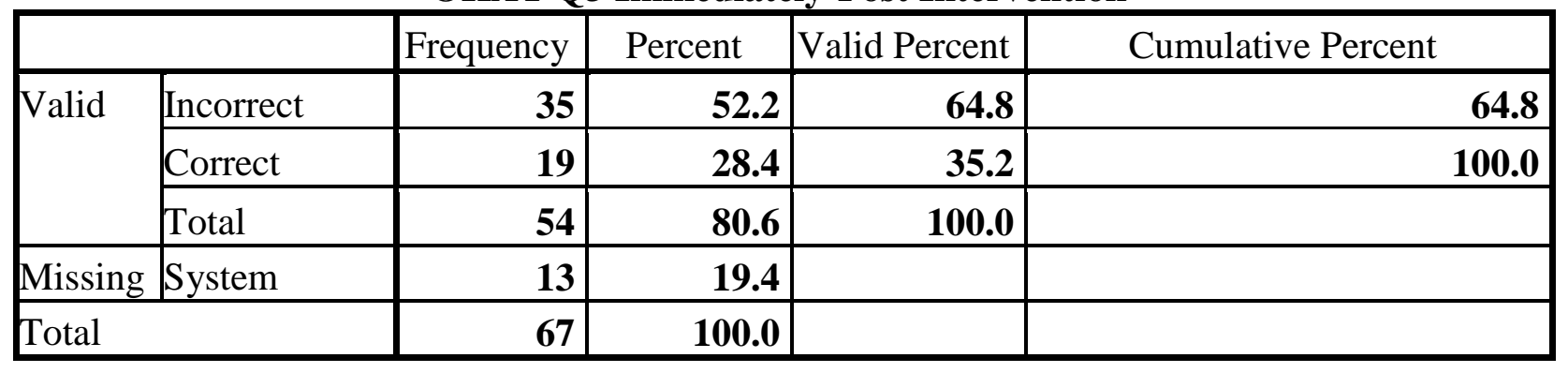


OKAT Q4 Immediately-Post Intervention

\begin{tabular}{|l|l|r|r|r|r|}
\hline \multicolumn{2}{|c|}{} & Frequency & \multicolumn{1}{c|}{ Percent } & Valid Percent & Cumulative Percent \\
\hline \multirow{3}{*}{ Valid } & Incorrect & $\mathbf{3}$ & $\mathbf{4 . 5}$ & $\mathbf{5 . 6}$ & $\mathbf{5 . 6}$ \\
\cline { 2 - 7 } & Correct & $\mathbf{5 1}$ & $\mathbf{7 6 . 1}$ & $\mathbf{9 4 . 4}$ & $\mathbf{1 0 0 . 0}$ \\
\cline { 2 - 7 } & Total & $\mathbf{5 4}$ & $\mathbf{8 0 . 6}$ & $\mathbf{1 0 0 . 0}$ & \\
\hline Missing & System & $\mathbf{1 3}$ & $\mathbf{1 9 . 4}$ & & \\
\hline \multicolumn{1}{|l|}{ Total } & & $\mathbf{6 7}$ & $\mathbf{1 0 0 . 0}$ & & \\
\hline
\end{tabular}

OKAT Q5 Immediately-Post Intervention

\begin{tabular}{|l|l|r|r|r|r|}
\hline \multicolumn{2}{|c|}{} & Frequency & \multicolumn{1}{c|}{ Percent } & Valid Percent & Cumulative Percent \\
\hline \multirow{3}{*}{ Valid } & Incorrect & $\mathbf{4}$ & $\mathbf{6 . 0}$ & $\mathbf{7 . 4}$ & $\mathbf{7 . 4}$ \\
\cline { 2 - 7 } & Correct & $\mathbf{5 0}$ & $\mathbf{7 4 . 6}$ & $\mathbf{9 2 . 6}$ & $\mathbf{1 0 0 . 0}$ \\
\cline { 2 - 7 } & Total & $\mathbf{5 4}$ & $\mathbf{8 0 . 6}$ & $\mathbf{1 0 0 . 0}$ & \\
\hline Missing & System & $\mathbf{1 3}$ & $\mathbf{1 9 . 4}$ & & \\
\hline \multicolumn{2}{|l|}{ Total } & $\mathbf{6 7}$ & $\mathbf{1 0 0 . 0}$ & & \\
\hline
\end{tabular}

OKAT Q6 Immediately-Post Intervention

\begin{tabular}{|l|l|r|r|r|r|}
\hline \multicolumn{2}{|c|}{} & Frequency & \multicolumn{1}{c|}{ Percent } & Valid Percent & Cumulative Percent \\
\hline \multirow{3}{*}{ Valid } & Incorrect & $\mathbf{1 1}$ & $\mathbf{1 6 . 4}$ & $\mathbf{2 0 . 4}$ & $\mathbf{2 0 . 4}$ \\
\cline { 2 - 7 } & Correct & $\mathbf{4 3}$ & $\mathbf{6 4 . 2}$ & $\mathbf{7 9 . 6}$ & $\mathbf{1 0 0 . 0}$ \\
\cline { 2 - 7 } & Total & $\mathbf{5 4}$ & $\mathbf{8 0 . 6}$ & $\mathbf{1 0 0 . 0}$ & \\
\hline Missing & System & $\mathbf{1 3}$ & $\mathbf{1 9 . 4}$ & & \\
\hline \multicolumn{2}{|l|}{ Total } & $\mathbf{6 7}$ & $\mathbf{1 0 0 . 0}$ & & \\
\hline
\end{tabular}

OKAT Q7 Immediately-Post Intervention

\begin{tabular}{|l|l|r|r|r|r|}
\hline \multicolumn{2}{|c|}{} & Frequency & \multicolumn{1}{|c|}{ Percent } & Valid Percent & Cumulative Percent \\
\hline \multirow{3}{*}{ Valid } & Incorrect & $\mathbf{1 1}$ & $\mathbf{1 6 . 4}$ & $\mathbf{2 0 . 4}$ & $\mathbf{2 0 . 4}$ \\
\cline { 2 - 7 } & Correct & $\mathbf{4 3}$ & $\mathbf{6 4 . 2}$ & $\mathbf{7 9 . 6}$ & $\mathbf{1 0 0 . 0}$ \\
\cline { 2 - 7 } & Total & $\mathbf{5 4}$ & $\mathbf{8 0 . 6}$ & $\mathbf{1 0 0 . 0}$ & \\
\hline Missing & System & $\mathbf{1 3}$ & $\mathbf{1 9 . 4}$ & & \\
\hline \multicolumn{2}{|l|}{ Total } & $\mathbf{6 7}$ & $\mathbf{1 0 0 . 0}$ & & \\
\hline
\end{tabular}


OKAT Q8 Immediately-Post Intervention

\begin{tabular}{|l|l|r|r|r|r|}
\hline \multicolumn{2}{|c|}{} & \multicolumn{1}{|c|}{ Frequency } & \multicolumn{1}{c|}{ Percent } & Valid Percent & Cumulative Percent \\
\hline \multirow{3}{*}{ Valid } & Incorrect & $\mathbf{8}$ & $\mathbf{1 1 . 9}$ & $\mathbf{1 4 . 8}$ & $\mathbf{1 4 . 8}$ \\
\cline { 2 - 7 } & Correct & $\mathbf{4 6}$ & $\mathbf{6 8 . 7}$ & $\mathbf{8 5 . 2}$ & $\mathbf{1 0 0 . 0}$ \\
\cline { 2 - 7 } & Total & $\mathbf{5 4}$ & $\mathbf{8 0 . 6}$ & $\mathbf{1 0 0 . 0}$ & \\
\hline Missing & System & $\mathbf{1 3}$ & $\mathbf{1 9 . 4}$ & & \\
\hline \multicolumn{2}{|l|}{ Total } & $\mathbf{6 7}$ & $\mathbf{1 0 0 . 0}$ & & \\
\hline
\end{tabular}

OKAT Q9 Immediately-Post Intervention

\begin{tabular}{|l|l|r|r|r|r|}
\hline \multicolumn{2}{|c|}{} & \multicolumn{1}{|c|}{ Frequency } & \multicolumn{1}{c|}{ Percent } & Valid Percent & Cumulative Percent \\
\hline \multirow{3}{*}{ Valid } & Incorrect & $\mathbf{1 1}$ & $\mathbf{1 6 . 4}$ & $\mathbf{2 0 . 4}$ & $\mathbf{2 0 . 4}$ \\
\cline { 2 - 7 } & Correct & $\mathbf{4 3}$ & $\mathbf{6 4 . 2}$ & $\mathbf{7 9 . 6}$ & $\mathbf{1 0 0 . 0}$ \\
\cline { 2 - 7 } & Total & $\mathbf{5 4}$ & $\mathbf{8 0 . 6}$ & $\mathbf{1 0 0 . 0}$ & \\
\hline \multirow{2}{*}{ Missing } & System & $\mathbf{1 3}$ & $\mathbf{1 9 . 4}$ & & \\
\hline \multicolumn{2}{|l|}{ Total } & $\mathbf{6 7}$ & $\mathbf{1 0 0 . 0}$ & & \\
\hline
\end{tabular}

OKAT Q10 Immediately-Post Intervention

\begin{tabular}{|l|l|r|r|r|r|}
\hline \multicolumn{2}{|c|}{} & Frequency & Percent & Valid Percent & Cumulative Percent \\
\hline \multirow{3}{*}{ Valid } & Incorrect & $\mathbf{2 0}$ & $\mathbf{2 9 . 9}$ & $\mathbf{3 7 . 0}$ & $\mathbf{3 7 . 0}$ \\
\cline { 2 - 6 } & Correct & $\mathbf{3 4}$ & $\mathbf{5 0 . 7}$ & $\mathbf{6 3 . 0}$ & $\mathbf{1 0 0 . 0}$ \\
\cline { 2 - 6 } & Total & $\mathbf{5 4}$ & $\mathbf{8 0 . 6}$ & $\mathbf{1 0 0 . 0}$ & \\
\hline Missing & System & $\mathbf{1 3}$ & $\mathbf{1 9 . 4}$ & & \\
\hline \multicolumn{2}{|l|}{ Total } & $\mathbf{6 7}$ & $\mathbf{1 0 0 . 0}$ & & \\
\hline
\end{tabular}

OKAT Q11 Immediately-Post Intervention

\begin{tabular}{|l|l|r|r|r|r|}
\hline \multicolumn{2}{|c|}{} & Frequency & Percent & \multicolumn{1}{c|}{$\begin{array}{c}\text { Valid } \\
\text { Percent }\end{array}$} & Cumulative Percent \\
\hline \multirow{3}{*}{ Valid } & Incorrect & $\mathbf{4 3}$ & $\mathbf{6 4 . 2}$ & $\mathbf{7 9 . 6}$ & $\mathbf{7 9 . 6}$ \\
\cline { 2 - 7 } & Correct & $\mathbf{1 1}$ & $\mathbf{1 6 . 4}$ & $\mathbf{2 0 . 4}$ & $\mathbf{1 0 0 . 0}$ \\
\cline { 2 - 7 } & Total & $\mathbf{5 4}$ & $\mathbf{8 0 . 6}$ & $\mathbf{1 0 0 . 0}$ & \\
\hline Missing & System & $\mathbf{1 3}$ & $\mathbf{1 9 . 4}$ & & \\
\hline Total & $\mathbf{6 7}$ & $\mathbf{1 0 0 . 0}$ & & & \\
\hline
\end{tabular}


OKAT Q12 Immediately-Post Intervention

\begin{tabular}{|l|l|r|r|r|r|}
\hline \multicolumn{2}{|c|}{} & Frequency & Percent & \multicolumn{1}{c|}{$\begin{array}{c}\text { Valid } \\
\text { Percent }\end{array}$} & Cumulative Percent \\
\hline \multirow{3}{*}{ Valid } & Incorrect & $\mathbf{7}$ & $\mathbf{1 0 . 4}$ & $\mathbf{1 3 . 0}$ & $\mathbf{1 3 . 0}$ \\
\cline { 2 - 7 } & Correct & $\mathbf{4 7}$ & $\mathbf{7 0 . 1}$ & $\mathbf{8 7 . 0}$ & $\mathbf{1 0 0 . 0}$ \\
\cline { 2 - 7 } & Total & $\mathbf{5 4}$ & $\mathbf{8 0 . 6}$ & $\mathbf{1 0 0 . 0}$ & \\
\hline Missing & System & $\mathbf{1 3}$ & $\mathbf{1 9 . 4}$ & & \\
\hline \multicolumn{2}{|l|}{ Total } & $\mathbf{6 7}$ & $\mathbf{1 0 0 . 0}$ & & \\
\hline
\end{tabular}

OKAT Q13 Immediately-Post Intervention

\begin{tabular}{|l|l|r|r|r|r|}
\hline \multicolumn{2}{|c|}{} & Frequency & Percent & \multicolumn{1}{c|}{$\begin{array}{c}\text { Valid } \\
\text { Percent }\end{array}$} & Cumulative Percent \\
\hline \multirow{3}{*}{ Valid } & Incorrect & $\mathbf{1 5}$ & $\mathbf{2 2 . 4}$ & $\mathbf{2 7 . 8}$ & $\mathbf{2 7 . 8}$ \\
\cline { 2 - 7 } & Correct & $\mathbf{3 9}$ & $\mathbf{5 8 . 2}$ & $\mathbf{7 2 . 2}$ & $\mathbf{1 0 0 . 0}$ \\
\cline { 2 - 7 } & Total & $\mathbf{5 4}$ & $\mathbf{8 0 . 6}$ & $\mathbf{1 0 0 . 0}$ & \\
\hline Missing & System & $\mathbf{1 3}$ & $\mathbf{1 9 . 4}$ & & \\
\hline Total & $\mathbf{6 7}$ & $\mathbf{1 0 0 . 0}$ & & & \\
\hline
\end{tabular}

OKAT Q14 Immediately-Post Intervention

\begin{tabular}{|l|l|r|r|r|r|}
\hline \multicolumn{2}{|c|}{} & Frequency & Percent & \multicolumn{1}{c|}{$\begin{array}{c}\text { Valid } \\
\text { Percent }\end{array}$} & Cumulative Percent \\
\hline \multirow{3}{*}{ Valid } & Incorrect & 9 & $\mathbf{1 3 . 4}$ & $\mathbf{1 6 . 7}$ & $\mathbf{1 6 . 7}$ \\
\cline { 2 - 7 } & Correct & 45 & $\mathbf{6 7 . 2}$ & $\mathbf{8 3 . 3}$ & $\mathbf{1 0 0 . 0}$ \\
\cline { 2 - 7 } & Total & $\mathbf{5 4}$ & $\mathbf{8 0 . 6}$ & $\mathbf{1 0 0 . 0}$ & \\
\hline Missing & System & $\mathbf{1 3}$ & $\mathbf{1 9 . 4}$ & & \\
\hline Total & $\mathbf{6 7}$ & $\mathbf{1 0 0 . 0}$ & & & \\
\hline
\end{tabular}

OKAT Q15 Immediately-Post Intervention

\begin{tabular}{|c|c|c|c|c|c|}
\hline & & Frequency & Percent & $\begin{array}{c}\text { Valid } \\
\text { Percent }\end{array}$ & Cumulative Percent \\
\hline \multirow[t]{3}{*}{ Valid } & Incorrect & 12 & 17.9 & 22.2 & 22.2 \\
\hline & Correct & 42 & 62.7 & 77.8 & 100.0 \\
\hline & Total & 54 & 80.6 & 100.0 & \\
\hline Missing & System & 13 & 19.4 & & \\
\hline Total & & 67 & 100.0 & & \\
\hline
\end{tabular}


OKAT Q16 Immediately-Post Intervention

\begin{tabular}{|c|c|c|c|c|c|}
\hline & & Frequency & Percent & $\begin{array}{c}\text { Valid } \\
\text { Percent }\end{array}$ & Cumulative Percent \\
\hline \multirow[t]{3}{*}{ Valid } & Incorrect & 14 & 20.9 & 25.9 & 25.9 \\
\hline & Correct & 40 & 59.7 & 74.1 & 100.0 \\
\hline & Total & 54 & 80.6 & 100.0 & \\
\hline Missing & System & 13 & 19.4 & & \\
\hline Total & & 67 & 100.0 & & \\
\hline
\end{tabular}

OKAT Q17 Immediately-Post Intervention

\begin{tabular}{|c|c|c|c|c|c|}
\hline & & Frequency & Percent & $\begin{array}{c}\text { Valid } \\
\text { Percent }\end{array}$ & Cumulative Percent \\
\hline \multirow[t]{3}{*}{ Valid } & Incorrect & 9 & 13.4 & 16.7 & 16.7 \\
\hline & Correct & 45 & 67.2 & 83.3 & 100.0 \\
\hline & Total & 54 & 80.6 & 100.0 & \\
\hline Missing & System & 13 & 19.4 & & \\
\hline Total & & 67 & 100.0 & & \\
\hline
\end{tabular}

OKAT Q18 Immediately-Post Intervention

\begin{tabular}{|l|l|r|r|r|r|}
\hline \multicolumn{2}{|c|}{} & Frequency & Percent & \multicolumn{1}{c|}{$\begin{array}{c}\text { Valid } \\
\text { Percent }\end{array}$} & Cumulative Percent \\
\hline \multirow{3}{*}{ Valid } & Incorrect & $\mathbf{2 3}$ & $\mathbf{3 4 . 3}$ & $\mathbf{4 2 . 6}$ & $\mathbf{4 2 . 6}$ \\
\cline { 2 - 7 } & Correct & $\mathbf{3 1}$ & $\mathbf{4 6 . 3}$ & $\mathbf{5 7 . 4}$ & $\mathbf{1 0 0 . 0}$ \\
\cline { 2 - 7 } & Total & $\mathbf{5 4}$ & $\mathbf{8 0 . 6}$ & $\mathbf{1 0 0 . 0}$ & \\
\hline Missing & System & $\mathbf{1 3}$ & $\mathbf{1 9 . 4}$ & & \\
\hline \multicolumn{1}{|l|}{ Total } & $\mathbf{6 7}$ & $\mathbf{1 0 0 . 0}$ & & & \\
\hline
\end{tabular}

OKAT Q19 Immediately-Post Intervention

\begin{tabular}{|l|l|r|r|r|r|}
\hline \multicolumn{2}{|c|}{} & & & \multicolumn{1}{c|}{$\begin{array}{c}\text { Valid } \\
\text { Percent }\end{array}$} & Cumulative Percent \\
\hline \multirow{3}{*}{ Valid } & Frequency & Percent & \multicolumn{1}{c|}{ 50.0 } \\
\cline { 2 - 7 } & Correct & $\mathbf{2 7}$ & $\mathbf{4 0 . 3}$ & $\mathbf{5 0 . 0}$ & $\mathbf{1 0 0 . 0}$ \\
\cline { 2 - 7 } & Total & $\mathbf{2 7}$ & $\mathbf{4 0 . 3}$ & $\mathbf{5 0 . 0}$ & \\
\hline Missing & System & $\mathbf{5 4}$ & $\mathbf{8 0 . 6}$ & $\mathbf{1 0 0 . 0}$ & \\
\hline \multicolumn{2}{|l|}{ Total } & $\mathbf{1 3}$ & $\mathbf{1 9 . 4}$ & & \\
\hline
\end{tabular}


OKAT Q20 Immediately-Post Intervention

\begin{tabular}{|c|c|c|c|c|c|}
\hline & & Frequency & Percent & $\begin{array}{c}\text { Valid } \\
\text { Percent } \\
\end{array}$ & Cumulative Percent \\
\hline \multirow[t]{4}{*}{ Valid } & Incorrect & 5 & 7.5 & 9.3 & 9.3 \\
\hline & Correct & 48 & 71.6 & 88.9 & 98.1 \\
\hline & 16 & $\mathbf{1}$ & 1.5 & 1.9 & 100.0 \\
\hline & Total & 54 & 80.6 & 100.0 & \\
\hline Missing & System & 13 & 19.4 & & \\
\hline \multicolumn{2}{|c|}{ Total } & 67 & 100.0 & & \\
\hline
\end{tabular}

Table 15

Frequency Tables OKAT One Month Post-Intervention

OKAT Q1 One-Month Post

\begin{tabular}{|c|c|c|c|c|c|}
\hline & & Frequency & Percent & $\begin{array}{l}\text { Valid } \\
\text { Percent }\end{array}$ & Cumulative Percent \\
\hline Valid & Correct & 57 & 85.1 & 100.0 & 100.0 \\
\hline Missing & System & 10 & 14.9 & & \\
\hline Total & & 67 & 100.0 & & \\
\hline
\end{tabular}

OKAT Q2 One-Month Post

\begin{tabular}{|c|c|c|c|c|c|}
\hline & & Frequency & Percent & $\begin{array}{c}\text { Valid } \\
\text { Percent }\end{array}$ & Cumulative Percent \\
\hline \multirow[t]{3}{*}{ Valid } & Incorrect & 7 & 10.4 & 12.3 & 12.3 \\
\hline & Correct & 50 & 74.6 & 87.7 & 100.0 \\
\hline & Total & 57 & 85.1 & 100.0 & \\
\hline Missing & System & 10 & 14.9 & & \\
\hline Total & & 67 & 100.0 & & \\
\hline
\end{tabular}


OKAT Q3 One-Month Post

\begin{tabular}{|c|c|c|c|c|c|}
\hline & & Frequency & Percent & $\begin{array}{c}\text { Valid } \\
\text { Percent }\end{array}$ & Cumulative Percent \\
\hline \multirow[t]{3}{*}{ Valid } & Incorrect & 27 & 40.3 & 47.4 & 47.4 \\
\hline & Correct & 30 & 44.8 & 52.6 & 100.0 \\
\hline & Total & 57 & 85.1 & 100.0 & \\
\hline \multirow{2}{*}{\multicolumn{2}{|c|}{$\begin{array}{l}\text { Missing } \text { System } \\
\text { Total }\end{array}$}} & 10 & 14.9 & & \\
\hline & & 67 & 100.0 & & \\
\hline
\end{tabular}

OKAT Q4 One-Month Post

\begin{tabular}{|l|l|r|r|r|rr|}
\hline \multicolumn{2}{|c|}{} & Frequency & Percent & \multicolumn{1}{|c|}{$\begin{array}{c}\text { Valid } \\
\text { Percent }\end{array}$} & Cumulative Percent \\
\hline \multirow{3}{*}{ Valid } & Incorrect & $\mathbf{6}$ & $\mathbf{9 . 0}$ & $\mathbf{1 0 . 5}$ & $\mathbf{1 0 . 5}$ \\
\cline { 2 - 7 } & Correct & $\mathbf{5 1}$ & $\mathbf{7 6 . 1}$ & $\mathbf{8 9 . 5}$ & $\mathbf{1 0 0 . 0}$ \\
\cline { 2 - 7 } & Total & $\mathbf{5 7}$ & $\mathbf{8 5 . 1}$ & $\mathbf{1 0 0 . 0}$ & \\
\hline Missing & System & $\mathbf{1 0}$ & $\mathbf{1 4 . 9}$ & & & \\
\hline \multicolumn{2}{|l|}{ Total } & $\mathbf{6 7}$ & $\mathbf{1 0 0 . 0}$ & & & \\
\hline
\end{tabular}

OKAT Q5 One-Month Post

\begin{tabular}{|c|c|c|c|c|c|}
\hline & & Frequency & Percent & $\begin{array}{c}\text { Valid } \\
\text { Percent }\end{array}$ & Cumulative Percent \\
\hline \multirow[t]{3}{*}{ Valid } & Incorrect & 5 & 7.5 & 8.8 & 8.8 \\
\hline & Correct & 52 & 77.6 & 91.2 & 100.0 \\
\hline & Total & 57 & 85.1 & 100.0 & \\
\hline Missin & System & 10 & 14.9 & & \\
\hline \multicolumn{2}{|c|}{ Total } & 67 & 100.0 & & \\
\hline
\end{tabular}


OKAT Q6 One-Month Post

\begin{tabular}{|c|c|c|c|c|c|}
\hline & & Frequency & Percent & $\begin{array}{l}\text { Valid } \\
\text { Percent }\end{array}$ & Cumulative Percent \\
\hline \multirow[t]{3}{*}{ Valid } & Incorrect & 28 & 41.8 & 49.1 & 49.1 \\
\hline & Correct & 29 & 43.3 & 50.9 & 100.0 \\
\hline & Total & 57 & 85.1 & 100.0 & \\
\hline Missing & System & 10 & 14.9 & & \\
\hline \multicolumn{2}{|c|}{ Total } & 67 & 100.0 & & \\
\hline
\end{tabular}

OKAT Q7 One-Month Post

\begin{tabular}{|c|c|c|c|c|c|}
\hline & & Frequency & Percent & $\begin{array}{l}\text { Valid } \\
\text { Percent }\end{array}$ & Cumulative Percent \\
\hline \multirow[t]{3}{*}{ Valid } & Incorrect & 16 & 23.9 & 28.1 & 28.1 \\
\hline & Correct & 41 & 61.2 & 71.9 & 100.0 \\
\hline & Total & 57 & 85.1 & 100.0 & \\
\hline \multirow{2}{*}{\multicolumn{2}{|c|}{$\begin{array}{l}\text { Missing } \text { System } \\
\text { Total }\end{array}$}} & 10 & 14.9 & & \\
\hline & & 67 & 100.0 & & \\
\hline
\end{tabular}

OKAT Q8 One-Month Post

\begin{tabular}{|l|l|r|r|r|rr|}
\hline \multicolumn{2}{|c|}{} & \multicolumn{1}{|c|}{ Frequency } & Percent & \multicolumn{2}{c|}{$\begin{array}{c}\text { Valid } \\
\text { Percent }\end{array}$} & Cumulative Percent \\
\hline \multirow{3}{*}{ Valid } & Incorrect & $\mathbf{9}$ & $\mathbf{1 3 . 4}$ & $\mathbf{1 5 . 8}$ & $\mathbf{1 6 . 1}$ \\
\cline { 2 - 7 } & Correct & $\mathbf{4 8}$ & $\mathbf{7 1 . 6}$ & $\mathbf{8 4 . 2}$ & \\
\cline { 2 - 7 } & Total & $\mathbf{5 7}$ & $\mathbf{8 5 . 1}$ & $\mathbf{1 0 0 . 0}$ & \\
\hline Missing & System & $\mathbf{1 0}$ & $\mathbf{1 4 . 9}$ & & & \\
\hline \multicolumn{2}{|l|}{ Total } & $\mathbf{6 7}$ & $\mathbf{1 0 0 . 0}$ & & & \\
\hline
\end{tabular}

OKAT Q9 One-Month Post

\begin{tabular}{|c|c|c|c|c|c|}
\hline & Frequency & Percent & Valid Percent & Cumulative Percent \\
\hline \multirow[t]{3}{*}{ Valid } & Incorrect & 20 & 29.9 & 35.1 & 35.19 \\
\hline & Correct & 37 & 55.2 & 64.9 & 100.0 \\
\hline & Total & 57 & 85.1 & 100.0 & \\
\hline Missing & System & 10 & 14.9 & & \\
\hline Total & & 67 & 100.0 & & \\
\hline
\end{tabular}


OKAT Q10 One-Month Post

\begin{tabular}{|c|c|c|c|c|c|}
\hline & Frequency & Percent & Valid Percent & Cumulative Percent \\
\hline \multirow[t]{3}{*}{ Valid } & Incorrect & 32 & 47.8 & 56.1 & 56.1 \\
\hline & Correct & 25 & 37.3 & 43.9 & 100.0 \\
\hline & Total & 57 & 85.1 & 100.0 & \\
\hline Missing & System & 10 & 14.9 & & \\
\hline Total & & 67 & 100.0 & & \\
\hline
\end{tabular}

OKAT Q11 One-Month Post

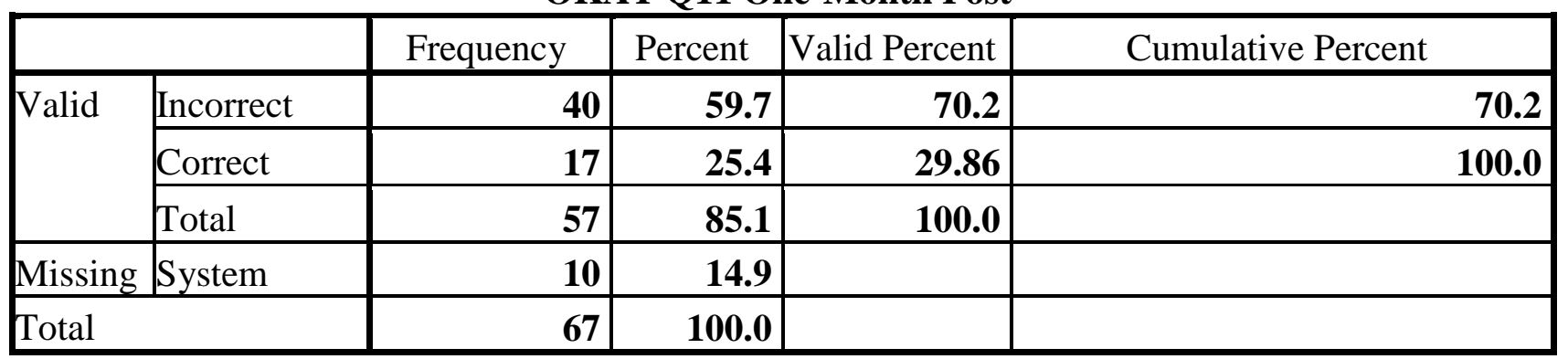

OKAT Q12 One-Month Post

\begin{tabular}{|l|l|r|r|r|rr|}
\hline \multicolumn{2}{|c|}{} & \multicolumn{2}{|c|}{ Frequency } & Percent & Valid Percent & \multicolumn{2}{|c|}{ Cumulative Percent } \\
\hline \multirow{3}{*}{ Valid } & Incorrect & $\mathbf{8}$ & $\mathbf{1 1 . 9}$ & $\mathbf{1 4 . 0}$ & $\mathbf{1 4 . 0}$ \\
\cline { 2 - 7 } & Correct & $\mathbf{4 9}$ & $\mathbf{7 3 . 1}$ & $\mathbf{8 6 . 0}$ & $\mathbf{1 0 0 . 0}$ \\
\cline { 2 - 7 } & Total & $\mathbf{5 7}$ & $\mathbf{8 5 . 1}$ & $\mathbf{1 0 0 . 0}$ & \\
\hline Missing & System & $\mathbf{1 0}$ & $\mathbf{1 4 . 9}$ & & & \\
\hline \multicolumn{2}{|l|}{ Total } & $\mathbf{6 7}$ & $\mathbf{1 0 0 . 0}$ & & & \\
\hline
\end{tabular}

OKAT Q13 One-Month Post

\begin{tabular}{|c|c|c|c|c|c|}
\hline & & Frequency & Percent & Valid Percent & Cumulative Percent \\
\hline \multirow[t]{3}{*}{ Valid } & Incorrect & 11 & 16.4 & \begin{tabular}{|r|}
19.3 \\
\end{tabular} & 19.3 \\
\hline & Correct & 46 & 68.7 & 80.7 & 100.0 \\
\hline & Total & 57 & 85.1 & 100.0 & \\
\hline Missing & System & 10 & 14.9 & & \\
\hline Total & & 67 & 100.0 & & \\
\hline
\end{tabular}


OKAT Q14 One-Month Post

\begin{tabular}{|l|l|r|r|r|rr|}
\hline \multicolumn{2}{|c|}{} & \multicolumn{2}{|c|}{ Frequency } & Percent & Valid Percent & \multicolumn{2}{|c|}{ Cumulative Percent } \\
\hline \multirow{3}{*}{ Valid } & Incorrect & $\mathbf{3}$ & $\mathbf{4 . 5}$ & $\mathbf{5 . 3}$ & $\mathbf{5 . 3}$ \\
\cline { 2 - 7 } & Correct & $\mathbf{5 4}$ & $\mathbf{8 0 . 6}$ & $\mathbf{9 4 . 7}$ & $\mathbf{1 0 0 . 0}$ \\
\cline { 2 - 7 } & Total & $\mathbf{5 7}$ & $\mathbf{8 5 . 1}$ & $\mathbf{1 0 0 . 0}$ & \\
\hline Missing & System & $\mathbf{1 0}$ & $\mathbf{1 4 . 9}$ & & & \\
\hline \multicolumn{2}{|l|}{ Total } & $\mathbf{6 7}$ & $\mathbf{1 0 0 . 0}$ & & & \\
\hline
\end{tabular}

OKAT Q15 One-Month Post

\begin{tabular}{|l|l|r|r|r|rr|}
\hline \multicolumn{2}{|c|}{} & \multicolumn{2}{|c|}{ Frequency } & Percent & Valid Percent & \multicolumn{2}{|c|}{ Cumulative Percent } \\
\hline \multirow{3}{*}{ Valid } & Incorrect & $\mathbf{3}$ & $\mathbf{4 . 5}$ & $\mathbf{5 . 3}$ & $\mathbf{5 . 3}$ \\
\cline { 2 - 7 } & Correct & $\mathbf{5 4}$ & $\mathbf{8 0 . 6}$ & $\mathbf{9 4 . 7}$ & $\mathbf{1 0 0 . 0}$ \\
\cline { 2 - 7 } & Total & $\mathbf{5 7}$ & $\mathbf{8 5 . 1}$ & $\mathbf{1 0 0 . 0}$ & \\
\hline Missing & System & $\mathbf{1 0}$ & $\mathbf{1 4 . 9}$ & & & \\
\hline \multicolumn{2}{|l|}{ Total } & $\mathbf{6 7}$ & $\mathbf{1 0 0 . 0}$ & & & \\
\hline
\end{tabular}

OKAT Q16 One-Month Post

\begin{tabular}{|l|l|r|r|r|rr|}
\hline \multicolumn{2}{|c|}{} & \multicolumn{2}{|c|}{ Frequency } & Percent & Valid Percent & \multicolumn{2}{|c|}{ Cumulative Percent } \\
\hline \multirow{3}{*}{ Valid } & Incorrect & $\mathbf{2 6}$ & $\mathbf{3 8 . 8}$ & $\mathbf{4 5 . 6}$ & $\mathbf{4 5 . 6}$ \\
\cline { 2 - 7 } & Correct & $\mathbf{3 1}$ & $\mathbf{4 6 . 3}$ & $\mathbf{5 4 . 4}$ & $\mathbf{1 0 0 . 0}$ \\
\cline { 2 - 7 } & Total & $\mathbf{5 7}$ & $\mathbf{8 5 . 1}$ & $\mathbf{1 0 0 . 0}$ & \\
\hline Missing & System & $\mathbf{1 0}$ & $\mathbf{1 4 . 9}$ & & & \\
\hline \multicolumn{2}{|l|}{ Total } & $\mathbf{6 7}$ & $\mathbf{1 0 0 . 0}$ & & & \\
\hline
\end{tabular}

OKAT Q17 One-Month Post

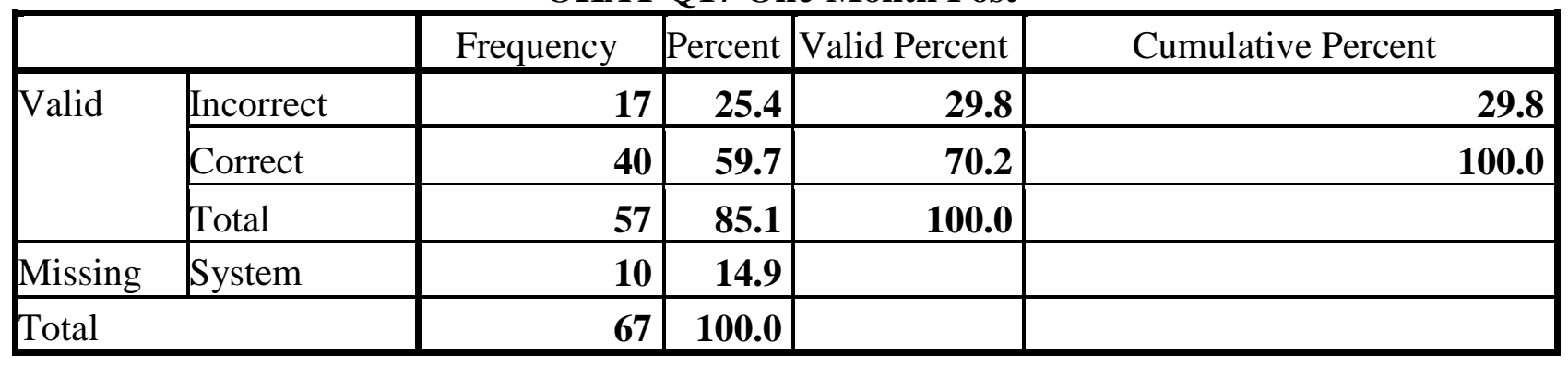


OKAT Q18 One-Month Post

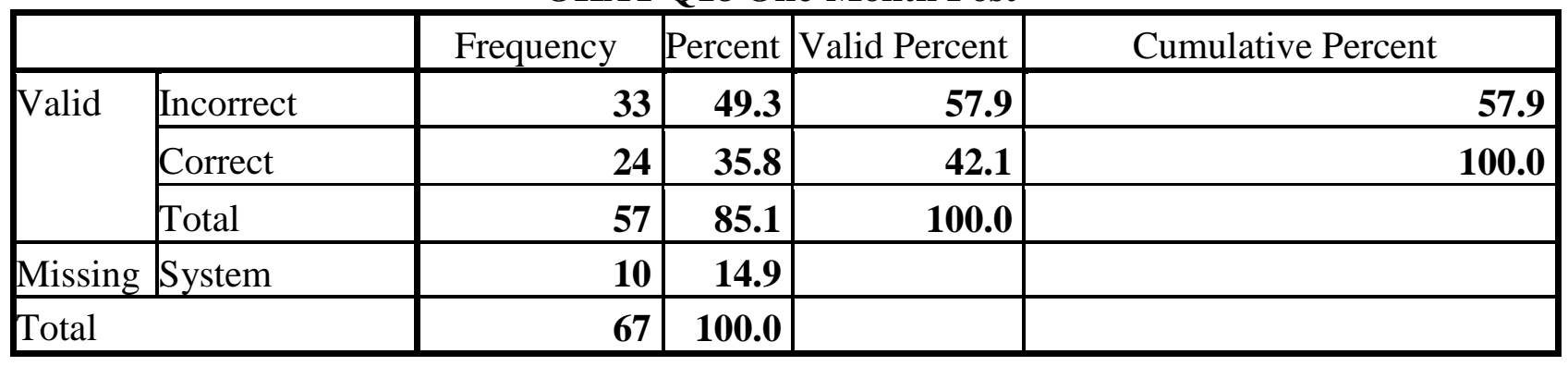

OKAT Q19 One-Month Post

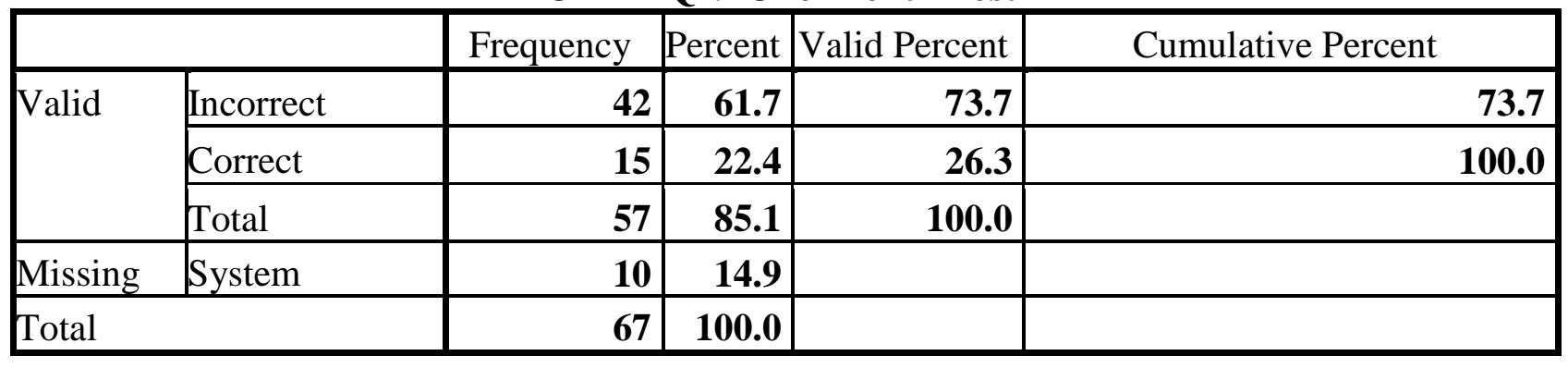

OKAT Q20 One-Month Post

\begin{tabular}{|c|c|c|c|c|c|}
\hline & & Frequency & Percent & Valid Percent & Cumulative Percent \\
\hline \multirow[t]{3}{*}{ Valid } & Incorrect & 6 & 9.0 & 10.5 & 10.5 \\
\hline & Correct & 51 & 76.1 & 89.5 & 100.0 \\
\hline & Total & 57 & 85.1 & 100.0 & \\
\hline Missin & System & 10 & 14.9 & & \\
\hline \multicolumn{2}{|l|}{ Total } & 67 & 100.0 & & \\
\hline
\end{tabular}




\section{Appendix Y}

Statistical Analysis for Calcium and Vitamin D Intake

Table 1

Calcium and Vitamin D Intake, Dietary and Supplemental, Pre- and One Month PostIntervention Paired Samples Statistics

\begin{tabular}{|c|c|c|c|c|c|}
\hline & & Mean & $\mathrm{N}$ & Std. Deviation & Std. Error Mean \\
\hline \multirow[t]{2}{*}{ Pair 1} & $\begin{array}{l}\text { Calcium One-Month } \\
\text { Post (mg) }\end{array}$ & $\begin{array}{r}862.54 \\
9\end{array}$ & 55 & 394.9439 & 53.2542 \\
\hline & Calcium Pre-Int (mg) & $\begin{array}{r}886.14 \\
7\end{array}$ & 55 & 493.5887 & 66.5555 \\
\hline \multirow[t]{2}{*}{ Pair 2} & $\begin{array}{l}\text { Calcium Supplements } \\
\text { One-Mth Post (mg) }\end{array}$ & 762.45 & 55 & 618.564 & 83.407 \\
\hline & $\begin{array}{l}\text { Calcium Supplements } \\
\text { Pre-Int (mg) }\end{array}$ & 520.93 & 55 & 598.755 & 80.736 \\
\hline \multirow[t]{2}{*}{ Pair 3} & $\begin{array}{l}\text { Total Calcium One- } \\
\text { Mth Post (mg) }\end{array}$ & $\begin{array}{r}1597.4 \\
37 \\
\end{array}$ & 56 & 725.8696 & 96.9984 \\
\hline & $\begin{array}{l}\text { Total Calcium Pre-Int } \\
(\mathrm{mg})\end{array}$ & $\begin{array}{r}1358.7 \\
34\end{array}$ & 56 & 805.1059 & 107.5868 \\
\hline \multirow[t]{2}{*}{ Pair 4} & $\begin{array}{l}\text { Vitamin D One-Mth } \\
\text { Post (IU) }\end{array}$ & $\begin{array}{r}181.79 \\
6 \\
\end{array}$ & 55 & 115.0553 & 15.5141 \\
\hline & Vitamin D Pre (IU) & $\begin{array}{r}192.93 \\
3\end{array}$ & 55 & 141.0557 & 19.0199 \\
\hline \multirow[t]{2}{*}{ Pair 5} & $\begin{array}{l}\text { Vitamin D } \\
\text { Supplements One-Mth } \\
\text { Post (IU) }\end{array}$ & $\begin{array}{r}2730.5 \\
1\end{array}$ & 55 & 3138.410 & 423.183 \\
\hline & $\begin{array}{l}\text { Vitamin D } \\
\text { Supplements Pre-Int } \\
\text { (IU) }\end{array}$ & $\begin{array}{r}2003.6 \\
0\end{array}$ & 55 & 2284.909 & 308.097 \\
\hline \multirow[t]{2}{*}{ Pair 6} & $\begin{array}{l}\text { Total Vit D One-Mth } \\
\text { Post (IU) }\end{array}$ & $\begin{array}{r}2749.4 \\
45\end{array}$ & 56 & 3122.3082 & 417.2360 \\
\hline & $\begin{array}{l}\text { Total Vitamin D Pre- } \\
\text { Int (IU) }\end{array}$ & $\begin{array}{r}2029.9 \\
34\end{array}$ & 56 & 2170.2229 & 290.0082 \\
\hline
\end{tabular}


Table 2

Calcium and Vitamin D Intake, Dietary and Supplemental, Pre- and One Month PostIntervention Paired Samples Correlations

\begin{tabular}{|c|c|c|c|c|}
\hline & & $\mathrm{N}$ & Correlation & Sig. \\
\hline Pair 1 & $\begin{array}{l}\text { Calcium One-Month } \\
\text { Post (mg) \& Calcium } \\
\text { Pre-Int (mg) }\end{array}$ & 55 & .562 & .000 \\
\hline Pair 2 & \begin{tabular}{|l} 
Calcium Supplements \\
One-Mth Post (mg) \& \\
Calcium Supplements \\
Pre-Int (mg) \\
\end{tabular} & 55 & .710 & .000 \\
\hline Pair 3 & $\begin{array}{l}\text { Total Calcium One- } \\
\text { Mth Post (mg) \& Total } \\
\text { Calcium Pre-Int (mg) } \\
\end{array}$ & 56 & .646 & .000 \\
\hline Pair 4 & \begin{tabular}{|l} 
Vitamin D One-Mth \\
Post (IU) \& Vitamin D \\
Pre (IU) \\
\end{tabular} & 55 & .436 & .001 \\
\hline Pair 5 & $\begin{array}{l}\text { Vitamin D } \\
\text { Supplements One-Mth } \\
\text { Post (IU) \& Vitamin D } \\
\text { Supplements Pre-Int } \\
\text { (IU) }\end{array}$ & 55 & .604 & .000 \\
\hline Pair 6 & $\begin{array}{l}\text { Total Vit D One-Mth } \\
\text { Post (IU) \& Total } \\
\text { Vitamin D Pre-Int (IU) }\end{array}$ & 56 & .589 & .000 \\
\hline
\end{tabular}


Table 3

Calcium and Vitamin D Intake, Dietary and Supplemental, Pre- and One Month PostIntervention Paired Samples Test

\begin{tabular}{|c|c|c|c|c|}
\hline & \multicolumn{3}{|c|}{ Paired Differences } \\
\hline & & Mean & $\begin{array}{c}\text { Std. } \\
\text { Deviation }\end{array}$ & Std. Error Mean \\
\hline Pair 1 & $\begin{array}{l}\text { Calcium One-Month } \\
\text { Post (mg) - Calcium } \\
\text { Pre-Int (mg) }\end{array}$ & -23.5982 & 424.9268 & 57.2971 \\
\hline Pair 2 & $\begin{array}{l}\text { Calcium Supplements } \\
\text { One-Mth Post (mg) - } \\
\text { Calcium Supplements } \\
\text { Pre-Int (mg) }\end{array}$ & 241.527 & 463.731 & 62.529 \\
\hline Pair 3 & $\begin{array}{l}\text { Total Calcium One- } \\
\text { Mth Post (mg) - Total } \\
\text { Calcium Pre-Int (mg) }\end{array}$ & 238.7036 & 647.7597 & 86.5605 \\
\hline Pair 4 & $\begin{array}{l}\text { Vitamin D One-Mth } \\
\text { Post (IU) - Vitamin D } \\
\text { Pre (IU) }\end{array}$ & -11.1365 & 137.7596 & 18.5755 \\
\hline Pair 5 & $\begin{array}{l}\text { Vitamin D } \\
\text { Supplements One-Mth } \\
\text { Post (IU) - Vitamin D } \\
\text { Supplements Pre-Int } \\
\text { (IU) }\end{array}$ & 726.909 & 2532.315 & 341.457 \\
\hline Pair 6 & $\begin{array}{l}\text { Total Vit D One-Mth } \\
\text { Post (IU) - Total } \\
\text { Vitamin D Pre-Int (IU) }\end{array}$ & 719.5107 & 2546.0790 & 340.2341 \\
\hline
\end{tabular}




\begin{tabular}{|c|c|c|c|c|c|c|}
\hline & \multirow{2}{*}{\multicolumn{2}{|c|}{$\begin{array}{c}\text { Paired Differences } \\
\begin{array}{c}\text { 95\% Confidence Interval of } \\
\text { the Difference }\end{array} \\
\end{array}$}} & \multirow[b]{3}{*}{$\mathrm{t}$} & \multirow[b]{3}{*}{$\mathrm{df}$} & \multirow{3}{*}{$\begin{array}{l}\text { Sig. }(2- \\
\text { tailed) }\end{array}$} \\
\hline & & & & & & \\
\hline & & Lower & Upper & & & \\
\hline Pair 1 & $\begin{array}{l}\text { Calcium One-Month } \\
\text { Post (mg) - Calcium } \\
\text { Pre-Int (mg) }\end{array}$ & -138.4720 & 91.2756 & -.412 & 54 & .682 \\
\hline Pair 2 & $\begin{array}{l}\text { Calcium Supplements } \\
\text { One-Mth Post (mg) - } \\
\text { Calcium Supplements } \\
\text { Pre-Int (mg) } \\
\end{array}$ & 116.163 & 366.891 & 3.863 & 54 & .000 \\
\hline Pair 3 & $\begin{array}{l}\text { Total Calcium One- } \\
\text { Mth Post (mg) - Total } \\
\text { Calcium Pre-Int (mg) } \\
\end{array}$ & 65.2324 & 412.1747 & 2.758 & 55 & .008 \\
\hline Pair 4 & $\begin{array}{l}\text { Vitamin D One-Mth } \\
\text { Post (IU) - Vitamin D } \\
\text { Pre (IU) } \\
\end{array}$ & -48.3782 & 26.1051 & -.600 & 54 & .551 \\
\hline Pair 5 & \begin{tabular}{|l} 
Vitamin D \\
Supplements One-Mth \\
Post (IU) - Vitamin D \\
Supplements Pre-Int \\
(IU) \\
\end{tabular} & 42.329 & 1411.490 & 2.129 & 54 & .038 \\
\hline Pair 6 & $\begin{array}{l}\text { Total Vit D One-Mth } \\
\text { Post (IU) - Total } \\
\text { Vitamin D Pre-Int (IU) } \\
\end{array}$ & 37.6663 & 1401.3551 & 2.115 & 55 & .039 \\
\hline
\end{tabular}




\section{Appendix Z}

\section{Statistical Analysis for the IPAQ}

Table 1

Paired Samples Statistics for the IPAQ Pre- and One Month Post-Intervention Paired Samples

\section{Statistics}

\begin{tabular}{|c|c|c|c|c|c|}
\hline & & Mean & $\mathrm{N}$ & $\begin{array}{c}\text { Std. } \\
\text { Deviation }\end{array}$ & Std. Error Mean \\
\hline \multirow[t]{2}{*}{ Pair 1} & $\begin{array}{l}\text { \# of Days/wk } \\
\text { Vigorous Physical } \\
\text { Activities Pre-Int }\end{array}$ & 1.89 & 55 & 2.242 & .302 \\
\hline & $\begin{array}{l}\text { \# of Days/wk Vigorous } \\
\text { Physical Activities } \\
\text { One-Mth Post }\end{array}$ & 1.96 & 55 & 2.177 & .294 \\
\hline \multirow[t]{2}{*}{ Pair 2} & $\begin{array}{l}\text { Time Minutes } \\
\text { Vigorous Physical } \\
\text { Activities Pre-Int } \\
\end{array}$ & 45.18 & 55 & 59.96 & 8.085 \\
\hline & $\begin{array}{l}\text { Time Minutes } \\
\text { Vigorous Physical } \\
\text { Activities One-Mth } \\
\text { Post }\end{array}$ & 50.55 & 55 & 69.626 & 9.388 \\
\hline \multirow[t]{2}{*}{ Pair 3} & $\begin{array}{l}\text { \# of Days/wk Moderate } \\
\text { Physical Activities Pre- } \\
\text { Int }\end{array}$ & 2.35 & 55 & 2.311 & .312 \\
\hline & $\begin{array}{l}\text { \# of Days/wk Moderate } \\
\text { Physical Act One-Mth } \\
\text { Post-Int }\end{array}$ & 3.38 & 55 & 2.564 & .346 \\
\hline \multirow[t]{2}{*}{ Pair 4} & $\begin{array}{l}\text { Time Minutes Daily } \\
\text { Moderate Physical } \\
\text { Activities Pre-Int }\end{array}$ & 51.36 & 55 & 57.465 & 7.749 \\
\hline & $\begin{array}{l}\text { Time Minutes Daily } \\
\text { Mod Physical Act One- } \\
\text { Mth Post }\end{array}$ & 82.18 & 55 & 87.410 & 11.786 \\
\hline
\end{tabular}




\begin{tabular}{|l|l|r|r|r|r|}
\hline Pair 5 & $\begin{array}{l}\text { \# of Days/wk Walking } \\
\text { Pre-Int }\end{array}$ & $\mathbf{3 . 6 9}$ & $\mathbf{5 5}$ & $\mathbf{3 . 0 4 2}$ & $\mathbf{4 1 0}$ \\
\cline { 2 - 6 } & $\begin{array}{l}\text { \# of Days/wk Walking } \\
\text { One-Mth Post-Int }\end{array}$ & $\mathbf{4 . 1 6}$ & $\mathbf{5 5}$ & $\mathbf{2 . 7 0 6}$ & $\mathbf{3 6 5}$ \\
\hline Pair 6 & $\begin{array}{l}\text { Time Minutes/Daily } \\
\text { Walking Pre-Int }\end{array}$ & $\mathbf{4 2 . 9 1}$ & $\mathbf{5 5}$ & $\mathbf{4 5 . 2 8 4}$ & $\mathbf{6 . 1 0 6}$ \\
\cline { 2 - 6 } & $\begin{array}{l}\text { Time Minutes/Daily } \\
\text { Walking One-Mth } \\
\text { Post-Int }\end{array}$ & $\mathbf{8 5 . 7}$ & $\mathbf{5 5}$ & $\mathbf{1 1 0 . 4 9 7}$ & $\mathbf{1 4 . 8 9 9}$ \\
\hline Pair 7 & $\begin{array}{l}\text { Total Minutes Sitting } \\
\text { Average One Day Last } \\
\text { Week Pre-Int }\end{array}$ & $\mathbf{3 3 8 . 6 4}$ & $\mathbf{5 5}$ & $\mathbf{1 5 7 . 3 0 2}$ & $\mathbf{2 1 . 2 1 1}$ \\
\cline { 2 - 6 } & $\begin{array}{l}\text { Total Minutes Sit } \\
\text { Average One Day Last } \\
\text { Week One-Mth Post }\end{array}$ & $\mathbf{3 0 0 . 0 0}$ & $\mathbf{5 5}$ & $\mathbf{1 3 5 . 4 9 3}$ & $\mathbf{1 8 . 2 7 0}$ \\
\hline
\end{tabular}


Table 2

Paired Samples Statistics for the IPAQ Pre-and One Month Post-Intervention Paired Samples Test

\begin{tabular}{|c|c|c|c|c|}
\hline & & \multicolumn{3}{|c|}{ Paired Differences } \\
\hline & & Mean & $\begin{array}{c}\text { Std. } \\
\text { Deviation }\end{array}$ & $\begin{array}{c}\text { Std. Error } \\
\text { Mean }\end{array}$ \\
\hline $\begin{array}{l}\text { Pair } \\
1\end{array}$ & $\begin{array}{l}\text { \# of Days/wk } \\
\text { Vigorous Physical } \\
\text { Activities Pre-Int - \# } \\
\text { of Days/wk Vigorous } \\
\text { Physical Activities } \\
\text { One-Mth Post }\end{array}$ & .073 & 2.379 & .321 \\
\hline $\begin{array}{l}\text { Pair } \\
2\end{array}$ & $\begin{array}{l}\text { Time Minutes } \\
\text { Vigorous Physical } \\
\text { Activities Pre-Int - } \\
\text { Time Minutes } \\
\text { Vigorous Physical } \\
\text { Activities One-Mth } \\
\text { Post }\end{array}$ & 5.364 & 73.225 & 9.874 \\
\hline $\begin{array}{l}\text { Pair } \\
3\end{array}$ & $\begin{array}{l}\text { \# of Days/wk } \\
\text { Moderate Physical } \\
\text { Activities Pre-Int - \# } \\
\text { of Days/wk Moderate } \\
\text { Physical Act One-Mth } \\
\text { Post-Int }\end{array}$ & 1.036 & 2.317 & .312 \\
\hline $\begin{array}{l}\text { Pair } \\
4\end{array}$ & $\begin{array}{l}\text { Time Minutes Daily } \\
\text { Moderate Physical } \\
\text { Activities Pre-Int - } \\
\text { Time Minutes Daily } \\
\text { Mod Physical Act } \\
\text { One-Mth Post }\end{array}$ & 30.818 & 94.784 & 12.781 \\
\hline $\begin{array}{l}\text { Pair } \\
5\end{array}$ & $\begin{array}{l}\text { \# of Days/wk Walking } \\
\text { Pre-Int - \# of Days/wk } \\
\text { Walking One-Mth } \\
\text { Post-Int }\end{array}$ & .473 & 2.808 & .379 \\
\hline
\end{tabular}




\begin{tabular}{|l|l|r|r|r|}
\hline Pair & Time Minutes/Daily & $\mathbf{4 2 . 8 1 8}$ & $\mathbf{1 0 6 . 1 7 0}$ & $\mathbf{1 4 . 3 1 6}$ \\
& $\begin{array}{l}\text { Walking Pre-Int - } \\
\text { Time Minutes/Daily } \\
\text { Walking One-Mth } \\
\text { Post-Int }\end{array}$ & & & \\
\hline $\begin{array}{l}\text { Pair } \\
7\end{array}$ & $\begin{array}{l}\text { Total Minutes Sitting } \\
\text { Average One Day Last } \\
\text { Week Pre-Int - Total } \\
\text { Minutes Sit Average } \\
\text { One Day Last Week } \\
\text { One-Mth Post }\end{array}$ & $\mathbf{- 3 8 . 6 3 6}$ & $\mathbf{1 6 5 . 9 4 7}$ & $\mathbf{2 2 . 3 7 6}$ \\
\hline
\end{tabular}

\begin{tabular}{|c|c|c|c|c|c|c|}
\hline & Paired Di & erences & \multirow[b]{3}{*}{$\mathrm{t}$} & \multirow[b]{3}{*}{ df } & \multirow{3}{*}{$\begin{array}{l}\text { Sig. (2- } \\
\text { tailed) }\end{array}$} \\
\hline & & \multicolumn{2}{|c|}{$\begin{array}{l}\text { 95\% Confidence Interval } \\
\text { of the Difference }\end{array}$} & & & \\
\hline & & Lower & Upper & & & \\
\hline $\begin{array}{l}\text { Pair } \\
1\end{array}$ & $\begin{array}{l}\text { \# of Days/wk } \\
\text { Vigorous Physical } \\
\text { Activities Pre-Int - \# } \\
\text { of Days/wk } \\
\text { Vigorous Physical } \\
\text { Activities One-Mth } \\
\text { Post }\end{array}$ & -.570 & .716 & .227 & 54 & .822 \\
\hline $\begin{array}{l}\text { Pair } \\
2\end{array}$ & $\begin{array}{l}\text { Time Minutes } \\
\text { Vigorous Physical } \\
\text { Activities Pre-Int - } \\
\text { Time Minutes } \\
\text { Vigorous Physical } \\
\text { Activities One-Mth } \\
\text { Post } \\
\end{array}$ & -14.432 & 25.159 & .543 & 54 & .589 \\
\hline $\begin{array}{l}\text { Pair } \\
3\end{array}$ & $\begin{array}{l}\text { \# of Days/wk } \\
\text { Moderate Physical } \\
\text { Activities Pre-Int - \# } \\
\text { of Days/wk } \\
\text { Moderate Physical } \\
\text { Act One-Mth Post- } \\
\text { Int }\end{array}$ & .410 & 1.663 & 3.317 & 54 & .002 \\
\hline
\end{tabular}




\begin{tabular}{|l|l|r|r|r|r|r|}
\hline Pair & $\begin{array}{l}\text { Time Minutes Daily } \\
\text { Moderate Physical } \\
\text { Activities Pre-Int - } \\
\text { Time Minutes Daily } \\
\text { Mod Physical Act } \\
\text { One-Mth Post }\end{array}$ & $\mathbf{5 . 1 9 4}$ & $\mathbf{5 6 . 4 4 2}$ & $\mathbf{2 . 4 1 1}$ & $\mathbf{5 4}$ & $\mathbf{. 0 1 9}$ \\
\hline $\begin{array}{l}\text { Pair } \\
5\end{array}$ & $\begin{array}{l}\text { \# of Days/wk } \\
\text { Walking Pre-Int - \# } \\
\text { of Days/wk Walking } \\
\text { One-Mth Post-Int }\end{array}$ & $\mathbf{- . 2 8 6}$ & $\mathbf{1 . 2 3 2}$ & $\mathbf{1 . 2 4 9}$ & $\mathbf{5 4}$ & $\mathbf{. 2 1 7}$ \\
\hline $\begin{array}{l}\text { Pair } \\
6\end{array}$ & $\begin{array}{l}\text { Time Minutes/Daily } \\
\text { Walking Pre-Int - } \\
\text { Time Minutes/Daily } \\
\text { Walking One-Mth } \\
\text { Post-Int }\end{array}$ & $\mathbf{1 4 . 1 1 6}$ & $\mathbf{7 1 . 5 2 0}$ & $\mathbf{2 . 9 9 1}$ & $\mathbf{5 4}$ & $\mathbf{. 0 0 4}$ \\
\hline $\begin{array}{l}\text { Pair } \\
7\end{array}$ & $\begin{array}{l}\text { Total Minutes Sitting } \\
\text { Average One Day } \\
\text { Last Week Pre-Int - } \\
\text { Total Minutes Sit } \\
\text { Average One Day } \\
\text { Last Week One-Mth } \\
\text { Post }\end{array}$ & $\mathbf{- 8 3 . 4 9 8}$ & $\mathbf{6 . 2 2 5}$ & $\mathbf{- 1 . 7 2 7}$ & $\mathbf{5 4}$ & $\mathbf{. 0 9 0}$ \\
\hline
\end{tabular}




\section{Appendix AA}

Returned Surveys

Table 1

\begin{tabular}{|l|l|l|}
\hline Workshop & Number Returned & Percentage \\
\hline Workshop One & 34 & $100 \%(34 / 34)$ \\
\hline Workshop Two & 14 & $100 \%(14 / 14)$ \\
\hline Workshop Three & 9 & $47.4 \%(9 / 19)$ \\
\hline Totals For All Workshops & 57 & $85.1 \%(57 / 67)$ \\
\hline
\end{tabular}




\section{Appendix AB}

\section{Osteoporosis Workshop Survey Comments}

1. "Learned everything wanted to and more. Length a little long. Presenter talks a little fast for me. A microphone would be helpful."

2. "Thank you. Very informative, interesting. The time went really fast."

3. "Great presenter!"

4. "Would like more re medications. Room too warm. Haven't looked at workbook yet."

5. "Learned everything wanted to and more! Presenter very helpful! Excellent source of information. Thank you!"

6. "The class was awesome and very informational! Presenter very helpful."

7. "Can always learn more but learned a lot of new things. Need to take this show on the road."

8. "A very good program. Well presented."

9. "You did a great job! Thank you! Could improve on seating space. Wonderful workbook. Wonderful presenter."

10. "Great job! Very informative! Room too small."

11. "Excellent! Thank you!"

12. "I would like more information on diets and foods."

13. "Very informative. Presenter very personable and knowledgeable. Materials extra nice and informative. Length a little long but helpful to people with questions."

14. "Very beneficial! Helpful. Speaker was enthusiastic, knowledgeable, helpful, answered questions. Learned everything wanted to and more!" 
15. "I really enjoyed this and think it was very helpful for me. Ms. Smith was an excellent person to do it. She is excellent."

16. "Room a bit warm and crowded. Workbook absolutely helpful. Presenter helpful!"

17. "Good learning process. A lot to absorb. Good handouts and workbook for additional help. Room a little crowded."

18. "Room a little crowded."

19. "Presenter excellent."

20. "Very informative. Great information. Didn't learn everything wanted to but have been given the resources and material to increase knowledge. Valuable presentation! Thank you!"

21. "I wish this class had been available ten years ago. I learned more now than I did from my talk with my doctor before I began treatment for osteoporosis."

22. "Liked all of the handouts and visual. Lots of good, practical advice. Cindy knew answers to questions-very informative."

23. "Wonderful speaker and very good teacher. Very informative. Presented in a manner that was interesting. Would recommend this to others."

24. "I would have liked to have a class at 6:30 PM or 7:00 PM. I didn't learn everything I wanted to, because I am sure there is so much more for me to learn with the handouts. “

25. "I thought you did an excellent job and should do more workshops. Make more people aware. Excellent speaker."

26. "Very helpful. Was presented very well on my level."

27. "Would absolutely recommend. Presenter wonderfully helpful."

28. "Would like shorter sessions divided into two days instead of one long session in one day. Concentration would be better. Too many handouts in one sitting." 
29. "Almost learned everything wanted to."

30. "Length a little long."

31. "Very informative. Am looking forward to reading the materials from the workshop!"

32. "Thank you!"

33. "I thought that this seminar was very informative. I could have listened longer. Thanks!"

34. "Room a little too warm."

35. "Presenter very helpful."

36. "Bigger room. Ask questions after presentation. Too long but good information." 


\section{Appendix AC}

Descriptive Statistics for the Osteoporosis Workshop Survey

Table One

Valid and Missing Data for Osteoporosis Workshop Survey

\begin{tabular}{|l|l|r|r|r|r|r|}
\hline \multicolumn{2}{|c|}{} & $\begin{array}{c}\text { Program } \\
\text { Helpful }\end{array}$ & $\begin{array}{c}\text { Recommend } \\
\text { to Others }\end{array}$ & $\begin{array}{c}\text { Time } \\
\text { Convenient }\end{array}$ & $\begin{array}{c}\text { Learn } \\
\text { Everything } \\
\text { Wanted To }\end{array}$ & $\begin{array}{c}\text { Was the } \\
\text { Length Right }\end{array}$ \\
\hline \multirow{2}{*}{$\mathrm{N}$} & Valid & $\mathbf{5 7}$ & $\mathbf{5 7}$ & $\mathbf{5 7}$ & $\mathbf{5 5}$ & $\mathbf{5 5}$ \\
\cline { 2 - 7 } & $\begin{array}{l}\text { Missi } \\
\text { ng }\end{array}$ & $\mathbf{0}$ & $\mathbf{0}$ & $\mathbf{0}$ & $\mathbf{2}$ & $\mathbf{2}$ \\
\hline
\end{tabular}

\begin{tabular}{|l|l|r|r|r|r|}
\hline \multicolumn{2}{|c|}{} & $\begin{array}{c}\text { Meeting } \\
\text { Place } \\
\text { Convenient }\end{array}$ & $\begin{array}{c}\text { Room } \\
\text { Comfortable }\end{array}$ & $\begin{array}{c}\text { Workbook } \\
\text { Helpful }\end{array}$ & $\begin{array}{c}\text { Presenter } \\
\text { Helpful }\end{array}$ \\
\hline N & Valid & $\mathbf{5 7}$ & $\mathbf{5 7}$ & $\mathbf{5 6}$ & $\mathbf{5 7}$ \\
\cline { 2 - 6 } & $\begin{array}{l}\text { Missi } \\
\text { ng }\end{array}$ & $\mathbf{0}$ & $\mathbf{0}$ & $\mathbf{1}$ & $\mathbf{0}$ \\
\hline
\end{tabular}

Table 2

Statistics for Question of the Program Being Helpful

\begin{tabular}{|l|l|r|r|c|c|}
\hline \multicolumn{2}{|c|}{} & $\begin{array}{c}\text { Frequen } \\
\text { cy }\end{array}$ & Percent & $\begin{array}{c}\text { Valid } \\
\text { Percent }\end{array}$ & $\begin{array}{c}\text { Cumulative } \\
\text { Percent }\end{array}$ \\
\hline Valid & Yes & $\mathbf{5 7}$ & $\mathbf{1 0 0 . 0}$ & $\mathbf{1 0 0 . 0}$ & $\mathbf{1 0 0 . 0}$ \\
\hline
\end{tabular}


Table 3

Statistics for Question of the Program Being Recommended to Others by the Participants

\begin{tabular}{|l|l|r|r|r|r|}
\hline \multicolumn{2}{|c|}{} & Frequency & Percent & \multicolumn{1}{|c|}{$\begin{array}{c}\text { Valid } \\
\text { Percent }\end{array}$} & Cumulative Percent \\
\hline \multirow{3}{*}{ Valid } & Yes & $\mathbf{5 6}$ & $\mathbf{9 8 . 2}$ & $\mathbf{9 8 . 2}$ & $\mathbf{9 8 . 2}$ \\
\cline { 2 - 6 } & $\begin{array}{l}\text { Don't Want to } \\
\text { Answer }\end{array}$ & $\mathbf{1}$ & $\mathbf{1 . 8}$ & $\mathbf{1 . 8}$ & $\mathbf{1 0 0 . 0}$ \\
\cline { 2 - 6 } & Total & $\mathbf{5 7}$ & $\mathbf{1 0 0 . 0}$ & $\mathbf{1 0 0 . 0}$ & \\
\hline
\end{tabular}

Table 4

Statistics for Question of the Osteoporosis Workshop Time Being Convenient

\begin{tabular}{|l|l|r|r|r|r|}
\hline \multicolumn{2}{|c|}{} & Frequency & Percent & Valid Percent & Cumulative Percent \\
\hline \multirow{3}{*}{ Valid } & Yes & $\mathbf{5 6}$ & $\mathbf{9 8 . 2}$ & $\mathbf{9 8 . 2}$ & $\mathbf{9 8 . 2}$ \\
\cline { 2 - 6 } & No & $\mathbf{1}$ & $\mathbf{1 . 8}$ & $\mathbf{1 . 8}$ & $\mathbf{1 0 0 . 0}$ \\
\cline { 2 - 6 } & Total & $\mathbf{5 7}$ & $\mathbf{1 0 0 . 0}$ & $\mathbf{1 0 0 . 0}$ & \\
\hline
\end{tabular}

Table 5

Statistics for Question of the Participants Learning Everything Wanted To

\begin{tabular}{|l|l|r|r|r|r|}
\hline \multicolumn{2}{|c|}{} & Frequency & Percent & $\begin{array}{c}\text { Valid } \\
\text { Percent }\end{array}$ & Cumulative Percent \\
\hline \multirow{3}{*}{ Valid } & Yes & $\mathbf{4 6}$ & $\mathbf{8 0 . 7}$ & $\mathbf{8 3 . 6}$ & $\mathbf{8 3 . 6}$ \\
\cline { 2 - 7 } & No & $\mathbf{8}$ & $\mathbf{1 4 . 0}$ & $\mathbf{1 4 . 5}$ & $\mathbf{9 8 . 2}$ \\
\cline { 2 - 7 } & $\begin{array}{l}\text { Don't Want } \\
\text { to Answer }\end{array}$ & $\mathbf{1}$ & $\mathbf{1 . 8}$ & $\mathbf{1 . 8}$ & $\mathbf{1 0 0 . 0}$ \\
\cline { 2 - 7 } & Total & $\mathbf{5 5}$ & $\mathbf{9 6 . 5}$ & $\mathbf{1 0 0 . 0}$ & \\
\hline Missing & System & $\mathbf{2}$ & $\mathbf{3 . 5}$ & & \\
\hline Total & & $\mathbf{5 7}$ & $\mathbf{1 0 0 . 0}$ & & \\
\hline
\end{tabular}


Table 6

Statistics for Question of Was the Length Right

\begin{tabular}{|l|l|r|r|r|r|}
\hline \multicolumn{2}{|c|}{} & Frequency & Percent & Valid Percent & Cumulative Percent \\
\hline \multirow{3}{*}{ Valid } & Yes & $\mathbf{5 3}$ & $\mathbf{9 3 . 0}$ & $\mathbf{9 6 . 4}$ & $\mathbf{9 6 . 4}$ \\
\cline { 2 - 7 } & No & $\mathbf{2}$ & $\mathbf{3 . 5}$ & $\mathbf{3 . 6}$ & $\mathbf{1 0 0 . 0}$ \\
\cline { 2 - 7 } & Total & $\mathbf{5 5}$ & $\mathbf{9 6 . 5}$ & $\mathbf{1 0 0 . 0}$ & \\
\hline Missing & System & $\mathbf{2}$ & $\mathbf{3 . 5}$ & & \\
\hline \multicolumn{2}{|l|}{ Total } & $\mathbf{5 7}$ & $\mathbf{1 0 0 . 0}$ & & \\
\hline
\end{tabular}

Table 7

Statistics for Question of the Meeting Place Being Convenient

\begin{tabular}{|l|l|r|r|r|r|}
\hline \multicolumn{2}{|l|}{} & Frequency & Percent & Valid Percent & Cumulative Percent \\
\hline Valid & Yes & $\mathbf{5 7}$ & $\mathbf{1 0 0 . 0}$ & $\mathbf{1 0 0 . 0}$ & $\mathbf{1 0 0 . 0}$ \\
\hline
\end{tabular}

Table 8

Statistics for Question of the Room Being Comfortable

\begin{tabular}{|l|l|r|r|r|r|}
\hline \multicolumn{2}{|c|}{} & Frequency & Percent & Valid Percent & Cumulative Percent \\
\hline \multirow{3}{*}{ Valid } & Yes & $\mathbf{5 0}$ & $\mathbf{8 7 . 7}$ & $\mathbf{8 7 . 7}$ & $\mathbf{8 7 . 7}$ \\
\cline { 2 - 6 } & No & $\mathbf{7}$ & $\mathbf{1 2 . 3}$ & $\mathbf{1 2 . 3}$ & $\mathbf{1 0 0 . 0}$ \\
\cline { 2 - 6 } & Total & $\mathbf{5 7}$ & $\mathbf{1 0 0 . 0}$ & $\mathbf{1 0 0 . 0}$ & \\
\hline
\end{tabular}


Table 9

Statistics for Question of the Workbook Being Helpful

\begin{tabular}{|c|c|c|c|c|c|}
\hline & & Frequency & Percent & Valid Percent & Cumulative Percent \\
\hline \multirow[t]{3}{*}{ Valid } & Yes & 55 & 96.5 & 98.2 & 98.2 \\
\hline & $\begin{array}{l}\text { Don't Want } \\
\text { to Answer }\end{array}$ & 1 & 1.8 & 1.8 & 100.0 \\
\hline & Total & 56 & 98.2 & 100.0 & \\
\hline Missing & System & $\mathbf{1}$ & 1.8 & & \\
\hline \multicolumn{2}{|l|}{ Total } & 57 & 100.0 & & \\
\hline
\end{tabular}

Table 10

Statistics for Question of the Presenter Being Helpful

\begin{tabular}{|l|l|r|r|r|r|}
\hline \multicolumn{2}{|c|}{} & Frequency & Percent & Valid Percent & Cumulative Percent \\
\hline Valid & Yes & $\mathbf{5 7}$ & $\mathbf{1 0 0 . 0}$ & $\mathbf{1 0 0 . 0}$ & $\mathbf{1 0 0 . 0}$ \\
\hline
\end{tabular}


Appendix AD

Estimated Versus Actual Expenditures

\begin{tabular}{|c|c|c|}
\hline $\begin{array}{l}\text { Estimated Original } \\
\text { Budget Cost per Item }\end{array}$ & $\begin{array}{c}\text { Actual Cost } \\
\text { Workshops One/Two }\end{array}$ & $\begin{array}{c}\text { Actual Cost Workshop } \\
\text { Three }\end{array}$ \\
\hline Food: $\$ 125$ & $\begin{array}{l}\text { Total Food Cost: } \\
\$ 90.00 \text { (including } \\
\text { bottled water) }\end{array}$ & $\begin{array}{l}\text { Total Food Cost: } \\
\$ 40.00 \text { (including } \\
\text { bottled water) }\end{array}$ \\
\hline $\begin{array}{l}\text { Plates, Napkins, Cups, } \\
\text { Silverware: } \$ 20.00\end{array}$ & $\$ 30.00$ & $\begin{array}{l}\$ 0.00 \text { (used remaining } \\
\text { from first two } \\
\text { workshops) }\end{array}$ \\
\hline $\begin{array}{c}\text { Tablecloths: Not } \\
\text { budgeted }\end{array}$ & Tablecloths: $\$ 5.00$ & Tablecloths $\$ 5.00$ \\
\hline $\begin{array}{c}\text { Copying/Paper } \\
\text { Supplies/Workbook } \\
\text { Creation: } \$ 180.00\end{array}$ & $\$ 403.00$ & $\$ 255.85$ \\
\hline $\begin{array}{l}\text { NOF Handouts: } \\
\quad \$ 25.00\end{array}$ & $\$ 25.00$ & $\mathrm{n} / \mathrm{a}$ \\
\hline $\begin{array}{c}\text { Postage Costs: } \\
\$ 150.00 \text { (one month } \\
\text { post-intervention, } \\
\text { second mailings, and } \\
\text { return postage) }\end{array}$ & $\begin{array}{c}\$ 144.00 \text { (not } \\
\text { including promotional } \\
\text { mailings) }\end{array}$ & $\begin{array}{l}\$ 69.60 \text { (not including } \\
\text { promotional mailings) }\end{array}$ \\
\hline Gift Cards: $\$ 250.00$ & $\$ 240.00$ & $\$ 95.00$ \\
\hline Pens: $\$ 5.00$ & $\$ 2.50$ & $\$ 2.50$ \\
\hline
\end{tabular}




\begin{tabular}{|c|c|c|}
\hline & & \\
\hline $\begin{array}{c}\text { Envelopes: Not } \\
\text { budgeted }\end{array}$ & $\$ 10.00$ & n/a \\
\hline $\begin{array}{c}\text { Promotional Mailings: } \\
\text { Not budgeted }\end{array}$ & $\$ 63.40$ & \\
\hline Totals: $\$ 755.00$ & Totals: $\$ 1007.90$ & Totals: \$472.95 \\
\hline
\end{tabular}


Appendix AE

Expenditures

\begin{tabular}{|c|c|c|c|}
\hline Item & $\begin{array}{c}\text { Cost For Workshops } \\
\text { One/Two }\end{array}$ & $\begin{array}{c}\text { Cost for Workshop } \\
\text { Three }\end{array}$ & $\begin{array}{c}\text { Total Cost All } \\
\text { Workshops Per } \\
\text { Item }\end{array}$ \\
\hline Post-It Notes & $\$ 5.00$ & $\$ 4.00$ & $\$ 9.00$ \\
\hline Labels & $\$ 9.00$ & $\$ 6.00$ & $\$ 15.00$ \\
\hline Copying Paper & $\$ 25.00$ & $\mathrm{n} / \mathrm{a}$ & $\$ 25.00$ \\
\hline $\begin{array}{l}\text { Copying Costs ( } \$ 0.05 \\
\text { a page) For } \\
\text { Workbooks ( } 115 \\
\text { pages total) }\end{array}$ & $\begin{array}{l}\$ 287.50(50 \\
\text { workbooks) }\end{array}$ & $\begin{array}{l}\$ 201.25(35 \\
\text { workbooks) }\end{array}$ & $\$ 488.75$ \\
\hline $\begin{array}{l}\text { Copying Costs For } \\
\text { Article on Exercise } \\
\text { (\$0.05 a page, } 11 \\
\text { pages total) }\end{array}$ & $\$ 27.5$ & $\$ 19.25$ & $\$ 46.75$ \\
\hline $\begin{array}{c}\text { Copying Costs for } \\
\text { Flyers ( } \$ 0.05 \text { a page) }\end{array}$ & $\$ 12.50$ (250 flyers) & $\$ 5.00$ (100 flyers) & $\$ 17.50$ \\
\hline $\begin{array}{c}\text { Copying Costs for } \\
\text { First Mailing ( } \$ 0.05 \text { a } \\
\text { page, } 8 \text { pages total) }\end{array}$ & $\$ 19.20$ (for 48 mailings) & $\$ 7.60$ (for 19 mailings) & $\$ 26.80$ \\
\hline $\begin{array}{l}\text { Copying Costs for } \\
\text { Second Mailing } \\
\text { (\$0.05 a page, } 8 \\
\text { pages total) }\end{array}$ & $\$ 4.80$ (for 12 mailings) & $\$ 4.00$ (for 10 mailings) & $\$ 8.80$ \\
\hline
\end{tabular}




\begin{tabular}{|c|c|c|c|}
\hline $\begin{array}{c}\text { Pens for Attendees } \\
\text { Use }\end{array}$ & $\$ 2.50$ & $\$ 2.50$ & $\$ 5.00$ \\
\hline Folders & $\$ 7.50$ & $\$ 8.75$ & $\$ 16.25$ \\
\hline Paper Clips & $\$ 5.00$ & $\mathrm{n} / \mathrm{a}$ & $\$ 5.00$ \\
\hline $\begin{array}{c}\text { Gift Cards (\$5.00 } \\
\text { each) }\end{array}$ & $\$ 240.00$ & $\$ 95.00$ & $\$ 335.00$ \\
\hline Envelopes & $\$ 10.00$ & $\$ 5.00$ & $\$ 15.00$ \\
\hline $\begin{array}{c}\text { One Month Post- } \\
\text { Intervention Mailings } \\
\quad(\$ 1.30 \text { each })\end{array}$ & $\$ 62.40$ (for 48 mailings) & $\begin{array}{c}\$ 24.70 \text { (for } 19 \\
\text { mailings) }\end{array}$ & $\$ 87.10$ \\
\hline $\begin{array}{c}\text { One Month Post- } \\
\text { Intervention Return } \\
\text { Postage ( } \$ 1.10 \text { each) }\end{array}$ & $\$ 52.80$ (for 48 mailings) & $\begin{array}{c}\$ 20.90 \text { (for } 19 \\
\text { mailings) }\end{array}$ & $\$ 73.70$ \\
\hline $\begin{array}{l}\text { Second Mailing Cost } \\
\text { (\$1.30 each) }\end{array}$ & $\$ 15.60$ (for 12 mailings) & $\begin{array}{c}\$ 13.00 \text { (for } 10 \\
\text { mailings) }\end{array}$ & $\$ 28.60$ \\
\hline $\begin{array}{c}\text { Second Mailing } \\
\text { Return Postage } \\
(\$ 1.10 \text { each })\end{array}$ & $\$ 13.20$ (for 12 mailings) & $\begin{array}{c}\$ 11.00 \text { (for } 10 \\
\text { mailings) }\end{array}$ & $\$ 24.20$ \\
\hline Bottled Water & $\$ 10.00$ & $\$ 10.00$ & $\$ 20.00$ \\
\hline Vegetable Trays & $\$ 40.00$ & $\$ 20.00$ & $\$ 60.00$ \\
\hline Fruit Trays & $\$ 30.00$ & $\mathrm{n} / \mathrm{a}$ & $\$ 30.00$ \\
\hline Nuts & $\$ 10.00$ & $\$ 10.00$ & $\$ 20.00$ \\
\hline
\end{tabular}




\begin{tabular}{|c|c|c|c|}
\hline Plates & $\$ 8.00$ & $\mathrm{n} / \mathrm{a}$ & $\$ 8.00$ \\
\hline Cups & $\$ 4.00$ & $\mathrm{n} / \mathrm{a}$ & $\$ 4.00$ \\
\hline Tablecloths & $\$ 5.00$ & $\$ 5.00$ & $\$ 10.00$ \\
\hline Plastic Utensils & $\$ 8.00$ & $\mathrm{n} / \mathrm{a}$ & $\$ 8.00$ \\
\hline Napkins & $\$ 5.00$ & $\mathrm{n} / \mathrm{a}$ & $\$ 5.00$ \\
\hline NOF Handouts & $\$ 25.00$ & $\$ 472.95$ & $\$ 1417.45$ (total cost \\
& $\$ 944.50$ & & of all three \\
\hline Costs & & & workshops) \\
\hline
\end{tabular}


Appendix AF

Flyer About the Presentation

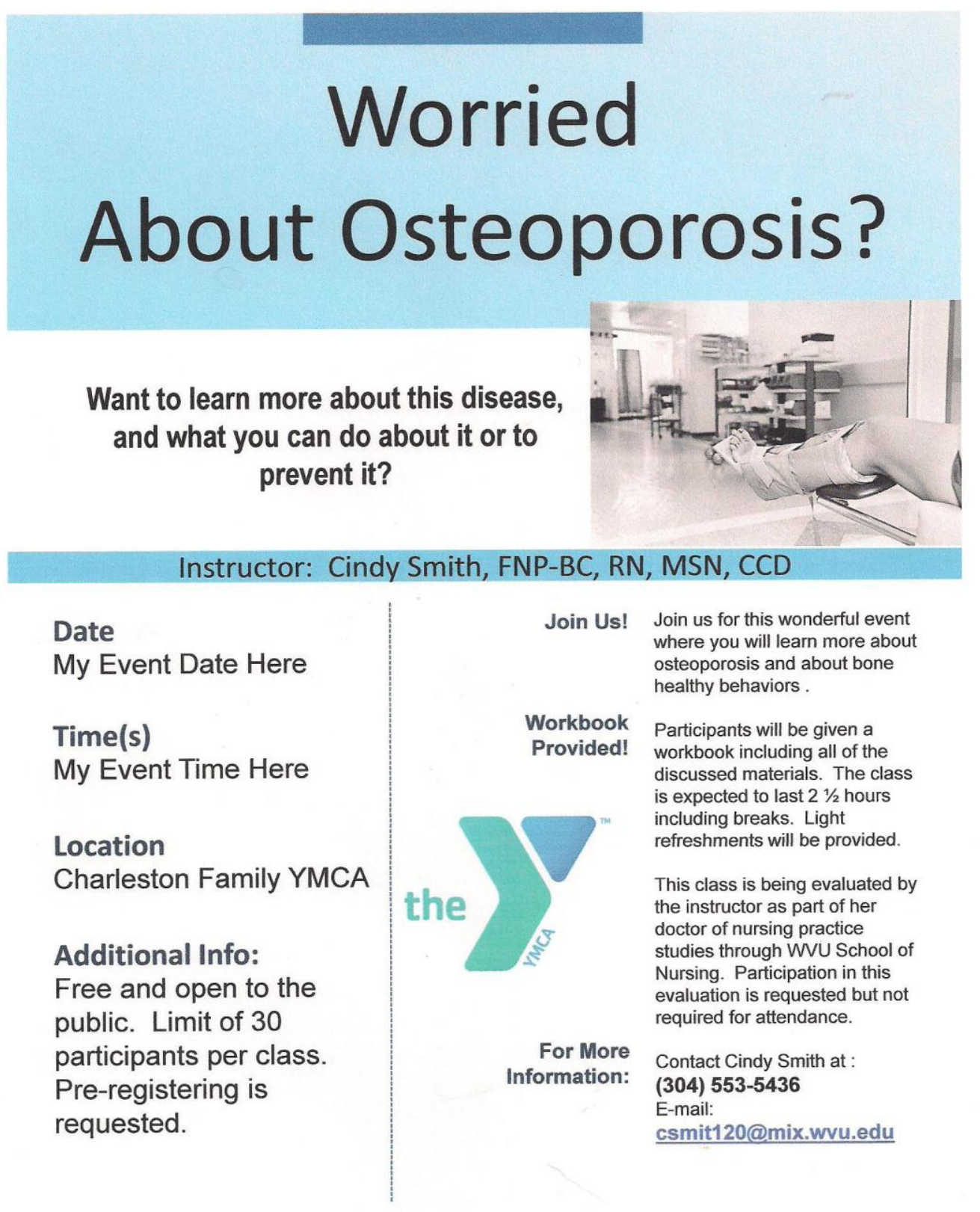




\section{Appendix AG}

Promotional Mailings for Workshops One and Two

\begin{tabular}{|c|c|}
\hline Mailed To & Cost \\
\hline WV Osteoporosis and Arthritis Program & $\$ 1.30$ \\
\hline $\begin{array}{l}\text { Kanawha-Charleston Health Department (two } \\
\text { locations) }\end{array}$ & $\$ 2.60$ \\
\hline $\begin{array}{l}\text { American Association of Retired Persons } \\
\text { (Charleston Division) }\end{array}$ & $\$ 1.10$ \\
\hline Women's Club of Charleston & $\begin{array}{c}\text { n/a (e-mail sent regarding osteoporosis } \\
\text { workshop) }\end{array}$ \\
\hline Women's Club of Nitro, WV & $\begin{array}{l}\text { n/a (e-mail sent regarding osteoporosis } \\
\text { workshop) }\end{array}$ \\
\hline Presbyterian Woman-The Presbytery of WV & $\$ 1.10$ \\
\hline Central WV Aging Services, Inc. & $\$ 1.30$ \\
\hline YWCA of Charleston-Encore Program & $\$ 1.30$ \\
\hline United Methodist Women, Charleston, WV & $\$ 1.10$ \\
\hline WV Bureau for Senior Services & $\begin{array}{c}\text { n/a (e-mail sent regarding osteoporosis } \\
\text { workshop) }\end{array}$ \\
\hline WV Women's Commission & $\$ 1.30$ \\
\hline $\begin{array}{c}\text { WVU Extension Service, Kanawha County } \\
\text { office }\end{array}$ & $\$ 1.10$ \\
\hline YWCA of Charleston & $\$ 1.30$ \\
\hline
\end{tabular}




\begin{tabular}{|c|c|}
\hline Partnership for a Health WV & $\begin{array}{c}\text { n/a (e-mail sent regarding osteoporosis } \\
\text { workshop) }\end{array}$ \\
\hline Ripley Senior Center (Jackson County) & $\$ 1.10$ \\
\hline Ravenswood Senior Center (Jackson County) & $\$ 1.10$ \\
\hline Kenna Grange Senior Center (Jackson County) & $\$ 1.10$ \\
\hline Tiskelwah Center, Charleston, WV & $\$ 1.30$ \\
\hline Kanawha Valley Senior Services & n/a (e-mail sent regarding osteoporosis \\
workshop)
\end{tabular}




\section{Appendix AH}

\section{Advertising Script}

Osteoporosis Workshop Being Offered.

Worried about osteoporosis? Want to learn more about this disease and what you can do about it or to prevent it? The Charleston Family YMCA at 100 YMCA Drive Charleston, WV 25311 is hosting an osteoporosis workshop. Join us for this wonderful event where you will learn more about osteoporosis and about bone healthy behaviors. Participants will be given a workbook including all of the discussed materials. The workshop is free and open to the public. There is a limit of 30 participants per class. Pre-registration is requested. The class is expected to last $21 / 2$ hours including breaks. Light refreshments will be provided.

Instructor: Cindy Smith, FNP-BC, RN, MSN, CCD.

Date: (event date)

Time(s): (event time(s))

This class is being evaluated by the instructor as part of her doctor of nursing practice studies through WVU School of Nursing Health Promotion/Risk Reduction. Participation in this research study is requested but not required for attendance. WVU IRB approval is on file.

For More Information: Contact Cindy Smith at (304) 553-5436

E-mail: csmit120@mix.wvu.edu 
Appendix AI

Additional Promotional Efforts

\begin{tabular}{|c|c|}
\hline Workshops One and Two & Workshop Three \\
\hline $\begin{array}{c}\text { Posting on Radio Station Electric 102.7's } \\
\text { Community Bulletin Board }\end{array}$ & $\begin{array}{c}\text { Posting on Radio Station Electric 102.7's } \\
\text { Community Bulletin Board }\end{array}$ \\
\hline $\begin{array}{c}\text { Posting on Radio Station WKWS 96.1's } \\
\text { Community Bulletin Board }\end{array}$ & $\begin{array}{c}\text { Posting on Radio Station WKWS 96.1's } \\
\text { Community Bulletin Board }\end{array}$ \\
\hline Bosting on WQBE 97.5's Community Bulletin & Posting on WCHS Channel 8's Community \\
Bosting on WCHS Channel 8's Community & Bulletin Board \\
Bulletin Board & Bulletin Board \\
\hline Posting on WOWK Channel 13's Community & Posting on WSAZ Channel 3's Community \\
& Bulletin Board \\
\hline Bosting on WSAZ Channel 3's Community & Posting in the Charleston Gazette's \\
Community Event Section
\end{tabular}




\section{Appendix AJ}

\section{Spontaneous Comments Written on Instruments/Questionnaires}

1. On Osteoporosis Workshop Information Form: "Not reliable instruments"

2. On One Month Follow-Up: “Changed from prescription vitamin D to daily vitamin D"

3. On Osteoporosis Workshop Information Form in section regarding calcium and vitamin D supplement use: "Don't remember".

4. On Pre-intervention IPQA: "I have been unable to exercise due to hip-leg pain; usually I do."

5. Written on Osteoporosis Workshop Information Form: "Not a reliable instrument."

6. Included note: "Thank you so much for the all the information. The workshop was one of the best I've ever attended. Thanks, too, for the Target gift card."

7. On one month post-intervention IPAQ: "Not typical due to exhaustion from family illness."

8. On one month post-intervention IPAQ: "Please note: Due to knee surgery in January, I have been unable to participate in my regular exercise program.”

9. Note enclosed: "Thanks for such a helpful and informative workshop."

10. On one month post-intervention OKAT: “Thank you. I really learned a lot!"

11. Attached Post-It Note: "Thanks for a very informative session!"

12. Attached note: "I enjoyed the workshop so much. Thank you for an abundance of information. I am trying to improve my level of physical activity and I have started to include a couple of the Citracal gummies each day." 